\title{
ADVANCING \\ INTEGRATED PEST MANAGEMENT \\ FOR DERMANYSSUS GALLINAE IN LAYING HEN FACILITIES
}


Advancing Integrated Pest Management for Dermanyssus gallinae in laying hen facilities

Monique F. Mul 


\section{Thesis committee}

\section{Promotors}

Prof. Dr P.W.G. Groot Koerkamp

Professor of Farm Technology

Wageningen University

Prof. Dr M. Dicke

Professor of Entomology

Wageningen University

\section{Co-promotors}

Dr B.G. Meerburg

Head of department Livestock \& Environment

Wageningen Livestock Research

Dr D.R. George

Director of Entomology \& Sustainability

Stockbridge Technology Centre, United Kingdom

\section{Other members}

Prof. Dr Y. Schukken, Wageningen University

Prof. Dr R. Ducatelle, Ghent University, Belgium

Dr R. Bronneberg, AviVet BV, Austerlitz, The Netherlands

Dr H. van den Brand, Wageningen University

This research was conducted under the auspices of the Graduate School for Production Ecology and Resource Conservation (PE\&RC) 


\title{
Advancing Integrated Pest Management for Dermanyssus gallinae in laying hen facilities
}

\author{
Monique F. Mul
}

Thesis

submitted in fulfilment of the requirements for the degree of doctor at Wageningen University by the authority of the Rector Magnificus Prof. Dr A.P.J. Mol, in the presence of the Thesis Committee appointed by the Academic Board to be defended in public on Friday 13 January 2017 at 1.30 p.m. in the Aula. 
Monique F. Mul

Advancing Integrated Pest Management for Dermanyssus gallinae in laying hen facilities. 194 pages.

PhD thesis, Wageningen University, Wageningen, NL (2017)

With references, with summaries in English and Dutch

ISBN: 978-94-6343-003-6

DOI: http://dx.doi.org/10.18174/394911 


\section{Contents}

Chapter 1 General introduction 1

Chapter 2 Control methods for Dermanyssus gallinae in systems for laying hens: results of an international seminar

Chapter 3 Preventing introduction and spread of Dermanyssus gallinae in poultry facilities using the HACCP method

Chapter 4 Structured design of an automated monitoring tool for pest species

Chapter 5 Validation of an automated mite counter for Dermanyssus gallinae in experimental laying hen cages

Chapter 6 Model based approaches to forecast Dermanyssus gallinae population dynamics and to describe the source of population growth variation in laying hen facilities for advancing Integrated Pest Management

Chapter $7 \quad$ General discussion

Summary

Samenvatting

Dankwoord/Acknowledgements

About the author

List of publications

Training and Education Statement 



\section{Chapter 1}

General introduction 


\section{Losses in global food production}

Pests and diseases in agricultural production systems cause severe losses to food production with associated economic impacts (Oerke et al. 1994; FAO 2001). Current global trades, global climate changes, and agricultural intensification result in a wider spread of pests and diseases, more pest-susceptible crops and development of pesticide resistance and are thus associated with an increase in pests and diseases related to crop losses and an increase in pest outbreaks (Oerke et al. 1994; Pinstrop-Anderson 2001, Rosenzweig et al. 2001). Offsetting production losses through increased production areas to feed the increasing human (and livestock) population is not a viable option, as only limited additional land is available for production (FAO 2009, National Research Council 2000). Consequently, there is an urgent need to improve current pest management to optimize production on the available land.

\section{Pest control in modern agriculture}

From the beginning of agriculture, many years $\mathrm{BC}$, people use techniques to control pests mainly in cropping systems (Dent 2000). Cultural methods (e.g. manipulation of planting dates, burning), botanical insecticides and predators were used to control, amongst others, arthropod pests like ants, lice and beetles (Dent 2000). Arthropods are invertebrates with an exoskeleton, a segmented body, and jointed appendages. Prior to the advent of synthetic pesticides in the 1940's, arthropod pests were controlled using cultural practices and knowledge-based methods focused on the manipulation of pest biology and ecology (Gaines 1957). After the advent of synthetic pesticides, pests were almost exclusively controlled using synthetic chemistry, with knowledge based methods being largely side-lined. At the end of the 1950's the detrimental effects of complete reliance on synthetic pesticides began to emerge, with harmful residues reported in food chains, increasing levels of pesticide resistance observed and resurgence of pests (Peshin et al. 2009). Public concerns about pesticides and environmental pollution arose after the publication of Silent Spring, an influential book about the detrimental effects of indiscriminate pesticides use on the environment (Carson 1962). In the 1950's methods were proposed to reduce resistance and use of natural enemies. One method, developed by a biological control scientist and an ecologist from California who jointly worked on the combination of biological control with chemical control methods, was called Integrated Control (Perkins 2002). This terminology has since subsequently changed into Protective Population Management, Pest management, Integrated Pest Control, to Integrated Pest Management (IPM) (Kogan 1998).

At around the same time as IPM was first being proposed, the CILB (Commission Internationale de Lutte Biologique), the predecessor of the IOBC (International Organisation for Biological and Integrated Control) was founded with the aim of promoting international cooperation for the development of biological control and the application of biological control in integrated pest management and integrated production (Franz 1988). 
From 1959, the IOBC formed international, multidisciplinary teams which focussed on a particular pest species to identify methods for biological control of the pests (Peshin et al. 2009). IPM guidelines were subsequently produced for all major crops via the activities of the IOBC. This was first supported and promoted by many European countries and by the European Union and later globally when the IOBC became a world-wide organisation (Peshin et al. 2009). Today, IPM is globally promoted by the Food and Agricultural Organisation of the United Nations (FAO) and World Health Organisation (WHO) to improve food security and public health (Bonnefoy et al. 2008; FAO 2015; WHO 2015).

\section{Integrated Pest Management (IPM)}

Many definitions of IPM have been proposed, amongst others by Kogan (1998). He analysed the various definitions of IPM that existed at that time to derive the following general definition: "IPM is a decision support system for the selection and use of pest control tactics, singly or harmoniously coordinated into a management strategy, based on cost/benefit analyses that take into account the interests of and impacts on procedures, society, and the environment". Kogan also provides definitions for each of the elements in the term IPM. Integration is the harmonious use of multiple methods to control single pests or multiple pests. Pest is defined as any organism, detrimental to humans, including vertebrate and invertebrate animals, pathogens, and weeds. Management is described as a set of decision rules based on ecological principles where economics and social interaction are considered, realising that the Economic Injury Level (EIL) should guide management interventions. Later, the FAO (2015) defined IPM as: "The careful consideration of all available pest control techniques and subsequent integration of appropriate measures that discourage the development of pest populations and keep pesticides and other interventions to levels that are economically justified and reduce or minimize risks to human health and the environment. IPM emphasizes the growth of a healthy crop with the least possible disruption to agro-ecosystems and encourages natural pest control mechanisms."

There are clear differences in the definition of IPM and subsequently how IPM is applied. Where Kogan emphasizes IPM as a decision tool for pest control aiming for a minimum economic, societal and environmental negative impact, the FAO emphasizes that IPM uses a combination of methods to control pests with minimum impact on human health and the environment. In this thesis, the framework of the EU Directive 2009/128/EC is used as a guideline to understand and better implement the IPM approach (European Union 2009). This European Directive is based on the definition of the FAO and is applied throughout the region for plant protection, requiring that all professional persons applying plant protection products should implement all eight IPM steps mentioned in the Directive (Barzman et al. 2015). This Directive should be considered as a guideline for the development of national legislation on use of pesticides for plant protection, and is likely to be extended to biocidal products in the future. This could mean that anyone applying pesticides in animal husbandry systems will need to similarly adhere to the steps covered (Barzman et al. 2015). 
Below, the eight IPM steps are described in general terms (ANNEX III of Framework Directive 2009/128/EC; shorthand titles from Barzman et al. 2015), with suggested amendments to apply to animal husbandry systems given in parenthesis (where applicable). All these steps together contribute to sustainable reduction of pests.

1. Prevention and/or suppression of harmful organisms: The prevention and/or suppression of harmful organisms should be achieved or supported.

2. Monitoring: Harmful organisms must be monitored by adequate methods and tools, where available. Such adequate tools should include observations in the field (animal facility) as well as scientifically sound warning, forecasting and early diagnosis systems, where feasible, as well as the use of advice from professionally qualified advisors.

3. Decision based on monitoring and thresholds: Based on the results of the monitoring the professional user has to decide whether and when to apply plant protection (animal health and welfare) measures. Robust and scientifically sound threshold values are essential components for decision making. For harmful organisms threshold levels defined for the region, specific areas, crops (animals) and particular climatic conditions must be taken into account before treatments, where feasible.

4. Non-chemical methods: Sustainable biological, physical and other non-chemical methods must be preferred to chemical methods if they provide satisfactory pest control.

5. Pesticide selection: The pesticides applied shall be as specific as possible for the target and shall have the least side effects on human health, non-target organisms and the environment.

6. Reduced pesticide use: The professional user should keep the use of pesticides and other forms of intervention to levels that are necessary, e.g. by reduced doses, reduced application frequency or partial applications, considering that the level of risk in vegetation (animal facility) is acceptable and they do not increase the risk for development of resistance in populations of harmful organisms.

7. Anti-resistance strategies: Where the risk of resistance against a plant protection (animal health and welfare) measure is known and where the level of harmful organisms requires repeated application of pesticides to the crops (animal or animal facility), available antiresistance strategies should be applied to maintain the effectiveness of the products. This may include the use of multiple pesticides with different modes of action.

8. Evaluation: Based on the records on the use of pesticides and on the monitoring of harmful organisms the professional user should check the success of the applied plant protection (animal health and welfare) measures.

Vänninen (LUKE, Finland) displayed the eight above mentioned steps as a jigsaw puzzle, indicating that all steps together contribute to effective IPM (Figure 1.1). 


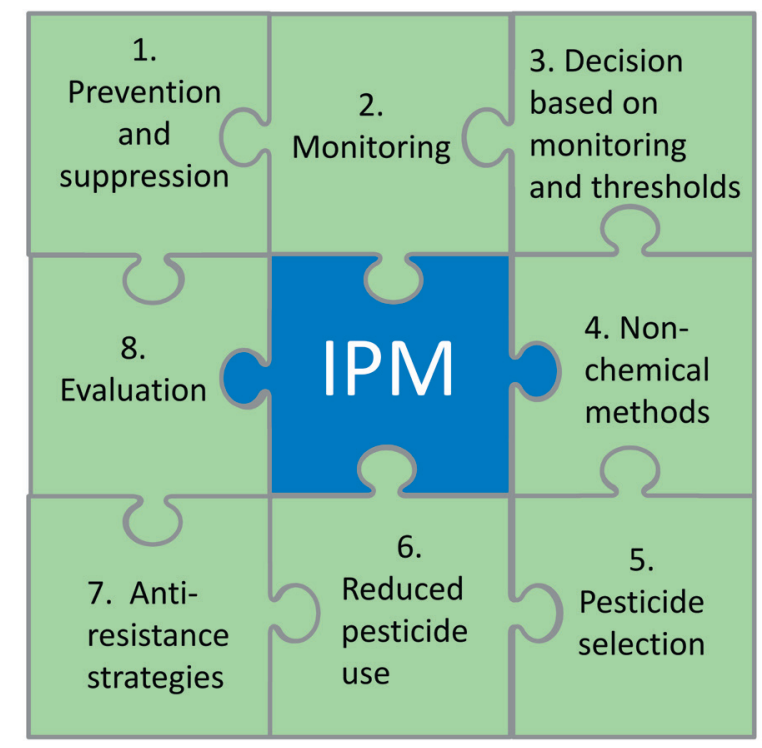

Figure 1.1 Eight steps of IPM (ㄷ I. Vänninen LUKE, Finland)

To assess the adoption or the implementation level of IPM, Benbrook (1996) divided the IPM continuum into four categories; 'No IPM', 'Low IPM' or level I, 'Medium IPM' or level II and 'High IPM'or 'Biointensive IPM' or level III. Biointensive IPM fully takes the advantage of natural resistance and management of, amongst others, predators and biodiversity enabling to manage biological processes in the ecosystem and in the pests lifecycle to control the pest population. At the very least, IPM should consist of pest control tactics 1) using an action threshold, 2) monitoring of pests, and 3) preventive measures. An action threshold is a number or level of pests after which an action should be taken to prevent increasing damage. This action threshold could be just one (when it concerns a human health hazard), or a high number (for example when the pest is just annoying or when the economic damage increases with the number of pests). If these three basic tactics of IPM are not applied, then the farm will be in IPM category 'No IPM'. IPM level I is reached when, in addition to these basic tactics, only selective pesticides are applied during the most optimal time, some preventive practices like crop rotation are applied and natural enemies are at least considered. Level II is reached when multi-tactic preventive measures limiting the pest habitat, and measures to increase bio-diversity, are implemented (natural control, cultural control methods, natural enemies, habitat management), and corrective actions are applied to reduce the use of broad-spectrum pesticides (mechanical, physical methods, biological control, selective pesticides). Level II is also realised when expert systems and pest models are deployed and when the processes are controlled at biological community level. Expert systems could forecast the population development and the moment in time when the threshold will be exceeded and action should be taken. In IPM level III, control of pests is a process undertaken at agro-ecosystem level, utilising multiple species interactions and enhancing plant defences. Here pests are controlled without using broad-spectrum products and pesticides only used as a last resort. 


\section{Implementation of IPM}

Implementation or adoption of IPM is greatly influenced by governmental and nongovernmental bodies and consumer organisation. Governmental and non-governmental bodies encourage on-farm implementation and finance research into IPM to reduce the difficulty of implementing IPM in practice (Lefebvre et al. 2014; Barzman et al. 2015). It is understood that this research, to find new systems for better adoption of IPM, greatly contributes to adoption of IPM by farmers (Peshin et al. 2009). Conversely, perceived 'complexity' and 'risk' of IPM appears to contribute negatively to its adoption by farmers, just like the perception that IPM would be 'time consuming and laborious' and 'noncommunicable'. On the other hand, 'compatibility' and 'a relative advantage' seemed to contribute positively to the adoption of IPM (Peshin et al. 2009). When considering any research related to advancing IPM programmes, the above mentioned attributes should be taken into account prior to the identification of the research aims and drafting the research design.

\section{IPM in animal husbandry}

At present, IPM is applied primarily to control plant pests. Nevertheless, a limited amount of research is focusing on the application of IPM in animal production also called Livestock Integrated Pest Management or Integrated Vector Management (IVM)(Narladkar 2014). The latest branch of IPM in animal production is Integrated Pest and Vector Management (IPVM), which is a combination of IPM and IVM and focuses on the control of vector borne diseases which proliferate as a result of the beneficial habitats for vectors created by agroecosystems (e.g. mosquito breeding supported by the food an feed producing rice fields). With IPVM, agro production is improved according to the IPM strategy and simultaneously the human health risks are reduced by changing farming practices and community behaviour (Van den Berg et al. 2006; Wielgosz et al. 2012).

Control of flies, ticks and worms via IPM in dairy farming and pig production is explored, discussed and supported by multiple works (Quarles 2006; Fasanmi and Onyima 1992; Van Wyk et al. 2006).

In egg production systems, Axtell (1981 and 1999) has emphasized opportunities for IPM in controlling poultry pests like flies, rodents and ecto-parasites. Moreover, IPM for Dermanyssus gallinae, economically the most important ectoparasite in laying hen facilities, has been suggested as a control method by Arends and Robertson (1986), Axtell and Arends (1990), Axtel (1999), Harrington et al. (2011), and Sparagano et al. (2014b). Currently, adoption of comprehensive and effective IPM programmes for D. gallinae are rare in laying hen facilities, with any integrated management mostly limited to the application of a combination of a) chemically or physically-acting products/sanitisers, b) some level of biosecurity and c) preventive cleaning of premises between two flocks. 


\section{Dermanyssus gallinae}

Dermanyssus gallinae, also called Poultry Red Mite (PRM), is an ectoparasite that feeds primarily on the blood of avian hosts, with feeding being necessary for development from a protonymph into a deutonymph, from a deutonymph into the adult stage and for females to produce eggs thereafter (Figure 1.2). For the development from egg to larvae and from larvae to protonymph a blood meal is not needed (Axtell and Arends 1990).

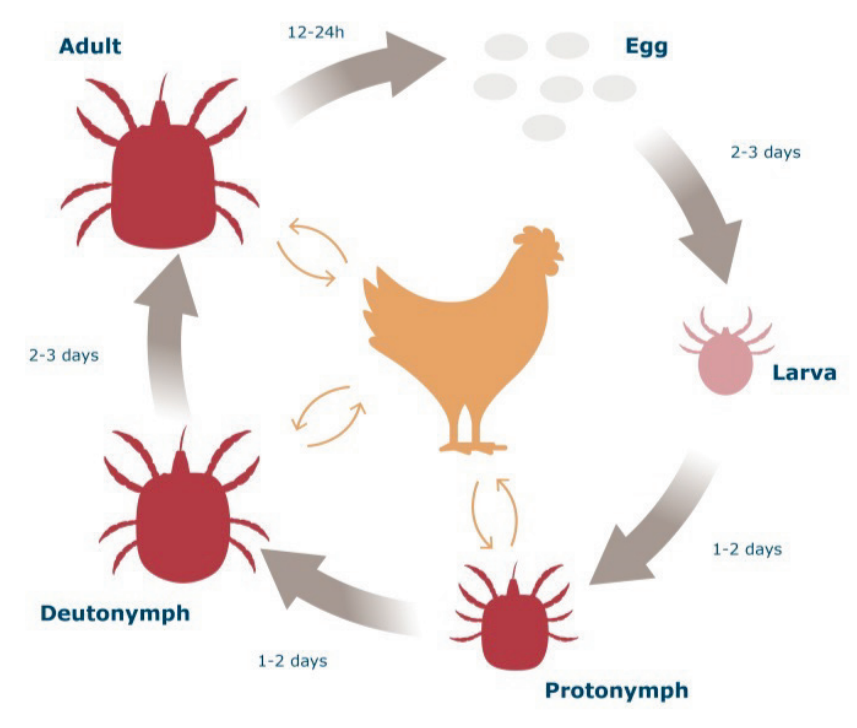

Figure 1.2 Life-cycle of Dermanyssus gallinae (Adapted from V. Maurer, FiBL, Switzerland)

Although D. gallinae reproduction is most successful when feeding upon avian hosts, blood from, amongst others, humans, mice, and rabbits, can also be digested by the mite (Sikes and Chamberlain 1954). Unfed D. gallinae are white-grey in colour, turning to redbrown after feeding and when digesting a blood meal (Hoffman 1987). The length of the mite varies between approximately 0.40 - 1.13 mm (Sikes and Chamberlain 1954; Reynaud et al. 1997), depending on the developmental stage and the presence of a fresh blood meal.

Dermanyssus gallinae can be found in laying hen facilities worldwide. The environment in most laying hen facilities, with temperatures generally maintained between 18 and $21^{\circ} \mathrm{C}$, provide D. gallinae with favourable conditions for development, which, coupled to an abundant food supply, permit rapid completion of the mite's life-cycle. Under such conditions, the D. gallinae lifecycle can be completed within 7 to 17 days. This permits rapid population growth of D. gallinae in laying hen facilities, with each female mite being able to lay a total of 30-50 eggs in several clutches, during her lifetime (Maurer and Baumgärtner 1992). In laying hen facilities, D. gallinae hide, rest, digest and reproduce in cracks and crevices in the vicinity of the hens nightly resting place (Sikes and Chamberlain 1954; Axtell and Arends 1990). Preferably during hours of darkness, D. gallinae walks towards the hen, climbs onto its host via the bird's legs, and proceeds towards the neck and back of the hen to feed (Wood 1917). After a 30 - 60 minutes feeding bout, D. gallinae climbs back via the legs 
of the hen to the cracks and crevices in which its spends the majority of its time, with feeding only occurring every few days (Maurer et al. 1988). Without hiding places, $D$. gallinae form clusters out of reach of the laying hen, with mite aggregation being induced by pheromones (Entrekin and Oliver 1982). All types of housing equipment in laying hen facilities provide the mites with abundant refuges and facilitates ease of movement from these resting sites to (and from) hens (Van Emous et al. 2005).

\section{Effects of Dermanyssus gallinae}

Large populations of $D$. gallinae in laying hen facilities may result in decreased egg production, egg quality and animal welfare (increased stress and most likely feather pecking) and may lead to an increase in mortality and morbidity among the poultry present (Axtell and Arends 1990; Mul et al. 2009; Sparagano and Giangaspero 2011). Dermanyssus gallinae can act as a vector for bacteria and viruses (Baselga et al. 1996; Chauve 1998; Kilpinen et al. 2005; Valiente Moro et al. 2009) and may also affect the natural resistance of birds (Mul et al. 2009). In humans, D. gallinae may cause allergic reactions (Chauve 1998; Sahibi et al. 2008; Cafiero et al. 2008) (Figure 1.3). Costs associated with a D. gallinae infestation in laying hen facilities were estimated by farmers as $€ 0.29$ per laying hen per round for losses in egg production and €0.14 per laying hen per round for treatment (Van Emous et al. 2005). With a total of 47.7 million laying hens in The Netherlands (CBS 2014), the total loss per annum for the Dutch egg industry is estimated to amount ca. $€ 20.5$ million.

\section{Control of Dermanyssus gallinae}

Control of D. gallinae is difficult for numerous reasons. For one, the mites spend the majority of their time in hard-to-target refuges within the sub-structure of the laying hen facility. Depending on the walking distance between the laying hen and the refuges, the mites may spend only one hour outside the refuges every few days (Maurer et al. 1988). This hampers successful treatment with standard contact acaricides that need to contact the target to have an effect. Currently authorized acaricidal products, however, tend to display shorter residual activities to satisfy lowered Maximum Residue Limits (MRLs) than the older generation of acaricides, many of which have been withdrawn from the market. However, shorter residual efficacies are ill-suited to target D. gallinae which may not encounter treated surfaces for several days (or more) after application. Control of D. gallinae is becoming increasingly difficult due to development of mite resistance to multiple acaricides (Chauve 1998; Nordenfors et al. 2001; Marangi et al. 2009) and withdrawal of others following stricter legislation concerning active ingredients.

Implementation of more advanced IPM programmes for D. gallinae in laying hen facilities, may improve control prospects, as suggested by several authors (Arends and Robertson 1986; Axtell and Arends 1990; Axtel 1999; Harrington et al. 2011). As noted, current implementation of IPM in egg production facilities is limited to some combination of preventive measures, acaricide use and limited cleaning between flocks (Maurer et al. 
2009). Whilst there is significant scope to improve upon current IPM practice, several barriers need to be overcome before this can be realised. Practically, there is currently a lack of knowledge about a) D. gallinae prevention, b) the size of D. gallinae infestations present in laying hen houses, and c) the efficacy of treatments due to the fact that monitoring is restricted, if applied, to laborious manual methods. Socially, a similar lack of knowledge on IPM's costs and benefits to the egg producers economics, limit improved implementation of IPM for D. gallinae. This in mind, the current research project was designed to deliver improvements in these areas and overcome the barriers they present to more rigorous IPM for D. gallinae in laying hen systems.

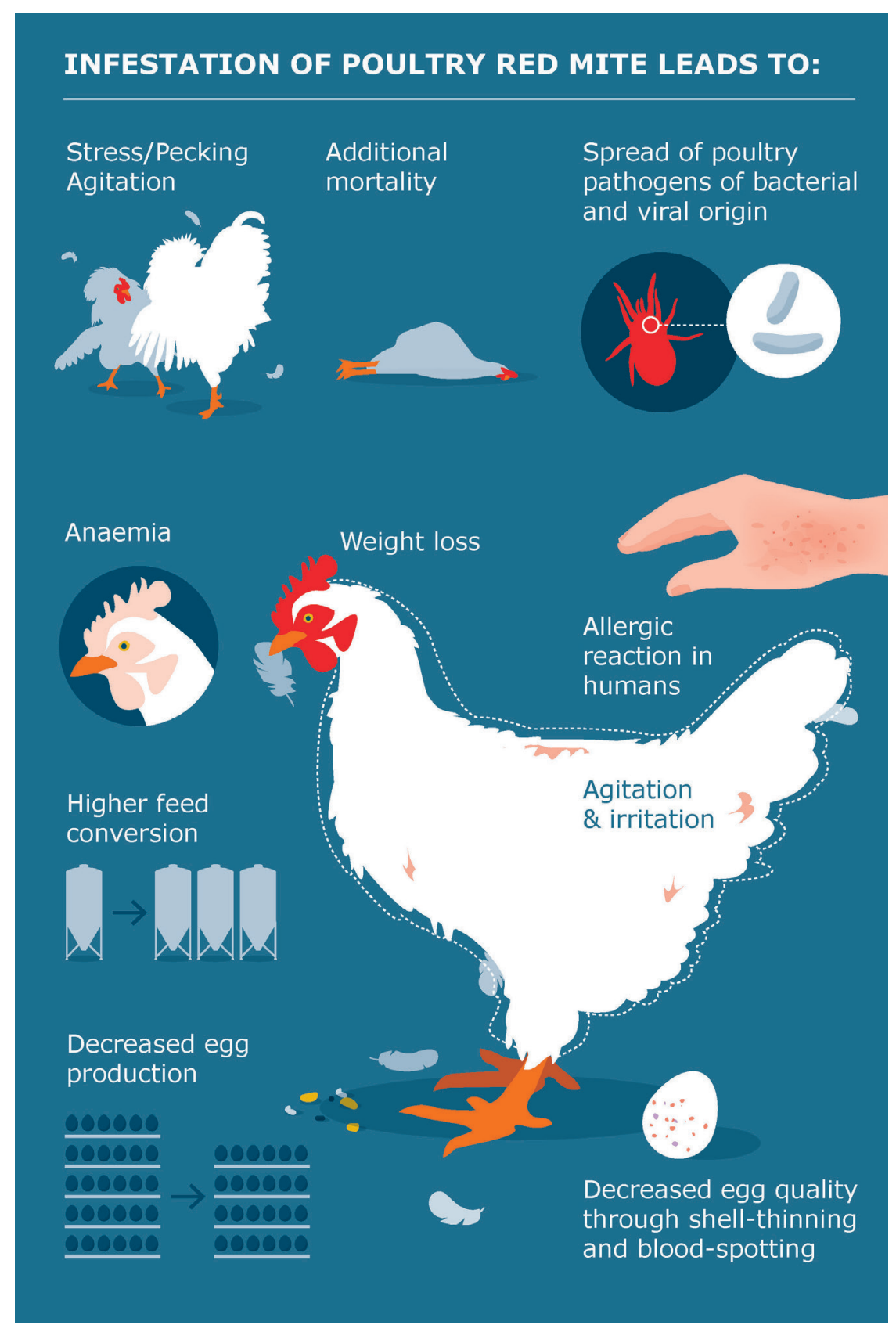

Figure 1.3 Possible effects of Dermanyssus gallinae 


\section{Research objectives}

The main objective of this research was to obtain knowledge and insights and to develop methods and tools to contribute to more advanced IPM programmes for D. gallinae in laying hen facilities. The research focused on preventive measures and continuous monitoring of $D$. gallinae as being key advances in IPM. Monitoring permits early detection of pests when preventive measures fail, and provides insights into treatment effects and pest population dynamics. The main objective was divided into three sub objectives:

1) Assessment of the state of the art knowledge on the biology of D. gallinae, the negative effects of this pest in laying hen facilities and available and promising control methods for D. gallinae in laying hen facilities (Chapter 2).

2) Provide insight into routes of introduction and spread of D. gallinae in laying hen facilities to enable preventive measures to be identified (Chapter 3 ).

3) Obtain knowledge and develop methods enabling the design, development (Chapter 4) and validation of a monitoring tool (Chapter 5) to evaluate the D. gallinae population dynamics and treatment efficacy in laying hen facilities (Chapter 6).

\section{Outline of this thesis}

This thesis comprises five chapters contributing to the main objective and a General discussion. The relationship between the thesis content and the aforementioned eight steps of IPM is shown in Figure 1.4. 
Objective:

Obtain knowledge and insights and develop methods and tools to contribute to more advanced IPM programmes for D. gallinae in laying hen facilities.

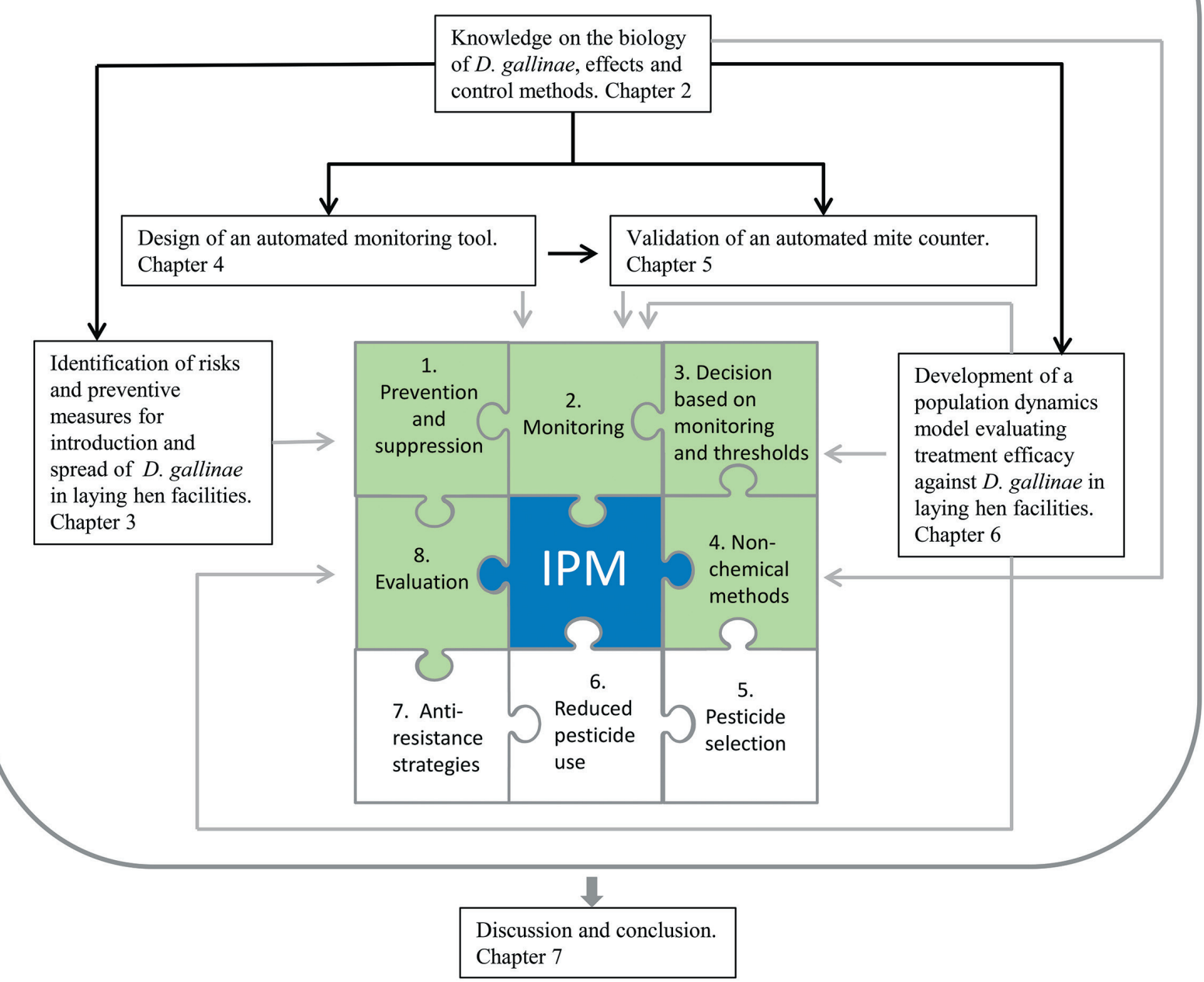

Figure 1.4 Diagrammatical representation of information flows contained within the current thesis. Black lines depict knowledge flows between chapters and grey lines depict the steps of IPM to which individual chapters contribute

Chapter 2 assesses the available knowledge on D. gallinae and possible control methods. The knowledge obtained through a literature research and a two day seminar, was used as input into the research described in Chapters 3 to 6 . Chapter 3 identifies risk factors, preventive measures and corrective actions to prevent or minimize the introduction and spread of D. gallinae in laying hen farms using the Hazard Analysis and Critical Control Point method. Chapter 4 describes the design of an automated monitoring tool for pest species, with D. gallinae as an example. The validation of the prototype of the designed automated mite counter, which is a part of the monitoring tool, is described in Chapter 5. The designed and validated automated mite counter for D. gallinae provides continuous data on the population dynamics of D. gallinae. An operational model coupled to this continuous data, enables forecasting the population dynamics by providing knowledge about treatment efficacy. The development of that adaptive population dynamics model for D. gallinae in 
laying hen facilities, its performance and the compatibility with different monitoring methods in different housing systems is described and shown in Chapter 6. Chapter 7, the General discussion, presents the implication of achieved results for future developments and perspectives for applications further advancing IPM programmes for D. gallinae. The main conclusions of this thesis are also presented in this chapter. 


\section{References}

European Union. Directive 2009/128/Ecof the European parliament and of the council of 21 October 2009 establishing a framework for community action to achieve the sustainable use of pesticides. Off. J. Eur. Union 52: 71-86. http://eurlex.europa.eu/LexUriServ/LexUriServ.do?uri=0J:L:2009:309:0071:0086:en:PDF (9-52016)

Arends JJ, Robertson SH (1986) Integrated pest management for poultry production: Implementation through integrated poultry companies. Poult Sci 65: 675-682

Axtell RM (1981) Livestock integrated pest management (IPM): principles and prospects. In: Systems approach to animal health and production: 31-40. F.W. Knapp (ed.), Lexington: University of Kentucky

Axtell R (1999) Poultry integrated pest management: status and future. Integr Pest Manag Rev 4: 53-73

Axtell RC, Arends JJ (1990) Ecology and management of arthropod pests of poultry. Annu Rev Entomol 35: 101-126

Barzman M, Bàrberi P, Birch ANE, Boonekamp P, Dachbrodt-Saaydeh S, Graf B, Hommel B, Jensen JE, Kiss J, Kudsk P, Lamichhane JR, Messéan A, Moonen A-C, Ratnadass A, Ricci P, Sarah JL, Sattin M (2015) Eight priciples of integrated pest management. Agron Sustain Dev 35: 1199-1215

Baselga E, Drolet BA, Esterly NB (1996) Avian mite dermatitis. Pediatrics 97: 743-745

Benbrook CM, Groth E, Halloran JM, Hansen MK, Marquardt S (1996) Pest Management at the crossroads. Consumers Union, Yonkers, New York

Bonnefoy X, Kampen H, Sweeney K (2008) Public health significance of urban pests. World Health Organization. Regional Office for Europe. Copenhagen: WHO Regional Office for Europe

Cafiero M, Camarda A, Circella E, Santagada G, Schino G, Lomuto M (2008) Pseudoscabies caused by Dermanyssus gallinae in Italian city dwellers: a new setting for an old dermatitis. J Eur Acad Dermatol Venereol 22: 1382-1383

Carson R (1962) Silent spring. Boston, Cambridge: Houghton Mifflin

CBS (2016) Centraal Bureau voor de Statistiek, Den Haag/Heerlen. http://statline.cbs.nl/StatWeb/publication/?DM=SLNL\&PA=80780NED\&D1=518$529 \% 2 \mathrm{C} 556-557 \% 2 \mathrm{C} 564 \& \mathrm{D} 2=0 \& \mathrm{D} 3=0 \% 2 \mathrm{C} 5 \% 2 \mathrm{C}(1-2) \% 2 \mathrm{C}(\mathrm{l}-$

1)\%2Cl\&HDR=G1\%2CG2\&STB=T\&VW=T (9-5-2016)

Chauve CM (1998) The poultry red mite Dermanyssus gallinae (De Geer, 1778) : current situation and future prospects for control. Vet Parasitol 79: 239-245

Dent D (2000) Insect pest management. 2nd edition CABI International, UK. ISBN 0-85199$341-9$

Entrekin DL, Oliver JH jr (1982) Aggregation of the chicken mite, Dermanyssus gallinae (Acari: Dermanyssidae). J Med Entomol 19: 671-678 
FAO (2001) The future world food situation and the role of plant diseases. The Plant Health Instructor. http://www.fao.org/emergencies/emergency-types/plant-pests-anddiseases/en/

FAO (2009) The state of food and agriculture. Rome, issn 00814539

FAO (2015)

http://www.fao.org/agriculture/crops/thematicsitemap/theme/pests/ipm/en/ (277-2015)

Fasanmi F, Onyima VC (1992) Current concepts in the control of ticks and tick-borne diseases in Nigeria. A review. Insec Sci Appl 13: 615-619

Franz JM (1988) Highlights in the development of the International Organization for Biological Control of noxious animals and plants. From CILB to IOBC/OILB and WPRS/SROP. Entomophaga 33: 131-134

Gaines JC (1957) Cotton insects and their control in the United States. Annu Rev Entomol 2: 319-338

Harrington DWJ, George DR, Guy JH, Sparagano OAE (2011) Opportunities for integrated pest management to control the poultry red mite, Dermanyssus gallinae. World Poult Sci J 67: 83-94

Kilpinen O, Roepstorff A, Permin A, Nørgaard-Nielsen G, Lawson LG, Simonsen HB (2005) Influence of Dermanyssus gallinae and Ascaridia galli infections on behaviour and health of lying hens (Gallus gallus domesticus). Br Poult Sci 45: 26-34

Kogan M (1998) Integrated pest management: Historical perspectives and contemporary developments. Annu Rev Entomol 43: 243-270

Lefebvre M, Langrell SRH, Gomez-y-Paloma S (2014) Incentives and policies for integrated pest management in Europe: a review. Agron Sustain Dev: 1107

Marangi M, Cafiero MA, Capelli G, Camarda A, Sparagano OAE, Giangaspero A (2009) Evaluation of the poultry red mite, Dermanyssus gallinae, (Acari: Dermanyssidae), susceptibility to some acaricides in field populations from Italy. Exp Appl Acarol 48: 11-18

Maurer V, Bieri M, Fölsch DW (1988) Das suchverhalten von Dermanyssus gallinae in hühnerställen. Archiv Geflügelkd 5: 209-215

Maurer V, Baumgärtner J (1992) Temperature influence on life table statistics of the chicken mite Dermanyssus gallinae (Acari: Dermanyssidae). Exp Appl Acarol 15: 27-40

Maurer V, Perler E, Heckendorn F (2009) In vitro efficacies of oils, silicas and plant preparations against the poultry red mite Dermanyssus gallinae. Exp Appl Acarol 48: 31-41

Mul M, Niekerk T van, Chirico J, Maurer V, Kilpinen O, Sparagano O, Thind B, Zoons J, Moore D, Bell B, Gjevre A-G, Chauve C (2009) Control methods for Dermanyssus gallinae in systems for laying hens: results of an international seminar. World Poult Sci J 6: 589600 
Narladkar BW (2014) Integrated management of arthropod pests of veterinary importance: Recent up-dates on unconventional but feasible measures. Indian J Anim Sci 84: 11431156

National Research Council (2000) Nutrient requirements of beef cattle, seventh revised edition: update 2000

Nordenfors H, Höglund J, Tauson R, Chirico J (2001) Effect of permethrin impregnated plastic strips on Dermanyssus gallinae in loose-housing systems for laying hens. Vet Parasitol 102: 121-131

Oerke EC, Dehne HW, Schonbeck F, Weber A (1994) Crop production and crop protection: estimated losses in major food and cash crops. Elsevier Science Publishers, Amsterdam, $808 \mathrm{pp}$

Perkins JH (2002) History. In: Encyclopedia of pest management. Pimentel D (Eds.), Marcel Dekker New York: 368-372

Peshin R, Bandral RS, Zhang W, Wilson L, Dhawan AK (2009) Integrated pest management: A global overview of history, programs and adoption. In: Integrated pest management volume 1: Innovation-development process. Peshin RD, Ashok K (Eds.) 49 pp.

Pinstrop -Anderson P (2001) The future world food situation and the role of plant diseases. The plant health instructor DOI: 10.1094/PHI-I-2001-0425-01

Quarles W (2006) Biological control of nuisance flies with pupal parasitoids. IPM practitioner 28 (9/10): 1-10

Reynaud MC, Chauve CM, Beugnet F (1997) Dermanyssus gallinae (De Geer, 1778): experimental life cycle and test of the acaricidal action of moxidectin and ivermectin. Rev Med Vet 148: 433-438

Rosenzweig CE, Iglesias A, Yang XB, Epstein PR, Chivian E (2001) Climate change and extreme weather events: Implications for food production, plant diseases, and pests. Ecohealth 2: 90-104

Sahibi H, Sparagano O, Rhalem A (2008) Dermanyssus gallinae: Acari parasite highly aggressive but still ignored in Morocco. In: BSP spring trypanosomiasis, leishmaniasis and malaria meetings. March $30^{\text {th }}-$ April $2^{\text {nd }}$, Newcastle upon Tyne, 173

Sikes RK, Chamberlain RW (1954) Laboratory observations on three species of bird mites. J Parasitol 40: 691-697

Sparagano OAE, Giangaspero A (2011) Parasitism in egg production systems: the role of the red mite (Dermanyssus gallinae). In: Improving the safety and quality of eggs and egg products. Volume 1: Egg chemistry, production and consumption. Woodhead Publishing Series in Food science, technology and nutrition. Nys Y, Bain M, Van Immerseel F (Eds.): 394-414. ISBN: 978-1-84569-754-9

Sparagano OAE, George DR, Harrington DWJ, Giangaspero A (2014) Significance and control of poultry red mite, Dermanyssus gallinae. Ann Rev Entomol 59: 447-466 
Valiente Moro C, Luna CJ de, Tod A, Guy JH, Sparagano OAE, Zenner L (2009) The poultry red mite (Dermanyssus gallinae): a potential vector of pathogenic agents. Exp Appl Acarol 48: 93-104

Van den Berg H, Das PK, Von Hildebrand A, Ragunathan V (2006) Evaluation of the integrated pest and vector management (IPVM) project in Sri Lanka: mission report, July 2006. New Delhi: WHO Regional Office for South-East Asia. Available at: http://www.searo.who.int/EN/Section23/Section1001/Section1110 12796.htm

Van Emous RA, Fiks-van Niekerk TGCM, Mul MF (2005) Bloedluizen (vogelmijten) op papier en in de praktijk. PraktijkRapport 17, Animal Sciences Group - Praktijkonderzoek ISSN 15708624

Van Wyk JA, Hoste, H, Kaplan RM, Besier RB (2006) Targeted selective treatment for worm management - how do we sell rational programs to farmers. Vet Parasitol 139: 336346

WHO (2015) http://www.who.int/heli/risks/toxics/chemicals/en/ (27072015)

Wielgosz B, Mangheni M, Tsegai D, Ringler C (2012) Malaria and agriculture: a global review of the literature with a focus on the application of integrated pest and vector management in East Africa and Uganda. IFPRI - Discussion Papers (1232): vii. International Food Policy Research Institute, Washington, USA

Wood HP (1917) The chicken mite: its life history and habits. USDA Bull 553 


\section{Chapter 2}

\section{Control methods for Dermanyssus gallinae in systems for laying hens: results of an international seminar}

Monique F. Mul ${ }^{1}$, Thea G.C.M. van Niekerk ${ }^{1}$, Jan Chirico ${ }^{2}$, Veronika Maurer ${ }^{3}$, Ole Kilpinen ${ }^{4}$, Olivier A.E. Sparagano ${ }^{5}$, Bharat B. Thind ${ }^{6}$, Johan Zoons ${ }^{7}$, David Moore ${ }^{8}$, Barbara Bell ${ }^{9}$, AnneGerd Gjevre ${ }^{10}$ and Claude M. Chauve ${ }^{11}$

1 Wageningen UR Livestock Research, PO Box 65, 8200 AB Lelystad, The Netherlands

2 National Veterinary Institute, SE-751 89 Uppsala, Sweden

3 Research Institute of Organic Agriculture (FiBL), Postfach, CH-5070 Frick, Switzerland

${ }^{4}$ Institute of Integrated Pest Management, University of Aarhus, Skovbrynet 14, DK-2800 Kgs. Lyngby, Denmark

5 School of Agriculture, Food and Rural Development, Newcastle University, NE1 7RU, UK

${ }^{6}$ Central Science Laboratory, Department for Environment, Food and Rural Affairs (DEFRA), Sand Hutton,York, Y041 1LZ, UK

7 GBP Proefbedrijf voor de Veehouderij, Poiel 77, B-2440 Geel, Belgium

8 CABI, Bakeham Lane, Egham, Surrey, TW20 9TY, UK

9 ADAS,11D Milton Park, Abingdon, Oxfordshire, OX14 4RS, UK

10National Veterinary Institute, Section of Pathology, PO Box 750, Sentrum, N-0106 Oslo, Norway

11Laboratory of Parasitology, Veterinary School of Lyon, 1 Avenue Bourgelat, B.P. 8369280 Marcy L'Etoile, France

Reprinted with permission.

World's Poultry Science Journal (2009) 65: 589-599 


\begin{abstract}
Here we report the results of a seminar on poultry red mite (PRM), Dermanyssus gallinae. Eighteen researchers from eight European countries discussed lifecycle issues of the mite, effects of mites on hens and egg production, and monitoring and control methods for PRM in poultry facilities. It was determined that PRM probably causes more damage than envisaged, with the cost in The Netherlands alone reaching 11 million euro per annum. However a great deal is still unknown about PRM (e.g. reproduction, survival methods) and that PRM monitoring is an important instrument in recognising and admitting the problem and in taking timely measures. Currently, the most promising control method combines heating the hen house in combination with chemical treatments. Future areas of development which show promise include the use of entomopathogenic fungi, vaccination and predatory mites. The final aim is to solve the problem of D. gallinae in housing systems for laying hens.
\end{abstract}




\section{Introduction}

The poultry red mite (PRM), Dermanyssus gallinae, can cause serious damage. An infestation of these mites can reduce poultry welfare, increase mortality and even cause allergic reactions in poultry facility workers. To get an idea of the scale of the problem, PRM costs Dutch poultry farmers (30 million laying hens) an estimated 11 million euro/year (Emous et al. 2005).

On 7-9 November 2006, an international seminar was held to discuss most current knowledge and state of the art research regarding the poultry red mite. The aim of the seminar was to bring international scientists in this area together to detect knowledge gaps and where possible to fill in these knowledge gaps by sharing knowledge. To do this, the seminar was divided into four sessions, dealing with the following aspects of the PRM:

- Life cycle issues of $D$. gallinae

- Effects of D. gallinae on hen and egg production

- Monitoring methods for D. gallinae infestation in poultry facilities

- Control methods for D. gallinae in poultry facilities

Researchers actively involved in PRM research (as manifest from publications and/or congress participation) across Europe were invited. Eighteen researchers participated, coming from eight European countries: Norway, Sweden, Denmark, United Kingdom, The Netherlands, Belgium, France and Switzerland. This paper describes the results and conclusions of that seminar and incorporates information on key publications.

\section{Life cycle and habitat issues of $D$. gallinae}

D. gallinae was first described by De Geer in 1778. It belongs to the sub-class Arachnida. The common name is poultry red mite (PRM) or chicken mite (in the US). This mite is the most common ectoparasite in poultry. It feeds on blood of the host and, although it favours poultry and other birds, it will also feed on blood from other animals, including humans (Sikes and Chamberlain 1954).

PRM has three juvenile stages from egg to adult: larva, protonymph and deutonymph (Figure 2.1). For the development of PRM larva to protonymph no host is needed. PRM requires blood from a host for the development of protonymph to deutonymph to the adult stage (Axtell and Arends 1990). PRM also requires blood for adult reproduction. Therefore, during the last three stages, PRM lives as a parasite on poultry, wild birds and sometimes even on humans. An important characteristic of PRM is that it does not permanently reside on its host, but only feeds there. PRM spends 30-60 minutes on the hen, during an average visit (Maurer et al. 1988), whilst the rest of the time it hides in cracks and crevices in the neighbourhood of its host, seeking shelter where it can digest its blood meal, mate and lay eggs. PRM usually feeds every 2-4 days generally 5-11 hours after onset of the dark period (at a 12/12h light/dark cycle) (Maurer et al. 1988). Only very few mites feed during daylight 
and not all mites crawl of the host in the morning (Wood 1917). However, the seasonal activity of the mites is mainly driven by temperature (Kirkwood 1968).

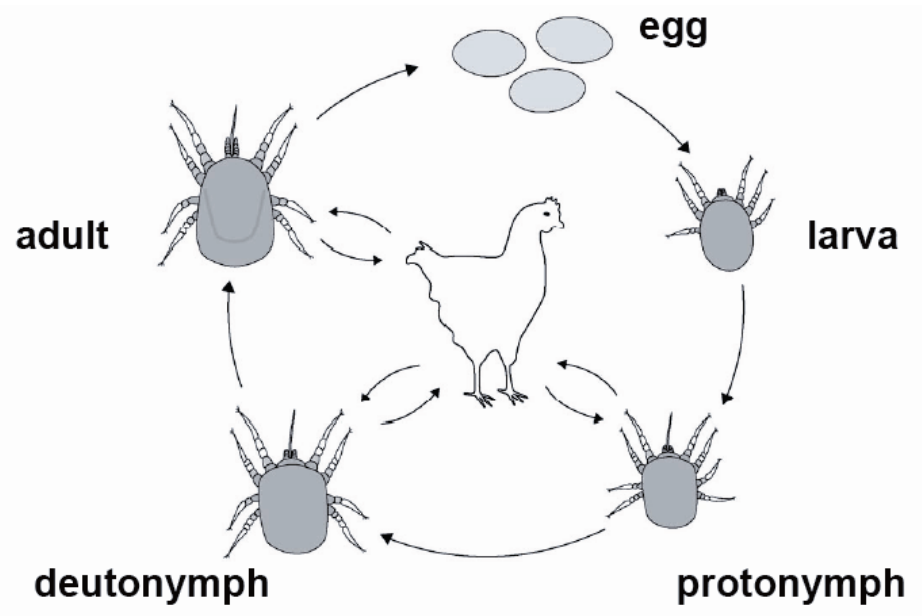

Figure 2.1 Life-cycle of Dermanyssus gallinae (C) V. Maurer FiBL)

The optimum temperature for PRM to produce eggs is $25-30^{\circ} \mathrm{C}$ and the most favourable temperatures for juvenile development are between 25 and $37^{\circ} \mathrm{C}$, where developmental rates are highest and mortalities low (Maurer and Baumgärtner 1992). Their best survival rate is observed at a relative humidity $(\mathrm{RH})$ of $70-90 \%$ (Nordenfors et al. 1999). Temperatures below $-20^{\circ} \mathrm{C}$ and above $45^{\circ} \mathrm{C}$ are considered lethal. Although sub-optimal conditions reduce the speed of reproduction, the mites are able to survive and reproduce within a wide temperature and RH range. For example, in Sweden between May and October more mites are found in traps in poultry houses than from November to April (Nordenfors and Höglund 2000). Under moderate climatic circumstances $\left(5-25^{\circ} \mathrm{C}\right)$, PRM may survive up to 9 months without feeding (Nordenfors et al. 1999).

Hungry mites have several resources that help them find food. A very sensitive response to changes in temperature and odours enables PRM to migrate and locate its host; starved PRM can detect a temperature gradient as low as $0.005^{\circ} \mathrm{C} / \mathrm{sec}$ (Kilpinen 2001). Resting mites react to a heat stimulus with increasing activity, probably as part of this host location process. This effect is most pronounced after 8-10 days of starvation (Kilpinen and Mullens 2004). PRM react to surface skin lipids of the host, which act as feeding stimulants (Zeman 1988). Furthermore, kairomones are thought to play a role in the host location behaviour, but it is unknown what specific kairomones are involved. Finally, carbon dioxide, which is known for its role in the host location behaviour of other haematophagous arthropods, is important for host detection by PRM (Kilpinen 2005). Once fed, PRM congregate in cracks and crevices to mate, they seem to return to the places where mites have previously congregated, a behaviour that is guided by pheromones (Entrekin and Oliver 1982).

Under laboratory rearing conditions, PRM eggs have a sex-ratio of 50:50 (i.e. ratio of haploid and diploid eggs) (Oliver 1965). In similar conditions a 50:50 ratio was found 
(Maurer and Baumgärtner 1992) in young adult PRM, thus making it reasonable to assume that mortalities of both sexes during juvenile development are similar. However, the normal male:female ratio in a natural population is unclear.

Inside poultry houses, PRM seem to prefer cracks smaller than 2 millimetres for breeding and hiding. Preferred hiding places are composed of paper, plastic and wood, whereas aluminium and glass are not preferred (Chirico unpublished data). As Maurer (1993) found during her experiments, PRM can drop from the ceiling, prefer to feed on the neck and back of the hen, and are also found in the manure and litter of heavily infested poultry houses.

Topics identified as requiring further research include lifespan and behaviour, survival and necessary conditions for eggs and the different stages of PRM, host finding and the cause of aggregation, attracting and repelling substances, the specific behaviour of the hens towards PRM and how feeding behaviour is influenced by (different kinds of) light, by lightdark cycles and by different dose of sunlight. Researchers in various countries have different experiences with sex ratios under field conditions ranging from 50/50 males/females to 1 male per few hundred females. This difference may be due to difficulties in distinguishing the deutonymph of D. gallinae and male of D. gallinae. Generally it appears that only a few males are needed for reproduction. Questions were also raised about the mating behaviour of PRM males and females.

\section{Effects of D. gallinae on hen, egg productivity and human health}

PRM infestations have various negative effects on hens, both directly due to their presence on the bird, and indirectly through their blood meals and as a vector for infectious diseases. An adult mite ingests approximately $0.2 \mu \mathrm{l}$ blood (Sikes and Chamberlain 1954) and high infestation rates of mites may cause anaemia and mortality of the hen/host. Infested hens increase their production of new blood cells, but during periods of rapid mite population growth, blood loss exceeds blood production capacity resulting in severe anaemia (Kilpinen et al. 2005). Other negative effects of PRM include high mortality, stress behaviour (higher levels of preening, head scratching and gentle feather pecking), lower body weight and reduced egg quality due to blood spots (Chauve 1998). Commercial farmers often claim lower egg production, but this has not been confirmed by experimental research. The productivity link could be that a severe mite infestation can increase mortality, and as Arkle (2007) showed, there is a direct effect of the size of the mite population on bird mortality. This of course means lower flock productivity; however, lower egg production per hen has not been found as a result of a mite infestation (Kilpinen et al. 2005).

PRM can have a serious impact upon human health. Apart from causing skin irritation and itching, the mites can cause allergic skin reactions (Sahibi et al. 2008; Potenza et al. 2008). The chemicals used to control PRM may have adverse effects on humans as well, both directly, for workers exposed to chemicals and indirectly through consumption of poultry eggs containing pesticide residues (Hamscher et al. 2003). Moreover, the eggs may have blood spots on the shells and would therefore be downgraded. This is caused when eggs roll 
over fed red mites. Effects on humans and eggs were not extensively discussed during the seminar.

Scientific information on the effects of PRM on hens is incomplete as information is mainly sourced from the industry and is not well documented. Researchers agree that there are indications for the following effects of PRM, which include

- increased water intake in infested hens

- lower egg production from the flock overall

- increased feed intake and a lower feed conversion ratio in infested hens

- hens avoiding places with high infestations

- general increase of immune response and/or immune suppression of infested hens

- disease transmission by PRM to hens

- reduced feather quality of infested hens

- hen genotype dependent effects and changes in mite populations due to the immune response of the hen

\section{Monitoring methods for a D. gallinae infestation in layer houses}

Various monitoring systems have been put forward for PRM. Until 2006 the majority of the poultry farmers noticed infestations because workers were being bitten by PRM, or found faecal (mite) spots on feeders and other equipment, clumps of mites on the belt and feeders, or blood spots on eggs. However, when these signs are evident, the infestation is already heavy and widespread. Specially designed corrugated cardboard traps for mites have been developed and evaluated by Nordenfors and Chirico (2001); Thind (personal communication) has demonstrated four types of traps: the ADAS monitoring trap (Figure 2.2a), the corrugated cardboard/plastic trap (Figure 2.2b), the perch trap and the tube trap (Figure 2.2c).

These traps may be improved by 1) varying the exposure duration, 2) selecting the most suitable sites for the traps, 3) good management and use of traps, 4) adding lures and attractants to the traps and 5) treating the traps with biological or chemical acaricides as part of lure and kill strategy. Traps treated with these acaricides should be placed out of reach of the birds (Chirico and Tauson 2002; Lundh et al. 2005). Traps can be used as both monitoring devices and a control method. In the future, monitoring may be improved by developing electronic sensors (Thind personal communication).

Participants agreed that no simple advice could be given regarding number of spots in the poultry facilities to monitor or the method of monitoring. Being able to quantify the infestations would reduce negative effects of PRM on the hens, and could reduce the costs of mite control, if early awareness resulted in producers only having to treat a restricted infected zone rather than a complete layer house. Thus monitoring the flocks and a subsequently quick reactions are paramount to prevent an increase of the mite population. However, it must be borne in mind that the currently available monitoring methods only 
indicate trends in the mite population and are unable to give the actual number of PRM present.

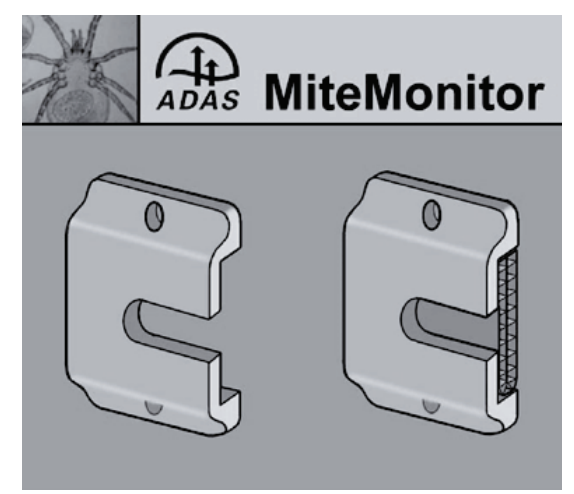

Figure 2.2a ADAS monitoring trap (C) ADAS, UK)

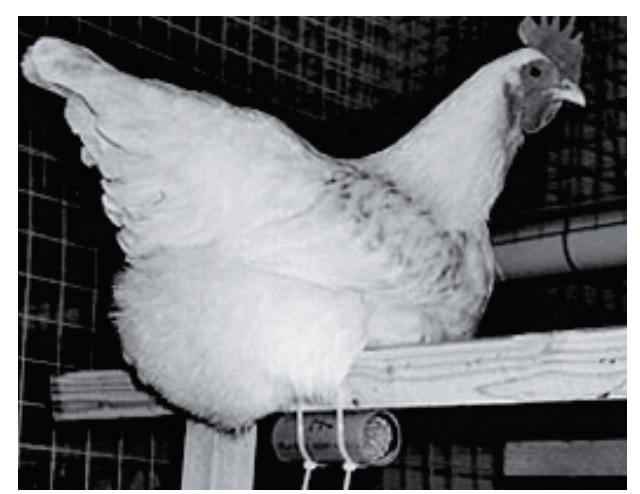

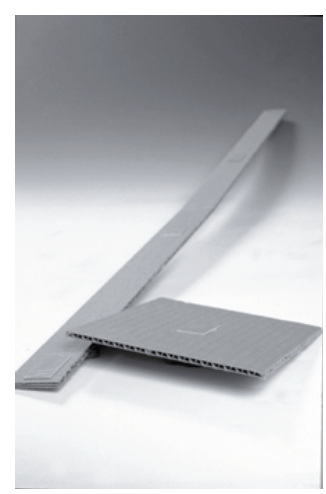

Figure 2.2b Corrugated cardboard trap (C) Bengt Ekberg, SVA)

Figure 2.2c Tube trap (C Van Emous, WUR)

\section{Control methods}

Control can be divided into two parts: conventional methods and alternative methods. Conventional methods mostly focus on killing PRM or preventing infestations. 'Alternative' methods included using light, odours, predatory mites, fungus or vaccines. These ideas and approaches are in various stages of development.

\section{Conventional methods}

Regular cleaning of poultry facilities and maintaining good hygiene practices is still considered laborious and their benefits are grossly underestimated. These approaches can aid in the removal of large proportions of the mite populations. Simple cleaning with water can remove a large number of mites and eggs (Nordenfors and Höglund 2000). Another conventional method is the use of acaricides although this may carry the risk of exposing eggs, poultry and humans to their residues (Hamscher et al. 2003).

Furthermore, experts indicated that it is only a matter of time before PRM develops resistance to acaricides as pyrethroids, making them ineffective, as already shown in Italy (Marangi et al. 2009), UK (Thind and Ford 2007), Sweden (Nordenfors et al. 2001) and 
France (Beugnet et al. 1997). With diminishing numbers of approved chemicals available, chemical treatments were not considered as sustainable solutions. However one new compound which may show a) a rapid response, b) no indication of cross resistance and c) an extremely low mammalian toxicity may offer a short term solution or be used as part of an integrated approach in parallel with other control methods presented later in this paper.

The use of various types of silica dusts was considered, as they demonstrate no known poisoning effect to hens and humans and resistance is unlikely. The main benefit of silica is through its ability to immobilise a mite by adhering to its body, especially to the tarsal part of legs, and preventing locomotion. Silica products are also thought to cause damage to the protective cuticle of PRM, impairing their water balance so that they rapidly dehydrate and die. In humans there is a small risk of silicosis especially during application. Consequently appropriate precautions must be taken. Silica products, especially powdered forms, can cause skin irritations, but other formulations are available (e.g. gel, fluid). The efficacy depends on the quality of the silica, environmental factors and the extent the silica attaches to the treated surfaces.

Controlling PRM by heating hen houses to temperatures above $45^{\circ} \mathrm{C}$ is a well-known and commonly applied method in The Netherlands and Norway. Heat treatment is usually carried out between the production cycles. In Norway, this method can be combined with a chemical treatment called phoxime prior to introducing the new flock. In a trial, all six treated hen houses remained free of PRM during the production cycle after the treatment (Gjevre unpublished data). In the Netherlands, heat treatment without chemical treatment failed to offer similar control and the houses were re-infested within six months (Van Emous personal communication). This may be due to a number of factors, including being unable to achieve the required temperature throughout the building, given the larger and more complex hen houses and the high farm density in The Netherlands, or the absence of the use of chemicals. The main disadvantage of heat-treatment is its high cost; another disadvantage of the heat treatment is the risk of heat related damage to the hen house equipment. To avoid damage, it is of great importance to continuously measure the temperature and to circulate the hot air with fans to minimise areas with sublethal temperatures where mites could survive. Because it may be possible for some mites to survive by escaping into areas with non-lethal temperature, chemical treatment should always follow the heat treatment (Gjevre personal communication).

In The Netherlands, several designs of housing systems have been tested to prevent PRM from reaching the hens. In these systems there are very few contact points between the perches and the floor. To minimise migration of PRM to the perches, barriers containing oil or silicas are installed to prevent mites reaching the hens during the night. Another designrelated method for lowering the mite burden in the hen houses is to minimize the hiding places by using slatted floors and laying nest floors with more open structures and fewer hiding places for the mites. Although these adaptations do not solve the problem, they can give good results when integrated with other measures. 
Finally, another conventional approach to controlling PRM is to consider the production chain. It is generally known that PRM is not only present in layer farms, but also in rearing farms. Transport of eggs, birds and manure are known risk factors for introducing PRM. Visitors, including those related to work that needs to be done with the birds, are a risk factor. Good hygiene processes and openness in relation to PRM problems is important in reducing the spread of PRM along the production chain.

\section{Alternative methods}

One alternative method to control PRM infestation is to use a specific lighting programme. Research in Belgium indicated that a light schedule of $1 / 4$ hour light and $3 / 4$ hour dark could reduce PRM infestations (Zoons 2004). This effect has been verified by research from other countries, although some farms reported that the effect disappeared after a time. It is unclear why this lighting programme affects PRM. Possible explanations are that PRM activity is inhibited by light and thus with short periods of darkness the mites cannot reach the hens and/or PRM are unable to reach their hiding places in time, so the hens are able to eat them. As EU-Directive 1999/74 for the protection of laying hens dictates a continuous dark period of at least 8 hours, this light schedule is not allowed in Europe and thus no light pattern option is available. Whether there are other possibilities within the regulations to control PRM with light has not been discussed.

Another alternative method is the use of attractant or repellent odours. French research indicates that PRM respond to these odours, but the reactions are not always predictable and the strength of the odours can confound responses (Chauve personal communication). Furthermore PRM produces odours themselves to attract other PRM, and, in case of high infestations, it is not clear which will be more attractive: the appealing natural odours of clusters of PRM or artificially applied odours. Researchers agreed that odours could be manipulated to give some control, but more research is needed to find a workable concept.

Natural acaricides include essential oils, herbs or plant extracts which contain a chemical component that kills PRM (George et al. 2008a,b; Maurer et al. 2009). Despite their natural origin, these acaricides may be harmful to humans and animals and may result in residues in the manure. The existing commercial products also lack consistency in the concentration of the actual components due to influences of weather, sun, soil, etc. on the growing plants and due to the variability in concentration of active ingredients in existing commercial products. Furthermore, resistance can build up just as it does with chemical acaricides. Success therefore will depend greatly on the way of application. Participants considered the prospect of success of this measure as only moderate.

Predatory mites are another alternative option. Mites are already widely used in the control of pests in greenhouses. The use of these predators to control PRM appears promising, especially if the predators will attack all stages of PRM. If these predatory mites hide in the daytime in the same cracks and crevices as PRM, they may disrupt the natural aggregation of PRM and also would not be easily pecked by the hens. The speed of 
reproduction of the predator mites would need to reflect the population dynamics of PRM and they would have to be capable of keeping the number of PRM at an acceptably low level. Additionally, they should be able to withstand and survive the conditions found in the poultry houses. The selection of suitable candidate predatory mites should also take into account any impact on human and poultry health (Lesna personal communication).

There are many species of predatory mites, and research will focus on those species that fit the basic profile. To select these, mites and insects will be collected from the nests of birds that reuse nesting sites (Lesna et al. 2009). The predators found will be assessed on their ability to feed on PRM and its different stages, and the candidate predators will be reared and assessed under conditions similar to those in poultry houses. The best candidate will then be tested on a small scale. This research will be undertaken by researchers at the University of Amsterdam and the University of Groningen, who have a wide experience in the biological control of pests in crops and the ecology of birds. Knowledge of poultry will be brought into the project by researchers of Wageningen UR Livestock Research.

Danish and UK researchers recently took part in the EU CHIMICO-project which included studies on entomopathogenic fungi (Steenberg et al. 2005). These fungi are capable of infecting and killing insect and mite species. The spores of the fungi germinate on the host cuticle, penetrate it and spread through the body. After the fungus has killed the mite, it can grow out of the mite cadaver and produce more spores, increasing the chance for other PRM to be infested, potentially increasing persistence of control. There is a wide variety of fungi, many of which are well documented in terms of specific characteristics and their area of application. To control PRM, a fungus is needed that affects PRM and/or its eggs and thus prevents their multiplication. A very important aspect is safety to non-targets, such as humans, poultry and eggs, but the record of these fungi is excellent in this (Vestergaard et al. 2003) and safe isolates will be available. The selected fungi should be able to survive in PRM and the ecosystem of PRM (e.g. the high ammonia levels, $25^{\circ} \mathrm{C}$ and $75 \% \mathrm{RH}$ in poultry houses). In some preliminary studies, fungi were able to affect PRM, but the multiplication rate of the fungi was too low to reduce the PRM population effectively. These first results indicate that it is possible to use fungi as a control method for PRM. The persistence of fungal isolates on materials such as metals (Hong et al. 2005) that may be found in poultry units suggests that long term protection is feasible. With selection of a suitable isolate, fungi appear to have the potential to provide a successful eradication strategy for the future.

In the UK, research is being conducted to develop a vaccine against PRM (Arkle et al. 2008). The idea is that hens develop a natural defence reaction if they are bitten by PRM. This reaction can have many different expressions. For example, the hen can react by making its skin thicker and thus more difficult to penetrate. Another proposal is introducing an antibody in the blood that makes the blood coagulate the moment it enters the mite. Natural resistance like this usually starts slowly, but can be accelerated by vaccinating animals with mite components. Researchers in the UK already have obtained some positive 
results in their preliminary studies. However, it will take time to develop the most effective vaccine, and it is likely that it will be several years before the first vaccines is available.

\section{Conclusions}

Much is still unknown about PRM (e.g. reproduction, survival methods, etc.). Sustained and extensive investigations are necessary to make PRM control efficient. PRM probably causes more damage than envisaged, the projected costs in Europe indicating a large expenditure (Emous et al. 2005; Bell personal communication). Monitoring is an important instrument in recognising and admitting the problem and taking measures in time, but needs to be more finely tuned. Co-operation is needed to prevent transmission of mites along the production chain. Wide-ranging investigations into control strategies focused on fine-tuning of current control measures is urgently required. Furthermore, an approach wherein knowledge from different research fields is integrated will help to identify effective new control or eradication methods.

In the short term, the most promising control method is heating of the hen house combined with chemical treatment. Future areas of development which show promise are:

1) Use of entomopathogenic fungi. Some very promising results have been obtained, but more work needs to be done regarding practical application in poultry farms;

2) Vaccination. Rapid developments are made in this area and the first preliminary results are very promising;

3) Predatory mites. They will not eradicate PRM but have the potential to allow an acceptable low-level infestation with no harm to poultry, product, environment and people.

Several European Research groups are working on these promising concepts and the international seminar was the first initiative to exchange information on PRM among researchers. Because this cross-fertilisation was felt to be useful and productive, effort should be made to convene such meetings on a regular basis in the future.

\section{Acknowledgements}

This international seminar was funded by the Dutch National Egg Board. The authors also would like to thank L. McPhee for helpful comments on an earlier version of the manuscript and all other participants of the workshop: S. Arkle (School of Agriculture, Food and Rural Development, University of Newcastle, UK), D. van Doorn (Animal Health Services, The Netherlands), R. van Emous (Animal Sciences Group of Wageningen UR, The Netherlands), J. Guy (School of Agriculture, Food and Rural Development, University of Newcastle, UK) and I. Lesna (Institute for Biodiversity and Ecosystem Dynamics, The Netherlands). 


\section{References}

Arkle S (2007) Development of a vaccine against the poultry red mite (Dermanyssus gallinae), PhD Thesis, Newcastle University, UK

Arkle S, Harrington D, De Luna C, George D, Guy J and Sparagano, OA (2008) Immunological control of poultry red mite: the use of whole mite antigens as a candidate vaccine. Annals of the New-York Academy of Sciences 1149(1): 36-40(5)

Axtell RC, Arends JJ (1990) Ecology and management of arthropod pests of poultry. Annu Rev Entomol 35: 101-126

Beugnets F, Chauve C, Gauthey M, Beert L (1997) Resistance of the red poultry mite to pyrethroids in France. Vet Rec 140: 577-579

Chauve C. (1998) The poultry red mite Dermanyssus gallinae (De Geer, 1778): current situation and future prospects for control. Vet Parasitol 79: 239-245

Chirico J, Tauson R (2002) Traps containing acaricides for the control of Dermanyssus gallinae. Vet Parasitol 110: 109-116

Emous RA van, Fiks-Van Niekerk TGCM, Mul MF (2005) E11 miljoen schade voor de sector: enquête vogelmijten op leghennenbedrijven. (€ 11 million damage for the sector: enquiry into the cost of mites to the poultry industry. In Dutch). De pluimveehouderij 35: 8-9

Entrekin DL, Oliver JH Jr (1982) Aggregation of the chicken mite, Dermanyssus gallinae (Acari: Dermanyssidae). J Med Entomol 19: 671-678

George D, Calaghan K, Guy JH, Sparagano OAE (2008a) Lack of prolonged activity of lavender essential oils as acaricides against the poultry red mite (Dermanyssus gallinae) under laboratory conditions. Res Vet Sci 85(3): 540-542

George DR, Smith TJ, Sparagano OAE, Gut JH (2008b) The influence of 'time since last blood meal' on the toxicity of essential oils to the poultry red mite (Dermanyssus gallinae). Vet Parasitol 155: 333-335

Hamscher G, Priess B, Hartung J, Nogossek MI, Gluender G, Nau H (2003) Determination of propoxur residues in eggs by liquid chromatography-diode array detection after treatment of stocked housing facilities for the poultry red mite (Dermanyssus gallinae). Anal Chim Acta 483: 19-26

Hong TD, Edgington S, Ellis RH, Aquino de Muro M, Moore D (2005) Saturated salt solutions for humidity control and the survival of dry powder and oil formulations of Beauveria bassiana conidia. J Invertebr Pathol 89: 136-143

Kilpinen $O$ (2001) Activation of the poultry red mite, Dermanyssus gallinae (Acari: Dermanyssidae), by increasing temperatures. Exp Appl Acarol 25: 859-867

Kilpinen $O$ (2005) How to obtain a blood meal without being eaten by the host: the case of the poultry red mite, Dermanyssus gallinae. Physiological Entomology 30: 232-240

Kilpinen 0, Mullens BA (2004) Effect of food deprivation on response of the mite, Dermanyssus gallinae, to heat. Med Vet Entomol 18: 368-371 
Kilpinen O, Roepstorff A, Permin A, Norgaard-Nielsen G, Lawson LG, Simonsen HB (2005) Influence of Dermanyssus gallinae and Ascaridia galli infections on behaviour and health of laying hens (Gallus gallus domesticus). Br Poult Sci 46: 2634

Kirkwood AC (1968) Some observation on the feeding habits of the poultry mites Dermanyssus gallinae and Liponyssus sylviarum. Entomol Exp Appl 11: 315-320

Lesna I, Wolfs P, Faranji, F, Roy L, Komdeur J, Sabelis MW (2009) Candidate predators for biological control of the poultry red mite Dermanyssus gallinae. Exp Appl Acarol 48: 63-80

Lundh J, Wiktelius D, Chirico J (2005) Azadirachtin-impregnated traps for the control of Dermanyssus gallinae. Vet Parasitol 130: 337-342

Marangi M, Cafiero MA, Capelli G, Camarda A, Sparagano OAE, Giangaspero A (2009) Evaluation of poultry red mite (Dermanyssus gallinae, Acarina:Dermanyssidae) susceptibility to some acaricides in a field population from Italy. Exp Appl Acarol 48: 11-18

Maurer V (1993) The dynamics of Dermanyssus gallinae (Acari: Dermanyssidae) populations interacting with laying hens and the predatory mite Cheyletus eruditus (Acari: Cheyletidae). Dissertation ETHZ No.10330, 104pp

Maurer V, Baumgärtner J (1992) Temperature influence on life table statistics of the chicken mite Dermanyssus gallinae (Acari: Dermanyssidae). Exp Appl Acarol 15: 27-40

Maurer V, Bieri M, Folsch DW (1988) Das suchverhalten von Dermanyssus gallinae in hühnerställen. Host-finding of Dermanyssus gallinae in poultry -houses. Arch Geflügelkd 52: 209-215

Maurer V, Perler E, Heckendorn F (2009) In vitro efficacies of oils, silicas and plant preparations against the poultry red mite Dermanyssus gallinae. Exp Appl Acarol 48: 31-41

Nordenfors H, Höglund J (2000) Long term dynamics of Dermanyssus gallinae in relation to mite control measures in aviary systems for layers. Br Poult Sci 41: 533-540

Nordenfors H, Chirico J (2001) Evaluation of a sampling trap for Dermanyssus gallinae (Acari: Dermanyssidae). J Econ Entomol 94: 1617-1621

Nordenfors H, Höglund J, Uggla A (1999) Effects of temperature and humidity on oviposition, molting and longevity of Dermanyssus gallinae (Acari: Dermanyssidae). J Med Entomol 36: $68-72$

Nordenfors H, Höglund J, Tauson R, Chirico J (2001) Effect of permethrin impregnated plastic strips on Dermanyssus gallinae in loose-housing systems for laying hens. Vet Parasitol 102: 121-131

Oliver JH Jr (1965) Karyotypes and sex determination in some Dermanyssid mites (Acarina: Mesostigmata). Ann Entomol Soc Am 58 (4): 567-573

Potenza L, Cafiero M, Cucchiarini L, La Salandra G, Giangaspero A, Sparagano OAE, Camarda A (2008) Dermanyssus gallinae mites collected from pigeon nests and laying hens: a 
molecular study based on the ITS region. BSP Spring, Trypanosomiasis/ Leishmaniasis \& Malaria Meetings. March 30th, April 2nd, Newcastle upon Tyne, UK: 169

Sahibi H, Sparagano 0, Rhalem A (2008) Dermanyssus gallinae: Acari parasite highly aggressive but still ignored in Morocco. BSP Spring, Trypanosomiasis/Leishmaniasis \& Malaria Meetings. March 30th, April 2nd, Newcastle upon Tyne, UK: 173

Sikes RK, Chamberlain RW (1954) Laboratory observations on three species of bird mites. J Parasitol 40: 691-697

Steenberg T, Kilpinen O, Jespersen JB, Soler-Cruz MD, Vega-Robles C, Birkett M, Dewhirst S, Pickett J (2005) Advances in the development of novel control methods against chicken mites (Dermanyssus gallinae). Bulletin -OILB/SROP 28: 89-91

Thind BB, Ford HL (2007) Assessment of susceptibility of the poultry red mite Dermanyssus gallinae (Acari: Dermanyssidae) to some acaricides using an adapted filter paper based bioassay. Vet Parasitol 144: 344-348

Vestergaard S, Cherry A, Keller S, Goettel M (2003) Safety of Hyphomycete fungi as microbial control agents. In: Hokkanen HMT, Hajek AE (Eds) Environmental Impacts of Microbial Insecticides: 32-62 (Kluwer Academic Publishers, Dordrecht)

Wood HP (1917) The chicken mite: its life history and habits. United States Department of Agriculture, Bulletin 553

Zeman P (1988) Surface skin lipids of birds, a proper host kairomone and feeding inducer in the poultry red mite, Dermanyssus gallinae. Exp Appl Acarol 5: 163-173

Zoons J (2004) The effect of light programs on red mite (Dermanyssus gallinae) in battery cage housing. In: Perry GC (Ed.) Welfare of the Laying Hen: 416 (CABI) 


\section{Chapter 3}

\section{Preventing introduction and spread of Dermanyssus gallinae in poultry facilities using the HACCP method}

Monique F. Mul ${ }^{1}$ and Constantianus J.M. Koenraadt ${ }^{2}$

${ }^{1}$ Wageningen University and Research, Department Animal husbandry and environment, P.O. Box 6700 AH Wageningen, The Netherlands

2 Laboratory of Entomology, Department of Plant Sciences, Wageningen University, P.O. Box 8031, 6700 EH Wageningen, The Netherlands

Reprinted with permission of Springer.

Experimental and Applied Acaralogy (2009) 48: 167-181 


\begin{abstract}
Preventing the establishment of ectoparasitic poultry red mite (Dermanyssus gallinae) populations is key in ensuring welfare and egg production of laying hens and absence of allergic reactions of workers in poultry facilities. Using the Hazard Analysis and Critical Control Point method, a panel of experts identified hazards and associated risks concerning the introduction and spread of this mite in poultry facilities. Together we provide an overview of possible corrective actions that can be taken to prevent population establishment. Additionally, a checklist of the most critical control points has been devised as management tool for poultry farmers. This list was evaluated by Dutch and British poultry farmers. They found the checklist feasible and useful.
\end{abstract}




\section{Introduction}

Dermanyssus gallinae (De Geer 1778) is the most common ectoparasite in poultry. It belongs to the subclass Acari and is known under the common name poultry red mite (PRM) or chicken mite. Adult poultry red mites are on average 751 microns in length and 461 microns in width when engorged and are found in cracks and crevices within the poultry facilities in the vicinity of the hens. In these cracks and crevices the mites mate, deposit their eggs and molt. The lifecycle of the mite contains five stages: egg, larva, protonymph, deutonymph, and adult (Wood 1917). The protonymph, deutonymph, and adult feed on blood of poultry and other birds, but also of other animals, including humans (Sikes and Chamberlain 1954). The poultry red mite usually stays at the hen for a blood meal during the dark period. Within 8 weeks one female may produce an estimated amount of two and a half thousand offspring (Wood 1917).

Infestations with the poultry red mite can reduce the welfare of chickens, increase mortality and initiate allergic reactions of workers in the poultry facilities (Baselga et al. 1996; Chauve 1998; Kilpinen et al. 2005; Nordenfors 2000). The mite is a potential vector of various pathogens, such as Salmonella and the causative agents of fowl cholera, Newcastle disease and eastern equine encephalitis (Moro et al. 2005). Control of D. gallinae has become more difficult due to development of resistance to permethrin (Chauve 1998; Marangi et al. 2008; Nordenfors et al. 2001) and a ban on other acaricides in some countries such as carbaryl (a carbamate). Therefore, recent research has been focused on alternative control methods for D. gallinae such as the use of entomopathogenic fungi, silica, improved hygiene (e.g., heat cleansing, washing) and the use of natural predators (Gjevre, personal communication; Maurer and Hertzberg 2001; Maurer and Perler 2006; Nordenfors 2000; Steenberg et al. 2005). However, control could be more efficiently employed if prevention of the introduction and spread of $D$. gallinae was more rigorously enforced.

The Hazard Analysis and Critical Control Points (HACCP) system was introduced in the 1960s by NASA for design and manufacturing of food for spaceflights. Since then HACCP has been recognized internationally as a logical tool in the adaptation of traditional inspection methods to a modern, science-based, food safety system (Mayes 1993, 1998; Sun and Ockerman 2005). The advantages of such a structured and formalized concept was recognized and adapted for use in safeguarding animal welfare and health (Bonde and Sørensen 2004; Noordhuizen and Frankena 1999). For example, HACCP allows one to identify the risk factors for introduction and spread of bacteria and parasites such as Salmonella and Toxoplasma gondii (Kijlstra et al. 2004; Mul and Van der Gaag 2003). Moreover, it has been employed in risk assessment of the introduction of unwanted organisms on passenger ships (Mouchtouri et al. 2008) and it has been nominated for the prevention of fire ant introduction and spread in Australia (Rayment 2006). It is hypothesized that, in a similar way, the HACCP method can be used for risk factor assessment concerning introduction and spread of D. gallinae on poultry farms. Earlier work demonstrated that poultry red mites are considered the most severe and most frequent 
hazard in relation to 9 other poultry-related hazards such as pasteurellosis and cannibalism (Hegelund and Sørensen 2007). This paper further elaborates on the identification of the risk factors and critical control points, and presents suggestions for corrective actions. Based on this information and evaluation by farmers, we have developed a checklist that can be used to control D. gallinae more readily and effectively on poultry facilities.

\section{HACCP development}

HACCP is a method of controlling hazards and reducing risks. It comprises seven principles (Mayes 1998): (1) conduct a hazard analysis, (2) identify critical control points, (3) establish critical limits for each critical control point, (4) establish critical control point monitoring requirements, (5) establish corrective actions, (6) establish record keeping procedures, and (7) establish procedures to ensure that the HACCP system is working as intended (validation and verification). In order to apply this method to achieve insight in the hazards for introduction and spread of D. gallinae some adjustments were required. For example, instead of eradication or control of a critical control point (demand of HACCP), a reduction of the hazard had to be accepted and instead of analysing the risk of a product we analysed the risk of the potential (rate and extent) introduction or spread of D. gallinae in the poultry facility.

\section{Hazard analysis}

A hazard analysis is conducted by compiling a schedule of all farm processes. Due to the scarcity of quantitative information on epidemiological risk factors for introduction and spread of D. gallinae infestations, an expert opinion study was performed as others have in the past (Bonde and Sørensen 2004; Noordhuizen and Frankena 1999). Assessment of the risk of D. gallinae infestation and spread was judged by four experts. Three of them were experts in poultry husbandry and two of them were experts on D. gallinae. The farm processes under assessment were divided into 13 hazard categories (Table 3.1). In total 41 hazards were identified. Risk was calculated by multiplying likelihood and severity. Likelihood was classified into three categories: (1) occurring seldom or only theoretically, (2) occurring approximately once a year, and (3) occurring repeatedly or more than once a year throughout the year. Severity was classified as (1) low when only a single place in the poultry facility becomes infested with D. gallinae, (2) moderate, when the poultry facility becomes infested with D. gallinae at more than one location or (3) high, when D. gallinae infestation occurs at almost all places within the poultry facility. The panel of experts made several suggestions for possible corrective action. Details of the hazards are shown in Table 3.2 . 
Table 3.1 Overview of hazard categories, number of hazards and CCP's per category and associated total and average risk (details of the hazards are shown in table 3.2)

\begin{tabular}{lcccccc}
\hline Hazard category & $\begin{array}{c}\text { Risk for } \\
\text { introduction }\end{array}$ & $\begin{array}{c}\text { Risk } \\
\text { for } \\
\text { spread }\end{array}$ & $\begin{array}{c}\text { No. of } \\
\text { hazards }\end{array}$ & $\begin{array}{c}\text { No. } \\
\text { of } \\
\text { CCP's }\end{array}$ & $\begin{array}{c}\text { Total } \\
\text { risk } \\
\text { score }\end{array}$ & $\begin{array}{c}\text { Average } \\
\text { risk } \\
\text { score }\end{array}$ \\
\hline Environment & $\mathrm{x}$ & $\mathrm{x}$ & 7 & 5 & 28 & 4.0 \\
Feed & $\mathrm{x}$ & $\mathrm{x}$ & 4 & 1 & 10 & 2.5 \\
Litter & $\mathrm{x}$ & & 1 & 1 & 3 & 3.0 \\
Growing hens & $\mathrm{x}$ & & 4 & 3 & 23 & 5.8 \\
Material / equipment & $\mathrm{x}$ & $\mathrm{x}$ & 3 & 2 & 13 & 4.3 \\
Manure & $\mathrm{x}$ & $\mathrm{x}$ & 3 & 2 & 16 & 5.3 \\
Eggs & $\mathrm{x}$ & $\mathrm{x}$ & 4 & 4 & 21 & 5.3 \\
Manure aeration & $\mathrm{x}$ & $\mathrm{x}$ & 2 & 2 & 12 & 6.0 \\
Cadavers & $\mathrm{x}$ & $\mathrm{x}$ & 2 & 2 & 12 & 6.0 \\
Visitors / external personnel & $\mathrm{x}$ & $\mathrm{x}$ & 3 & 3 & 14 & 4.7 \\
Poultry farmer / employee & $\mathrm{x}$ & $\mathrm{x}$ & 3 & 3 & 24 & 8.0 \\
Ventilation & $\mathrm{x}$ & $\mathrm{x}$ & 3 & 1 & 7 & 2.3 \\
Unproductive hens & $\mathrm{x}$ & & 2 & 2 & 6 & 3.0 \\
\hline
\end{tabular}


Table 3.2 Explanation of hazards and associated risks for introduction and spread of D. gallinae in poultry systems

\begin{tabular}{|c|c|c|c|c|c|c|}
\hline $\begin{array}{l}\text { Hazard } \\
\text { category }\end{array}$ & Hazard & $\begin{array}{c}\text { Likeli- } \\
\text { hood }\end{array}$ & $\begin{array}{c}\text { Seve- } \\
\text { rity }\end{array}$ & Risk & Motivation & Corrective action \\
\hline Environment & $\begin{array}{l}\text { Introduction of } \\
\text { mites via pest } \\
\text { animals such as } \\
\text { rats, mice, etc. }\end{array}$ & 2 & 2 & 4 & $\begin{array}{l}\text { Poultry houses are attractive to rats, mice etc. } \\
\text { because of the presence of food, water and } \\
\text { opportunities for shelter. These animals are } \\
\text { potential carriers of mites as well. }\end{array}$ & $\begin{array}{l}\text { - Professional pest/vermin control } \\
\text { - No storage against poultry house } \\
\text { - Strip of } 2 \mathrm{~m} \text { along the poultry house free } \\
\text { of vegetation } \\
\text { - Hard pavement (e.g. gravel or } \\
\text { cobblestones) next to poultry house } \\
\text { instead of grass }\end{array}$ \\
\hline Environment & $\begin{array}{l}\text { Introduction of } \\
\text { mites into poultry } \\
\text { house via wild birds }\end{array}$ & 2 & 2 & 4 & $\begin{array}{l}\text { Mites may be present on a wild bird outside of } \\
\text { its nest }\end{array}$ & $\begin{array}{l}\text { - Close poultry house for birds (bird-proof) } \\
\text { - Install door springs on doors } \\
\text { - No shelter/runs for hobby poultry/birds } \\
\text { next to poultry house }\end{array}$ \\
\hline Environment & $\begin{array}{l}\text { Introduction of } \\
\text { mites because of } \\
\text { bird nests attached } \\
\text { to the poultry house }\end{array}$ & 2 & 2 & 4 & $\begin{array}{l}\text { Many wild bird nests are infested with mites. } \\
\text { After fledging of young birds in spring, mites } \\
\text { starve and will seek new hosts inside the poultry } \\
\text { house. }\end{array}$ & $\begin{array}{l}\text { - Fill space underneath the (corrugated) } \\
\text { roof to prevent breeding of birds } \\
\text { - No vegetation alongside poultry house } \\
\text { that could house bird nests } \\
\text { - No nesting boxes against wall of poultry } \\
\text { house }\end{array}$ \\
\hline Environment & $\begin{array}{l}\text { Introduction of } \\
\text { mites into poultry } \\
\text { house via pets }\end{array}$ & 1 & 2 & 2 & $\begin{array}{l}\text { In the absence of birds or chickens, mites can } \\
\text { chose dogs or cats as host, but the likelihood is } \\
\text { considered low. }\end{array}$ & $\begin{array}{l}\text { - Do not allow pets in poultry house or } \\
\text { associated spaces } \\
\text { - Install door springs on outside doors }\end{array}$ \\
\hline Environment & $\begin{array}{l}\text { Spread of mites via } \\
\text { rats, mice, flies etc. }\end{array}$ & 2 & 3 & 6 & $\begin{array}{l}\text { Pest animals such as rats and mice are potential } \\
\text { carriers of mites. They can spread mites within a } \\
\text { poultry house. Severity is higher, because mites } \\
\text { have already been introduced before further } \\
\text { spread occurs. }\end{array}$ & - Professional pest/vermin control \\
\hline Environment & $\begin{array}{l}\text { Spread of mites via } \\
\text { wild birds }\end{array}$ & 2 & 3 & 6 & $\begin{array}{l}\text { Wild birds could carry mites and thus spread } \\
\text { them within the poultry house. The likelihood } \\
\text { depends on infestation pressure among wild } \\
\text { birds. Wild birds could reach many areas within } \\
\text { the poultry house. }\end{array}$ & $\begin{array}{l}\text { - If possible, remove wild birds from } \\
\text { poultry house }\end{array}$ \\
\hline
\end{tabular}




\begin{tabular}{|c|c|c|c|c|c|}
\hline $\begin{array}{l}\text { Hazard } \\
\text { category }\end{array}$ & Hazard & $\begin{array}{l}\text { Likeli- } \\
\text { hood }\end{array}$ & $\begin{array}{l}\text { Seve- } \\
\text { rity }\end{array}$ & Risk & Motivation \\
\hline Environment & $\begin{array}{l}\text { Spread of mites via } \\
\text { pets }\end{array}$ & 1 & 2 & 2 & Pets could carry and spread mites. \\
\hline Feed & $\begin{array}{l}\text { Introduction of } \\
\text { mites into poultry } \\
\text { house via unloading } \\
\text { feed truck }\end{array}$ & 1 & 2 & 2 & $\begin{array}{l}\text { Feed trucks visit different farms and could } \\
\text { theoretically carry mites from one farm to } \\
\text { another. Likelihood and severity are low, } \\
\text { because even if infested, it will be hard for mites } \\
\text { to move from truck to poultry house }\end{array}$ \\
\hline Feed & $\begin{array}{l}\text { Introduction of } \\
\text { mites into poultry } \\
\text { house via feed bags }\end{array}$ & 1 & 1 & 1 & $\begin{array}{l}\text { Feed bags, though prepared clean from the } \\
\text { factory, could be infested because feed truck } \\
\text { visits different farms. }\end{array}$ \\
\hline Feed & $\begin{array}{l}\text { Spread between } \\
\text { barns via feed } \\
\text { transport system }\end{array}$ & 1 & 1 & 1 & $\begin{array}{l}\text { The feed transport system is a very low hazard } \\
\text { for transport of mites between barns. }\end{array}$ \\
\hline Feed & $\begin{array}{l}\text { Spread within barn } \\
\text { via feeding system }\end{array}$ & 2 & 3 & 6 & $\begin{array}{l}\text { Mites hide in (bent) edges/rims of the feeding } \\
\text { system and may end up in the food or on the } \\
\text { transporting chain and thus spread throughout } \\
\text { the poultry house. }\end{array}$ \\
\hline Litter & $\begin{array}{l}\text { Introduction of } \\
\text { mites in poultry } \\
\text { house through } \\
\text { scattering litter }\end{array}$ & 1 & 3 & 3 & $\begin{array}{l}\text { Litter is clean and generally not a good hiding } \\
\text { place for mites (low likelihood). However, if } \\
\text { litter is infested, it will be spread throughout the } \\
\text { entire poultry house (high severity) }\end{array}$ \\
\hline Growing hens & $\begin{array}{l}\text { Introduction of } \\
\text { mites with new } \\
\text { flock of growing } \\
\text { hens }\end{array}$ & 3 & 3 & 9 & $\begin{array}{l}\text { Chickens from production farms are caught } \\
\text { early in the morning. If the production farm is } \\
\text { infested, some chickens could carry the mites to } \\
\text { the laying facility. }\end{array}$ \\
\hline
\end{tabular}

Corrective action

- Do not allow pets in poultry house or associated spaces

- Keep distance between truck and poultry house

- Store feed bags in different area

- Close holes where transport system enters/leaves the barn with cement

- Treat feeding system with control agent

- Close edges and rims of feeding system with silicone sealant

- Only use dry, clean litter

- More attention for prevention and monitoring of mites during growing phase

- Switch on lights one hour before collection in battery systems

- Switch on lights one hour before and switch to blue light during collection in free-range and aviary systems

- Mix garlic through drinking water several days before transport 


\begin{tabular}{|c|c|c|c|c|c|c|}
\hline $\begin{array}{l}\text { Hazard } \\
\text { category }\end{array}$ & Hazard & $\begin{array}{l}\text { Likeli- } \\
\text { hood }\end{array}$ & $\begin{array}{c}\text { Seve- } \\
\text { rity }\end{array}$ & Risk & Motivation & Corrective action \\
\hline Growing hens & $\begin{array}{l}\text { Introduction of } \\
\text { mites with } \\
\text { containers/crates }\end{array}$ & 3 & 3 & 9 & $\begin{array}{l}\text { A large proportion of mites that are on the } \\
\text { chicken during collection, will move from the } \\
\text { chicken and hide in containers/crates. These } \\
\text { crates are placed throughout the entire poultry } \\
\text { house when new flock is set-up (high severity). }\end{array}$ & - Containers/crates should be clean \\
\hline Growing hens & $\begin{array}{l}\text { Introduction of } \\
\text { mites by driver }\end{array}$ & 2 & 1 & 2 & $\begin{array}{l}\text { Mites could move from chickens onto the truck } \\
\text { driver. }\end{array}$ & - Driver should not enter poultry house \\
\hline Growing hens & $\begin{array}{l}\text { Introduction of } \\
\text { mites by employees }\end{array}$ & 1 & 3 & 3 & $\begin{array}{l}\text { Teams that set up new flocks visit different } \\
\text { farms and could thus carry an infestation from } \\
\text { one location to the other. }\end{array}$ & $\begin{array}{l}\text { - Personnel should be clean upon arrival at } \\
\text { the farm (clean clothing) }\end{array}$ \\
\hline $\begin{array}{l}\text { Material/ } \\
\text { equipment }\end{array}$ & $\begin{array}{l}\text { Introduction of } \\
\text { mites via material } \\
\text { or equipment }\end{array}$ & 1 & 1 & 1 & $\begin{array}{l}\text { New equipment or tools from maintenance } \\
\text { personnel will not have mites. }\end{array}$ & - Equipment should be clean \\
\hline $\begin{array}{l}\text { Material/ } \\
\text { equipment }\end{array}$ & $\begin{array}{l}\text { Spread of mites } \\
\text { between barns via } \\
\text { shared } \\
\text { material/equipment }\end{array}$ & 3 & 2 & 6 & $\begin{array}{l}\text { Material or equipment from another barn could } \\
\text { spread mites. Maintenance of the poultry house } \\
\text { occurs regularly and at various locations leading } \\
\text { to a relatively high risk. }\end{array}$ & $\begin{array}{l}\text { - Tools that could harvest mites such as a } \\
\text { broom should be kept in the same barn } \\
\text { and regularly cleaned or disinfected }\end{array}$ \\
\hline $\begin{array}{l}\text { Material/ } \\
\text { equipment }\end{array}$ & $\begin{array}{l}\text { Spread of mites } \\
\text { within a barn via } \\
\text { material/equipment }\end{array}$ & 3 & 2 & 6 & $\begin{array}{l}\text { Infested equipment could spread mites within a } \\
\text { barn. Cleaning takes place regularly, leading to } \\
\text { relatively high risk. }\end{array}$ & $\begin{array}{l}\text { - Regularly clean equipment that may } \\
\text { harvest mites } \\
\text { - Keep equipment located centrally and } \\
\text { attached to a board }\end{array}$ \\
\hline Manure & $\begin{array}{l}\text { Introduction of } \\
\text { mites via manure } \\
\text { belts }\end{array}$ & 1 & 1 & 1 & $\begin{array}{l}\text { In case the manure container is not close to the } \\
\text { barn, the likelihood and severity are considered } \\
\text { very small. }\end{array}$ & - Clean manure belt regularly \\
\hline Manure & $\begin{array}{l}\text { Spread of mites } \\
\text { between barns via } \\
\text { cross-belts }\end{array}$ & 3 & 2 & 6 & $\begin{array}{l}\text { Many mites can be encountered on manure } \\
\text { belts. Between barns mites could spread via the } \\
\text { cross-belts. }\end{array}$ & $\begin{array}{l}\text { - Regularly treat transfer points between } \\
\text { manure belts and cross-belts with control } \\
\text { agent }\end{array}$ \\
\hline
\end{tabular}




\begin{tabular}{|c|c|c|c|c|c|c|}
\hline $\begin{array}{l}\text { Hazard } \\
\text { category }\end{array}$ & Hazard & $\begin{array}{l}\text { Likeli- } \\
\text { hood }\end{array}$ & $\begin{array}{l}\text { Seve- } \\
\text { rity }\end{array}$ & Risk & Motivation & Corrective action \\
\hline Manure & $\begin{array}{l}\text { Spread of mites in } \\
\text { poultry house via } \\
\text { manure belts }\end{array}$ & 3 & 3 & 9 & $\begin{array}{l}\text { In practice, many mites are encountered on } \\
\text { manure belts. Mites could also hide on the inside } \\
\text { and thus spread throughout the entire poultry } \\
\text { house. }\end{array}$ & $\begin{array}{l}\text { - Automated control during transport of } \\
\text { manure? }\end{array}$ \\
\hline Eggs & $\begin{array}{l}\text { Introduction of } \\
\text { mites via egg } \\
\text { containers and } \\
\text { pallets }\end{array}$ & 3 & 1 & 3 & $\begin{array}{l}\text { Containers and pallets move from farm to farm. } \\
\text { Containers/pallets have lots of hiding } \\
\text { opportunities. However, these materials will not } \\
\text { move further than the egg collection } \\
\text { compartment on the farm (low severity). }\end{array}$ & $\begin{array}{l}\text { - Egg containers and pallets should be } \\
\text { cleaned and disinfected by the packing } \\
\text { station }\end{array}$ \\
\hline Eggs & $\begin{array}{l}\text { Introduction of } \\
\text { mites via egg trays }\end{array}$ & 3 & 1 & 3 & $\begin{array}{l}\text { Used trays have lots of hiding opportunities. } \\
\text { However, trays will not move further than the } \\
\text { egg collection compartment on the farm (low } \\
\text { severity). }\end{array}$ & $\begin{array}{l}\text { - Use new trays } \\
\text { - Have packing station clean plastic egg } \\
\text { trays }\end{array}$ \\
\hline Eggs & $\begin{array}{l}\text { Spread of mites } \\
\text { between barns via } \\
\text { egg cross-belts }\end{array}$ & 3 & 2 & 6 & $\begin{array}{l}\text { Frequently, mites are encountered on eggs and } \\
\text { egg remains. Cross-belts between main belts } \\
\text { may carry mites from barn to barn. Especially } \\
\text { transfer points between cross and main belts } \\
\text { can harvest large mite colonies. }\end{array}$ & $\begin{array}{l}\text { - Treat transfer points between main and } \\
\text { cross belts regularly } \\
\text { - Remove egg remains on conveyor belts. }\end{array}$ \\
\hline Eggs & $\begin{array}{l}\text { Spread of mites } \\
\text { within poultry } \\
\text { house via conveyor } \\
\text { belts }\end{array}$ & 3 & 3 & 9 & $\begin{array}{l}\text { The likelihood that mites hide on egg conveyor } \\
\text { belts is relatively large, especially for woven } \\
\text { belts. }\end{array}$ & $\begin{array}{l}\text { - Remove egg remains } \\
\text { - Keep conveyor belts free of dust } \\
\text { - Do not use woven belts } \\
\text { - Treat belts with silica dust }\end{array}$ \\
\hline $\begin{array}{l}\text { Manure } \\
\text { aeration }\end{array}$ & $\begin{array}{l}\text { Spread of mites via } \\
\text { manure aeration } \\
\text { pipes }\end{array}$ & 3 & 3 & 9 & $\begin{array}{l}\text { With intermittent aeration, pipes offer a good } \\
\text { hiding place for mites. After a period of non- } \\
\text { aeration, mites could be spread throughout the } \\
\text { barn if aeration is switched on again. }\end{array}$ & $\begin{array}{l}\text { - Use continuous aeration } \\
\text { - Blow silica dust through the aeration } \\
\text { system }\end{array}$ \\
\hline
\end{tabular}




\begin{tabular}{|c|c|c|c|c|c|c|}
\hline $\begin{array}{l}\text { Hazard } \\
\text { category }\end{array}$ & Hazard & $\begin{array}{l}\text { Likeli- } \\
\text { hood }\end{array}$ & $\begin{array}{l}\text { Seve- } \\
\text { rity }\end{array}$ & Risk & Motivation & Corrective action \\
\hline $\begin{array}{l}\text { Manure } \\
\text { aeration }\end{array}$ & $\begin{array}{l}\text { Spread of mites via } \\
\text { air mixing box }\end{array}$ & 1 & 3 & 3 & $\begin{array}{l}\text { Mites could hide in ventilation shafts and end up } \\
\text { in the air mixing box. This may result in spread } \\
\text { of the mites throughout the barn. Likelihood is } \\
\text { low, because there is only one air mixing box per } \\
\text { barn. }\end{array}$ & - Treat air mixing box with control agent. \\
\hline Cadavers & $\begin{array}{l}\text { Introduction of } \\
\text { mites from infested } \\
\text { cadaver dump }\end{array}$ & 3 & 1 & 3 & $\begin{array}{l}\text { If the cadaver dump is located alongside the } \\
\text { poultry house, mites could enter from here. }\end{array}$ & $\begin{array}{l}\text { - Do not place cadaver dump alongside the } \\
\text { poultry house } \\
\text { - Provide a barrier of silica dust between } \\
\text { cadaver dump and poultry house }\end{array}$ \\
\hline Cadavers & $\begin{array}{l}\text { Spread of mites via } \\
\text { removal of cadavers }\end{array}$ & 3 & 3 & 9 & $\begin{array}{l}\text { Cadavers that remain in the poultry house for an } \\
\text { extended period ( }>24 \mathrm{hrs} \text { ) offer excellent hiding } \\
\text { places for mites. During cadaver removal, mites } \\
\text { could fall out and infest other places in the } \\
\text { poultry house. }\end{array}$ & $\begin{array}{l}\text { - Remove cadavers the same day } \\
\text { - Collect cadavers in a clean plastic bag or } \\
\text { bucket }\end{array}$ \\
\hline $\begin{array}{l}\text { Visitors / } \\
\text { External } \\
\text { personnel }\end{array}$ & $\begin{array}{l}\text { Introduction of } \\
\text { mites via visitors or } \\
\text { external personnel }\end{array}$ & 2 & 2 & 4 & $\begin{array}{l}\text { If visitors/external personnel have been in } \\
\text { contact with mites, these mites could be taken to } \\
\text { the next farm. Visits will be occasionally and } \\
\text { limited to only a few places (medium likelihood } \\
\text { and severity). }\end{array}$ & $\begin{array}{l}\text { - Bar visitors from poultry house as much } \\
\text { as possible } \\
\text { - Visitors should shower, wear work } \\
\text { clothing and a hairnet }\end{array}$ \\
\hline $\begin{array}{l}\text { Visitors / } \\
\text { External } \\
\text { personnel }\end{array}$ & $\begin{array}{l}\text { Spread of mites } \\
\text { between barns via } \\
\text { visitors or external } \\
\text { personnel }\end{array}$ & 2 & 2 & 4 & $\begin{array}{l}\text { Mites may land or crawl onto visitors/external } \\
\text { personnel during their visit. Mites may thus be } \\
\text { carried to other barns if these are visited as well. }\end{array}$ & $\begin{array}{l}\text { - Bar visitors as much as possible } \\
\text { - Change upper layer of clothing per barn } \\
\text { - Possibly shower per barn visit }\end{array}$ \\
\hline $\begin{array}{l}\text { Visitors / } \\
\text { External } \\
\text { personnel }\end{array}$ & $\begin{array}{l}\text { Spread of mites } \\
\text { within poultry } \\
\text { house via visitors or } \\
\text { external personnel }\end{array}$ & 3 & 2 & 6 & $\begin{array}{l}\text { Similarly, visitors or external personnel may } \\
\text { spread mites within the poultry house. They will } \\
\text { probably visit only a limited number of places. }\end{array}$ & - Bar visitors as much as possible \\
\hline
\end{tabular}




\begin{tabular}{|c|c|c|c|c|c|c|}
\hline $\begin{array}{l}\text { Hazard } \\
\text { category }\end{array}$ & Hazard & $\begin{array}{c}\text { Likeli- } \\
\text { hood }\end{array}$ & $\begin{array}{c}\text { Seve- } \\
\text { rity }\end{array}$ & Risk & Motivation & Corrective action \\
\hline $\begin{array}{l}\text { Poultry farmer } \\
\text { / Employee }\end{array}$ & $\begin{array}{l}\text { Introduction of } \\
\text { mites via poultry } \\
\text { farmer/employee }\end{array}$ & 2 & 3 & 6 & $\begin{array}{l}\text { Farmer and employees could carry mites into } \\
\text { the poultry house after getting in touch with } \\
\text { them outside of their poultry house. Severity is } \\
\text { high, because these persons move through the } \\
\text { entire poultry house. }\end{array}$ & $\begin{array}{l}\text { - Showering, wearing work clothing and a } \\
\text { hairnet. }\end{array}$ \\
\hline $\begin{array}{l}\text { Poultry farmer } \\
\text { / Employee }\end{array}$ & $\begin{array}{l}\text { Spread of mites } \\
\text { between barns via } \\
\text { poultry } \\
\text { farmer/employee }\end{array}$ & 3 & 3 & 9 & $\begin{array}{l}\text { Farmer and employees will touch hens and the } \\
\text { housing system. Thus, there is a high likelihood } \\
\text { that they get infested and carry mites to other } \\
\text { barns. Severity is high, because these persons } \\
\text { move through the entire poultry house. }\end{array}$ & - Change outer clothing per barn \\
\hline $\begin{array}{l}\text { Poultry farmer } \\
\text { / Employee }\end{array}$ & $\begin{array}{l}\text { Spread of mites } \\
\text { within barn via } \\
\text { poultry } \\
\text { farmer/employee }\end{array}$ & 3 & 3 & 9 & Similarly, mites may be spread within a barn & - Limit movement throughout the barn \\
\hline Ventilation & $\begin{array}{l}\text { Introduction of } \\
\text { mites via intake of } \\
\text { outside air that is } \\
\text { infested with mites }\end{array}$ & 2 & 2 & 4 & $\begin{array}{l}\text { Mites are extremely light (adults } \sim 0.075 \mathrm{mg} \text {; } \\
\text { nymphs } \sim 0.01-0.025 \mathrm{mg} \text { ). Mites that are in the } \\
\text { direct surroundings of the poultry house could } \\
\text { be taken in through the ventilation system. }\end{array}$ & $\begin{array}{l}\text { - Keep direct surroundings of the poultry } \\
\text { house free of bird nests that may harbou } \\
\text { mites } \\
\text { - Do not use under pressured ventilation } \\
\text { - Air inlet through top of the roof }\end{array}$ \\
\hline Ventilation & $\begin{array}{l}\text { Spread of mites } \\
\text { between barns via } \\
\text { air ventilation } \\
\text { currents }\end{array}$ & 1 & 2 & 2 & $\begin{array}{l}\text { Air that is withdrawn from the barn via the } \\
\text { ventilation fans, could be carried out to other } \\
\text { barns. However, the likelihood of this to happen } \\
\text { is small. }\end{array}$ & \\
\hline Ventilation & $\begin{array}{l}\text { Spread of mites } \\
\text { within barns via air } \\
\text { currents }\end{array}$ & 1 & 1 & 1 & $\begin{array}{l}\text { Air currents within a barn are small and so is the } \\
\text { likelihood for spread with these currents. }\end{array}$ & \\
\hline
\end{tabular}




\begin{tabular}{|c|c|c|c|c|c|c|}
\hline $\begin{array}{l}\text { Hazard } \\
\text { category }\end{array}$ & Hazard & $\begin{array}{l}\text { Likeli- } \\
\text { hood }\end{array}$ & $\begin{array}{c}\text { Seve- } \\
\text { rity }\end{array}$ & Risk & Motivation & Corrective action \\
\hline $\begin{array}{l}\text { Unproductive } \\
\text { hens }\end{array}$ & $\begin{array}{l}\text { Introduction of } \\
\text { mites via hen } \\
\text { collecting teams }\end{array}$ & 1 & 3 & 3 & $\begin{array}{l}\text { Hen collecting teams visit several farms and } \\
\text { could carry an infestation. Hen collection takes } \\
\text { place only once per round (low likelihood), but } \\
\text { personnel will visit the entire barn (high } \\
\text { severity). }\end{array}$ & $\begin{array}{l}\text { - Because hen collection staff visit several } \\
\text { farms, they should arrive clean or take a } \\
\text { shower } \\
\text { - Wear clean work clothing }\end{array}$ \\
\hline $\begin{array}{l}\text { Unproductive } \\
\text { hens }\end{array}$ & $\begin{array}{l}\text { Introduction of } \\
\text { mites via containers } \\
\text { or crates }\end{array}$ & 1 & 3 & 3 & $\begin{array}{l}\text { Containers and crates used for transport of hens } \\
\text { come at different farms and could thus carry an } \\
\text { infestation. This only happens once per round } \\
\text { (low likelihood), but containers/crates are used } \\
\text { throughout the entire barn (high severity). }\end{array}$ & $\begin{array}{l}\text { - Containers/crates for transport of hens } \\
\text { should be clean }\end{array}$ \\
\hline
\end{tabular}




\section{Critical control point identification}

A critical control point (CCP) is a step, point or procedure in any production procedure. This can also be applied to the egg production facility to identify and manage potential hazards or reduce them to an acceptable level. In our study, a point, step or procedure was regarded as a CCP when the calculated risk had a value of 3 or higher on a scale of 1-9. Based on these criteria, 31 of the 41 hazards could be regarded as CCPs. Table 3.2 shows the results of the hazard analysis and identification of CCPs together with suggestions for control measures (corrective actions) for prevention of D. gallinae infestations and spread in poultry facilities.

\section{Establishing critical limits}

Establishment of critical limits for each CCP for infestation and spread of D. gallinae in poultry facilities is difficult. The logical aim is a critical limit of zero mites, because under optimal conditions, introduction of only a few mites could develop into a major infestation within a few weeks, especially when measures for effectively killing the mites are not available. However, the current literature does not quantify the relationships between mite infestation level and the risk factors present in and outside the poultry facility and poultry welfare/health.

\section{Monitoring}

Monitoring of CCPs is a matter of regular and thorough checking of possible entry routes for mites, either in relation to the structure of the poultry facility (barn design and immediate surroundings, ventilation system, etc.) or to those elements that regularly enter or leave the poultry facility (feed, manure, workers, etc.; Table 3.2). In addition to monitoring the flocks for poultry red mite presence it is of utmost importance that a subsequent quick response is possible to limit an increase of the mite population. Detrimental effects of D. gallinae and extra costs of mite eradication can be reduced when early awareness leads to isolation of restricted infected zones rather than a complete layer house (Mul et al. unpublished data). Due to the small size of the mite and vast number in which it aggregates, it is difficult for existing monitoring methods to provide accurate estimates of actual D. gallinae numbers (Nordenfors and Chirico 2001). At present, infestations of $D$. gallinae are mostly noticed when farmers or workers are bitten by $D$. gallinae, when mites are seen on the belt and feeders, clumps of mites are seen or when blood spots are detected on eggs. In the Netherlands, farmers were made more aware of $D$. gallinae infestations by using traps consisting of PVC tubing containing a wooden stick as an attractive hiding place for mites (Van Emous, personal communication). These traps were installed throughout the houses of the laying hens to identify the best location. The scale for scoring mite density (score $0-5$; no poultry red mites-very many poultry red mites) is quite rough and insensitive to small changes in infestation level. Therefore cases of extreme 
infestations (higher than "many") remain difficult to quantify. Similar monitoring tools involve corrugated cardboard traps (Nordenfors and Chirico 2001), the ADAS monitoring trap and a trap consisting of a tube containing a fabric or cloth (Maurer et al. 1993). An alternative trap is treated with acaricides (Chirico and Tauson 2001; Lundh et al. 2005). Applying traps in the poultry house alone will not prevent the introduction and spread of $D$. gallinae, but is merely intended to detect infestations and monitor population trends. The farmer needs to be aware that improvements in hygiene (extra cleaning) will reduce the number of mites, but only for a limited period (Maurer, personal communication).

\section{Corrective actions}

An overview of possible corrective actions is provided in Table 3.2. Establishing corrective actions is a continuing process that should be repeated regularly. A farmer should check his farm by going through a checklist (see below) every few months. If the checklist indicates that corrective action is required, then this should be performed immediately in order to limit infestation and spread of D. gallinae.

\section{Documentation and validation}

From a practical point of view, farmers can plan in advance on a calendar when to go through the checklist. These checklists should be archived and well documented to show whether they are performed regularly and if necessary when and where corrective actions have been carried out. Documentation of date and place of treatment within the poultry facilities provide information concerning the effectiveness of treatments and indicate emergence of resistance to chemical control agents, especially when compared to records from other (nearby) poultry facilities. Validation of the corrective actions should be tested in research or farm trials. Collection of all available farm data on a regional and national basis may prove to be a valuable tool in the evaluation of corrective actions.

\section{Checklist}

As an extra management aid to farmers, we have prepared a checklist to help identify the most important points of action in the prevention of D. gallinae infestations and spread. This checklist was evaluated during an in depth workshop by five Dutch poultry farmers and briefly by 40 British poultry farmers during a course on D. gallinae. The five Dutch farmers identified the checklists added value and improved it. They owned family farms, their laying hens were housed in Dutch barn systems, in free range systems and in cage layer systems with between 20,000 and 100,000 birds. The Dutch farmers described their current prevention measures with regard to infestation and spread of D. gallinae at their poultry farm. Before providing the checklist, farmers were encouraged to discuss their measures. During the discussions, several preventive actions were suggested and added to the farmers own lists of preventive measures. Their suggestions included: 
- Heating the henhouse to temperatures above $55^{\circ} \mathrm{C}$,

- Regular washing down of the housing system,

- Treatment of the walls and floors with silica dust or carbolineum prior to introduction of the new hens.

Subsequently, the farmers received the checklist and were asked to fill it out to ensure its feasibility and usefulness and to indicate which measures were additional to their list of preventive measures made prior to receiving the checklist. The farmers' advice led to a new draft in which questions were removed and/or adapted. All five farmers indicated that the checklist had encouraged them to take new or alternative preventive measures including:

- Checking if all persons and material entering the farm were free of D. gallinae,

- Placement of cobblestones directly around the poultry facilities in order to reduce the number of pests that are potential carriers of mites,

- Treating the edges of the feeding troughs with silica dust or glue,

- Treatment of the manure conveyor belt,

- Checking the cleanliness of egg trays,

- Treating the air mixing box,

- Order D. gallinae free growing hens,

- Monitoring poultry facilities for D. gallinae.

The overall conclusion of the five farmers was that the checklist was potentially a useful tool.

In the UK, the checklist was adapted to the egg production system in the UK. Of the 40 British poultry farmers, 28 own battery units with between 40,000 and 100,000 birds, 8 poultry farmers own free-range units with between 3,000 and 8,000 birds and 4 poultry farmers produce eggs in barns with houses for between 5,000 and 8,000 birds. The most interesting remarks of the egg producers were that (1) UK egg producers never have hobby birds at the site, (2) corrugated roofs are always insulated, (3) only very few farms have a shower, (4) cadaver dumps are not used in the UK, (5) workers often wear the same overalls all week and do not change between units, and (6) the use of silica dust on conveyor belts was thought to be a useful recommendation. They mentioned that the checklist stimulated them to be more critical about the way they run their units and highlighted things that could be improved. All found the checklist feasible and useful. The adjusted and final checklist is shown in the Appendix of this chapter (Appendix 3, Figure A3.1). 


\section{Conclusions and discussion}

Because poultry red mite is considered a major hazard to the health and welfare of poultry (Hegelund and Sørensen 2007), we elaborated on all possible risk factors for introduction and spread of D. gallinae by conducting an analysis using the HACCP method. In general, this method was evaluated as very helpful. We should note that the checklist is based on opinions of a limited number of experts and poultry farmers who were involved in this study. For example, it is possible that other experts would assign different likelihood and severity scores because of differing conditions in other regions or countries (e.g. differences in housing systems or environment in the vicinity of the poultry facility) or other judgements. Therefore, we consider it desirable to evaluate the developed procedures for other (European) countries. However, a farmer will only use the developed checklist when he is aware of the variety of effects of a D. gallinae infestation. Therefore, we argue that educative measures should be undertaken. For example, educative illustrations that show the possible points of introduction and routes of further spread of D. gallinae may be a good way to spread information. A major challenge remains in determination of critical limits of control points in unique situations, and, when and how to take action when such limits are exceeded. More quantitative, epidemiological studies are essential for the provision of clear targets for effective on-farm mite control. Additionally, more studies are needed that elucidate the various behaviours of D. gallinae, such as host seeking and aggregation. Insights obtained from such studies could be used to improve understanding of the various routes of infestation and spread. Moreover, this information will facilitate the development of alternative and environmentally safe control methods such as those based on the attract and kill principle (Stetter and Lieb 2000). Finally, although the HACCP process may seem cumbersome and extensive, we agree with an earlier statement that: "the concept is structuring and formalizing what truly good farmers are doing anyway" (after Ryan 1997, in: Noordhuizen and Frankena 1999).

\section{Acknowledgments}

This research was funded by the Dutch Product Board for Poultry and Eggs and the Dutch Ministry of Agriculture, Nature and Food Quality. We are grateful to T. Fiks-Van Niekerk, R. van Emous and B. Reuvekamp (Animal Sciences Group, Wageningen University) for their knowledgeable contribution to this research. We would like to thank all Dutch and British farmers that participated in the evaluation of the checklist. We also thank B. Bell (ADAS) for testing the checklist during her course for poultry farmers on D. gallinae. 


\section{References}

Baselga E, Drolet BA, Esterly NB (1996) Avian mite dermatitis. Pediatrics 97: 743-745

Bonde MJ, Sørensen JT (2004) Herd health management in organic pig production using a quality assurance system based on hazard analysis and critical control Points. NJASWag J Life Sci 52: 133-143

Chauve CM (1998) The poultry red mite Dermanyssus gallinae (De Geer, 1778) : current situation and future prospects for control. Vet Parasitol 79: 239-245

Chirico J, Tauson R (2001) Traps containing acaricides for the control of Dermanyssus gallinae. Vet Parasitol 110: 109-116

Hegelund L, Sørensen JT (2007) Developing a HACCP-like system for improving animal health and welfare in organic egg production-based on an expert panel analysis. Animal 1: 1018-1025

Kijlstra A, Meerburg BG, Mul M (2004) Animal-friendly production systems may cause reemergence of Toxoplasma gondii. NJAS-Wag J Life Sci 52: 119-132

Kilpinen O, Roepstorff A, Permin A, Nørgaard-Nielsen G, Lawson LG, Simonsen HB (2005) Influence of Dermanyssus gallinae and Ascaridia galli infections on behaviour and health of lying hens (Gallus gallus domesticus). Br Poult Sci 45: 26-34

Lundh J, Wiktelius D, Chirico J (2005) Azadirachtin-impregnated traps for the control of Dermanyssus gallinae. Vet Parasitol 130: 337-342

Marangi M, Giangaspero A, Raele D, Assunta Cafiero M, Camarda A, Sparagano OAE (2008). Evaluation of poultry red mite susceptibility, Dermanyssus gallinae (Acarina: Dermanyssidae), to some acaricides in Italy. In: Abstracts of the BSP Spring, Trypanosomiasis/Leishmaniasis \& Malaria Meetings. Newcastle upon Tyne, UK: 168 30 March-2 April

Maurer V, Hertzberg H (2001) Ökologische legehennenhaltung. Was tun die kleinen vampire? DGS-Mag 40: 49-52

Maurer V, Perler E (2006) Silicas for control of the poultry red mite Dermanyssus gallinae. Paper presented at the Joint Organic Congress, Odense, Denmark, 30-31 May (http://orgprints.org/7274/01/Maurer_Dermanyssus_Odense.pdf)

Maurer V, Baumgärtner J, Bieri M, Fölsch DW (1993) The occurrence of the chicken mite Dermanyssus gallinae in Swiss poultry houses. Mitt Schweiz Entomol Ges 66: 87-97

Mayes T (1993) The application of management systems to food safety and quality. Trends Food Sci Technol 4: 216-219

Mayes T (1998) Risk analysis in HACCP: burden or benefit? Food Contr 9: 171-176

Moro CV, Chauve C, Zenner L (2005) Vectorial role of some Dermanyssoid mites (Acari, Mesostigmata, Dermanyssoidea). Parasite 12: 99-109

Mouchtouri VA, Anagnostopoulou R, Samanidou-Voyadjoglou A, Theodoridou K, Hatzoglou C, Kremastinou J, Hadjichristodoulou C (2008) Surveillance study of vector species on board passenger ships risk factors related to infestations. BMC Public Health 8: 100 
Mul M, Van der Gaag M (2003) Control of Salmonella at pig finishing farms with a farm decision tree. Proceedings of the 5th International Symposium on the Epidemiology and Control of Foodborn Pathogens in Pork, Crete, Greece: 149-151

Noordhuizen JPTM, Frankena K (1999) Epidemiology and quality assurance: applications at farm level. Prev Vet Med 39: 93-110

Nordenfors H (2000). Epidemiology and control of the Poultry Red Mite, Dermanyssus gallinae. Doctoral thesis, Swedish University of Agricultural Sciences, Uppsala, Sweden, $19-20$

Nordenfors H, Chirico J (2001) Evaluation of a sampling trap for Dermanyssus gallinae (Acari: Dermanyssidae). J Econ Entomol 94: 1617-1621

Nordenfors H, Höglund J, Tauson R, Chirico J (2001) Effect of permethrin impregnated plastic strips on Dermanyssus gallinae in loose-housing systems for laying hens. Vet Parasitol 102: 121-131

Rayment GE (2006) Australian efforts to prevent the accidental movement of pests and diseases in soil and plant samples. Commun Soil Sci Plant Anal 37: 2107-2117

Sikes RK, Chamberlain RW (1954) Laboratory observations on three species of bird mites. J Parasitol 40: 691-697

Steenberg T, Kilpinen O, Jespersen JB, Soler-Cruz MD, Vega-Robles C, Birkett M, Dewhirst S, Pickett J (2005) Advances in the development of novel control methods against chicken mites (Dermanyssus gallinae). Bull-OILB/SROP 28: 89-91

Stetter J, Lieb F (2000) Innovation in crop protection: trends in research. Angew Chem Int Ed 39: 1724-1744

Sun YM, Ockerman HW (2005) A review of the needs and current applications of hazard analysis and critical control point (HACCP) system in foodservice areas. Food Contr 16: 325-332

Wood HP (1917) The chicken mite: its life history and habits. USDA Bulletin No. 553 


\section{Appendix 3}

Figure A3.1 Checklist with corrective actions for preventing the introduction and spread of D. gallinae in laying hen facilities
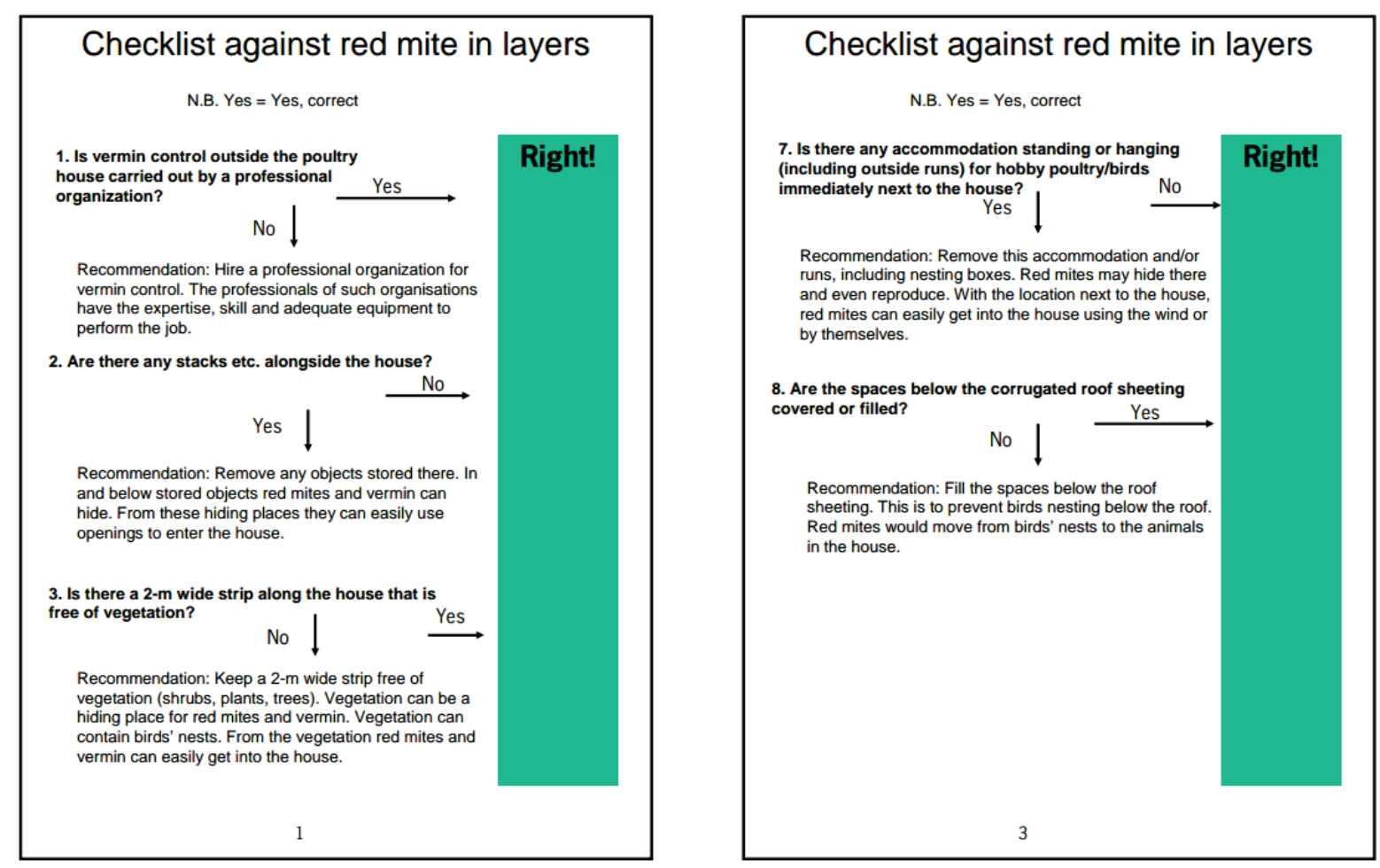

\section{Checklist against red mite in layers}

N.B. Yes $=$ Yes, correct

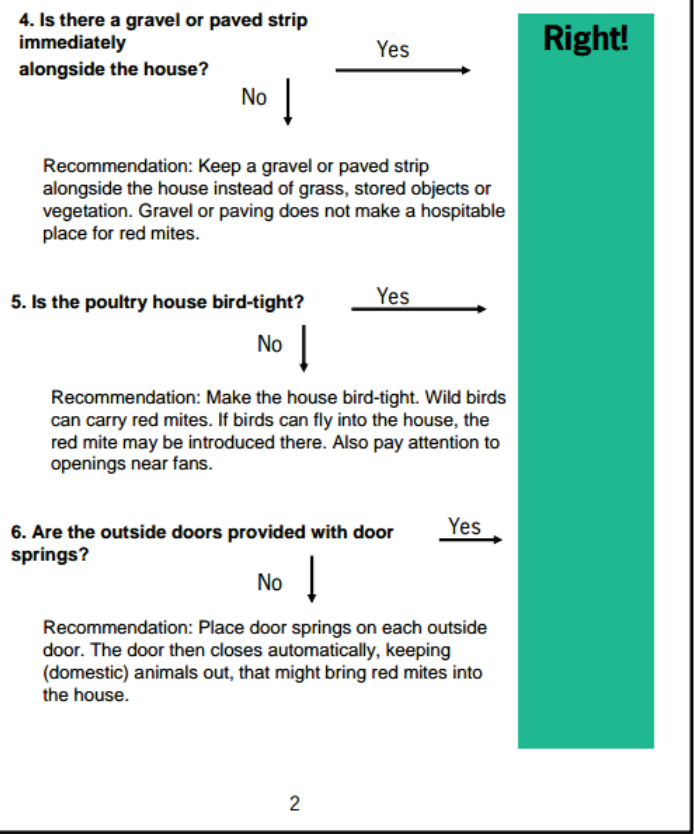

Checklist against red mite in layers

N.B. Yes $=$ Yes, correct

9. Do you use only dry and clean litter?

No $\downarrow$

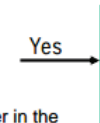

Right!

Recommendation: Only use dry and clean litter in the poultry house. Clean and dry litter is less popular as a hiding place for red mites. 10. Are the members of the set-up group wearing
clean work clothing and have they taken a shower clean work clothing and have they taken a shower
before coming to the farm? No $\stackrel{\text { Yes }}{\longrightarrow}$

Recommendation: As the set-up-groups come from various farms and consequently can carry red mites, various farms and consequently can carry red mites, the set-up group is preferably received on the farm work clothing shall be provided to prevent red mites to be brought in.

11. Do you demand from your rearing farm that clean containers and crates are used to transport the hens?

No

Recommendation: Demand that your rearing farm uses clean crates and containers for the transport of hens. Red mites may hide in and on crates and containers that have not been properly cleaned. This can create the danger of red mites being brought to your farm. 

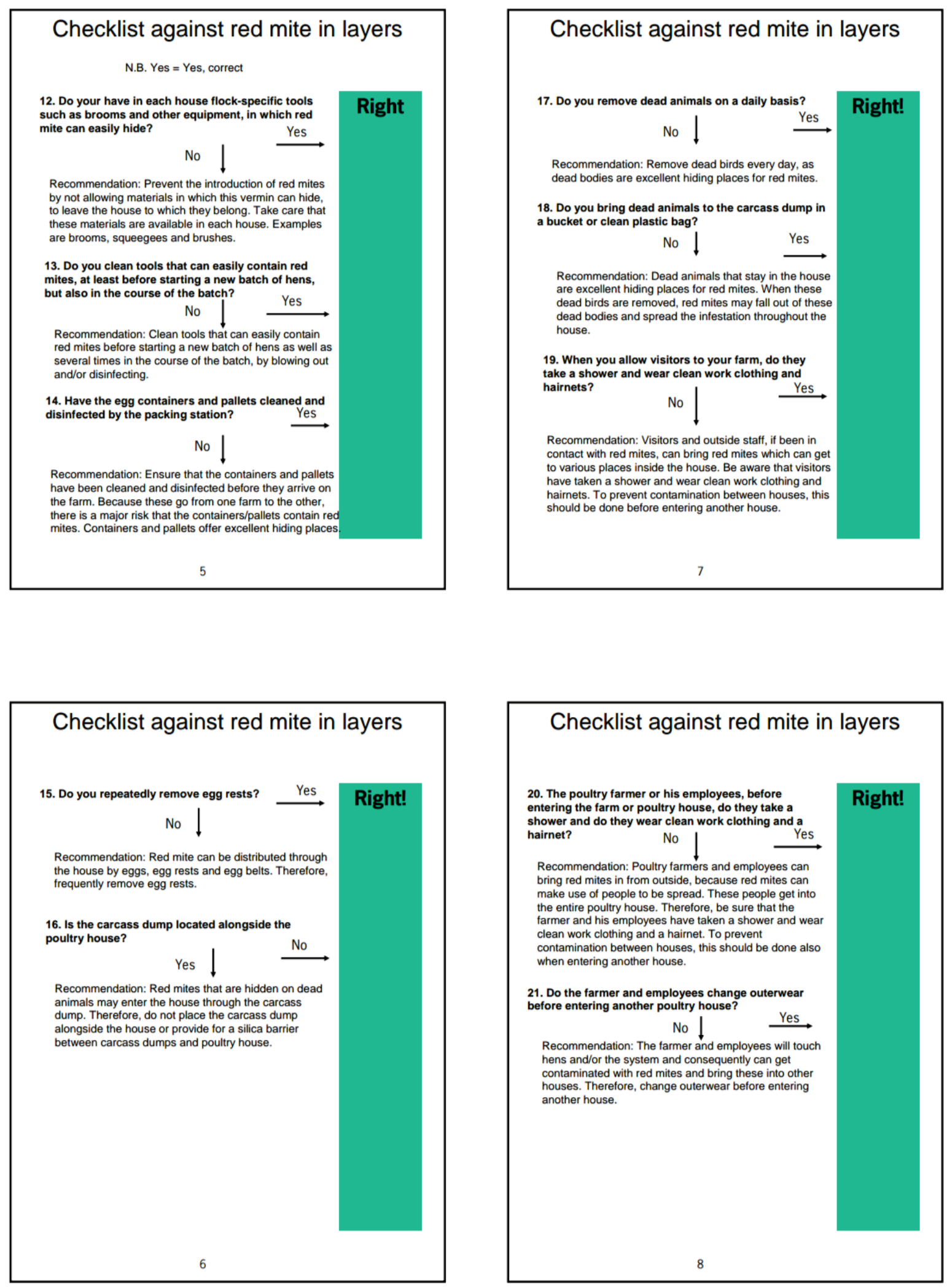


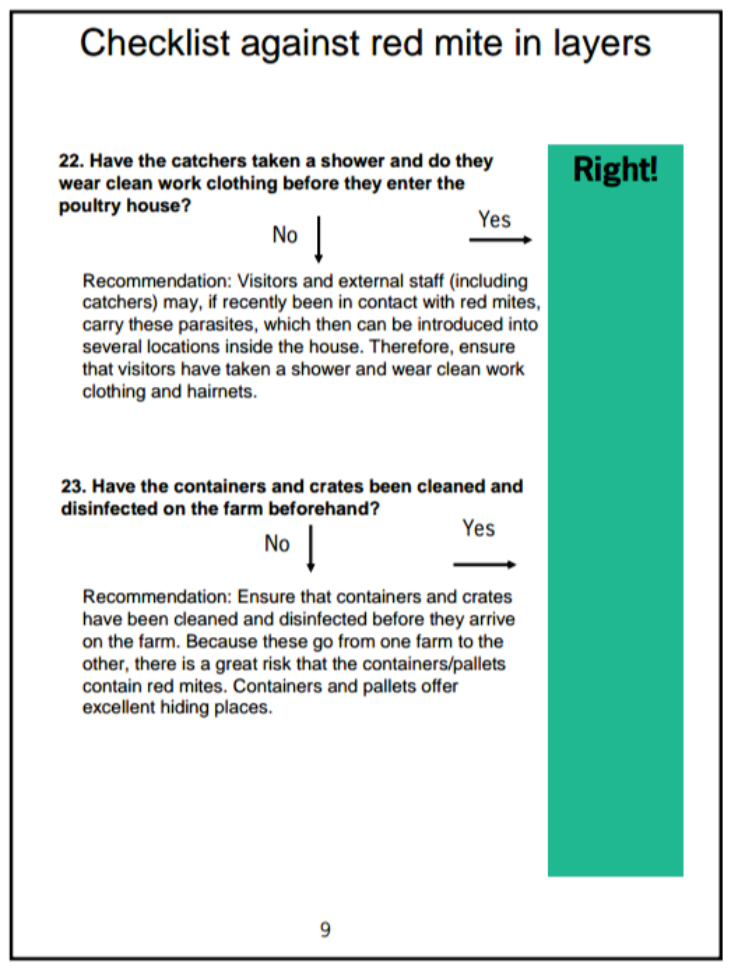

\section{Brief checklist against red mite in pullets before transport to the farm}

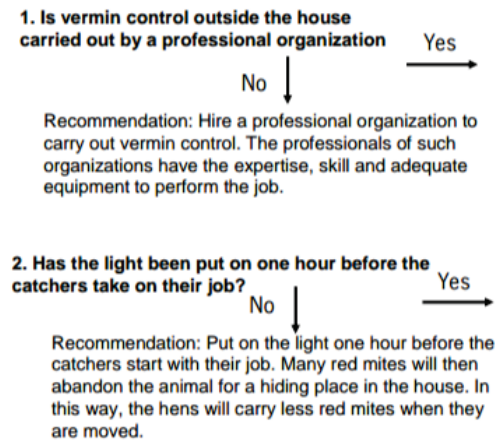

Recommendation: Hire a professional organization to carry out vermin control. The professionals of such organizations have the expertise, skill and adequate equipment to perform the job.

2. Has the light been put on one hour before the catchers take on their job?$$
\text { No }
$$

Recommendation: Put on the light one hour before the catchers start with their job. Many red mites will then abandon the animal for a hiding place in the house. In this way, the hens will carry less red mites when they are moved.

3. Do you use only clean crates and containers for the transport of pullets?

$$
\text { No } \downarrow \text { Yes }
$$

Recommendation: Only use clean crates and containers for the transport of hens. Red mites may hide in and on crates and containers that have not been properly cleaned. Uncleaned crates or containers entail the risk infested

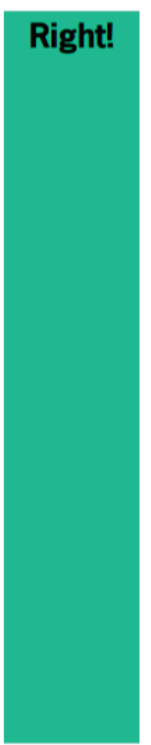




\section{Chapter 4}

\section{Structured design of an automated monitoring tool for pest species}

Monique F. Mul' ${ }^{1}$, Johan P.M. Ploegaert ${ }^{1}$, David R. George ${ }^{2}$, Bastiaan G. Meerburg' ${ }^{1}$, Marcel Dicke $^{3}$, Peter W.G. Groot Koerkamp ${ }^{1,4}$

1 Wageningen Livestock Research, P.O. Box 338, 6700 AH Wageningen, The Netherlands.

2 Department of Entomology and Sustainable Agriculture, Stockbridge Technology Centre, North Yorkshire, Y08 3TZ, United Kingdom

3 Laboratory of Entomology, Wageningen University, P.O. Box 16, 6700 AA Wageningen, The Netherlands

${ }^{4}$ Farm Technology Group, Wageningen University, P.O. Box 16, 6700 AA Wageningen, The Netherlands

Reprinted with permission.

Biosystems Engineering (2016) 151: 126-140 


\begin{abstract}
Pests and diseases in agricultural systems cause severe production losses with associated economic impact. Integrated Pest Management (IPM) is a sustainable method to limit these losses. For improved implementation of IPM, fully automated monitoring tools are needed to provide instantaneous pest monitoring data and associated real time, user-friendly treatment advice for producers. The application of the Reflexive Interactive Design approach to design an automated pest monitoring tool including an automated pest detection sensor is described with Poultry Red Mite (PRM) as a model target. Three different concepts were designed for the automated mite detection sensor based on a combination of solutions to carry out the key functions. The functioning of the main solutions in the three concepts was tested with live mites to ensure that solutions aligned with the behaviour and biology of PRM in vivo. The best solutions were combined into two different prototypes, which were subsequently tested in the laboratory and on-farm. The most successful prototype of the automated mite detection sensor was situated under the bird's perch, had a through-beam sensor and was able to remove mites from the through-beam sensor area once recorded. Involvement of various multidisciplinary actors, users and varied user networks in the design process was vital for its rapid progress, the quality of the final product and the limited number of set-backs encountered. It is expected that this same design structure, with the addition of an evaluation step, is applicable to the design of automated monitoring tools for other pest species.
\end{abstract}




\section{Introduction}

Pests and diseases in agricultural systems cause severe production losses both pre- and post-farm, with economic impacts that infiltrate multiple stakeholders along the supply chain (FAO 2001; Oerke 2006). The implementation of integrated pest management (IPM) is globally promoted by both the Food and Agricultural Organisation of the United Nations (FAO) and World Health Organisation (WHO) to increase food security and public health (Bonnefoy et al. 2008; FAO 2015; WHO 2015), and is a requirement for European Union (EU) crop producers following the implementation of the Sustainable Use Directive (EU Directive $2009 / 128 / E C)$. IPM is a multi-disciplinary approach that aims to control pests and diseases whilst minimising any negative environmental and economic effects associated with pest management activities (Narladkar 2014). Monitoring of pest populations is a critical component of IPM programmes that can be used to inform treatment timings and evaluate applied treatments according to the eight general principles of IPM laid down in Directive 2009/128/EC. Continuous monitoring of pest species in IPM permits earlier detection of pests, and provides higher resolution insights into treatment effects and pest pre- and posttreatment population dynamics, than can be achieved through non-continuous monitoring methods. When effective control measures are applied quickly after pests exceed action thresholds, the spread of pests and consequent production losses can be minimised (Mul et al. 2009; Flint 2012). Currently, however, monitoring of pests and diseases is typically timeconsuming and often relies on visual observation of pest numbers (in situ or on/in traps) that can be affected by monitoring schedules and observer experience (Mul, unpublished results). Fully automated pest monitoring circumvents these issues by providing repeatable real-time data and subsequent decision-making support for a quick and targeted reaction to pests and diseases. When fully developed, automated monitoring devices can send data on pest numbers to a central computer that runs a model forecasting pest population growth and informs the user about the moment when the population is expected to exceed the economic threshold for treatment (Shuman et al. 1996; Shuman et al. 2003).

Remote sensing and sensor-based methods, amongst others, are innovative tools currently being applied to automated monitoring of plant diseases (Polder et al. 2014; Martinelli et al. 2015). Automated monitoring of pests has also been developed for use in stored products, crops, in pastures and in buildings (Jianhua and Jingxue 1992; Shuman et al. 1996; Trompen 2003; Zhao et al. 2014). Nevertheless, no automated monitoring tools are currently available for invertebrate pests in animal husbandry systems, or for vertebrate pests such as mice and rats. Yet, these pests cause considerable production losses in this sector (FAO 2001; Meerburg et al 2009a; Meerburg et al. 2009b), which could be minimised through automated monitoring systems. Design of automated monitoring tools is potentially complex, though methods already exist to facilitate the design process (Cannessa 1989; Siers 2004; Cross 2008; Hemming et al. 2008). These methods aim to assist the methodical process by ensuring that developers "avoid jumping to conclusions, obtain a good overview of the stages in the designing process, reduce the chances for overlooking essential items, 
facilitate the taking of justifiable decisions, and to increase the chances on feasible design" (Siers 2004). However, the aforementioned approaches focus on design aspects only, with little attention given to social structures and participation of actors and stakeholders to allow for field implementation of the solution. As a form of structured design, the Reflexive Interactive Design (in Dutch: Reflexief Interactief Ontwerpen or RIO) approach has been successfully used in the design of new concepts for husbandry systems for pigs, laying hens, broiler hens, goats, and dairy cows (Bos 2010) and of semi structures in animal facilities (Van Weeghel et al. 2016), of which some have been further developed and realized by industry actors (e.g. Spoelstra et al. 2013). RIO as described by Bos et al. (2009) is an interdisciplinary interactive method for structured design and consists of three stages: 1) "system and actor analysis", 2) "structured design" and 3) "anticipating niche and structural change".

The work presented in this paper is the first application of the RIO approach to the design of automated monitoring tools for pests. This approach could accelerate the development and adoption of fully automated pest monitoring in sectors where this has yet to be achieved, and support implementation of improved IPM as a result. In this paper we present a case study on the use of the RIO approach to design an automated monitoring tool for the Poultry Red Mite (PRM) Dermanyssus gallinae. PRM is the most significant pest of egg-laying hens in many areas of the globe (Sparagano et al. 2014), and monitoring has been noted as key to IPM implementation to control pest species (Kogan 1998; Van Lenteren and Woets 1988), and PRM more specifically (Sparagano et al. 2014). Moreover, monitoring is one of the seven basic principles of the hazard analysis and critical control points (HACCP) method (Mayes 1993, 1998; Sun and Ockerman 2005), proven to reduce the risk of introduction and spread of PRM into poultry facilities (Mul and Koenraadt 2009). Nevertheless, at present PRM monitoring in layer facilities is based almost exclusively on passive trapping (Mul et al. 2009; Zenner et al. 2009; Schulz 2014) or visually scoring infestations (Zenner et al. 2009; Vervaert et al. 2005). The disadvantages of these methods is that they are either highly labour intensive or affected by mite behaviour, with both techniques providing lowaccuracy assessments of pest populations (Zenner et al. 2009; Schulz 2014). Adoption of comprehensive and effective IPM programmes for PRM are rare in laying hen facilities, but could be encouraged by reliable, user-friendly, labour extensive and accurate monitoring tools.

The goal of this paper is to demonstrate that the RIO approach can generate effective and technically feasible solutions to the complex problem of monitoring pests, such as PRM, in food production systems. A further aim was to contribute to the implementation of IPM for PRM in laying hen facilities by designing an automated monitoring tool including an automated mite detection sensor for PRM. 


\section{Material and methods}

The three stages of RIO each consist of several steps. The stages are shown in Figure 4.1 with the three circles intended to show how, upon realising new insights, stages may be repeated. For the design of an automated monitoring tool for PRM, RIO was tailored to our specific needs.

Steps A - F (stage 1), were followed for the design of the automated monitoring tool consisting of a sensor automatically detecting PRM, a population dynamics model, an economic model and an algorithm generating treatment advice. Steps H, G, I, and J (stage 2) were followed in this order to design the sensor for automatically detecting PRM. From the design concepts of the mite detection sensor to an actual working prototype, laboratory testing and field trials were carried out. Stage 3, "anticipating niche \& structural change", is not described in this paper as it is currently being performed.

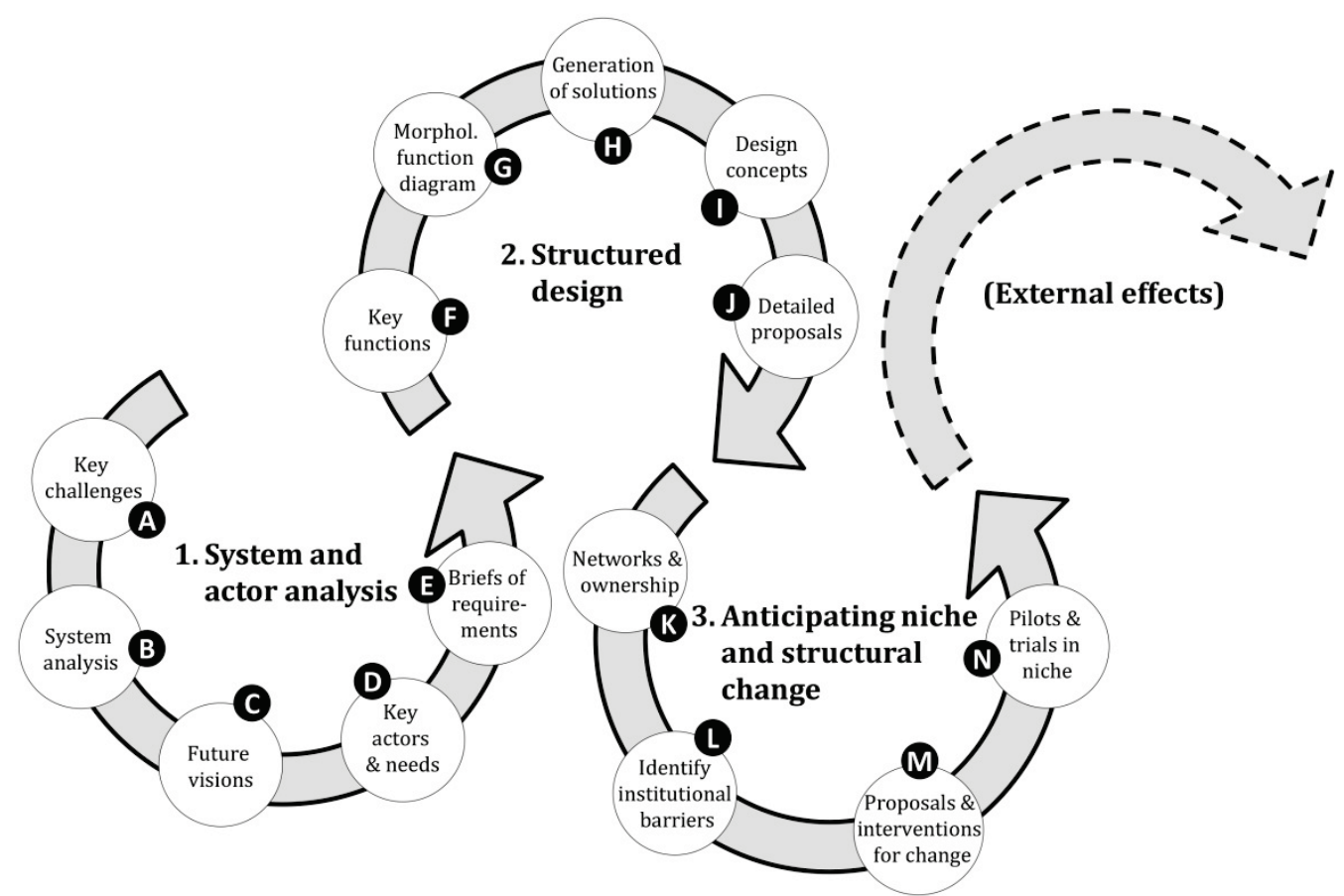

Figure 4.1 Scheme of the design approach used in Reflexive Interactive Design (in Dutch: RIO) (Bos et al. 2009)

\section{System and actor analysis}

Prior to the structured design (stage 2), the objectives of the design have to be clarified. For this, Bos et al. (2009) described a set of activities as "System and actor analysis" (stage 1): determine the key challenges (A), carry out the system analysis of functions and processes and their relation in the current and desired situation (B), develop a future vision in which the main challenges are addressed (C), identify the key actors, their needs and issues (D) and formulate a Brief of Requirements (E). 
In order to fulfil steps $\mathrm{A}$ and $\mathrm{C}$, a literature review was undertaken, experts (including industry) and layer farmers were interviewed (Van Emous et al. 2005), and an international seminar was organized (Mul et al. 2009). To ensure that information obtained through these activities remained relevant at the time of writing, ongoing literature review surveyed relevant additions to the PRM biology and behaviour knowledge. Systemic analysis of functions of the current and desired situation concerning control of PRM in laying hen facilities was carried out using the IDEF-0 tool (Integrated DEfinition for Function modelling - zero) (Lightsey 2001). IDEF-0 diagrams describe functions of a system, in this case the system to produce eggs, and nested sub-functions. IDEF-0 shows all functions and their relations by means of diagrams and the ICOM arrows are used to indicate the Input, Controls (stakeholder requirements), Output (information, materials or energy), and Mechanisms (solutions as being a combination of labour, technical means of production and capital) of each process step.

Performance of steps A-E resulted in more insight into the problem of PRM in poultry houses and a future vision (A, C), insight into problem related system elements, stakeholders and influencing factors (B), an organisation tree with stakeholders and their issues and needs (D), and a brief of requirements (E). The requirements of the farmer, the animal care taker, the industry and suppliers, and the need of laying hens were described in detail, quantified and defined as fixed, variable or desirable.

\section{Structured design}

Following 'system and actor analysis' the design of the automated mite detection sensor (PRM sensor) was achieved by subsequently carrying out the following steps of RIO (Bos et al. 2009):

F) Select the key functions to realize the PRM sensor, H) Generate a range of solutions per key function, G) Compose a Morphologic Function diagram, I) Make a number of design concepts by combining single solutions, J) Elaborate into a detailed proposal and evaluate them against the Brief of Requirements.

- Determine the key functions (F)

The key functions of the design of the PRM sensor (step F) were selected with experts in animal husbandry, farm technology and entomology.

- From generating solutions to design concepts (H, G, I, J)

For identifying potential solutions to carry out the key-functions (step H), a patent search with Espacenet (Espacenet.com) and a literature search using the CAB Abstracts database (1910 - 2011) was carried out based on the search terms "monitoring" plus "insects" or "arthropods" or "mites" or "Dermanyssus gallinae". The number of solutions were extended by 1) using IHS Goldfire Decision Engine Platform Software (Anonymous 2015), 2) conducting interviews with experts in PRM biology, laying hen husbandry and PRM control, 
3) organising a brainstorming session with multi-sector actors with various expertise to encourage identification of cross-disciplinary solutions (the attendees were experts in animal husbandry, laying hen husbandry, technology (electronics and measuring techniques), entomology, integrated pest management, horse husbandry and process facilitation), and 4) consultation with a creative consultant and designer. All solutions and working principles were ordered in a Morphologic Function diagram (Step G). Three combinations of solutions, i.e. the design concepts, were determined using the criteria as listed in the Brief of Requirements (Step I and J).

\section{From design concepts to a working prototype}

Two different prototype PRM sensors were constructed and tested, after carrying out laboratory tests and field trials to determine the most effective and mite preferred solutions.

\section{- Test of solutions}

The most preferred solutions for the key PRM sensor functions were individually tested and fine-tuned using live PRM. Three types of tests were carried out: mite preference tests in the laboratory, mite challenge tests in the laboratory and mite preference tests in a laying hen house. Mite preference tests were carried out to test the effects of:

1) Temperature at $20^{\circ} \mathrm{C}$ and $33^{\circ} \mathrm{C}$, with $33^{\circ} \mathrm{C}$ representing a significant temperature increase compared to the desired indoor climate for laying hen facilities, this being $18-21^{\circ} \mathrm{C}$ (Animal Science Group 2010),

2) Type of material (brass, polyvinyl chloride (PVC), metal, copper, steel, aluminium), assessed to avoid constructing the sensor with a repellent material. Materials were selected as those most likely to be used in commercial sensor development.

3) Tube diameter ( 1.5 and $4.35 \mathrm{~mm}$ ) to test the hypothesis that cracks smaller than $2 \mathrm{~mm}$ are preferred for PRM hiding places (Mul et al. 2009),

4) Transparent and non-transparent tube, to determine if a preference for one or the other existed when mites were selecting a hiding place,

5) Tubes with round and squared corners, again to assess if a preference existed for one over the other that could be exploited during sensor development.

During daylight conditions, between 08:00 and 17:00, ten mites were placed in-between two different objects in a Petri-dish and allowed to choose between the two objects over 24 $\mathrm{h}$ at room temperature. Adult mites and nymphs were randomly chosen from samples collected daily from a laying hen farm. No distinction was made between engorgement status, life stage or sex as an experimental population representative of all mobile, host seeking stages of a natural population was desired. To serve as a barrier to mite escape, the Petri-dishes were placed in an unheated water bath with detergent to break the surface film. After $24 \mathrm{~h}$, or $60 \mathrm{~s}$ when testing the temperature preference, the number of mites on, in or under the objects were counted. The tests were repeated 36 times for the same objects. 
In the laboratory, mite challenge tests were carried out for 1) the ability to fall, 2) the ability to climb on slippery surfaces (glass and polytetrafluoretheen (PTFE)), and 3) air velocity. The challenge tests were performed in a laboratory fume hood under fluorescent lighting without the presence of birds. For testing the ability to fall, a mite was placed at a plastic board which was fixed at the edge of a glass tube and bent downwards toward the inside of the glass tube. A heated copper element $\left(30-35{ }^{\circ} \mathrm{C}\right)$ was placed within a tube to attract the mite. The behaviour of the mite was determined within $120 \mathrm{~s}$. For testing the ability of climbing on slippery surfaces, mites were placed under tubes made of glass and PTFE and their ability to climb upwards on these objects was assessed.

For the air velocity tests, 20 mites per 'stage' (visually differentiated as; starved adults, fed adults, starved nymphs, fed nymphs and larvae) were tested to determine the air velocity in which the mites were no longer able to hold on a vertically orientated tube. This was measured in two ways: 1) by step-wise increase of the air velocity in a tube, and 2) by a sudden increase of the air velocity in a tube. The tube had an outer diameter of $3.2 \mathrm{~mm}$ and an inner diameter of $1.5 \mathrm{~mm}$. The tube was connected to a compressor with a constant pressure of $200 \mathrm{kPa}$. An analogue airflow meter (Platon B6D, CT Platon SAS, Domont, France) was used to regulate the airflow manually. This airflow meter was connected with a digital DryCal DC-Lite, BIOS International, Pompton Plains, New Jersey, United States), flow meter to measure the actual flow. When the airflow was set at $0 \mathrm{l} / \mathrm{min}$, a mite was placed inside the tube moving in the opposite direction of the applied airflow. The increase of the airflow was stopped when the mite was blown out of the tube into a water-detergent solution.

Preferred materials and cavity diameter identified in laboratory tests were tested for in vivo mite preference in a laying hen house with a high mite infestation (aggregations of mites larger than $1 \mathrm{~cm}^{2}$ were visible) and a daily eight-hour dark period with indoor temperatures maintained between 18 and $22^{\circ} \mathrm{C}$. The tubes with different diameters and the platelets made of different materials were fixed with cable ties to perches within the laying hen house. After $72 \mathrm{~h}$ the number of mites in and on the tubes or platelets were scored using a scale of 0 to $10(0=0$ mites, $1=0-5$ mites, $2=5-10$ mites, $3=10-15$ mites, $4=15-20$ mites, $5=20-25$ mites, $6=25-30$ mites, $7=30-35$ mites, $8=35-40$ mites, $9=40-50$ mites, $10=50-$ 100 mites).

A Wilcoxon Signed-Rank Test (Siegel 1956) using SPSS Statistics 22.0 (IBM Corp. Released IBM SPSS Statistics for Windows, Version 22. Armonk, NY, USA) was carried out to determine if significant differences in PRM preference existed between the objects and materials. Knowledge acquired during the 'test of solutions' was applied in the construction of the sensor prototypes. 
- Construction and testing of prototypes

The first prototype of the automated mite detection sensor was constructed based on design concept 2, with the combination of the best-tested solutions as shown in the morphologic function diagram (see figure 4.5). This first prototype was tested in the laboratory with live mites and subsequently tested in a laying hen house with a high mite infestation (aggregations of mites larger than $1 \mathrm{~cm}^{2}$ were visible at unprotected places) where it was fixed inside a vertically oriented U-shaped metal beam. The second prototype was based on design concept 3 in the morphologic diagram, and tested in the same laying hen house where it was fixed under the perch. This second prototype was not tested in the laboratory because of the observed differences in mite behaviour in tests with the first prototype when hens were absent (laboratory) or present (laying hen house).

\section{Involvement of actors and users}

The involvement of actors and users with multidisciplinary knowledge, originating from different networks and with different needs, was vital to fulfilling each step of the design scheme. An advisory committee, consisting of representatives of the two Dutch poultry farmers' associations, poultry farm supplier organisations and research organisations, strongly contributed to this research by providing practical knowledge of PRM in laying hen systems. This committee guided research directions, managed basic support from the poultry farmers involved and was instrumental in finding and providing financial support. In Table 1 the actors and users involved in each step of the design process are summarised. It should be noted that the actor with expertise in horse husbandry was not invited because of the possible effects of PRM on horses. 
Table 4.1 Actor and user involvement in each step of the RIO approach (Reflexive Interactive Design)

\begin{tabular}{|c|c|c|c|c|c|c|c|c|c|c|c|}
\hline \multirow[t]{2}{*}{ Actors, users } & \multicolumn{11}{|c|}{ Design stage and step } \\
\hline & \multicolumn{5}{|c|}{ System and Actor analysis } & \multicolumn{5}{|c|}{ Structured Design } & \multirow{2}{*}{$\begin{array}{c}\text { Anticipating } \\
\text { niche and } \\
\text { structural } \\
\text { change }\end{array}$} \\
\hline &  & 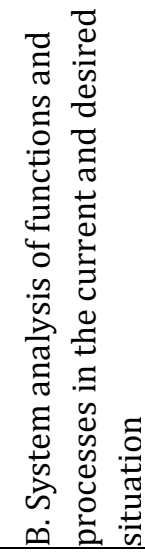 &  & 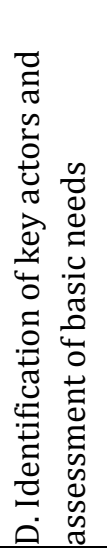 & 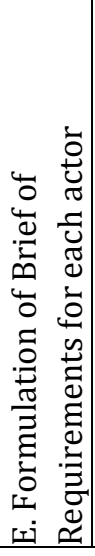 & 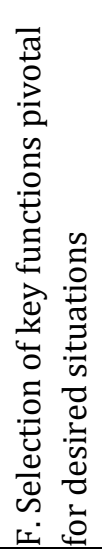 & 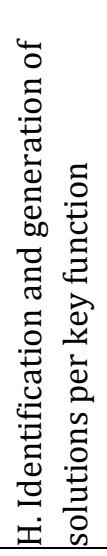 & 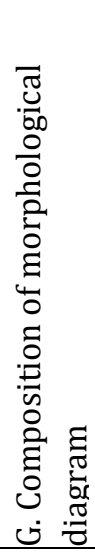 &  & 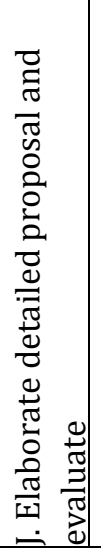 & \\
\hline Layer farmer & $\mathrm{X}$ & $\mathrm{X}$ & $\mathrm{X}$ & $\mathrm{X}$ & $\mathrm{X}$ & & $\mathrm{X}$ & & & & \\
\hline $\begin{array}{l}\text { Expert in animal } \\
\text { husbandry* }\end{array}$ & $\mathrm{X}$ & $\mathrm{X}$ & & $\mathrm{X}$ & $\mathrm{X}$ & $\mathrm{X}$ & $\mathrm{X}$ & $\mathrm{X}$ & $\mathrm{X}$ & $\mathrm{X}$ & \\
\hline $\begin{array}{l}\text { Expert in } \\
\text { technology }\end{array}$ & $\mathrm{X}$ & $\mathrm{X}$ & & & & $\mathrm{X}$ & & $\mathrm{X}$ & & & \\
\hline Entomologist & $\mathrm{X}$ & & $\mathrm{X}$ & $\mathrm{X}$ & & $\mathrm{X}$ & $\mathrm{X}$ & & & & \\
\hline $\begin{array}{l}\text { Expert in farm } \\
\text { economics }\end{array}$ & & $\mathrm{X}$ & & & & & & & & & \\
\hline $\begin{array}{l}\text { Expert in } \\
\text { modelling }\end{array}$ & & $\mathrm{X}$ & & & & & & & & & \\
\hline $\begin{array}{l}\text { Actors from the } \\
\text { poultry industry }\end{array}$ & & & $\mathrm{X}$ & $\mathrm{X}$ & $\mathrm{X}$ & & & & & & \\
\hline $\begin{array}{l}\text { Expert in animal } \\
\text { welfare }\end{array}$ & & & & $\mathrm{X}$ & $\mathrm{X}$ & & $\mathrm{X}$ & & & & \\
\hline $\begin{array}{l}\text { Expert in pest } \\
\text { management }\end{array}$ & & & & & & $\mathrm{X}$ & $\mathrm{X}$ & & & & \\
\hline $\begin{array}{l}\text { Expert in } \\
\text { behaviour of } \\
\text { horses }\end{array}$ & & & & & & & $\mathrm{X}$ & & & & \\
\hline $\begin{array}{l}\text { Mechanical } \\
\text { engineer }\end{array}$ & & & & & & & $\mathrm{X}$ & $\mathrm{X}$ & $\mathrm{X}$ & $\mathrm{X}$ & \\
\hline Electrical engineer & & & & & & & $\mathrm{X}$ & $\mathrm{X}$ & $\mathrm{X}$ & $\mathrm{X}$ & \\
\hline Creative designer & & & & & & & $\mathrm{X}$ & & & & \\
\hline Process facilitator & & & & & & & $\mathrm{X}$ & & & & \\
\hline
\end{tabular}

* The expert in animal husbandry was specialised in PRM in laying hen facilities and therefore added entomological knowledge. 


\section{Results}

Here, we describe the results of design stage 1 (steps A-E), design stage 2 (steps F-J), and the phase wherein the prototype design was further developed into a working prototype.

\section{System and actor analysis (Stage 1)}

A future vision (step C) was developed for reducing the negative consequences of PRM infestations in layer farms. The advisory committee based its vision on the available literature and the results of an international workshop (Van Emous et al. 2005; Mul et al. 2009). Their long-term vision was to focus on preventive measures, PRM monitoring and environmentally friendly biological treatments, these being key for the implementation of IPM.

For the current work we focused on preventive measures and monitoring of PRM in layer houses, where in this article we focus on the key challenge (step A) of designing an automated monitoring tool for PRM in layer houses. The tool should be able to 1) monitor PRM automatically, providing farmers and researchers with an insight into mite population dynamics, 2) provide farmers with advice on treatment timings, and 3) determine the effect of treatments on the PRM population. In planning of the project, we agreed that an automated monitoring tool for PRM should consist of 1) a sensor automatically detecting and counting PRM, 2) a population dynamics model, 3) an economic model and 4) an algorithm generating treatment advice. A PRM sensor counts the number of PRM in a laying hen facility. The population dynamics model determines the growth of the PRM population throughout the laying hen house and forecasts mite population dynamics. The economic model determines the economic consequences of a PRM population in a laying hen house. The algorithm advises the farmer to apply a treatment by forecasting the moment in time when production losses due to the PRM infestation exceed the costs of a PRM treatment (the economic threshold). The future vision of the researchers was that the PRM sensor should provide at least weekly, but preferably minute by minute, information on PRM numbers and it should be able to send the data to a central computer with a model forecasting mite population growth for e.g. a week ahead, and automatically calculating the moment when the population exceeds the economic threshold, thus functioning as a real-time decision tool for IPM.

The poultry farmer, animal care taker, laying hen, and the immediate industry and suppliers were determined as the key actors in the design of the automated monitoring tool for PRM (step D). These stakeholders were deemed most important because: 1) PRM negatively effects hen health and welfare and egg production in layer farms worldwide, costing poultry farmers an estimated $€ 0.37$ per hen per year (Chauve 1998; Mul et al. 2010), 2) In addition to attacking hens and causing irritation, restlessness and even anaemia in their hosts (Chauve 1998), PRM can bite animal care takers and may cause severe skin irritation (Cafiero et al. 2009), 3) Without precautionary measures PRM may be spread between poultry farms and their suppliers (on/in material, feed, pullets, trays, pellets) (Mul 
and Koenraadt 2009), 4) Within a poultry farm PRM is able to spread between laying hen houses by walking or by being transported via cadavers, manure and egg belts or persons (Mul and Koenraadt 2009). 5) Laying hen houses provide PRM with food (laying hens), refugia (e.g. manure, transport belts, litter, dust, sub-structures, cadavers) and favourable conditions for rapid population growth (Maurer and Baumgartner 1992).

The issues and needs per stakeholder of the automated monitor for PRM are shown in Figure 4.2 and addressed in a Brief of Requirements (step E). This is available in full on request from the corresponding author, though can be summarised as follows:

- The needs of the laying hen were already listed in a separate project (Bos et al. 2004).

- The automated monitor should meet the safety rules and rules for working conditions according to the national legislation.

- The preferred maximum labour input by farmers for monitoring PRM was determined as 0.05 hour/day.

- The farmers' costs for the total number of mite counters including installation, consumption of electricity, maintenance contract and amortisation should be less than $€ 0.15$ per laying hen per year, with the mite counter having an expected life time of five years.

- For the industry and suppliers, the product should be compatible with various housing systems.

- The PRM sensor should be at least $80 \%$ sensitive to PRM adults, nymphs and larvae.

- Accuracy in determining the increase or decrease of the PRM population is more important than assessing the absolute number of PRM present.

- A maximum of $1 \%$ of the mites counted may be a false positive count.

- The preferred maximum time interval of two population assessments should be a week.

- The time between two breakdowns of the PRM sensor should be a maximum of 365 days. In short, the requirements of the automated monitoring tool show that it should be costeffective, efficacious, safe and available at a price that is lower than the production losses expected from PRM over a five-year period. 


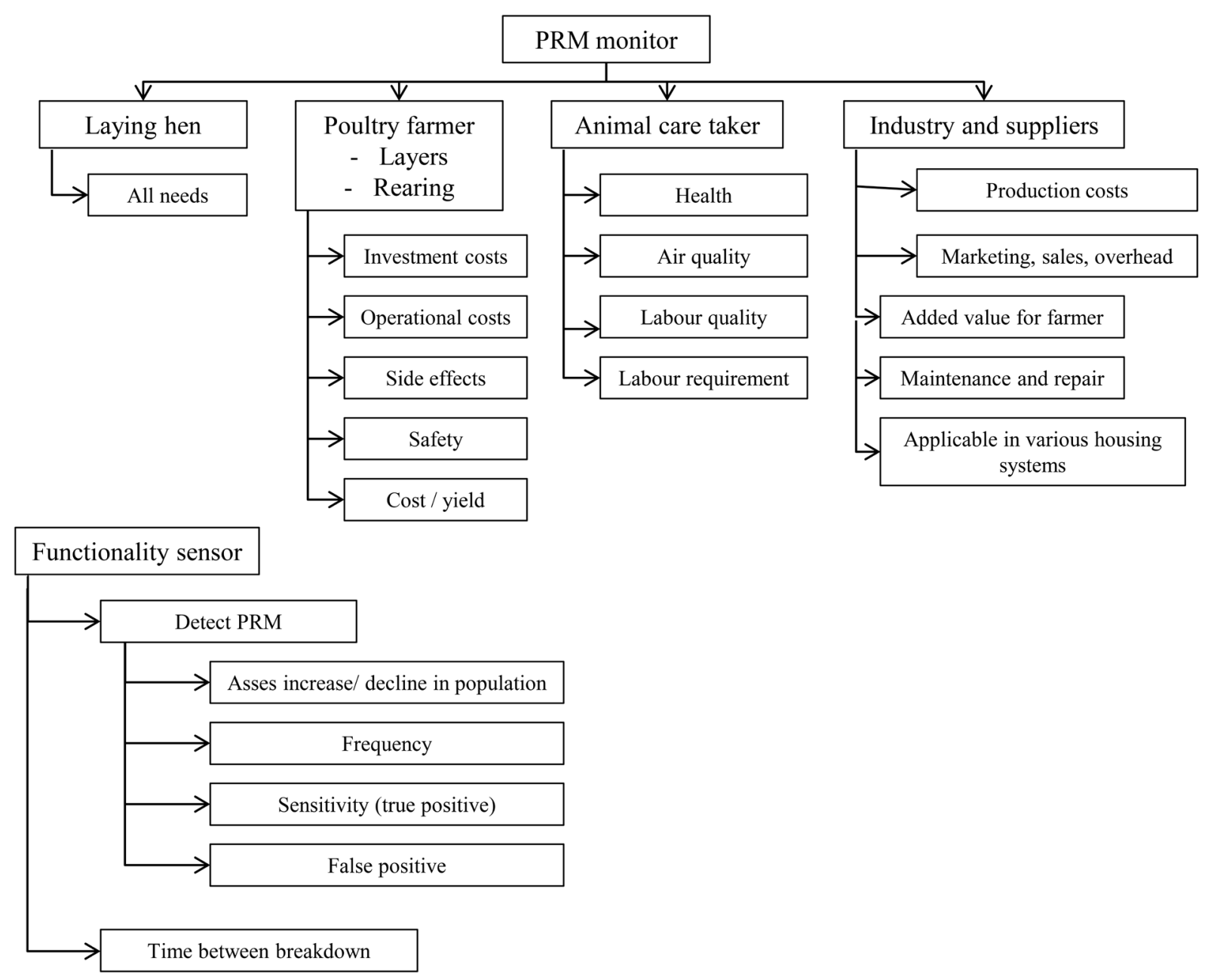

Figure 4.2 Sustainability issues of the automated monitor for PRM and aspects for a functional sensor for detecting PRM reported per stakeholder and needs of the laying hens

A systemic analysis of all functions (step B) related to current PRM control in laying hen houses, revealed that the main function was 'Produce eggs'. This main function was supported by four primary sub functions; 1) Process eggs, 2) House hens, 3) Relocate subjects and objects, and 4) Control farm economics. The sub functions 'House hens' and 'Relocate subjects and objects' are the most important to PRM control in laying hen houses in the current situation. Relocation of subjects and objects includes relocation of PRM and thus removal of mites present in the laying hen house.

The primary sub function 'House hens' contains, amongst others, the secondary sub function 'Control threats'. This sub function contains the tertiary sub function 'Control PRM' which is the most important function to PRM control in laying hen houses. Current methods to control PRM in laying hen houses consist of preventive measures, as described earlier by Mul and Koenraadt (2009), the introduction of predatory mites (Lesna et al. 2012), curative application of acaricides/sanitisers, and curative/preventive use of diatomaceous earths 
(Sparagano et al. 2014). Despite these measures, the poultry industry still faces difficulties in controlling a PRM population and reducing the economic losses incurred through to PRM infestations (Sparagano et al. 2014). Future control of PRM in laying hen houses demands development of more robust and informed IPM programmes. To achieve this aim the tertiary sub function 'Control PRM' comprises both two existing sub functions: 1) Prevent PRM introduction and spread and 2) Reduce PRM population, and two additional desired sub functions: 1) Monitor PRM population dynamics and 2) Determine need of application of PRM reduction method (Figure 4.3). The output of the sub function 'Monitor PRM population dynamics' is knowledge about the size and the location of the PRM population at a certain point in time (Figure 4.4).

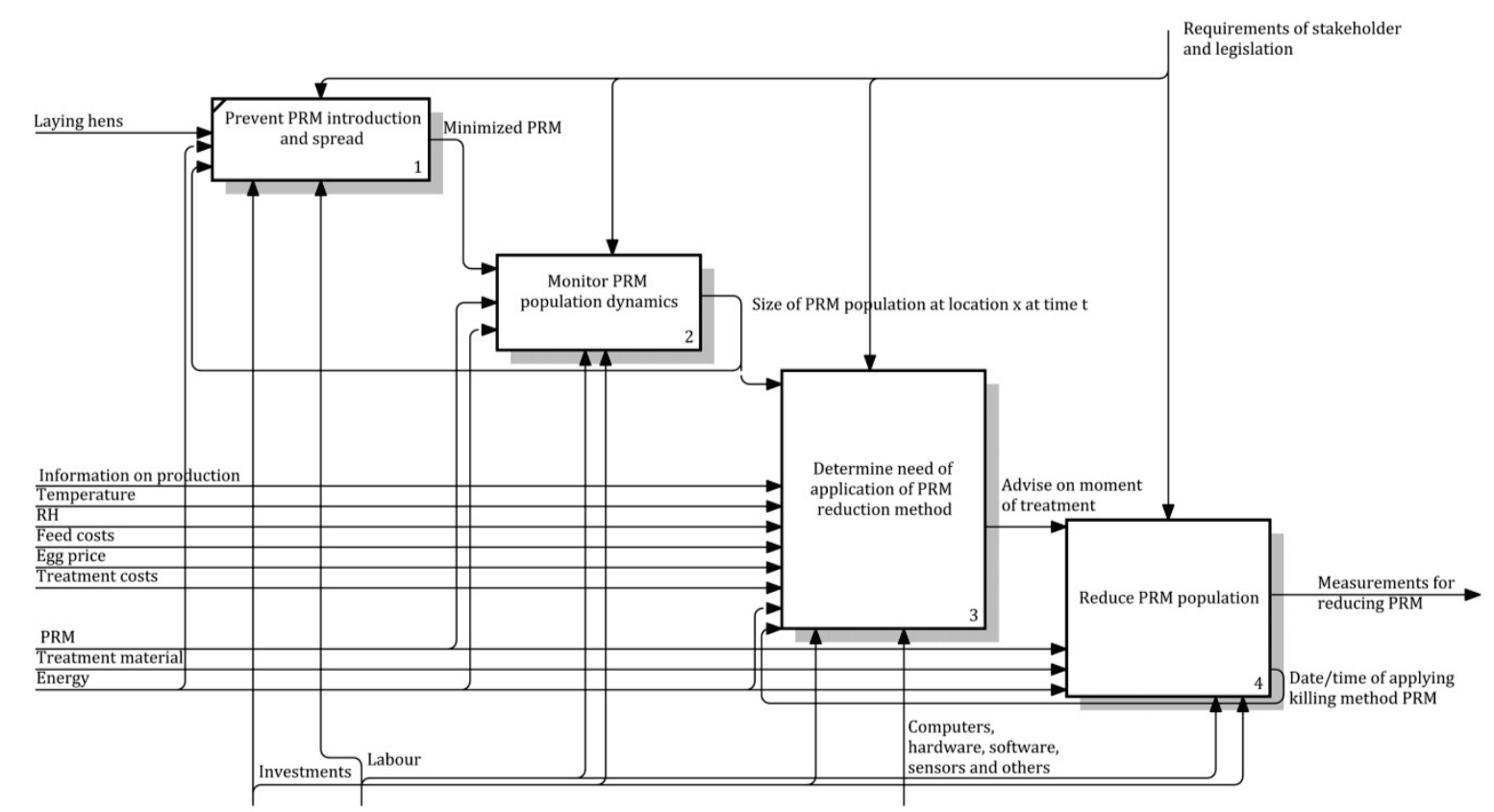

Figure 4.3 Processes of the tertiary sub function 'Control PRM' in the desired situation 


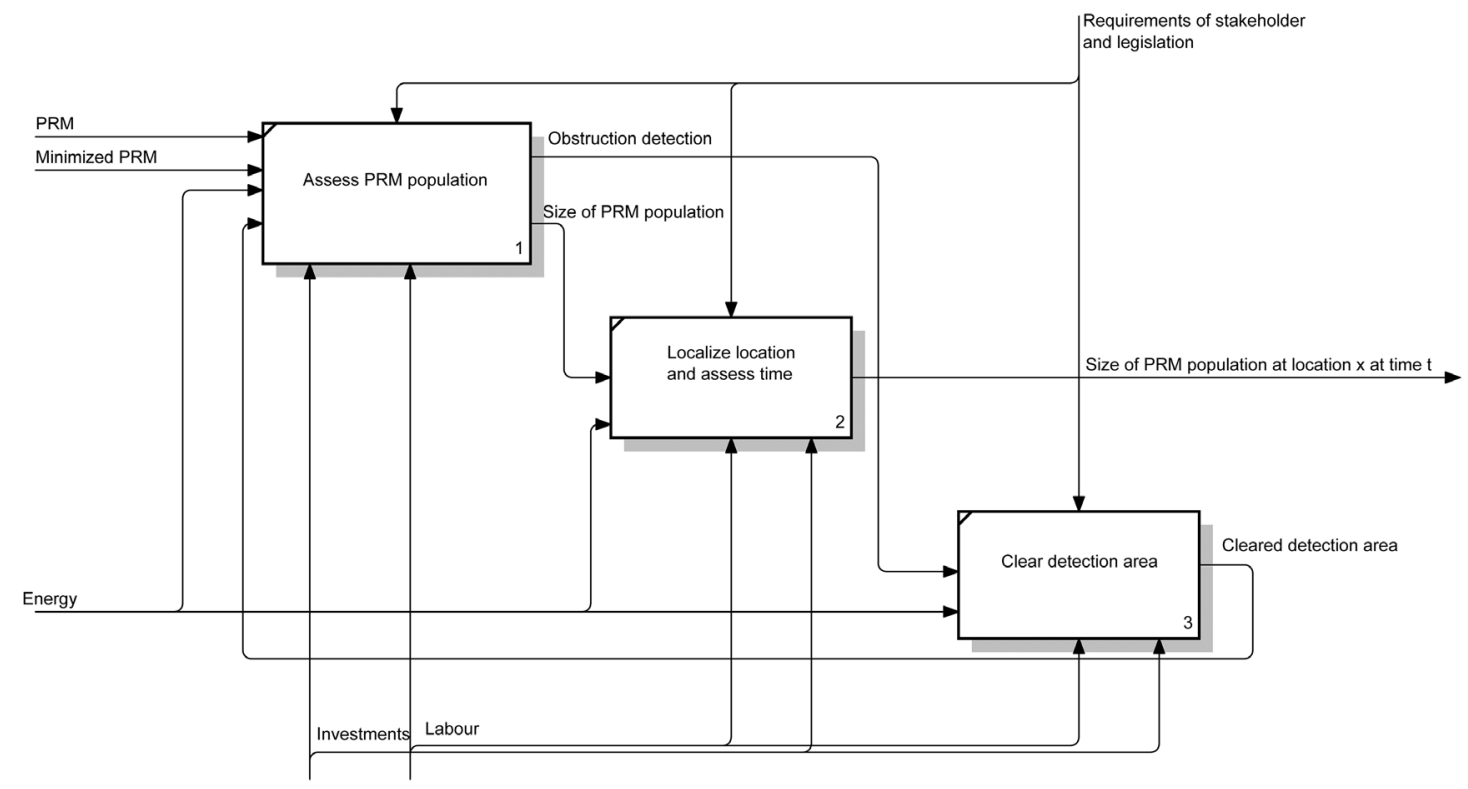

Figure 4.4 Processes of the quaternary sub function 'Monitor PRM population dynamics' in the desired situation

The output of the function 'Determine need of application of reducing method' is an advice for the farmer on the economically optimal moment of treatment application against PRM. The sub functions 'Forecast PRM population', 'Forecast PRM damage' and 'Advise on treatment' are necessary to fulfil this function. These sub functions are a tool for farmers to better and more easily implement IPM when controlling PRM populations in laying hen farms.

\section{Structured design}

- Determine the key function

The key functions of the design of the automated mite detection sensor were determined using the IDEF-0 diagram of 'Monitor PRM population dynamics'. This function comprises the sub functions 'Assess PRM population', 'Localise location and assess time' and 'Clear detection area' (Figure 4.4), which are determined to be the key functions of the automated mite detection sensor.

- From generating solutions to design concepts

Espacenet and the $\mathrm{CAB}$ abstract database were searched and revealed solutions of, amongst others, the possibility of the use of a through-beam sensor to detect invertebrates (Shuman et al. 1996; Litzkow et al. 1997), the possibility of detecting invertebrate populations using sound (Hagstrum and Flinn 1993), or by detecting invertebrate populations using indirect effects of PRM on hen behaviour (Zimmerman and Koene 1998). Using the IHS Goldfire Decision Engine Platform software revealed that detection, 
localisation and quantification are the initial core problems that must be solved prior to addressing any PRM problem per se later. Interviews with PRM experts were vital to revealing vertically-oriented mite host seeking behaviour. During the brainstorming session actors from multiple disciplines, and with diverse expertise, inspired each other and created their own common language, proposing placement of the PRM sensor on the 'road' (route) from the mite refuges ('the hotel') to the laying hen ('the restaurant'). Attendees of the session also proposed that the PRM sensor should be positioned inside of the vertical metal U-beam, or under the perch. To direct the mites towards the PRM sensor, a stimulodeterrent approach was proposed along the route between the 'hotel' and 'restaurant' involving so-called 'heaven' (attracting mites towards the sensor with, for example, warmth, moisture, nearby hosts, pheromones, $\mathrm{CO}_{2}$, or shelter) and 'hell' (repelling mites from areas without a sensor using, for example, light, open space, soap or silica, strong air flow, repellents, or physical disturbance). Finally, the creative consultant emphasised the importance of detecting low PRM numbers and provided insight into the variety of materials and structures available for sensor construction. All solutions identified were assessed against the requirements of the stakeholders, these being that solutions should be low cost, robust, feasible, user friendly, product safe, labour extensive, safe for the laying hen and achievable (in terms of PRM sensor development) within a two-year timeframe proposed by the advisory committee.

The Morphologic Function diagram (Figure 4.5) shows the solutions or working principles for the key functions for monitoring the PRM population: 1) Assess the PRM population, 2) Localise location and assess time, and 3) Clear detection area. The three lines show three combinations of solutions (so called design concepts) using the criteria in the Brief of Requirements. The first design concept was based on the Electronic Grain Probe Insect Counter (EGPIC), as described by Litzkow et al. (1997). This counter detects insect pest populations in stored products using a tube with small holes, where insects climb into these holes and subsequently fall through an infra-red emitter and receiver.

Design concepts 2 and 3 were developed using the knowledge that, during darkness, PRM's natural behaviour is to climb vertically upwards from the cracks and crevices of the poultry house sub structure in which the mites rest, shelter, mate and lay eggs (Maurer et al. 1988; Mul et al. 2009) to locate hens at roost on perches and other structures.

The combinations of working principles are:

- Design concept 1. A through-beam sensor to detect PRM when falling due to gravity or slippery surfaces at the inside of the tube.

- Design concept 2. A through-beam sensor to detect PRM when climbing vertically upwards from hiding places to the sleeping place of the hens.

- Design concept 3. Lure PRM towards a hiding place, in the vicinity of the sleeping place of the hens, by fitting a heated element within that hiding place. At the entrance of the hiding place a through-beam sensor detects PRM. A pump sucks air through the sensor and collects PRM in a filter.

Electrical power and data transport was provided by cables for all three design concepts. 


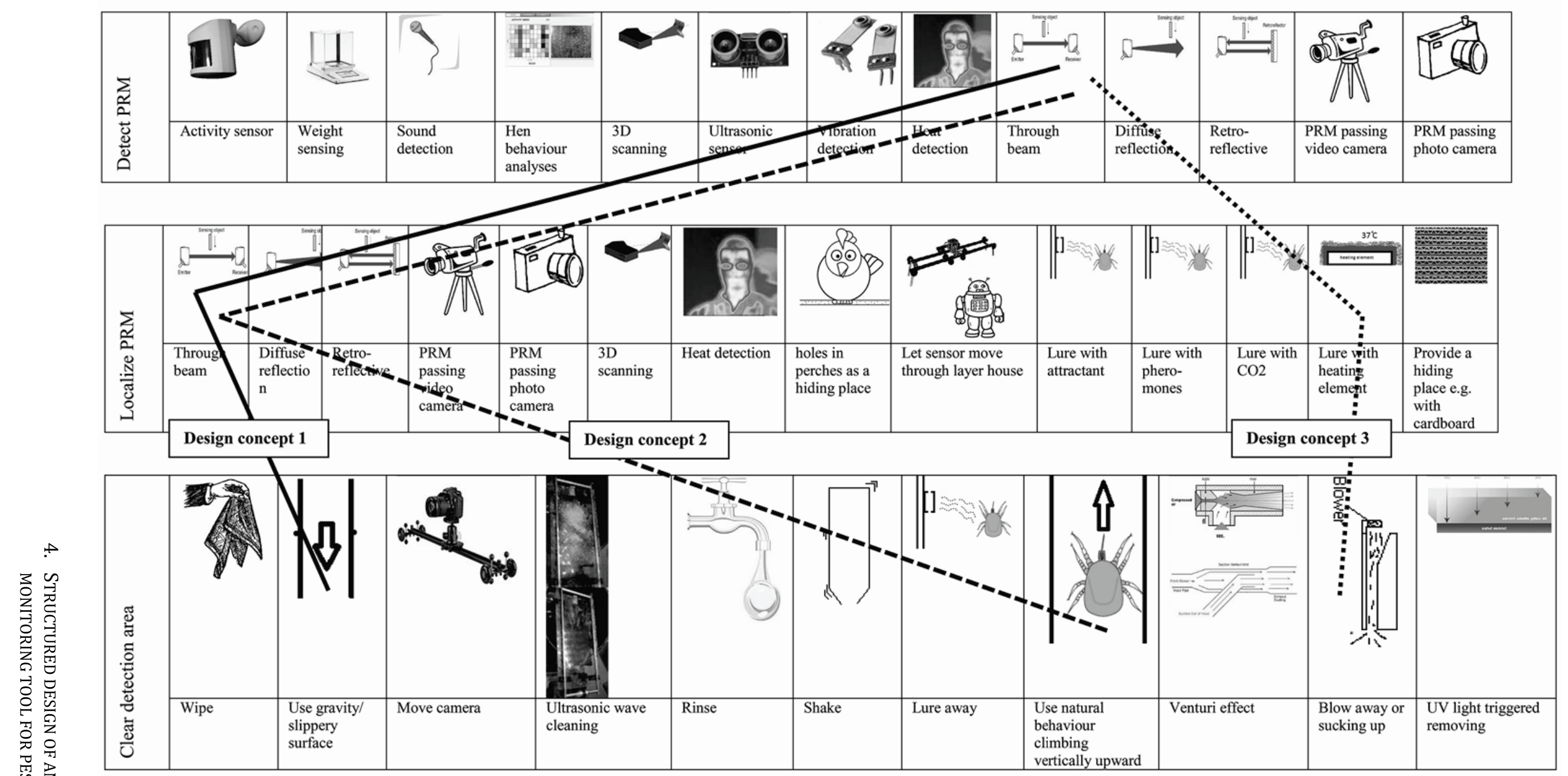

Figure 4.5 Morphologic Function diagram showing the solutions and various working principles for the key functions for monitoring the PRM population: 1) Assess PRM population, 2) Localize location and assess time, and 3) Clear detection area. The three lines show the three combinations (or design concepts) of solutions using the criteria in the Brief of Requirements 


\section{- Test of solutions}

The mite preference tests showed that:

1) Significantly more mites were attracted to a copper tablet at $33^{\circ} \mathrm{C}(3.3 \pm 1.8$ mites) (mean \pm standard deviation) compared to a copper tablet at $20^{\circ} \mathrm{C}(1.6 \pm 1.5$ mites $)(p=0.001)$,

2) Not significantly more mites were attracted to a tube with an inner tube diameter of 1.5 $(0.6 \pm 0.8$ mites $)$ versus $4.4 \mathrm{~mm}(0.7 \pm 0.8$ mites $)(p=0.9)$,

3) Significantly more mites were attracted to non-transparent tubes ( $1.6 \pm 1.7$ mites $)$ as compared to transparent tubes $(0.5 \pm 0.9$ mites $)(p=0.005)$,

4) Not significantly more mites were attracted to round cavities $(2.2 \pm 2.3$ mites $)$ as compared to squared cavities ( $1.7 \pm 1.9$ mites) ( $p=0.3$ ).

In vivo on farm tests further supported that not significantly more mites were attracted to either of the two tube diameters tested $(p=0.6)$.

In the laboratory more PRM were attracted to a) copper (2.1 \pm 1.9 mites) (mean \pm standard deviation) compared to PVC ( $1.1 \pm 1.4$ mites) ( $\mathrm{p}=0.013)$, b) PVC (2.0 \pm 1.2 mites) compared to steel $(1.0 \pm 1.3$ mites $)(\mathrm{p}=0.002)$, and copper ( $3.7 \pm 2.9$ mites) compared to aluminum $(0.5 \pm 0.7$ mites $)(\mathrm{p}<0.001)$. There was no significant preference found between aluminum (1.3 \pm 1.6 mites) and brass ( $1.8 \pm 2.3$ mites) $(\mathrm{p}=0.3)$ and between brass $(1.5 \pm 1.7$ mites) and PVC (1.8 \pm 2.2 mites) ( $\mathrm{p}=0.4)$. On farm there was no significant preference for copper ( $3.4 \pm 3.1$ mites) compared to steel $(2.5 \pm 3.0$ mites) $(p=0.077)$, though the $p$-value obtained supported a trend for preference for the former. Similarly, no significant preference was found on farm for copper ( $1.8 \pm 1.2$ mites) when compared to PVC $(2.4 \pm 1.8$ mites) ( $\mathrm{p}=0.138)$, or for PVC $(2.0 \pm 2.3$ mites) when compared to steel $(\mathrm{p}=0.765)$.

The mite challenge tests showed that PRM 1) were not falling or jumping voluntarily towards an (attractive) heated copper tablet, and 2) that they were able to climb on a slippery surface made from glass or PTFE. With increased air velocity, satiated adult PRM dislodged at the highest velocity of $20.3 \pm 12.2 \mathrm{~m} / \mathrm{s}$. Upon a sudden release of air, all PRM life stages were dislodged at an air velocity of $47.6 \pm 0.07 \mathrm{~m} / \mathrm{s}$.

\section{- Construction and testing of prototypes}

The first design concept using gravity and slippery surfaces was rejected based on the results of the mite challenge test (see former section). The second design concept (Figure 4.6) was successfully tested in the laboratory with live mites though the test in the laying hen house was unsuccessful with mites not passing the through-beam sensor and residing in and on the processor housing. 

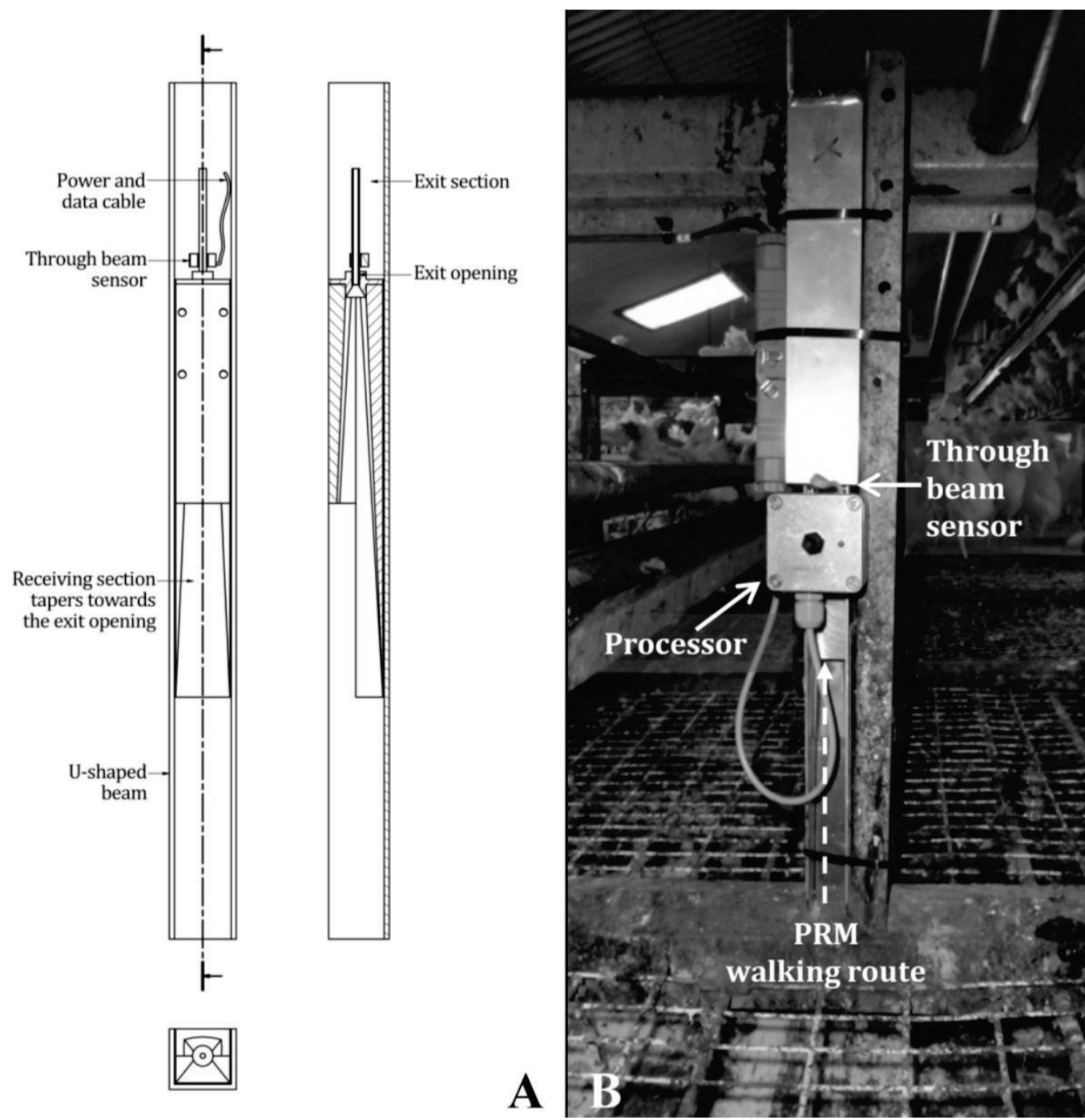

Figure 4.6 Design concept 2 of the PRM sensor placed in a metal U-shaped beam of the interior of a laying hen house, top view, side view and bottom view. PRM walk from their hiding places upward to the laying hen resting on the perch. PRM are lead via the tapering receiving section towards the detecting infra-red emitter and receiver to be registered by a processor (not shown) (Panel A) and Design concept 2 with a processor (metal square box with an electricity and data cable fixed just below the sensor) fixed in a metal U-shaped beam in an aviary system inside a laying hen house. The PRM walking route is indicated with the dashed arrow (Panel B)

The third design concept was constructed and tested in the laying hen house. A pump and filter, protecting the pump, were placed in a PVC casing with a hole (1-2 mm diameter) and an infra-red emitter and receiver plus a processor (Figure 4.7). This processor also functioned as an attracting element for PRM as more mites were attracted into a PVC casing with processor compared to the same PVC casing without processor as tested in the laying hen house. In the layer house, PRM were observed to be attracted to, counted by and captured in the filter. Mite counts aligned well with the numbers of mites found in the filters, 
although assessment of the latter was not always possible due to crushing of PRM inside the filter. The mite counting started approximately two hours after the onset of the dark period until approximately $30 \mathrm{~min}$ after the onset of the light period, to align with known mite activity patterns published by Maurer et al. (1988). A prototype of design concept 3 was subsequently made and successfully tested in the layer house for two weeks. A validation with 12 prototypes proved to count a representative number of PRM present in the laying hen facility (Mul et al. 2015). 

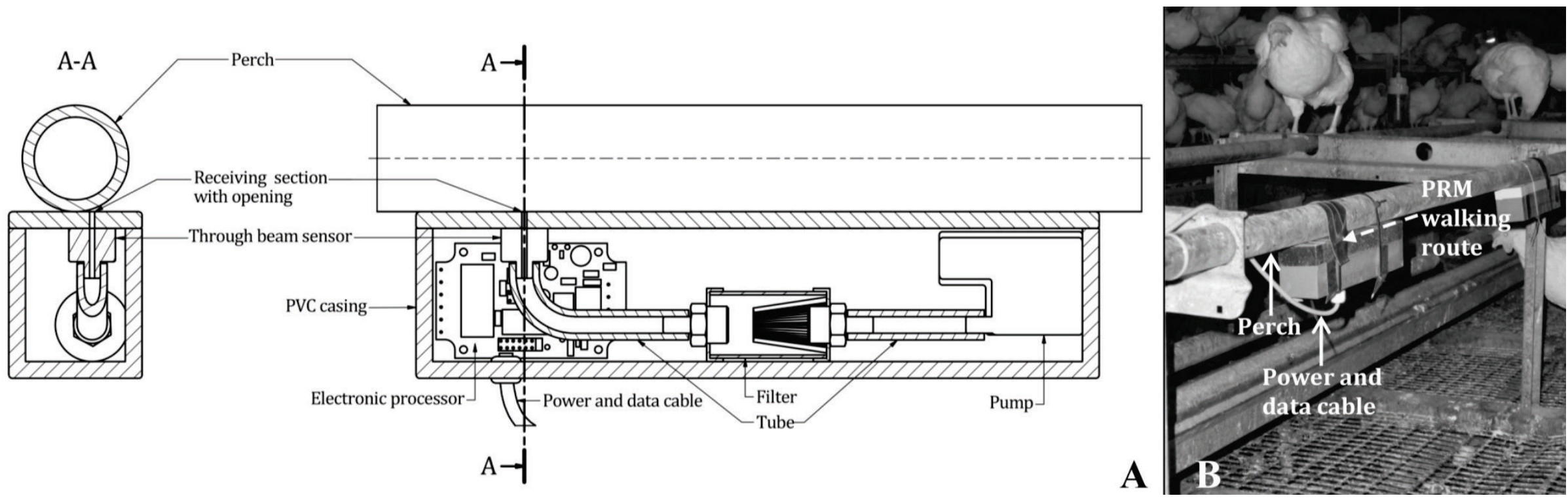

Figure 4.7 Design concept 3 of the PRM sensor, side view and front view. PRM walks at the lower side of the perch in the crevice of the perch and the PVC casing. PRM enter the sensor via a hole (1-2 $\mathrm{mm}$ in diameter) or receiving section and are detected with an infra-red emitter and receiver and registered with a processor which switches on the pump to suck the PRM into a filter, protecting the pump. The processor sends data to a data logger and also functioned as a heated element to attract PRM (Panel A) and Design concept 3 fixed under the perch in a laying hen house within an aviary system. The PRM walking route is indicated with the dashed arrow (Panel B) 


\section{Discussion}

The work conducted supports that the RIO approach can be of significant benefit for the design of automated monitoring tools for pest species, here with the parasitic mite PRM as an example. This approach provided a structured method to focus on the synthesis of knowledge of multi-disciplinary actors and users to assemble multiple concepts and at least one feasible and functional prototype.

The RIO approach was chosen above other design methods as RIO emphasises the need for deliberation and involvement of actors as stakeholders, also recognising these persons as key for the implementation of the solution (Bos et al. 2009). Other available design methods only partially fulfil these criteria. The methods of Van den Kroonenberg (Siers 2004) and Cross (2008), for example, follow a structure to avoid prematurely making conclusions and are part of the RIO approach, but are more limited in scope than RIO itself. Similarly, the method of Cannessa (1989) who used the IDEF diagrams to identify their required level of design detail, lack the social features of societal system engagement achieved by RIO.

To date, RIO has been applied to design (elements of) sustainable animal husbandry systems for laying hens, pigs, dairy cows, broilers and rabbits (Bos 2010). The current work adds further support to the value of the RIO approach when designing pest monitoring tools for animal husbandry systems. This work has shown that each step within the RIO approach contributed to the final successful prototype by "avoiding jumping to conclusions, obtaining a good overview of the stages in the designing process, reducing the chances for overlooking essential items, facilitating the taking of justifiable decisions and increasing the chances on feasible design" (Siers 2004). The RIO approach, and in particular the exact phrasing of the problem, the goal, the (set-up of the) Brief of Requirements, the choices for the three design concepts and discussion of test results, helped in the communication between the diverse, multi-lingual, multi-sector stakeholder group of people; choices became explicit, and the meaning and interpretation of words and phrases used in these steps was clearly aligned.

Not included within the current work, the next stage of the RIO approach to be carried out is step $\mathrm{K}$ of stage 3: Establish networks of stakeholders around the concept in general and around specific solutions. As mentioned by Bos et al. (2009) this should be a natural progression of all the previous steps. In our case, as shown in Table 1, various stakeholders were involved in the design process from the start. The final prototype of the automated mite detection sensor, based on design concept 3, was constructed by the Technical Development Studio, Wageningen UR and based on choices for methods and components which were already known and preferred by the actors involved in the design steps A-J. A commercial partner willing to produce and to market the automated mite detection sensor was not involved in these design steps, but has been engaged following the validation of the prototype (Mul et al. 2015). This successful validation of the prototype of the automated mite detection sensor and the involvement of many stakeholders and the reflection of their requirements in the Brief of Requirements have clearly contributed to convince a company 
to become the commercial partner aiming to produce, develop and sell PRM sensors to farmers. With hindsight, the involvement of the commercial partner was evaluated as too late as several hurdles had to be taken in the transfer of knowledge, experience and choices for hardware technology and PRM sensor lay-out from the early involved actors and stakeholders to the commercial partner. Earlier involvement of the commercial partners would have led to other choices in the prototype for e.g. hardware components in the prototype and consequently to less time needed for retesting of the PRM sensor designed and developed for mass production by the commercial partner.

The RIO approach used in the current study resulted in a functional combination of solutions. However, it deserves note that small details do matter in the design process and detailed knowledge of the pest was vital for optimising the design concepts and prototypes produced. For example, almost invisible 'obstacles' within sensors may present significant physical barriers for PRM, this being a relatively small species with females measuring only $1 \mathrm{~mm}$ in length when adult. Therefore, limiting the presence of any cracks, crevices or other obstacles near the entrance of the sensor, or even within the sensor itself, is a key component in PRM sensor design. Furthermore, a thorough understanding of mite biology was vital enabling to explain the PRM sensor being less attractive to the mites when PRM clusters occurred (Mul et al. 2015). PRM displays thigmokinesis, which leads to mite aggregation (Entrekin and Oliver 1982). These mite aggregations seemed to be more attractive than the sensor.

The Brief of Requirements facilitated efficient selection of the solutions for the key functions, providing insight into costs farmers would be willing to accept for an automated mite monitor. Moreover, this Brief of Requirements proved critical in determining detection parameters (i.e. sensitivity, false positives) and measurement thresholds used during testing and development of the sensor. As part of ongoing commercial development an economic evaluation of the automated mite monitor described has already been conducted by the commercial partner. This assessment, though commercially sensitive and thus confidential, has nevertheless concluded that the system is financially viable, both for the manufacturer and poultry producer.

Involvement of actors and users with multidisciplinary knowledge and different networks and needs was vital for the development of the PRM sensor. Each design step was completed by the most appropriately skilled actors in order to increase the probability of generating solutions and new ideas, and to optimise the value of the results obtained and any discussion based upon them. All knowledge generated during the process was integrated into new solutions, thus minimising the rejection rate of developments and hastening project progress towards the end goal of a fully functional sensor.

Mite preference tests, mite challenges tests and laboratory prototype tests were included in the design structure. When compared with the field data, the results of the mite preference tests, and of the laboratory test with the prototype of design concept 2 , proved to be non-transferable from in vitro to in vivo situations. The extent to which these laboratory 
tests contributed to the final design is, therefore, questionable. Importantly, this result supports that in vitro behavioural testing with PRM should be carried out in the presence of hosts, or at least host cues, if results are intended to be transferable to the field. Mite challenge tests of ability, rather than behaviour, are likely to be less affected by host presence and more suitable for reliable transfer of results from laboratory to field.

The automated mite monitor, designed by the RIO approach as described in this paper, comprises a PRM sensor to assess the PRM population, a population dynamics model, an economic model and an algorithm to advise end-users on treatment application timings and success. The prototype of design concept 3 was replicated and subsequently validated in 12 experimental laying hen cages with live birds and a growing population of PRM. This validation showed that the PRM sensor was able to accurately monitor the mite population (Mul et al. 2015). At the time of writing, the population dynamics model, the economic model and the algorithm required for full commercial realisation were under construction, supported by monitoring data from multiple research institutes throughout Europe. These data will have been collected either visually or by counting the numbers of trapped mites, both of which are laborious and time-consuming methods. We expect that when a validated automated monitoring is commercially available, more data on PRM populations can be generated within shorter time frames, leading to reduced lengths and costs of treatment trials, increased knowledge on PRM population dynamics and better insights into the economic effects of a PRM population.

Once realised, development of a commercially available monitoring system for PRM should greatly improve IPM against this species, allowing farmers to significantly reduce economic losses and animal welfare and health issues associated with PRM through timely treatment applications. Accurate monitoring will also be key to underpin, and instil farmers' confidence in, preventive methods of PRM control (such as the HACCP method).

The RIO approach described here should be equally applicable to designing monitoring tools for numerous pest species, assuming a prior knowledge of the pest and production system exists. Every step of the RIO approach requires knowledge about the target pest behaviour and other key characteristics to determine the key functions and to select the best solutions or working principles. The RIO process can, however, be used to generate additional knowledge where required. In the design of the PRM sensor described here, the additional step of testing the solutions, and consequently constructing and testing the prototypes, showed that Design concept 1, using gravity to clear the detection area, was effective for pests of stored grain (Shuman et al. 1996), but not for PRM. It appears that PRM were more able to transverse any smooth and slippery surface than the stored grain pests previously tested. Thus, we conclude that testing of the solutions generated with individual pests is a crucial step in prototype development to generate effective and technically feasible solutions. 


\section{Conclusion}

The RIO approach was successfully used in the current study to design a fully automated pest monitoring tool including an automated mite detection sensor for PRM. The involvement of actors and users with multidisciplinary knowledge and different networks and needs were vital for assuring project progression, the quality of the final product and limiting the number of design rejections required to realise the end product. Through inclusion of an evaluation step of the best-preferred solutions using live pests, the current method could be expected to be applicable to other pests. Indeed, the knowledge of the pest is incorporated in each design step of the structure and linked to other fields, safeguarding the applicability of this structure to all pests.

\section{Acknowledgements}

This research was funded by the Dutch Product Board for Poultry and Eggs and the Dutch Ministry of Economic Affairs (TKI-AF-12048 Poultry4Food). We are grateful to the Farm Measurement Team, Thea van Niekerk, Geert André (in memoriam), Piet van Wikselaar (all at Wageningen UR Livestock Research), Sam Blaauw (Wageningen University Farm Technology Group), Iza Lesna (University of Amsterdam), staff and co-workers of Pluimveebedrijf Salomons BV, Eric Karruppannan and Hans Meijer (Technical Development Studio of Wageningen University and Research), Hugo Bens (layer farmer, president of the committee 'Aanpak Bloedluis'), Committee “Aanpak bloedluis", Renate Smallegange (medical and veterinary entomologist), Fransje Gorter (creative designer), Roelof de Jong, Sander Bouwknegt and Kevin Niessen (students Biosystems Engineering, Wageningen University) for their contribution to this research. The authors would also like to acknowledge the networking support by the EU COST Action FA1404. 


\section{References}

Animal Sciences Group (2010) Klimaatplatform pluimveehouderij. Leghennen volièrestal. http://www.wageningenur.nl/upload_mm/b/a/6/7e1c04a9-a6ca-4059-a506fb7f0481126d_Klimaatrichtlijnen\%20leghennen\%20voliere\%20okt\%202010.pdf (03012015)

Anonymous (2015) https://www.ihs.com/products/design-standards-softwaregoldfire.html (03012015)

Bonnefoy X, Kampen H, Sweeney K (2008) Public health significance of urban pests. World Health Organisation, WHO Regional Office for Europe, Denmark. ISBN 978-92-8907188-8

Bos AP, Greef KH de, Groot Koerkamp PWG, Hierden YM van, Kommers MAW, Kroon SMA van der, Ruth JA van, Wijk EEC van (2004) Houden van hennen: programma van eisen op basis van de behoeften van pluimveehouder, leghen en burger : nieuwe ontwerpen voor leghen en duurzame houderij. Wageningen UR rapportnummer: ASG 04/0006786

Bos AP, Groot Koerkamp PWG, Gosselink JMJ, Bokma S (2009) Reflexive interactive design and its application in a project on sustainable dairy husbandry systems. Outlook Agric 38: 137-145

Bos AP (2010) Reflexief Interactief Ontwerpen (RIO). Rapport 344, Wageningen UR Livestock Research, ISSN 1570-8616

Cafiero MA, Camarda A, Circella E, Galante D, Lomuto M (2009) An urban outbreak of red mite dermatitis in Italy. Int J Dermatol 48: 1119-1121

Canessa DG (1989) Systems analysis, modelling and design. The Welding Institute Bulletin, Jan/Feb is., Cambridge, U.K

Chauve CM (1998) The poultry red mite Dermanyssus gallinae (De Geer, 1778): current situation and future prospects for control. Vet Parasitol 79: 239-245

Cross N (2008) Engineering design methods: strategies for product design. 4th edition. John Wiley \& Sons Ltd, England. ISBN 978-0-470-51926-4

Entrekin DL, Oliver JH jr (1982) Aggregation of the chicken mite, Dermanyssus gallinae (Acari: Dermanyssidae). J Med Entomol 19: 671-678

FAO (2001) The state of food and agriculture 2001. Food and agriculture organization of the united nations, Rome.

http://www.fao.org/docrep/003/x9800e/x9800e00.htm\#TopOfPage (27072015).

FAO (2015) http://www.fao.org/agriculture/crops/thematicsitemap/theme/pests/ipm/en/_(27072015)

Flint ML (2012) IPM in practice: Principles and methods of Integrated Pest Management. Publication 3418, 2nd edition. The Regents of the University of California. ISBN13:978-1-60107-785-1 
Hagstrum DW, Flinn PW (1993) Comparison of acoustical detection of several species of stored-grain beetles (Coleoptera: Curculionidae, Tenebrionidae, Bostrichidae, Cucujidae) over a range of temperatures. J Econ Entomol 86: 1271-1278

Hemming S, Van Henten E, Van 't Ooster B, Vanthoor B, Bakker S (2008) Systematic design of greenhouse crop production systems. Paper presented at INCOSE 18th Annual International Symposium in Utrecht

Jianhua Y, Jingxue Q (1992) Automatic insect pest monitor. Patent CN2116195 (U) - 199209-16

Kogan M (1998) Integrated Pest Management: Historical perspectives and contemporary developments. Annu Rev Entomol 43: 243-270

Lesna I, Sabelis MW, Van Niekerk TGCM, Komdeur J (2012) Laboratory tests for controlling poultry red mites (Dermanyssus gallinae) with predatory mites in small 'laying hen' cages. Exp Appl Acarology 58: 371-383

Lightsey B (2001) Systems Engineering Fundamentals. Defense Acquisition University Press, Fort Belvoir, Virginia. 20010320076

Litzkow CA, Shuman D, Kruss S, Coffelt JA (1997) Electronic grain probe insect counter (EGPIC). Patent US5646404 (A)-1997-07-08

Martinelli F, Scalenghe R, Davino S, Panno S, Scuderi G, Ruisi P, Villa P, Stroppiana D, Boschetti M, Goulart LR, Davis CE, Dandekar AM (2015) Advanced methods of plant detection. A review. Agron Sustain Dev 35: 1-25

Maurer V, Bieri M, Fölsch DW (1988) Das suchverhalten von Dermanyssus gallinae in hühnerställen. Arch Geflugelkd 5: 209-215

Maurer V, Baumgartner J (1992) Temperature influence on life table statistics of the chicken mite Dermanyssus gallinae (Acari: Dermanyssidae). Exp Appl Acarol 15: 27-40

Mayes T (1993) The application of management systems to food safety and quality. Trends Food Sci Tech 4: 216-219

Mayes T (1998) Risk analysis in HACCP: burden or benefit? Food Control 9: 171-176

Meerburg BG, Singleton GR, Leirs H (2009a) The year of the rat ends: time to fight hunger! Pest Manag Sci 65: 351-352

Meerburg BG, Singleton GR, Kijlstra A (2009b) Rodent-borne diseases and their risks for public health. Crit Rev Microbiol 35: 221-270

Mul MF, Koenraadt CJM (2009) Preventing introduction and spread of Dermanyssus gallinae in poultry facilities using the HACCP method. Exp Appl Acarol 48: 167-181

Mul M, Niekerk T van, Chirico J, Maurer V, Kilpinen O, Sparagano O, Thind B, Zoons J, Moore D, Bell B, Gjevre A-G, Chauve C (2009) Control methods for Dermanyssus gallinae in systems for laying hens: results of an international seminar. World Poultry Sci J 6: 589600

Mul MF, Van Niekerk TGCM, Reuvekamp BFJ, Van Emous RA (2010) Dermanyssus gallinae in Dutch poultry farms: Results of a questionnaire on severity, control treatments, 
cleaning, and biosecurity. In: M.W. Sabelis, \& J. Bruin (Eds.), Trends in Acarology: proceedings of the 12th International Congress: 513-516

Mul MF, Van Riel JW, Meerburg BG, Dicke M, George DR, Groot Koerkamp PWG (2015) Validation of an automated mite counter for Dermanyssus gallinae in experimental laying hen cages. Exp Appl Acarol 66: 589-603

Narladkar BW (2014) Integrated management of arthropod pests of veterinary importance: Recent up-dates on unconventional but feasible measures. Indian J Anim Sci 84: 11431156

Oerke E-C (2006) Crop losses to pests. J Agr Sci 144: 31-43

Polder G, Van der Heijden GWAM, Van Doorn J, Baltissen AHMC (2014) Automatic detection of tulip breaking virus (TBV) in tulip fields using machine vision. Biosyst Eng 117: 3542

Schulz J (2014) Massnahmen zur bekämpfung der roten vogelmilbe (Dermanyssus gallinae) in der ökologischen legehennenhaltung. Inaugural-Dissertation zur Erlangung des Grades eines Doktors der Veterinärmedizin and Freie Universität Berlin. ISBN: 978-386387-505-3

Shuman D, Coffelt JA, Weaver DK (1996) A computer-based electronic fall-through probe insect counter for monitoring infestation in stored products. T ASAE 39: 1773-1780

Shuman D, Epsky N, Crompton RD (2003) Commercialisation of a species-identifying automated stored-product insect monitoring system. Advances in stored product protection. Proceedings of the $8^{\text {th }}$ International Working Conference on Stored Product Protection, York, UK, 22-26 July 2002: 144-150

Siegel S (1956) Nonparametric statistics for the behavioral sciences. McGraw-Hill, New York Siers FJ (2004) Methodisch ontwerpen volgens H.H. van den Kroonenberg. Derde druk. Wolters-Noordhoff Groningen/Houten The Netherlands. ISBN 978-90-01-50901-9

Sparagano OAE, George DR, Harrington DWJ, Giangaspero A (2014) Significance and control of poultry red mite, Dermanyssus gallinae. Annu Rev Entomol 59: 447-466

Spoelstra SF, Groot Koerkamp PWG, Bos AP, Elzen B, Leenstra FR (2013) Innovation for sustainable egg production: realigning production with societal demands in The Netherlands. World Poultry Sci J 69: 279-297

Sun YM, Ockerman HW (2005) A review of the needs and current applications of hazard analysis and critical control point (HACCP) system in foodservice areas. Food Control 16: 325-332

Trompen M (2003) Apparatus, system and method for pest determination and notification. Patent US2003160699 (A1) - 2003-08-28

Van Emous RA, Fiks-van Niekerk TGCM, Mul MF (2005) Bloedluizen (vogelmijten) op papier en in de praktijk. PraktijkRapport 17, Animal Sciences Group - Praktijkonderzoek ISSN 15708624

Van Lenteren JC, Woets J (1988) Biological and integrated pest control in greenhouses. Annu Rev Entomol 33: 239-269 
Van Weeghel HJE, Bos AP, Spoelstra SF, Groot Koerkamp PWG (2016) Involving the animal as a contributor in design to overcome animal welfare related trade-offs: The dust bath unit as an example. Biosyst Eng 145: 76-92

Vervaert E, Zoons J, Suls L (2005) Bloedluisbestrijding in leghennenstallen. Landbouw Techniek, 10, 9:17-18

WHO (2015) http://www.who.int/heli/risks/toxics/chemicals/en/ (27072015)

Zenner L, Bon G, Chauve C, Nemoz C, Lubac S (2009) Monitoring of Dermanyssus gallinae in free-range poultry farms. Exp Appl Acarol 48: 157-166

Zimmerman PH, Koene P (1998) The effect of frustrative nonreward on vocalisation and behaviour in the laying hen, Gallus gallus domesticus. Behav Process 44: 73-79

Zhao B, Mao W, Zhou P, Yuan Y, Zhang X (2014) Automatic cotton field pest situation monitoring device and automatic cotton field pest situation monitoring method. Patent CN103903252 (A) - 2014-07-02 


\section{Chapter 5}

\section{Validation of an automated mite counter for Dermanyssus gallinae in experimental laying hen cages}

Monique F. Mul' ${ }^{1}$, Johan van Riel ${ }^{1}$, Bastiaan G. Meerburg${ }^{1}$, Marcel Dicke ${ }^{2}$, David R. George ${ }^{3}$, Peter W.G. Groot Koerkamp ${ }^{1,4}$

1 Wageningen Livestock Research, Department Animal husbandry and environment, P.O.Box $6700 \mathrm{AH}$ Wageningen, The Netherlands

2 Laboratory of Entomology, Wageningen University, P.O. Box 16, 6700 AA Wageningen, The Netherlands

3 Stockbridge Technology Centre, North Yorkshire, Y08 3TZ, United Kingdom

4 Farm Technology Group, Wageningen University, P.O. Box 16, 6700 AA Wageningen, The Netherlands

Experimental and Applied Acaralogy (2015) 66: 589-603 


\begin{abstract}
For Integrated Pest Management (IPM) programs to be optimally effective, monitoring of the growth and decline of the pest populations is essential. Here, we present the validation results of a new automated monitoring device for the poultry red mite (Dermanyssus gallinae), a serious pest in laying hen facilities world-wide. This monitoring device (called an "automated mite counter") was validated in experimental laying hen cages with live birds and a growing population of D. gallinae. This validation study resulted in 17 data points of 'number of mites counted' by the automated mite counter and the 'number of mites present' in the experimental laying hen cages. The study demonstrated that the automated mite counter was able to track the D. gallinae population effectively. A wider evaluation showed that this automated mite counter can become a useful tool in Integrated Pest Management of D. gallinae in laying hen facilities.
\end{abstract}




\section{Introduction}

Integrated Pest Management (IPM) is a method that is frequently used in numerous cropping systems. This method is based on the integration of all ecological and biological knowledge about a certain pest species, including the effect of both biotic and abiotic factors on population development. IPM aims to minimize economic losses by including different environmentally safe methods to prevent and control pests whilst deploying pesticides only as a last resort, thus reducing issues with pesticide contamination and resistance (Anonymous 1969). With IPM, an action threshold is typically set and the pest species is closely monitored so that any kind of treatment is only deployed as necessary, and when any preventative measures have failed. If monitoring indicates that the economic threshold of the pest population is exceeded, effective interventions (e.g. extra interim releases of biological controls or application of pesticides) are initiated. Consequently, IPM requires efficient pest monitoring for optimal deployment of the interventions used. In livestock production systems, application of all but basic IPM programmes is still relatively rare. This is despite the fact that livestock systems could benefit from application of this approach (e.g. by reduced economic losses), poultry egg production included (Sparagano et al. 2014).

The poultry red mite (Dermanyssus gallinae De Geer, 1778) is a significant pest of egg laying hens, present in a large percentage of layer houses worldwide (Sparagano et al. 2014). Dermanyssus gallinae is generally referred to as an ectoparasitic mite, though based on its feeding behaviour it is perhaps better described as a micro predator (Lafferty and Kuris 2002). Dermanyssus gallinae feeds on the blood of numerous avian hosts, including laying hens, though they may also pose a risk to poultry workers (George et al. 2013). Dermanyssus gallinae requires a blood meal for development from protonymph to deutonymph, and from here to the adult stage (Axtell and Arends 1990), with feeding also being required for adult female reproduction. Mite feeding upon hens causes agitation of the birds, and where pest populations proliferate they may even result in anaemia (Sikes and Chamberlain 1954; Kilpinen et al. 2005). High economic losses are associated with D. gallinae infestations, with costs of pest control and production losses estimated at more than 130 million euro per year for the EU egg industry (Emous et al. 2005). Even at low population levels, D. gallinae pose a risk of disease transmission within the flock, being implicated as vector for numerous poultry pathogens (Sparagano et al. 2014).

Control of D. gallinae is difficult due to the fact that this species spends the majority of its time secluded in hard-to-target refugia within the sub-structure of the poultry unit. Mites aggregate off-host in cracks and crevices where they seek shelter to digest their blood meal, where protonymphs and deutonymphs molt, and where adults mate and lay eggs. They only emerge, preferably during darkness, to feed and spend just 30-60 minutes on the hen during an average visit (Maurer et al. 1988). This hampers successful treatment with standard acaricides that need to contact the target to have an effect. Currently authorized acaricidal products display shorter residual activities to satisfy lowered Maximum Residue Limits (MRLs) than conventional acaricides, many of which have been withdrawn from the market. 
However, shorter residual efficacies are ill-suited to target D. gallinae which may not encounter treated surfaces for several days (or more) after application. Successful treatment is also hampered by the ability of $D$. gallinae to develop resistance to multiple acaricides (Chauve 1998; Nordenfors et al. 2001; Marangi et al. 2009).

In order to achieve better control of D. gallinae in laying systems, several authors have proposed a more rigorous implementation of IPM, which is currently largely limited to some combination of biosecurity, acaricide use and clean down between flocks (Arends and Robertson 1986; Harrington et al. 2011; Sparagano et al. 2014). Monitoring is a key factor in facilitating the development of IPM regimes for D. gallinae (Sparagano et al. 2014) and a number of relatively basic monitoring methods are available (Table 5.1).

Table 5.1 Description of the most frequently used methods for monitoring D. gallinae

\begin{tabular}{|c|c|c|}
\hline Monitoring method & Limitations & Reference \\
\hline 1. ADAS@ Mite Monitor & $\begin{array}{l}\text { Labour intensive; not sensitive to } \\
\text { very small populations }\end{array}$ & Anonymous 2014 \\
\hline 2. Perch trap & $\begin{array}{l}\text { Labour intensive; not easily } \\
\text { applicable in most poultry facilities }\end{array}$ & Kirkwood 1963 \\
\hline $\begin{array}{l}\text { 3. Tube containing a fabric } \\
\text { or cloth }\end{array}$ & $\begin{array}{l}\text { Labour intensive; not sensitive to } \\
\text { very small populations }\end{array}$ & Maurer et al. 1993 \\
\hline $\begin{array}{l}\text { 4. Corrugated } \\
\text { cardboard/plastic trap }\end{array}$ & Labour intensive & $\begin{array}{l}\text { Nordenfors et al. } \\
1999\end{array}$ \\
\hline $\begin{array}{l}\text { 5. A tube trap with a } \\
\text { wooden stick or } \\
\text { corrugated cardboard }\end{array}$ & $\begin{array}{l}\text { Labour intensive; indicates trends } \\
\text { only (infestation rates from } 0-4 \text { ); not } \\
\text { sensitive to very small populations }\end{array}$ & $\begin{array}{l}\text { Emous and Ten } \\
\text { Napel } 2007\end{array}$ \\
\hline $\begin{array}{l}\text { 6. Detecting D. gallinae in } \\
\text { dust, feathers and } \\
\text { impurities }\end{array}$ & $\begin{array}{l}\text { Labour intensive; not sensitive to } \\
\text { very small populations; sub optimal } \\
\text { sampling site specification }\end{array}$ & $\begin{array}{l}\text { Pavlicevic et al. } \\
2007\end{array}$ \\
\hline $\begin{array}{l}\text { 7. Examining dried } \\
\text { droppings for presence of } \\
\text { D. gallinae }\end{array}$ & $\begin{array}{l}\text { Labour intensive; not sensitive to } \\
\text { very small populations; sub optimal } \\
\text { sampling site specification }\end{array}$ & Zenner et al. 2009 \\
\hline $\begin{array}{l}\text { 8. Mite Monitoring Score } \\
\text { (MMS) method }\end{array}$ & $\begin{array}{l}\text { Labour intensive; indicates trends } \\
\text { only (infestation rates } 0-4 \text { ); not } \\
\text { sensitive to very small populations }\end{array}$ & Cox et al. 2009 \\
\hline
\end{tabular}

Generally, the major disadvantages of existing mite monitoring methods is that they are labour intensive and only give a rough indication of population growth or decline in mite populations (Mul et al. 2009). As a result existing mite monitoring methods are scarcely used by egg producers. Where monitoring is undertaken, this is typically achieved using 'traditional' methods (1-5 in the Table 5.1), involving the use of passive and static refuge traps (e.g. corrugated card board). Unless carefully positioned at multiple sites, with consideration given to mite aggregation and feeding behaviour, such monitoring methods can easily underestimate D. gallinae infestation levels. 
As a solution to the monitoring problems reported above we have previously designed, developed and tested an automated mite counter (Mul and Ploegaert 2014). This counter was deliberately designed to monitor a $D$. gallinae population in a layer house in an economically feasible manner using low cost but durable materials and solutions. The aim of the current study was to assess the validity of this counter to monitor a range of $D$. gallinae population sizes from small (when only a few specimens are present and infestations are visually undetectable) to large (when clusters of D. gallinae are visible). Here we present the outcome of this validation study under semicontrolled conditions, and evaluate the contribution of this automated mite counter to a more effective IPM regime in laying hen facilities.

\section{Materials and Methods}

Experimental laying hen cages, containing live birds and one automated mite counter, were repeatedly experimentally infested with a known population of D. gallinae. During defined time periods, initial mite populations were supplemented to established populations to achieve five levels of infestation (after Cox et al. 2009 see Table 5.2). The automated mite counter was validated by comparing the data returned by the automated counter (\# of mites counted) to the absolute counts of D. gallinae present in the cages (\# of mites present).

Table 5.2 Classification of D. gallinae population levels (see Cox et al. 2009)

\begin{tabular}{ll}
\hline Level & Characteristics \\
\hline $\mathbf{0}$ & No mites visible \\
I & Mites visible in cracks and crevices \\
II & Mites visual at unprotected places \\
III & Clusters of mites (groups of mites larger than $1 \mathrm{~cm}^{2}$ ) visible in cracks and crevices \\
IV & Clusters of mites (groups of mites larger than $1 \mathrm{~cm}^{2}$ ) visible at unprotected places in \\
& and on the experimental cages \\
\hline
\end{tabular}

\section{Mites in the experiment}

During the experiment, mites originating from one of the two different Dutch layer farms used as sources of $D$. gallinae were released in the experimental cages in predefined numbers. These mites were collected in the morning and only viable nymphs and adults, that were able to walk on a petri dish, were used for the experiment and placed in a plastic vial with screw cap (102 mm height, $52 \mathrm{~mm}$ diameter, VWR International BV). At the end of the afternoon, in the dark, the vials were placed under the laying nests of the hens in the experimental cages and the screw caps were removed.

To ensure that comparable populations of D. gallinae were used throughout the study, the longevity of the mites from both farms in the laboratory was compared by determining the number of surviving mites after 14 days $(n=6)$. A Student's t-test confirmed that the longevity of mites from the two farms was similar $(P=0.35)$. 


\section{Layout of experimental laying hen cages}

Twelve experimental laying hen cages (Figure 5.1) were used during the experiment. These cages were confirmed as being free of D. gallinae prior to the start of the experiment by 1) thorough cleaning, 2) visual inspection and 3) confirmation by zero counts of the automated counter during two days prior to the start of the trial. Cages $(1.2 \times 0.6 \times 0.6 \mathrm{~m})$ were open at the top, but to prevent the hens from escaping a metal grid with an access hole was used as a cover. The front of the cages was made of a transparent Perspex plate, and the structure of each cage was supported by two wooden beams. In each cage, approximately $50 \%$ of the floor surface was filled with pine wood shavings. A manure tray, covered with a grid, filled the remaining floor surface. Above this manure tray, a metal perch was fixed through the front and rear cage wall. Under the perch, the automated mite counter was placed. Above the litter area, a feed box and a laying nest $(0.3 \times 0.4 \times 0.5 \mathrm{~m}$ with a hole of 0.2 $\mathrm{x} 0.3 \mathrm{~m}$ ) were placed. A drinking nipple with leakage cup was also placed above the manure tray, close to the right-hand wall. The nipple was connected to a closed water tank placed on a transparent plate on top of the metal grid. The whole cage was placed on bricks in a tray filled with water to ensure that mites could not move between different cages.

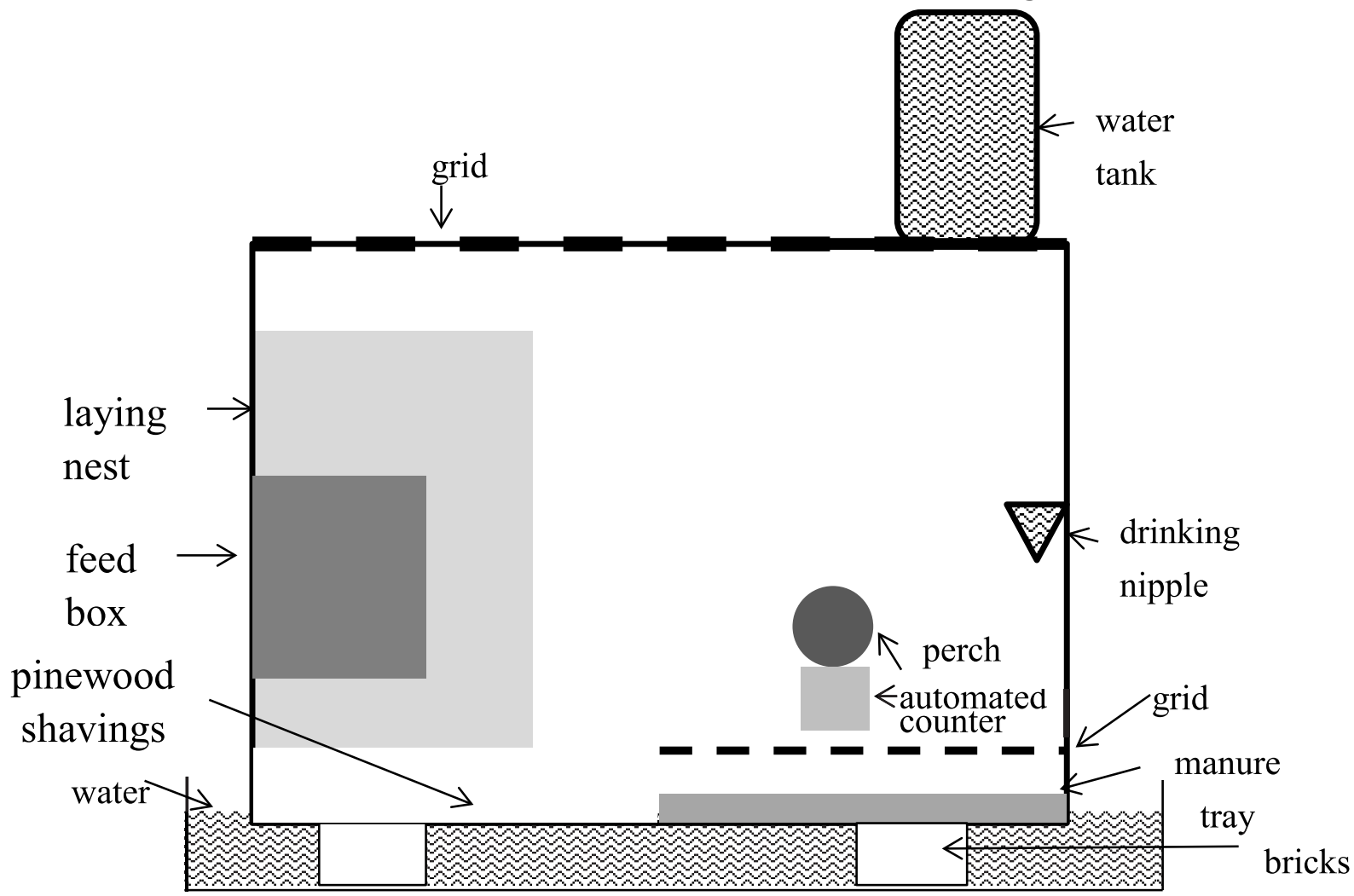

Figure 5.1 Schematic cross-section of the experimental laying hen cage

Each cage housed two 'Specific Pathogen Free', mite-free, beak-trimmed laying hens being 29 weeks of age at the start of the experiment (white leghorn, GD Animal Health, The Netherlands). Hens had never been exposed to acaricides nor treated against worms. Hens were assigned to cages based on their weight and allowed to settle for two days before mites were added. Feed was provided ad libitum with a commercial layer feed crumble, stored at 
$-20^{\circ} \mathrm{C}$ prior to use. Water was constantly available and a 16:8 light:dark light regime was implemented, switching the lights off at 06:00 PM. Hen health and welfare were checked daily by employees of the experimental farm of the Central Veterinary Institute of Wageningen UR, according to all legal requirements set by Dutch law (Approved Experimental Number 2013145).

\section{Automated mite counter}

Within each cage, an automated mite counter (Figure 5.2) was fixed to the perch using cable ties and tape. The entrance of the counter $(0)$ was positioned in the lid of the case next to the bottom of the round metal perch (Figure 5.1). Mites entering the counter through a hole (diameter of 1- $1.5 \mathrm{~mm}$ ) in the lid (1) were detected by a sensor device (3) when passing the sensor. When a mite was detected, the sensor device passed a signal to the processor (4), which subsequently switched on the insect removal device (7) to remove the mites in front of the sensor, by air suction, into a filter (6). This filter contained the mites until it was emptied outside the cage, at weekly intervals, to prevent blockage of the air flow. We assumed it very unlikely that the mites were able to escape from the filter as this would have required overcoming a series of physical obstacles. This was confirmed by the fact that no mites were counted during light periods. We assumed that, since it was dark on the inside of the counter, mites would have been willing to move within the counter at any time of the day.

Prior to the experiment, the sensitivity of the automated counter was assessed in vitro, revealing that it was able to detect $100 \%$ of adult D. gallinae and $97 \%$ of nymphs and larvae ( $n=35$ per life stage). All automated counters used in the experiment were also checked in vitro using both live mites and dummies (i.e. thin electrical wire of $0.09 \mathrm{~mm}$ diameter) and adjusted until no failure was detected and the sensor was registering the wire and live mites (all stages) with the pump activated and stopped properly.

During the experiment, every five minutes the counted number of mites in each cage were registered and saved by an external data logger that was connected with the automated counter by a cable (8), starting from two days before the first mite release (to ensure zero counts) until the end of the study. For analysis, the number of mites counted by the automated counter ('\# of mites counted'), was the summed total of all counted mites starting from $10.00 \mathrm{AM}$ (after caretaking activities) on the day prior to mite collection until $08.00 \mathrm{AM}$ on the day of mite collection. 


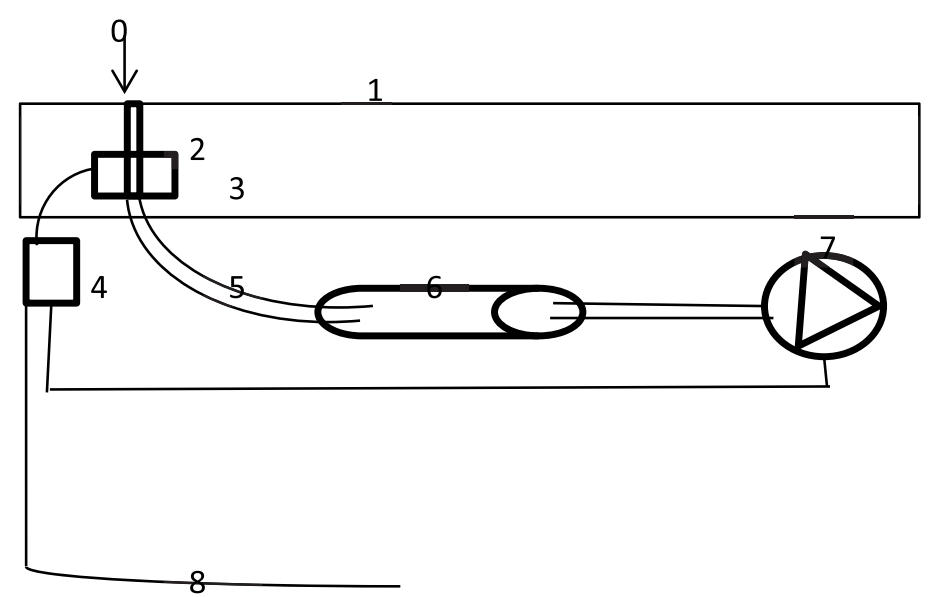

Figure 5.2 Schematic cross-sectional view of the automated mite counter, including an opening (diameter approximately $1-1.5 \mathrm{~mm}$ ) to the tube (0) in a body (1), comprising a casing and a lid closing the casing, a receiving section (2), a sensor device for counting the passing mites (3), an electronic processor (4), a tube (5), filter (6), a removal device using air suction (7) and a power and data cable (8)

\section{Collection and counting of mites from cages}

In order to obtain absolute counts of D. gallinae present in the cages (\# of mites present), mites in and on the following materials were collected separately: a) wet manure (from the manure tray); b) dry part of the manure and litter (in the manure tray, two types of manure were found; the dry part where the manure is mixed with litter, and wet manure without litter); c) dried manure attached to the grid above the manure tray; d) dust in the laying nest; e) surfaces of the cage (in- and outside); f) surfaces of grid and transparent plate on top of the cage; g) perch; h) outside of the laying nest and feed box; i) water tank; and j) wooden supporting beams. For a-d, manure and dust were collected into large transparent plastic bags and the number of mites present was determined by a two-step process. Initially, mites that aggregated at the top of the whole sample bag after 24 hours (dust) or 48 hours (manure) were counted and removed. Following this, four sub-samples of 1-2 g were removed after mixing and checked for mites under a microscope (variable magnification of $0-23 x)$. The total number of mites present in whole samples was calculated by multiplying up the number of mites in the sub samples (i.e. by multiplying by $100 /$ weight percentage of the sub sample), and adding the number of aggregated mites at the top of the whole sample bag. For e-j, samples were collected by brushing the mites from the surfaces with a broad brush (Elma 59-1 type) into a large glass vial (0.2 m diameter x $0.09 \mathrm{~m}$ height) containing $70 \%$ alcohol, from which mites were then counted. Low numbers of mites in the alcohol were counted in full under the microscope. Higher numbers of mites in the alcohol were sub-sampled. After stirring for a homogeneous distribution of mites in the alcohol layer, $10 \%$ of the sample was placed in petri dishes $(0.14 \mathrm{~m}$ diameter). The mites present in two sections (equivalent to $1 / 8$ of the solution) were then counted using a binocular microscope. The number of mites present per cage ('\# of mites present') at the day of collecting the mites 
was calculated as the sum from all counted and calculated mites present in all samples (a-j) per cage and the number of mites found on the hens per cage at the day of collecting the mites.

The mites counted by the automated mite counter were collected in the filter and remained there until the filter was refreshed. Mites in filters were not visually counted, nor compared with the number of mites counted during the monitoring period, because the mites 1) were able to produce eggs, larvae and protonymphs, and 2) were often crushed at high population levels, thus making it impossible to distinguish individual mites.

\section{Set up of the experiment}

The experiment was conducted in three phases; A, B and C. To achieve D. gallinae population sizes representing the five levels of Cox et al. (2009), low and high mite infestations treatments were released in the cages with a ratio of 1:10; low infestation treatment: high infestation treatment. Half of the mites released in the cages were adults (mixed gender) and the remaining half were nymphs. Activities undertaken during the experiment are summarized in Table 5.3.

Phase A, Day 0 - 33

In Phase A twelve cages were randomly allocated to treatments: six cages to a lowinfestation treatment group (50 mites; 25 nymphs and 25 adults) and six cages to a highinfestation treatment group (500 mites; 250 nymphs and 250 adults).

The relative humidity in the experimental unit was set at $70 \pm 5 \%$ and the temperature was set at $27 \pm 5{ }^{\circ} \mathrm{C}$. The manure tray was emptied on day 14 (post mite release), leaving the dry manure near the litter area in situ. The filters of the automated counters were refreshed on days 7 and 14.

Twenty-eight days after releasing the mites, two cages from the low infestation treatment group and two cages from the high infestation treatment group were removed from the study and the mites in the cages were collected and counted. Mites present on the hens from these cages were also counted. Thirty-three days after mite release counts were made from a further two cages from the high infestation treatment group. Mites present on the hens from these two cages were again counted at this time. These last two cages were not removed from the study, but used again in Phases B and C.

\section{Phase B, Day 33 - 54}

At the start of Phase B, hens were removed from the eight remaining cages and these cages were subsequently cleaned thoroughly with water and chlorine before drying with paper. The automated mite counters and the hens were then returned to these cages.

The relative humidity of the experimental unit was lowered to $60 \pm 5 \%$ and the temperature was set at $25 \pm 5^{\circ} \mathrm{C}$ to limit fungal growth (as observed in Phase A). On days 34, 38,44 and 50 , mites were released in four cages of the low infestation treatment group (250 
mites per release and per cage; 125 adults: 125 nymphs) and in four cages of the high infestation treatment group (2500 mites per release and per cage; 1250 adults: 1250 nymphs). On the morning of day 47 , the manure tray was emptied, leaving the dry manure near the litter area in situ. The filters of the automated mite counters were refreshed on days 40 and 47. On day 54 all of the mites from six of the eight cages were collected; two cages from the low-infestation treatment group and four cages from the high-infestation treatment group. Mites could not be collected from the remaining two cages due to limited availability of labor.

\section{Phase C, Day 54 - 75}

At the start of Phase C, all eight cages used in Phase B were cleaned and restocked as previously described. On days 55, 58, 68 and 72, mites were released in four cages of the low infestation treatment group (500 mites per release and per cage; 250 adults: 250 nymphs) and in four cages of the high infestation treatment group (5000 mites per release and per cage; 2500 adults: 2500 nymphs). On the morning of day 68, the manure tray was emptied, leaving the dry manure near the litter area in situ. The filters of the automated mite counters were refreshed on days 61 and 68. On day 75 all of the mites from six of the eight cages were collected; two cages from the low-infestation treatment group and four cages from the highinfestation treatment group. Mites could not be collected from the remaining two cages due to limited availability of labor.

Table 5.3 Activities per day during the validation experiment of 75 days split up in three phases A, B and C

\begin{tabular}{|c|c|c|}
\hline Phase & Day & Activity \\
\hline \multirow[t]{9}{*}{$\mathrm{A}$} & 0 & Release of mites. \\
\hline & & - Low infestation (LI) cages: 50; 25 nymphs and 25 adults \\
\hline & & - High infestation (HI) cages: 500; 250 nymphs and 250 adults \\
\hline & 7 & Filters refreshed \\
\hline & 14 & Manure tray emptied \\
\hline & & Filters refreshed \\
\hline & 28 & $\begin{array}{l}\text { Collecting and counting of mites in two high infestation cages and two low } \\
\text { infestation cages, mites on the hens counted and hens were culled (cages } \\
\text { taken out of experiment) }\end{array}$ \\
\hline & 33 & $\begin{array}{l}\text { Collecting and counting of mites in two high infestation cages, mites on the } \\
\text { hens were counted, the hens were not culled. }\end{array}$ \\
\hline & & All eight remaining cages were emptied, cleaned and dried \\
\hline \multirow[t]{5}{*}{ B } & 33 & All hens and automated counters returned to their own cages \\
\hline & 34 & Release of mites \\
\hline & & - LI cages: 250; 125 nymphs and 125 adults \\
\hline & & - HI cages: 2500; 1250 nymphs and 1250 adults \\
\hline & 38 & Release of mites \\
\hline
\end{tabular}




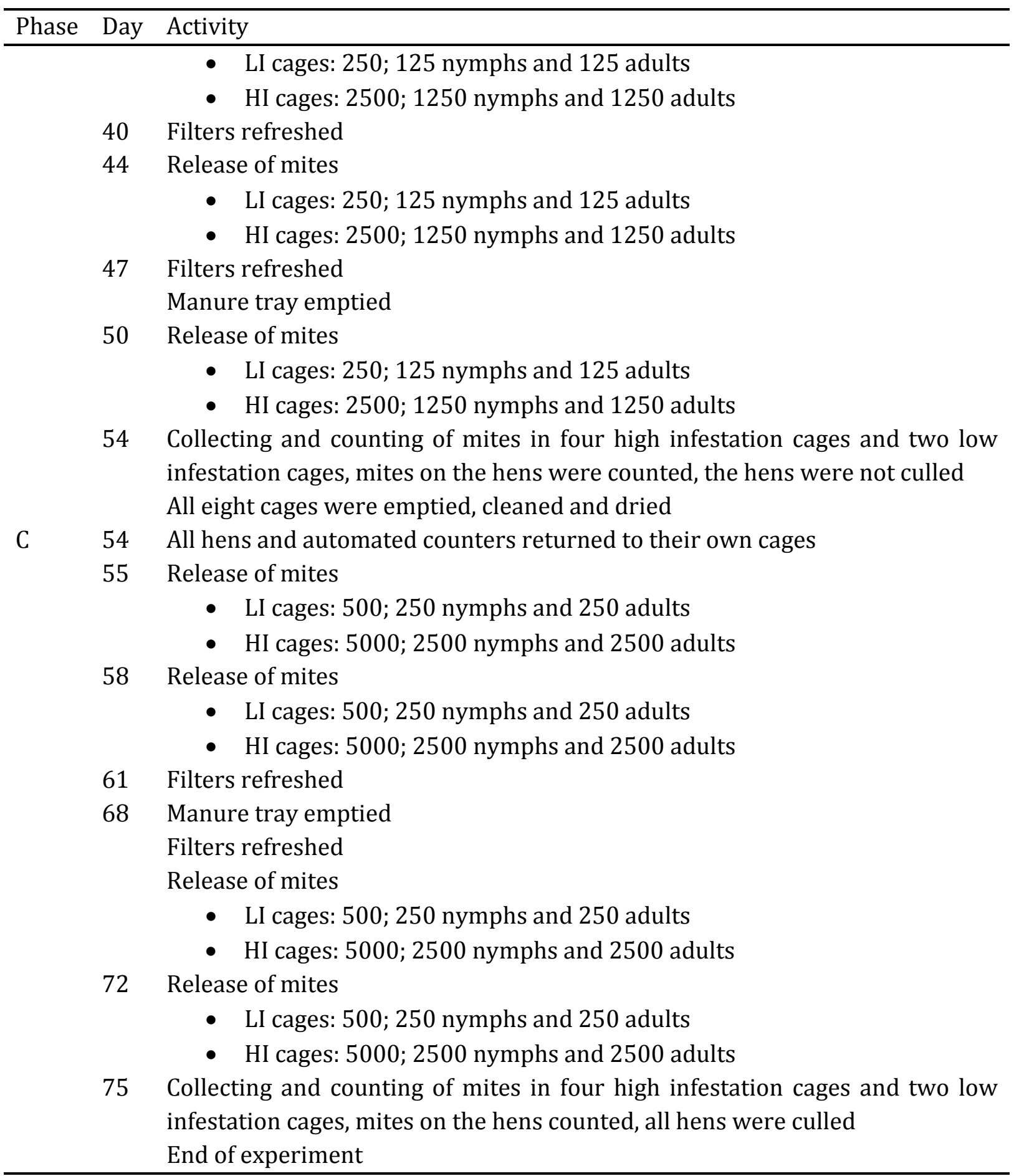

\section{Statistical analysis}

An analysis was performed to assess the degree to which '\# of mites counted' corresponded with '\# of mites present'. Linear regression analysis was performed within a restricted maximum likelihood (REML) variance component analysis using the GenStat software (16 ${ }^{\text {th }}$ edition) (Anonymous 2006). Parameters were estimated by REML (Searle et al. 1992). Both variables ('\# of mites counted' as the dependent variable and '\# of mites present' as the regression variable) were ln transformed. Differences between "cages" were estimated by a random effect $\varepsilon_{\mathrm{i}}$. 
The line of regression wherein the relationship was modelled between the '\# of mites counted' and the '\# of mites present' was as:

$\operatorname{Ln}\left(Y_{\mathrm{ij}}(\right.$ mites counted $\left.)\right)=\beta_{0}+\beta_{1} * \ln \left(\mathrm{Y}_{\mathrm{ij}}(\right.$ mites present $\left.)\right)+\underline{\varepsilon}_{\mathrm{i}}+\underline{\varepsilon}_{\mathrm{ij}}$

with :

$Y_{\text {mites counted }}=$ Number of counted mites by the automated counter during the last 22 hours

$\beta_{0}=$ intercept

$\beta_{1}=$ regression coefficient

$Y_{\text {mites present }}=$ reference $=$ number of mites in and on cage i (1-9) of phase $j(A, B, C)$

$\underline{\varepsilon}_{\mathrm{i}}=$ random effect of cage i with $\mathrm{N}\left(0, \sigma_{\mathrm{i}}^{2}\right)$

$\underline{\varepsilon}_{i j}=$ residual effect of cage i, phase $j$ with $N\left(0, \sigma_{i j}{ }^{2}\right)$

As '\# of mites counted' was analysed on ln scale, the relative standard deviation $\left(\mathrm{S}_{\mathrm{r}}\right)$ was calculated by taking the square root of the residual variance $\left(=s_{i j}^{2}\right)$. This $\mathrm{S}_{\mathrm{r}}$ was multiplied by a Student's t-value to yield a two-sided confidence interval for individual measurements. $95 \%-C I_{r}=S_{r} * t_{(0.975 ; n-2)}$

\section{Results}

The cages removed in Phase A showed very low numbers of mites present, possibly due to heavy infestation with fungi (Aspergillus spp., Penecilium spp., Mucor spp.). Therefore all remaining cages were thoroughly cleaned before commencing Phase B and C. Nevertheless, three data points of '\# of mites counted' and '\#of mites present' obtained from Phase A were included in the dataset.

Seventeen data points of '\# of mites counted' and '\# of mites present' were obtained for analysis; across all phases of the experiment, single sets of counts ('\# of mites counted' and '\# of mites present') were taken from three cages, two sets of counts were taken from four cages, and three sets of counts were taken from two cages. These data points were obtained from nine out of twelve available cages. One cage from Phase A was excluded since a zero mite count was returned by the automated counter and zero mites were present in that cage. From Phase B and Phase C, two cages with low mite infestations were excluded since the '\# of mites present' were never determined due to the limited availability of labor.

The intercept $\left(\beta_{0}\right)$ and the regression coefficient $\left(\beta_{1}\right)$ were determined as $-1.25(95 \%$ confidence interval: $-2.64,0.14)$ and 0.67 (95\% confidence interval: $0.50,0.84)$, respectively.

The 17 data points and the modelled regression line obtained from the analysis are shown in Figure 5.3. The Goodness of fit (R-square) of this line was 90.3\%, supporting that about 90 percent of the variation in "\# of mites counted" was explained by the level of the reference value ("\# of mites present"). The value for $95 \%-C I_{r}$ was 1.17 , meaning that $95 \%$ of the individual measurements were in the relative range of $(-117 \% ;+117 \%)$. 
The slope of the regression $\left(\beta_{1}\right)$ was smaller than 1 , meaning that there is a relationship between the number of mites present and the number of mites counted. When there is a relative increase in number of mites present, however, the increase in the number of mites counted was not increased by the same percentage, but rather by a factor 1.6 (i.e. with higher mite populations present in the cages a lower percentage of the population was detected). Ergo, it appears that at higher mite densities the counter is increasingly conservative. Nevertheless, relative increases in the number of mites present did correspond to an increase in the number of counted mites, thus demonstrating that the automated mite counter is able to track and detect a mite population increase.

It should be noted that there was a significant effect of cage $(P<0.05)$. The counters "1"and " 8 " deviated more from the predicted line than the other counters. The counter in cage " 1 " counted significantly more mites $(P<0.001)$ compared to the average of the other counters. The counter in cage 8 counted significantly fewer mites $(P<0.01)$ compared to the average of the other counters. These systematic effects were included in the random term $\underline{\varepsilon_{i}}$.

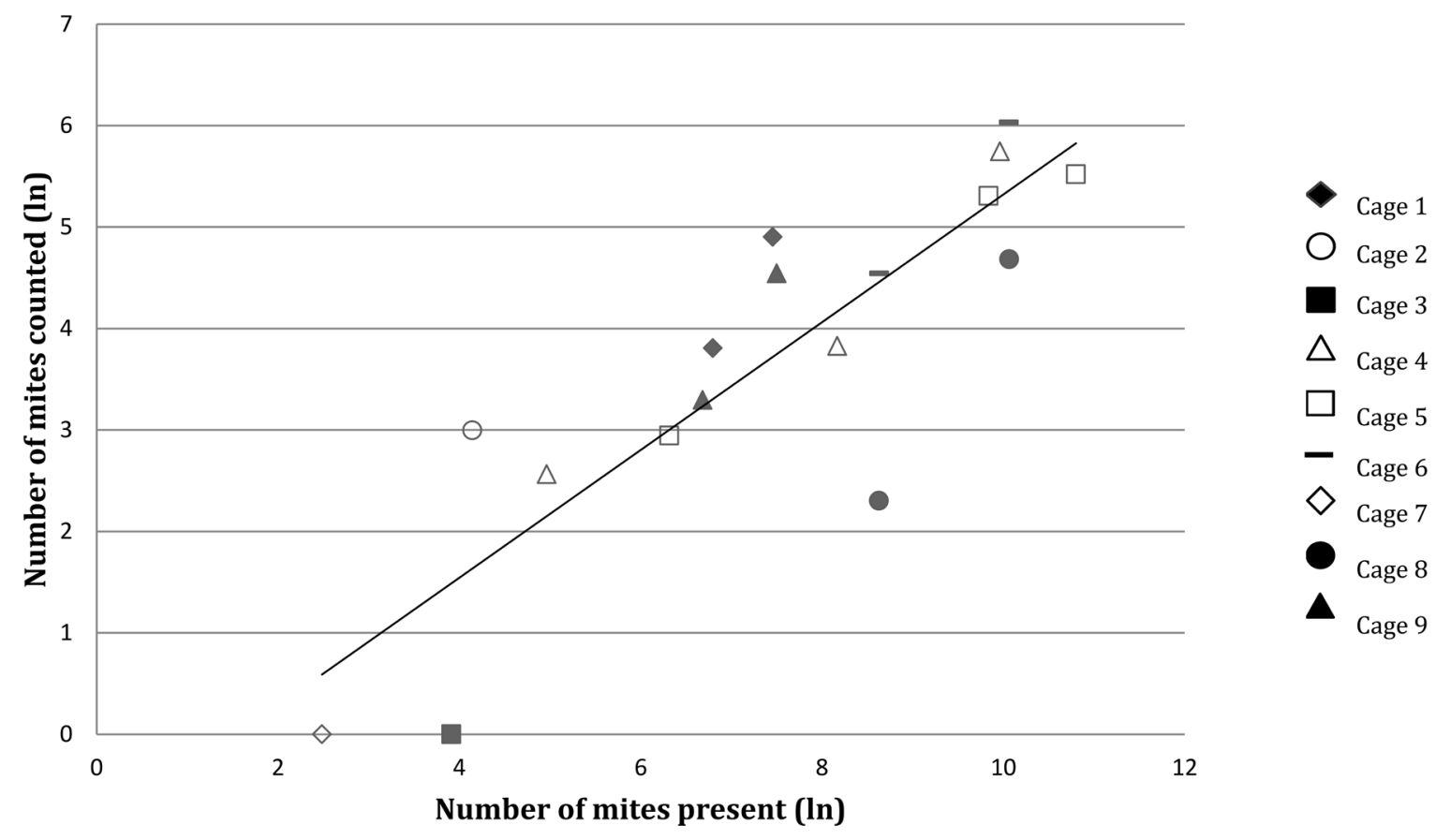

Figure 5.3 Measured data points for cage 1 to 9 and modelled relationship (line) for the number of mites present in the cages versus the number of mites counted (both ln transformed)

\section{Discussion}

The aim of this study was to validate a recently-developed automated mite counter for $D$. gallinae to determine its ability to monitor a range of D. gallinae population sizes. A range of experimental mite populations, from small to large, were achieved in populated cages to meet this aim, covering all five levels of D. gallinae infestation according to Cox et al. (2009); 
0 = no mites visible; $\mathrm{I}=$ Mites visible in cracks and crevices; $\mathrm{II}$ = Mites visual at unprotected places; III = Clusters of mites (groups of mites larger than $1 \mathrm{~cm}^{2}$ ) visible in cracks and crevices; IV = Clusters of mites (groups of mites larger than $1 \mathrm{~cm}^{2}$ visible at unprotected places in and on the experimental cages).

The results demonstrated that the automated mite counter was able to track and detect $D$. gallinae population growth. When mite populations increased, so did the number of mites counted. Moreover, when a decline of the mite population was visually observed during the study, the number of mites counted by the automated mite counter also decreased (personal observation MF Mul).

A strong correlation was observed on the ln-ln scale between the '\# of mites counted' and the '\#of mites present', with an estimated intercept $\left(\beta_{0}\right)$ of -1.25 . Although the intercept in the model was not strongly significant $(P<0.10)$, it was included in the model to avoid the regression line on a ln-ln scale passing through the zero points of the axes. On the original scale such a regression line would intersect at $(1,1)$, which we assumed not to be realistic.

The regression coefficient $\left(\beta_{1}\right)$ of the regression line was 0.67 in the current study, meaning that an increasing number of mites present in the cages resulted in a slightly smaller increase in the number of counted mites (as shown in Figure 5.4 on real scale). One possible explanation for this could be that the presence of abundant fungi in Phase A may have impaired the mites, or even killed them, as suggested by Tavassoli et al. (2011) and supported by personal observation in the current study (MF Mul). Post feeding, relatively low populations of impaired mites in Phase A may have been more responsive to the shelter provided by automated counters, with these mites being less able to travel greater distances to locate other refugia than 'healthier' mites present in other phases.

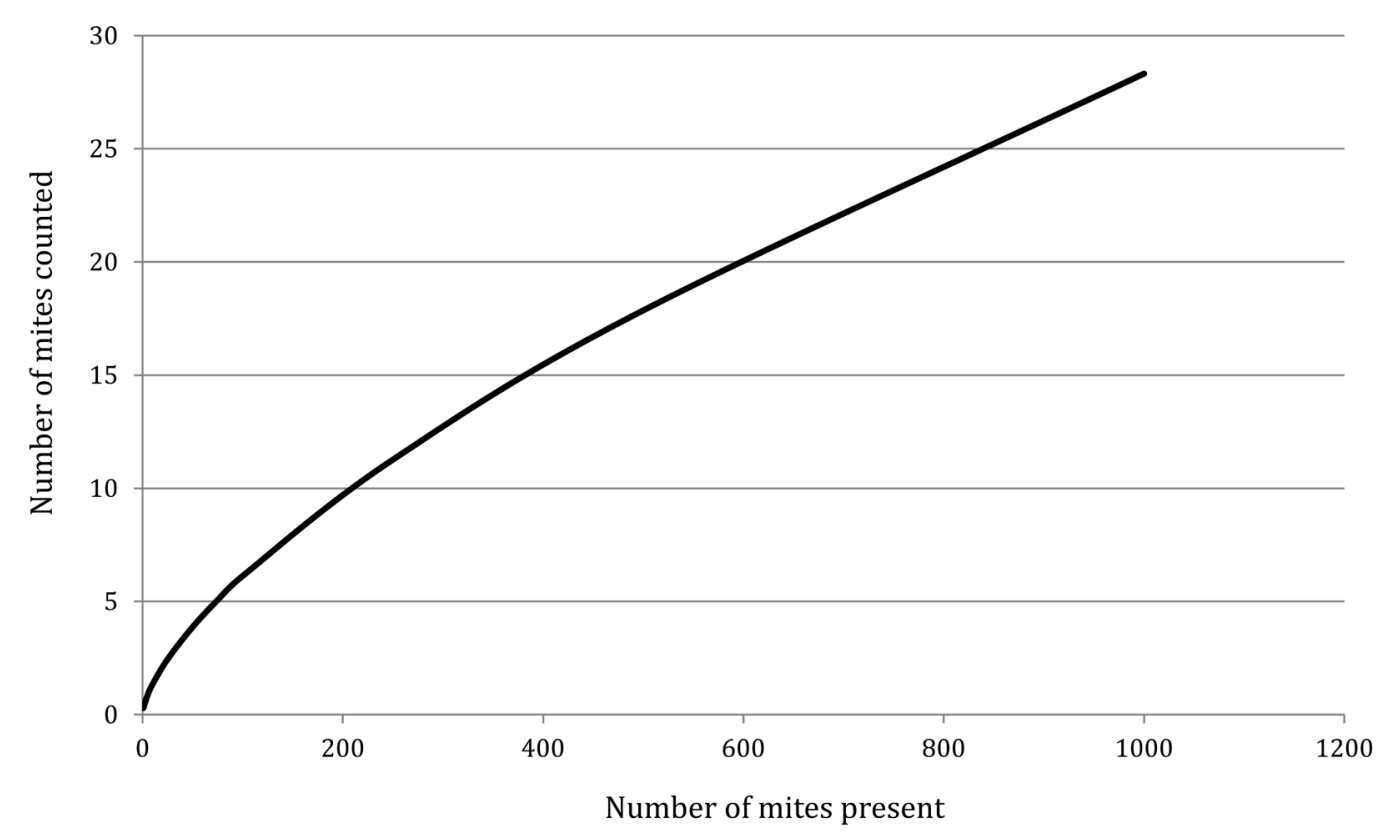

Figure 5.4 Line showing the regression between the number of mites present in the cages and the number of mites counted (real scale) 
Another possible explanation for the fact that an increasing number of mites present in the cages resulted in a relatively smaller increase in the number of counted mites could be the presence of aggregation cues from conspecifics. Pheromones are known to be attractive to D. gallinae (Koenraadt and Dicke 2010) and at lower population levels directional responses to these may have been weaker, with mites more likely to 'wander' and encounter the monitor as a result. The thigmokinetic response of D. gallinae to conspecifics (Entrekin and Oliver 1982) might have similarly contributed to lower-than-expected counts at higher mite population levels, with mites more likely to be arrested by contact with conspecifics (and thus less likely to 'wander' and encounter monitors) at higher D. gallinae population levels. In support, at high infestation levels in the current study, we noticed aggregations of mites in and on the experimental cages that were not seen at lower levels.

Though counters were designed to be optimally attractive to mites, providing a heat source (created by the internal processor) which should have attracted host-seeking mites (Kilpinen 2001), it is possible that pheromone cues provided a stronger stimulus (Koenraadt and Dicke 2010). This would be especially true for D. gallinae that had already fed, with Entrekin and Oliver (1982) observing that fed female mites cluster more rapidly than unfed females. As live hens may have provided a stronger heat stimulus (coupled with additional chemical stimuli) than counters, it is further possible that counters were more likely to record visits from fed $v s$ unfed mites in the current study, further exacerbating any relatively reduced counts at higher population levels. With future development of our mite monitoring tool it may be possible to overcome this constraint, for example by including a chemical attractant within the counter. However, although research has shown that chicken odours are attractive to D. gallinae, and that these mites produce an aggregation pheromone (Koenraadt and Dicke 2010), no synthetic attractants are presently available for this species. Moreover, including attractants would increase the systems maintenance time as these would need to be refreshed. A simpler solution in the short term, at least until attractants are developed for D. gallinae, is to accept that the monitor counts relatively fewer mites at higher infestation levels and correct for this accordingly.

A strong requirement for a good monitoring tool to improve IPM for D. gallinae is the detection of low numbers of mites. Monitoring mite population growth at low infestation levels is necessary to inform timely management interventions and reduce the detrimental effects of D. gallinae infestations (Mul and Koenraadt 2009). The reclusive life-style of $D$. gallinae, however, makes it more difficult to identify low mite population levels. As shown in Figure 5.3, the automated counter is able to provide a good impression of the number of mites present, even when the infestation is low. Although only three out of 17 data points used in the analysis had relatively low numbers of mites present in the cages (mites present $\leq 4$; cage 2, 3 and 7 in Figure 5.3), daily number of mites counted per cage support that the system is able to detect day-to-day variation and is sensitive to daily changes in the mite population from low to high levels (see Appendix 5 Figure A5.1 showing the daily counts of the automated mite counter during phase $\mathrm{C}$ as an example). 
The value for $95 \%-C I_{r}$ in the current work was 1.17 , demonstrating a substantial error in the predicted number of mites counted at certain levels of mites present. Analysis revealed a significant cage effect $(P<0.05)$ which could explain this large confidence interval, but as counters and cages were coupled it is not possible to separate the two, and equally possible that variability in counters (or any combination of cages and counters) led to a relatively high $95 \%-C I_{r}$. In future studies we aim to determine the measurement error of the counter, using multiple mite counters around one monitoring site, thereby allowing us to be able to reduce the prediction error. The need for multiple mite counters to monitor a D. gallinae infestation in poultry facilities is supported by Nordenfors and Höglund (2000), who recommend the use of multiple mite counters to compensate for the spatial differences in $D$. gallinae distribution.

In future commercial practice we envisage that the automated counter (and the statistical model) validated here will be effectively reversed for use: i.e. the counted number of mites will provide a prediction of the population at a certain point in time. The farmer will be informed on mite population development and effectiveness of treatment interventions. To this end, detecting relative changes of the population size over time will be more important than assessing the absolute number of mites at a given time-point to warn the egg producers about the growth or decline of the D. gallinae population. Though the current work focused on validating the counter based on single time-point counts, daily number of mites counted per cage (see Appendix 5 Figure A5.1) support that temporal changes can be detected by this system.

An IPM approach results in a more effective and economic control of pest species (Metcalf and Luckmann 1982). Monitoring the development of a pest population is a key factor of IPM as it indicates the moment that the action threshold of the pest population is exceeded. Monitoring also clearly shows the effect of a treatment or management measures, which are applied after any preventive measures have failed (Zehnder 2014). However, it is of utmost importance that the monitored pest is the same pest against which preventive measures are taken. The validated automated mite counter was developed for counting D. gallinae and was constructed based upon knowledge of the behavior of D. gallinae. When we were able to check all species in the filter during the experiment and the development of the automated counter in the layer house, we solely found D. gallinae in the filters, supporting that the automated mite counter only counts D. gallinae (pers. observation MF Mul).

After identifying the pest species, it is necessary to monitor the pest population, as with IPM no treatments are applied unless the pest is present and poses a threat (Zehnder 2014). Even though the requirements for a monitoring tool applicable for IPM are different per pest species, there are some general requirements. A monitoring tool applicable for IPM should be 1) able to detect small population sizes, 2) able to monitor a relative change of the population size in time, 3 ) able to monitor at relevant frequency intervals (for example with weekly intervals as the production data also is available on a weekly basis), 4) able to monitor the population throughout a facility as the spatial distribution of mites may change 
over time and, 5) carried out with a minimum of labor (Dively 2014). The tested automated mite counter meets all of these 5 requirements, especially when multiple mite counters are evenly spread throughout the poultry facility.

In conclusion, the automated mite counter developed and tested here is a potentially useful tool for the application of IPM against D. gallinae in layer production systems. It automatically monitors the mite population, even when the population is small, and meets all other requirements for an IPM monitoring tool as specified by Dively (2014). Using multiple mite counters in a closed environment (e.g. laying hen facility), monitoring the pest population size and spatial-temporal growth will be relatively straight-forward and less labour intensive when compared to other available D. gallinae monitoring methods (see Table 5.1). Coupled with the development of an operational population model for D. gallinae and determination of an economic threshold, this system could promote comprehensive IPM regimes for D. gallinae (Sparagano et al. 2014) resulting in improved detection and control of this pest. The next step for the system is to pursue commercial development, and this is currently underway.

\section{Acknowledgements}

This research was funded by the Dutch Product Board for Poultry and Eggs and the Dutch Ministry of Economic Affairs. We are grateful to Thea van Niekerk, Piet van Wikselaar, Leo Kruijt, Agnes de Wit (Wageningen University and Research Livestock Research), Berrian Lammers and Roland Bronneberg (AviVet), Iza Lesna (University of Amsterdam), Gerrit Jan Deetman, Albert ter Laak, Melis van Beek, Jan Truin, André Huiskes (employees of Central Veterinary Institute in Lelystad), Eric Karruppannan and Hans Meijer (Technical Development Studio of Wageningen University and Research) and Kevin Niessen for their knowledgeable contribution to this research. The authors would like to acknowledge networking support by the COST Action FA1404. 


\section{References}

Anonymous (1969) Insect pest management and control. Publication 1695 Washington DC National Academy of Sciences, $508 \mathrm{pp}$

Anonymous (2006) Genstat Release 9 Reference Manual. VSN International, Hemel Hempsted, UK

Anonymous (2014) Website http://www.theranger.co.uk/News/Keeping-an-eye-on- mitenumbers_38.html

Arends JJ, Robertson SH (1986) Integrated pest management for poultry production: Implementation through integrated poultry companies. Poultry Sci 65: 675-682

Axtell RC, Arends JJ (1990) Ecology and management of arthropod pests of poultry. Ann Rev Entomol 35: 101-126

Chauve CM (1998) The poultry red mite Dermanyssus gallinae (De Geer, 1778): current situation and future prospects for control. Vet Parasitol 79: 239-245

Cox M, De Baere K, Vervaet E, Zoons J, Fiks-Van Niekerk T (2009) Red mites: monitoring method and treatment. In: Book of Abstracts 8th European Symposium on Poultry Welfare, Cervia, Italy, 18-22 May: 83

Dively G (2014) Integrated pest management overview. http://www.udel.edu/IPM/cca/ipmoverview.html

Emous RA van, Napel J ten (2007) Buis met stokje zeer geschikt voor bewustwording. De Pluimveehouderij 37: 8-9

Emous RA van, Fiks-van Niekerk TGCM, Mul MF (2005) Bloedluizen (vogelmijten) op papier en in de praktijk. PraktijkRapport Pluimvee 17, Animal Sciences Group of Wageningen UR, ISSN 15708624

Entrekin DL, Oliver JH jr (1982) Aggregation of the chicken mite, Dermanyssus gallinae (Acari: Dermanyssidae). J Med Entomol 19: 671-678

George D, Finn B, Graham K, Mul M, Sparagano O (2013) Of mites and men: Preliminary evidence for increasing incidence of avian ectoparasitosis in humans and support for its potential threat to medical health. In: Book of Abstracts of XVIIIth WVPA Congress Nantes, France, 19-23 August 2013: 635-636

Harrington DWJ, George DR, Guy JH, Sparagano OAE (2011) Opportunities for integrated pest management to control the poultry red mite, Dermanyssus gallinae. World Poultry Sci J 67: 83-93

Kilpinen $O$ (2001) Activation of the poultry red mite, Dermanyssus gallinae (Acari: Dermanyssidae), by increasing temperatures. Exp Appl Acarol 25: 859-867

Kilpinen 0, Roepstorff A, Permin A, Nørgaard-Nielsen G, Lawson LG, Simonsen HB (2005) Influence of Dermanyssus gallinae and Ascaridia galli infections on behaviour and health of lying hens (Gallus gallus domesticus). Br Poultry Sci 45: 26-34

Kirkwood A (1963) Longevity of the Mites Dermanyssus gallinae and Liponyssus sylviarum. Exp Parasitol 14: 358-366 
Koenraadt CJM, Dicke M (2010) The role of volatiles in aggregation and host-seeking of the haematophagous poultry red mite Dermanyssus gallinae (Acari: Dermanyssidae). Exp Appl Acarol 50: 191-199

Lafferty KD, Kuris AM (2002) Trophic strategies animal diversity and body size. Trends Ecol Evol 17: 507-513

Marangi M, Cafiero MA, Capelli G, Camarda A, Sparagano OAE, Giangaspero A (2009) Evaluation of the poultry red mite, Dermanyssus gallinae, (Acari: Dermanyssidae), susceptibility to some acaricides in field populations from Italy. Exp Appl Acarol 48: 11-18

Maurer V, Bieri M, Folsch DW (1988) Das suchverhalten von Dermanyssus gallinae in hühnerställen. Host-finding of Dermanyssus gallinae in poultry -houses. Arch geflugelkd 52: 209-215

Maurer V, Baumgärtner J, Bieri M, Fölsch DW (1993) The occurrence of the chicken mite Dermanyssus gallinae in Swiss poultry houses. Mitt Schweiz Entomol Ges 66: 87-97

Metcalf RL, Luckmann WH (1982) Introduction to insect pest management. Environmental science and technology ISSN 0194-0287. John Wiley and Sons, Inc, United States of America

Mul MF, Koenraadt CJM (2009) Preventing introduction and spread of Dermanyssus gallinae in poultry facilities using the HACCP method. Exp Appl Acarol 48: 167-181

Mul M, Niekerk T van, Chirico J, Maurer V, Kilpinen O, Sparagano O, Thind B, Zoons J, Moore D, Bell B, Gjevre A-G, Chauve C (2009) Control methods for Dermanyssus gallinae in systems for laying hens: results of an international seminar. World Poultry Sci J 65: 589-600

Mul MF, Ploegaert JPM (2014) Crawling insect counting device, system and method for indicating crawling insect infestation and determining a moment for treatment and/or control of said insects. International Publication Number WO 2014/098579 A1

Nordenfors H, Höglund J (2000) Long term dynamics of Dermanyssus gallinae in relation to mite control measures in aviary systems for layers. Br Poultry Sci 41: 533-540

Nordenfors H, Höglund J, Uggla A (1999) Effects of temperature and humidity on oviposition, molting and longevity of Dermanyssus gallinae (Acari: Dermanyssidae). J Med Entomol 36: $68-72$

Nordenfors H, Höglund J, Tauson R, Chirico J ( 2001) Effect of permethrin impregnated plastic strips on Dermanyssus gallinae in loose-housing systems for laying hens. Vet Parasitol 102: 121-131

Pavlicevic A, Pavlovic I, Stajkovic N (2007) Method for early detection of poultry red mite Dermanyssus gallinae (De Geer, 1778). Biotechnol Anim Husb 23 (3-4): 119-127

Searle SR, Cassella G, McCullouch CE (1992) Variance components. Wiley, New York.

Sikes RK, Chamberlain RW (1954) Laboratory observations on three species of bird mites. J Parasitol 40: 691-697 
Sparagano OAE, George DR, Harrington DWJ, Giangaspero A (2014) Significance and control of poultry red mite, Dermanyssus gallinae. Ann Rev Entomol 59: 447-466

Tavassoli M, Allymehr M, Pourseyed SH, Ownag A, Bernousi I, Mardani K, Ghorbanzadegan M, Shokrpoor S (2011) Field bioassay of Metarhizium anisopliae strains to control the poultry red mite Dermanyssus gallinae. Vet Parasitol 178: 374-378

Zehnder G (2014) Overview of monitoring and identification techniques for insect pests. http://www.extension.org/pages/19198/overview-of-monitoring-and-identificationtechniques-for-insect-pests

Zenner L, Bon G, Chauve C, Nemoz C, Lubac S (2009) Monitoring of Dermanyssus gallinae in free-range poultry farms. Exp Appl Acarol 48: 157-166 


\section{Appendix 5}

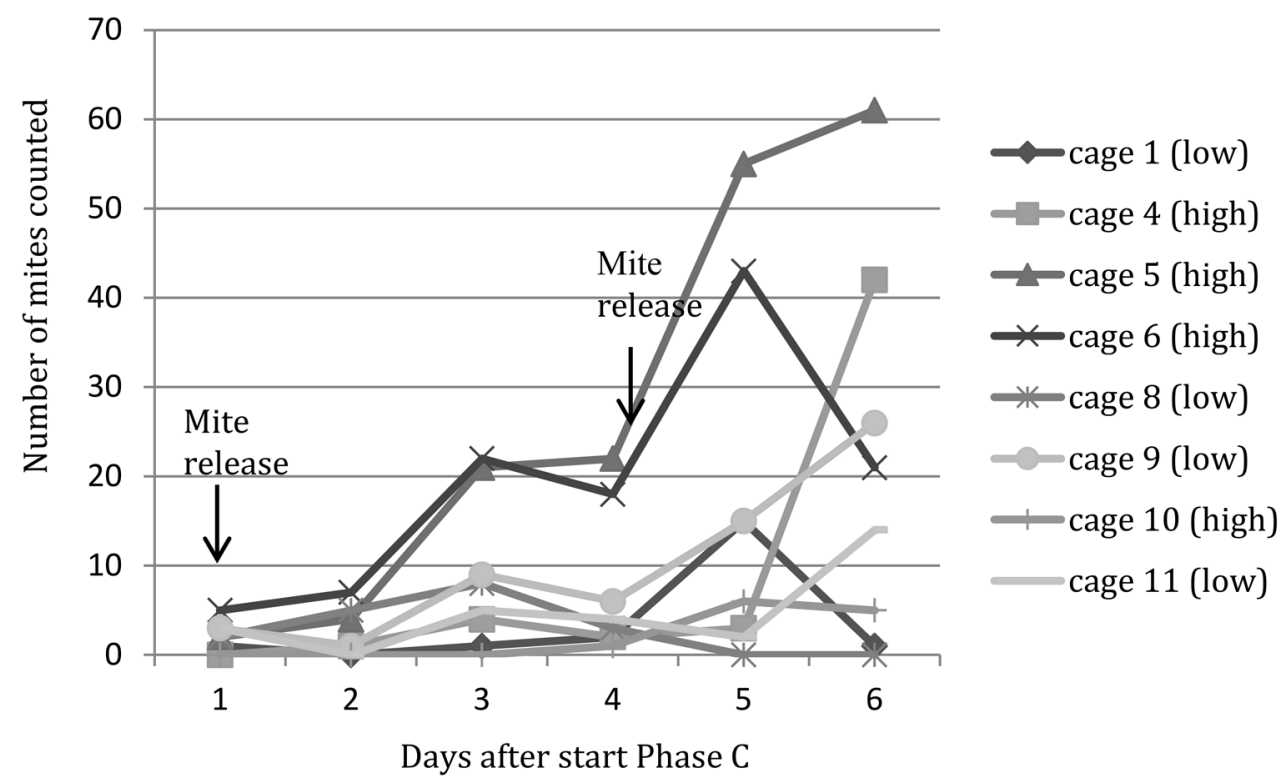

Figure A5.1 Number of mites counted by the automated mite counter at day one to six after the start of Phase $\mathrm{C}$ for eight different cages with either a low or a high mite infestation. On day one and four, 500 (low infestation treatment group) or 5000 (high infestation treatment group) mites were released. low = low infestation treatment group; high = high infestation treatment group. 


\section{Chapter 6}

\section{Model based approaches to forecast Dermanyssus gallinae population dynamics and to describe the source of population growth variation in laying hen facilities for advancing Integrated Pest Management}

Monique F. Mul ${ }^{1 *}$, Johan W. van Riel ${ }^{1 *}$, Lise Roy², Johan Zoons ${ }^{3}$, Geert André1,†, David R. George $^{4}$, Bastiaan G. Meerburg${ }^{1}$, Marcel Dicke ${ }^{5}$, Simon van Mourik6 ${ }^{6}$, Peter W.G. Groot Koerkamp ${ }^{1,6}$

1 Wageningen Livestock Research, P.O. Box 338, 6700 AH Wageningen, The Netherlands. Geert André deceased 1-10-2013

2 CEFE, CNRS - Univ Montpellier - Université P. Valéry - EPHE, Route de Mende, 34199 Montpellier cedex 5, France

3 Experimental Poultry Centre, Poiel 77, 2440 Geel, Belgium

${ }^{4}$ Department of Entomology and Sustainable Agriculture, Stockbridge Technology Centre, North Yorkshire, Y08 3TZ, United Kingdom

5 Laboratory of Entomology, Wageningen University and Research, P.O. Box 16, 6700 AA Wageningen, The Netherlands

${ }^{6}$ Farm Technology Group, Wageningen University and Research, P.O. Box 16, 6700 AA Wageningen, The Netherlands

Submitted for publication 


\begin{abstract}
The poultry red mite, Dermanyssus gallinae, is the most significant pest of egg laying hens in many parts of the world. Control of this pest could be greatly improved with advanced Integrated Pest Management (IPM) for D. gallinae in laying hen facilities. The development of a model forecasting D. gallinae's population dynamics in laying hen facilities pre- and post-treatment may contribute to this advanced IPM. The current work describes the development and demonstration of a model which can follow and forecast the population dynamics of $D$. gallinae in laying hen facilities. Herein we are the first reporting and explaining a high variation of the population growth. This high variation could partly be explained by temperature, flock age, treatment, and compartment. A substantial part of the total population growth variation, however, was the sum of the temporal and the unexplained variation with the temporal variation supporting a dynamic approach to forecast D. gallinae population development. The developed model is able to forecast the population dynamics of D. gallinae, requiring only population monitoring data, temperature data and information of the dates of any D. gallinae treatment interventions. Importantly, the model forecasted treatment effects, while compensating for location and time specific interactions, handling the variability of these parameters. The characteristics of this population model, and its compatibility with different mite monitoring methods, represent progression from existing approaches for forecasting D. gallinae that could contribute to advancing improved Integrated Pest Management (IPM) for D. gallinae in laying hen facilities.
\end{abstract}




\section{Introduction}

The poultry red mite, Dermanyssus gallinae, is the most common ectoparasite of egg laying hens in many parts of the world, though this haematophagous mite may feed upon a range of other hosts, including humans (Sikes and Chamberlain 1954; George et al. 2015). Dermanyssus gallinae has five developmental stages: egg, larva, protonymph, deutonymph and adult, with blood meals required for development from protonymph to deutonymph, to the adult stage, and for reproduction thereafter (Axtell and Arends 1990). In a poultry house, the development of heavy infestations can be realised within a short time period (30-70 days) (Maurer and Baumgartner 1992), where favourable temperature and humidity drive rapid population growth. Highest D. gallinae population developmental rates and lowest $D$. gallinae mortality rates are generally seen between 20 and $37^{\circ} \mathrm{C}$ (Maurer and Baumgärtner 1992; Nordenfors et al. 1999), with temperatures in laying hen facilities typically kept between 18 and $21^{\circ} \mathrm{C}$, rising to $28-30^{\circ} \mathrm{C}$ during the summer with higher outdoor temperatures (Anonymous 2010), the D. gallinae lifecycle can be completed within seven days (Maurer and Baumgärtner 1992).

High infestation rates of $D$. gallinae in egg-laying facilities may cause anaemia in hens (Kilpinen et al. 2005), and in extreme cases even hen mortality (Kilpinen et al. 2005; Arkle et al. 2006). Other negative effects of infestations include reduced animal welfare, reduced egg quality, and lower bird weight (Chauve 1998). Lower egg production and increased feed and water intake have also been linked to D. gallinae infestation in laying hens (Mul et al. 2009). The costs for EU egg producers, on per flock basis, have been estimated as $€ 0.29$ per hen due to reduced production and $€ 0.14$ per hen for control measures (Van Emous et al. 2005). Dermanyssus gallinae is known or suspected to vector numerous poultry pathogens (Valiente Moro et al. 2009), including Salmonella (Valiente Moro et al. 2007a,b). As well as presenting a threat to veterinary health, D. gallinae may also have an impact on human health, especially for people working with poultry, as this species may also attack humans (Cafiero et al. 2011; George et al. 2015).

Control of D. gallinae is difficult. The mites' reclusive and nocturnal lifestyle makes this pest hard to target using available conventional acaricides, particularly as D. gallinae exist off-host and feed only intermittently (Maurer et al. 1988), potentially not encountering treated surfaces for several days after application. Increasingly stringent pesticide legislation in many parts of the world, as well as the tendency of D. gallinae to rapidly develop resistance, further exacerbate this issue (Sparagano et al. 2014). Consequently, there is an urgent need for alternative control strategies. Possibilities for future control of $D$. gallinae are described by Mul et al. (2009) and Sparagano et al. (2014). The most promising approaches can be summarised as: a) a combination of control strategies, b) implementation of Integrated Pest Management (IPM), and c) implementation of the HACCP method (Hazard Analysis and Critical Control Points) (Mul et al. 2009; Harrington et al. 2011; Sparagano et al. 2014). 
In order to deliver improved IPM for control of D. gallinae, advances have recently been made in the field of automated monitoring (Mul et al. 2015). For further improving IPM, development of better models to forecast mite population dynamics are now needed. Also models to quantify the total economic costs due to the level of $D$. gallinae infestation present are required, as is a control algorithm to forecast and advise on timing of treatments when economic thresholds are exceeded (Benbrook et al. 1996; Legg 2004; Mul et al. 2016). Modelling ecosystem processes is nevertheless difficult, since the complexity of interactions and the effects of these interactions on pest population dynamics are broad and often unknown. Population dynamics models are nonetheless vital for forecasting and decision making in IPM programmes (Kogan 1998).

Currently, two models are available describing the population dynamics of D. gallinae (Maurer and Baumgärtner 1994; Huber et al. 2011). Maurer and Baumgärtner (1994) developed a population model to inform strategic and tactical decisions for control strategies, and to identify gaps in our understanding of D. gallinae biology. Huber et al. (2011) developed a tactical model describing the population dynamics of D. gallinae and the effect of a treatment on that population. This model was based on that of Maurer and Baumgartner (1994) and showed the population development in time, depending on the egg production of adults, their fecundity, sex ratio and inter-laying time. In this model, the equilibrium or steady state of a D. gallinae population was described when the number of eggs, nymphs and adults in the facility did not increase further. The effect of a treatment was incorporated as a constant effect and modelled as the time between treatment and the moment the population returned to the corresponding steady state. Practical implementation of both above models requires numerous and complex measurements of the mite population (with a differentiation between number of eggs, larvae, protonymphs, deutonymphs and adults at several points in time) and either the number of mites in the steady state, or the efficacy of the treatment. Obtaining this vital data, however, will be costly and time consuming, and therefore curirentldemabfeaslisse.practical benefit and advancing improved IPM programmes, review of available literature (Kogan 1998; Dent 1995; Dent 2000; Dively 2015; Radcliffe et al. 2015) supports that models and their required inputs need to be: 1) labour-extensive with minimal staff input, preferably automatically implementing "real time" measurement data into models; 2) operational, providing easily interpretable data, forecasting pest population dynamics and the moment a threshold will be exceeded; 3) able to compensate for different locations and time-specific-interactions and variables (e.g. management and temperature), enabling the handling of variability of the parameters of interest; 4) able to identify pest hotspots; 5) able to estimate and forecast treatment efficacy; and 6) applicable for different monitoring methods and therefore able to correct for monitoring measurement errors.

Where D. gallinae is concerned, and as shown in this paper, the variation of treatment effects on pests, and their population dynamics, are partly temporal, meaning that every flock has a different slope of the age effect, and a substantial unexplained part. This means 
that the population growth and the treatment effects on pests can vary between locations (facilities) and over time. This suggests that conventional population models are likely to be sub-optimal in forecasting D. gallinae population development and treatment efficacy. Under conditions of such high variation and different individual slopes, André et al. (2010) suggested that a time-series model with a dynamic approach (West and Harrison 1997) can help to improve the forecasting accuracy.

For advancing the implementation of IPM programmes, an operational model helping the farmers in their management to control D. gallinae, is needed. Such an operational model, forecasting the mite population dynamics, applicable to all poultry facilities, and estimating the efficacy of a curative treatment, has yet to be described for D. gallinae. The aim of the current study was to develop and subsequently demonstrate a model which can follow and forecast the population dynamics of D. gallinae in laying hen facilities given an unexplained and temporal variation of the population growth. A further aim was to acquire an indication on the source of this variation.

\section{Materials and Methods}

To develop and demonstrate a model for forecasting the population dynamics of $D$. gallinae, and to gain insights into the source of the variation of the population growth, three datasets derived from different types of monitoring data were used (Table 6.1). Mite monitoring data were collected at the Experimental Poultry Centre in Geel, Belgium (henceforth Dataset 1) and at an egg producing farm in Lyon, France (henceforth Datasets 2 and 3).

Dataset 1 was generated from monitoring based on the Mite Monitoring Score (MMS, Cox et al. 2009) covering five levels of $D$. gallinae infestation: $0=$ no mites visible; $1=$ mites visible in cracks and crevices; 2 = mites visual at unprotected places; 3 = clusters of mites (i.e. the size of all mites grouped together exceeds $1 \mathrm{~cm}^{2}$ ) visible in cracks and crevices; $4=$ clusters of mites visible at unprotected places in and on the housing equipment.

Dataset 2 utilised the Semi-Attractive water Trap (SAT, Chiron et al. 2014) method, consisting of a $40-\mathrm{ml}$ plastic vial, two-thirds of which were filled with water, with a screw cap. The vial was positioned on a metal wire (2.4 $\mathrm{mm}$ diameter) attached to the cap and to the grid near the egg belt, on the outside of the enriched cages present. The screw cap was perforated with seven holes of approximately $2 \mathrm{~mm}$ in diameter. The mites were attracted to the water and entered the vial via the metal wire through the holes in the screw cap. Soap was added to the water at a rate of $0.01 \%$ to make the mites drown and sink for subsequent assessment.

For Dataset 3 monitoring was undertaken using a Simplified Passive tape Trap (SPT, Roy et al. 2014; Chiron et al. 2014) method, whereby a 5 - $8 \mathrm{~cm}$ long section of $3 \mathrm{~cm}$ wide painter's masking tape was wrapped around cylindrical bars in the poultry system, joining the two ends, but leaving a central space near the bar to serve as a mite refuge (see Figure 6.1). The number of mites trapped on this sticky refuge was scored to four different levels: 0 
= no mites visible in the trap; $1=1-9$ mites visible in the trap; $2=$ sparse groups of $>10$ mites visible in the trap; 3 = clusters of mites visible in the trap.

Dataset 1 was used to obtain insight into the sources of the variation of D. gallinae growth rate, and to develop the adaptive population model described herein. Datasets 2 and 3 were used to demonstrate the models ability to perform given different monitoring methods and housing systems.

Table 6.1 Overview of the three datasets, housing systems, monitoring methods and the type of monitoring measurements used to obtain insight into the variation of the population growth, to develop or to demonstrate the dynamic adaptive model described herein for forecasting the population dynamics of D. gallinae.

\begin{tabular}{|c|c|c|c|c|c|c|}
\hline $\begin{array}{l}\text { Dataset } \\
\text { number }\end{array}$ & $\begin{array}{l}\text { Type of housing } \\
\text { system } \\
\text { (Compartment ID) }\end{array}$ & $\begin{array}{l}\text { Number } \\
\text { of flocks }\end{array}$ & $\begin{array}{l}\text { Monitoring } \\
\text { method }\end{array}$ & $\begin{array}{l}\text { Type of } \\
\text { measurements }\end{array}$ & Used for & $\begin{array}{l}\text { Number of } \\
\text { measuring } \\
\text { points for } \\
\text { calculating } \\
\text { AMIL }^{1}\end{array}$ \\
\hline \multirow[t]{3}{*}{1} & $\begin{array}{l}\text { Large enriched } \\
\text { cages } \\
\text { (Compartment A + } \\
\text { C) }\end{array}$ & 5 & $\mathrm{MMS}^{2}$ & Classes (0-4) & $\begin{array}{l}\text { Variation } \\
\text { population } \\
\text { growth, } \\
\text { development }\end{array}$ & 36 \\
\hline & $\begin{array}{l}\text { Aviary system } \\
\text { (Compartment B) }\end{array}$ & 5 & MMS & Classes (0-4) & $\begin{array}{l}\text { Variation } \\
\text { population } \\
\text { growth, } \\
\text { development }\end{array}$ & 36 \\
\hline & $\begin{array}{l}\text { Small enriched } \\
\text { cages } \\
\text { (compartment D) }\end{array}$ & 5 & MMS & Classes (0-4) & $\begin{array}{l}\text { Variation } \\
\text { population } \\
\text { growth, } \\
\text { development }\end{array}$ & 36 \\
\hline 2 & $\begin{array}{l}\text { Large enriched } \\
\text { cages }\end{array}$ & 1 & SAT $^{3}$ & Counts & Demonstration & 40 \\
\hline 3 & $\begin{array}{l}\text { Large enriched } \\
\text { cages }\end{array}$ & 1 & $\mathrm{SPT}^{4}$ & Classes (0-3) & Demonstration & 88 \\
\hline
\end{tabular}

${ }^{1}$ Average Mite Infestation Level

2 Mite Monitoring Score

${ }^{3}$ Semi-Attractive water Trap

${ }^{4}$ Simplified Passive tape Trap

\section{Mite Monitoring data Geel, Belgium}

Dataset 1 from the Experimental Poultry Centre in Geel (Belgium) consisted of mite monitoring data from twenty flocks (or laying rounds) between 2005 and 2011 from four laying hen houses (compartments) containing three different types of housing systems. Compartments $\mathrm{A}$ and $\mathrm{C}$ housed hens in large enriched cages (40 birds/cage), Compartment $B$ in an aviary system, and Compartment D in small enriched cages (20 birds/cage). Compartments A and C housed 2,400 hens each, Compartment B 2,000 hens and Compartment D 2,160 hens. 
An employee of the Experimental Poultry Centre monitored all four layer compartments to determine the necessity for D. gallinae treatment, as well as the efficacy of any treatment applied. During the period 2005-2011, three different employees carried out the monitoring as follows. The compartments were monitored every other week if no infection was present, or weekly after the first mite was detected, using the MMS method. In each compartment twelve designated locations were monitored, with scores returned for three heights per location (providing 36 observations overall). During the assessment, about $1 \mathrm{~m}^{2}$ of the housing sub structure was inspected for mites, with the use of a torch, from top to bottom of the system around the measuring point. All 36 scores were averaged per compartment (Average Mite Infestation Level = AMIL), as shown in Figure 6.2. All D. gallinae treatment dates and types of treatment were recorded, with silica being most typically used. A treatment was applied if the average score of all 36 points was higher than 1 , if a score higher than 3 was found anywhere in the compartment, or if workers reported D. gallinaerelated dermatological complaints or bloodspots on eggs. The indoor temperature (ranging from 14.17 to $26.77^{\circ} \mathrm{C}$ ) were recorded every hour in each compartment, but the calculated weekly mean temperature was used in the models.

\section{Mite Monitoring data, France}

Staff from the ITAVI (Institute Technique de l'AVIculture) collected Datasets 2 and 3 from a single French layer farm. In the layer house, 11,520 hens were housed in enriched cages, 60 hens per cage, in four rows at four levels.

For Dataset 2, obtained via the SAT monitoring method, vials used for mite trapping were refreshed every two weeks. In the laboratory, the water/soap solution in each vial was filtered through a sieve ( $4 \mathrm{~cm}$ diameter, 150 microns mesh size) and the mites on the mesh were counted under a binocular microscope on a Petri dish divided into squares. The number of trapped mites was determined per trapping point and averaged for the 40 trapping points (AMIL). At the same farm SPT traps (Dataset 3) were assessed and renewed weekly at 88 trapping points and the average of the 88 trapping points (AMIL) was calculated. 

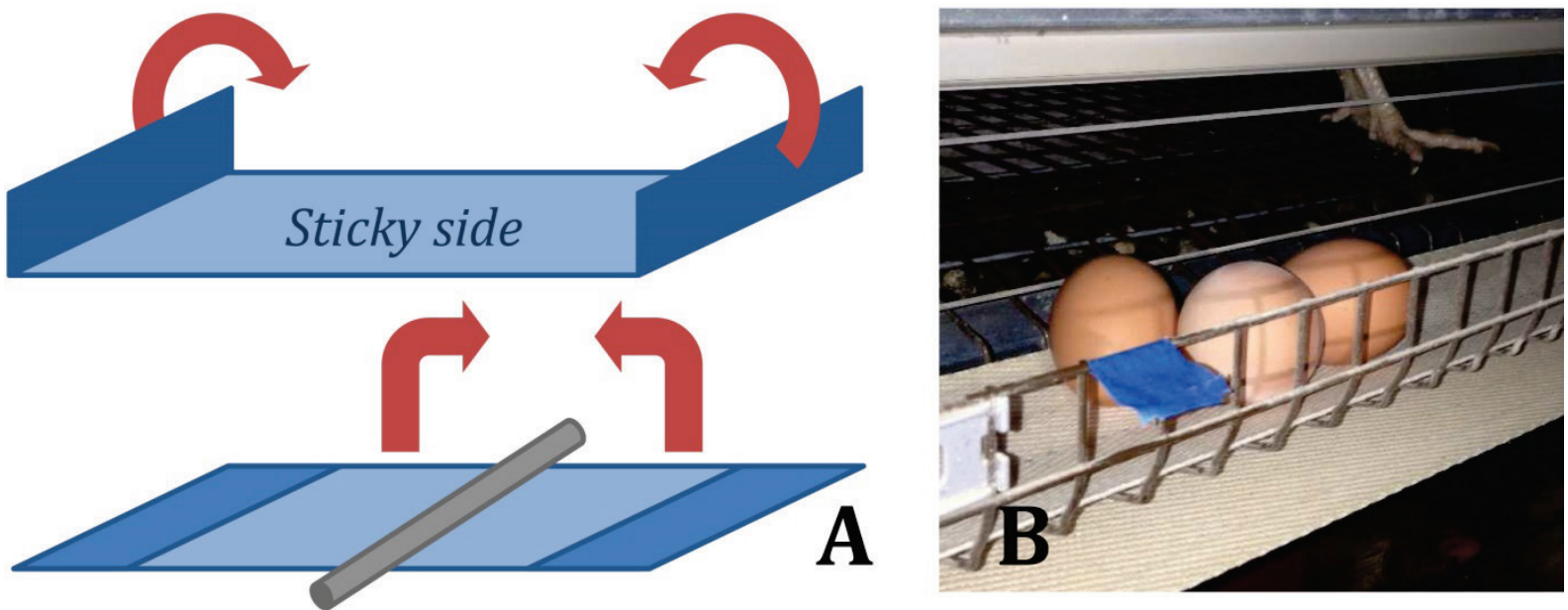

Figure 6.1 Use of Painter's Masking Tape to produce a simplified passive tape trap (SPT) for monitoring D. gallinae (panel A) (adapted from Roy et al. 2014) and an example of fixation of SPT in an egg laying facility (A.Varescon 2014) (panel B)

At the French farm, the D. gallinae population was monitored on a two-weekly basis with SAT for a period of 17 months from July 2012- December 2013, and on a weekly basis with SPT for a period of 19 months from the end of April 2012- December 2013. For the final thirteen weeks, however, the mite population was monitored on a weekly basis with both SAT and SPT. The temperature in this French laying hen house was recorded from the end of June 2012 until December 2013. The weekly mean temperature (ranging from 17.4 to $24.3^{\circ} \mathrm{C}$ ) was calculated and used in the model. Treatment dates and methods were recorded, again with silica being most typically used.

\section{Growth rate}

On the assumption that mite populations observed at two closely related time points followed an exponential growth relation, and that population growth rate is in practice always density independent as a result of the treatments applied, all monitoring data was converted to a variable describing the exponential "growth rate", derived from the exponential growth function as described by Edelstein-Keshet (1988).

Weekly growth rate (Rt, without unit) was calculated as

$$
\mathrm{Rt}=\frac{\operatorname{Ln}\left\{\frac{\left.\frac{\mathrm{Yt}-1+\mathrm{Yt}-2+\mathrm{Yt}-3}{3}\right\}}{\Delta t}\right.}{\Delta t}
$$

where: $\mathrm{Ln}=$ natural logarithm; $Y_{t}=$ average mite infestation level at week $\mathrm{t}$;

$\Delta \mathrm{t}=$ number of weeks between $\mathrm{t}-3$ and $\mathrm{t}$.

Hereafter, weekly growth rate is referred to as growth rate. 


\section{Variation in population growth}

A mixed model of systematic and random factors was used to gain insight into the source of the variation of the population growth. Systematic factors were included in the model to estimate the mean effects of compartment temperature, flock age of hens and treatment on mite population growth rate. Random factors were added to the model to estimate the deviating effects of individual flocks with increasing age on the growth rate (random regression). The regression coefficient for the age effect of a flock of hens was modelled using the inverse of flock age of the hens $\left(\frac{1}{\text { flock age }}\right)$. The inverse of flock age was chosen due to the fact that at low flock age the growth rate and treatment effects change more rapidly in time compared to high flock age. Growth rates were analysed with a linear random regression model (REML), using the statistical software package GenStat for Windows (17th edition 2015) (Anonymous 2006). Parameters were estimated by REML (Searle et al. 1992). For formulas, see Appendix A6.1.

\section{Development of a Population Dynamics Model}

To enable forecasting of D. gallinae population dynamics in any specific farm situation, and to meet most of the requirements for a model contributing to the development and implementation of practical IPM programmes for D. gallinae in laying hen facilities, an adaptive population model was developed. Such an adaptive model is suitable for forecasting near-future responses with temporal variation due to gradually changing factors. With D. gallinae the factors contributing to the temporal variation are most likely elements of flock management and flock characteristics which are as yet unidentified or unmeasurable.

In dynamic adaptive models the parameter estimates are time-varying and regularly updated based on recent observations of the processes involved. Parameter estimation and forecasting future observations for these types of dynamic models are based on a Bayesian approach for recursive analysis of time series (West and Harrison 1997).

In the dynamic adaptive model developed here, it was assumed that the growth rate $\left(\mathrm{R}_{\mathrm{t}}\right)$ of equation 1 is a linear response to housing temperature $\left(T_{t}\right)$ and treatment effect $\left(D_{t}\right)$ :

$\mathrm{R}_{\mathrm{t}}=\mathrm{C} 0_{\mathrm{t}}+\mathrm{C} 1_{\mathrm{t}}^{*}\left(\mathrm{~T}_{\mathrm{t}}-20\right)+\mathrm{C} 2_{\mathrm{t}}^{*} \mathrm{D}_{\mathrm{t}}$

where: $\mathrm{CO}_{\mathrm{t}}=$ the intercept or base level (growth rate at indoor temperature of $20^{\circ} \mathrm{C}$, without treatment); $\mathrm{C} 1_{\mathrm{t}}=$ the linear effect of temperature; $\mathrm{C} 2_{\mathrm{t}}=$ the linear effect of the treatment effect. 
After each individual measurement of the D. gallinae population size, the parameters (priors) that enable forecasting the growth rate, being $\mathrm{C}_{\mathrm{t}}, \mathrm{C} 1_{\mathrm{t}}$ and $\mathrm{C} 2{ }_{\mathrm{t}}$, were evaluated and adjusted (posterior) by a dynamic linear model (DLM). Therefore, $\mathrm{CO}_{\mathrm{t}}, \mathrm{C}_{\mathrm{t}}$ and $\mathrm{C} 2_{\mathrm{t}}$ can change gradually in time.

For further explanation about DLM and formulas, see Appendix A6.2.

\section{Model demonstration}

The validation of the dynamic adaptive model was demonstrated by assessing the model fit with the Mean Squared Prediction Error (MSPE). The MSPE assesses the quality of the prediction or forecast of the derived population model. For formulas, see Appendix A6.3.

The MSPE was determined, with and without outliers, for Datasets 1 - 3 with data obtained with the three different monitoring methods used. To estimate the differences in accuracy of the model using the SPT and the SAT monitoring methods, the MSPE was determined for Dataset 2 and for Dataset 3, including the AMIL of the dates which were available in both datasets. Differences in MSPE between dataset 2 and 3 were tested with a F-statistic with 32 and 32 degrees of freedom using the statistical software package GenStat for Windows (17th edition 2015) (Anonymous 2006). Due to significant differences between Belgian and French monitoring sites (hen breeds, housing system and flock management), no accuracy differences of the model were estimated between Dataset 1 and Datasets 2 and 3.

For graphic visualisation of the model, the fit of estimated forecasts of the mite infestation to real measurements (AMIL) were plotted.

\section{Results}

\section{Mite Monitoring data Geel, Belgium}

The AMIL of the 36 measuring points was determined for all four laying compartments during five flocks (or laying rounds), as shown in Appendix A6.4. Figure 6.2 shows, as an example, the mite population dynamics (AMIL) of the fifth flock in Compartment D. Here, five treatments, typically silica-based, were applied against D. gallinae. Before the hens reached 60 weeks of age, the mite population increased to level ' 2 '. Shortly after hens had passed 60 weeks of age, the mite population decreased considerably to a little above level ' 1 ' due to cleaning of the nest pads removing D. gallinae. This cleaning, however, was not considered as a treatment by the staff. The treatment applied just after the flock reached 70 weeks of age, and again just prior to 80 weeks, appeared to be less effective as there was no decline in the level of mite infestation at the first measurement after these treatments. 


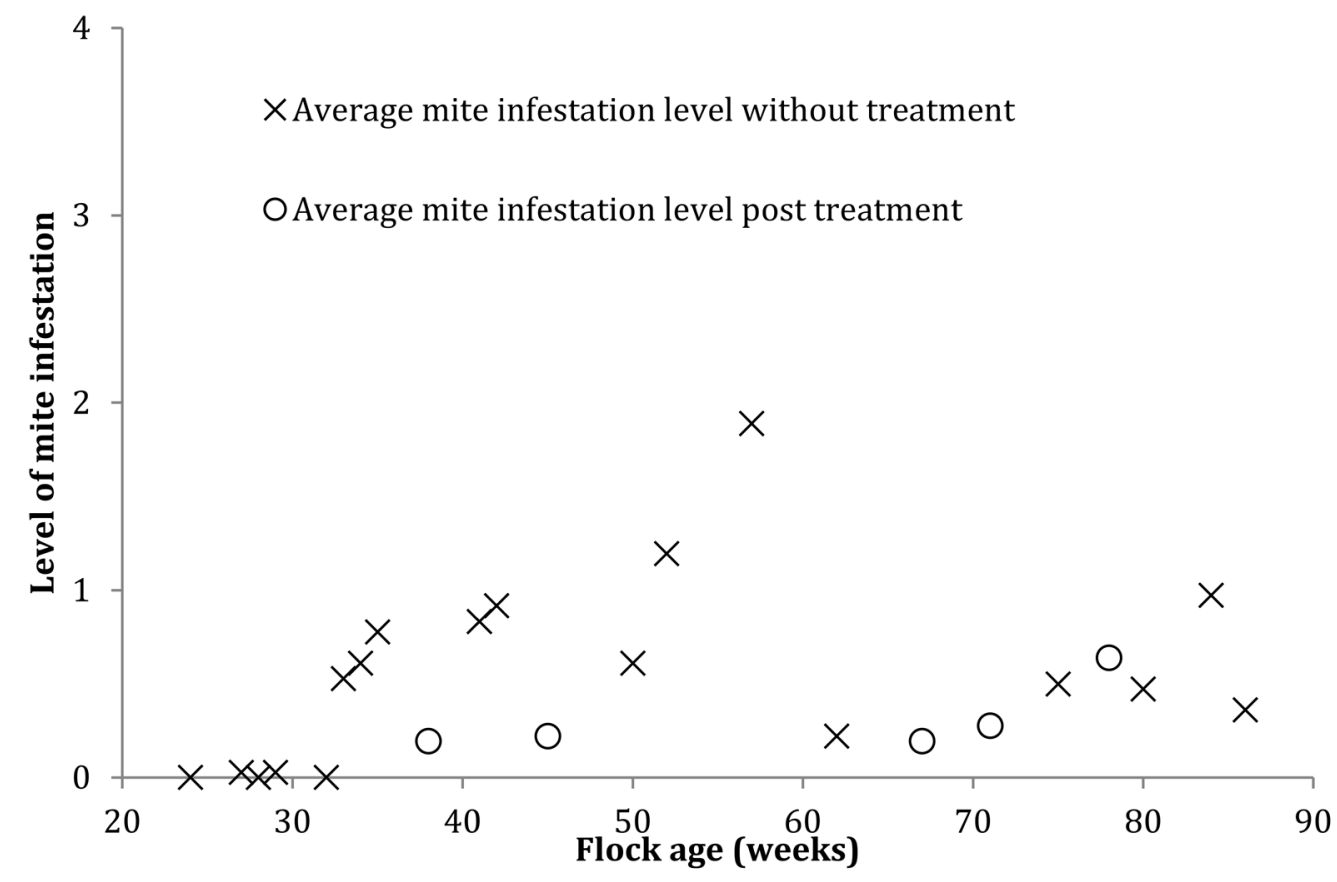

Figure 6.2 Population dynamics of Dermanyssus gallinae over 90 weeks with the level of mite infestation versus flock age (weeks). Each level was determined using the 36 data points (AMIL) in Compartment D, of the fifth flock of the Experimental Poultry Centre in Geel (Belgium)

\section{Mite Monitoring data, France}

Dataset 2 is shown in Figure 6.3. The average number of trapped mites (AMIL) is shown per monitoring date (flock age) and was ln transformed. The average number mites recorded using the SAT method reached $550\left(=e^{6.31}\right)$ when the hens were around 80 weeks old. Silica treatments applied against D. gallinae were repeated 12 times on a weekly basis and resulted in a decrease of the number of mites trapped. On the ln scale the AMIL shows a linear increase with increasing flock age, meaning that on a normal scale there is an exponential growth of the mite population with increasing flock age. The solid line shows the model forecast which will be discussed in Section 'Model demonstration'. 


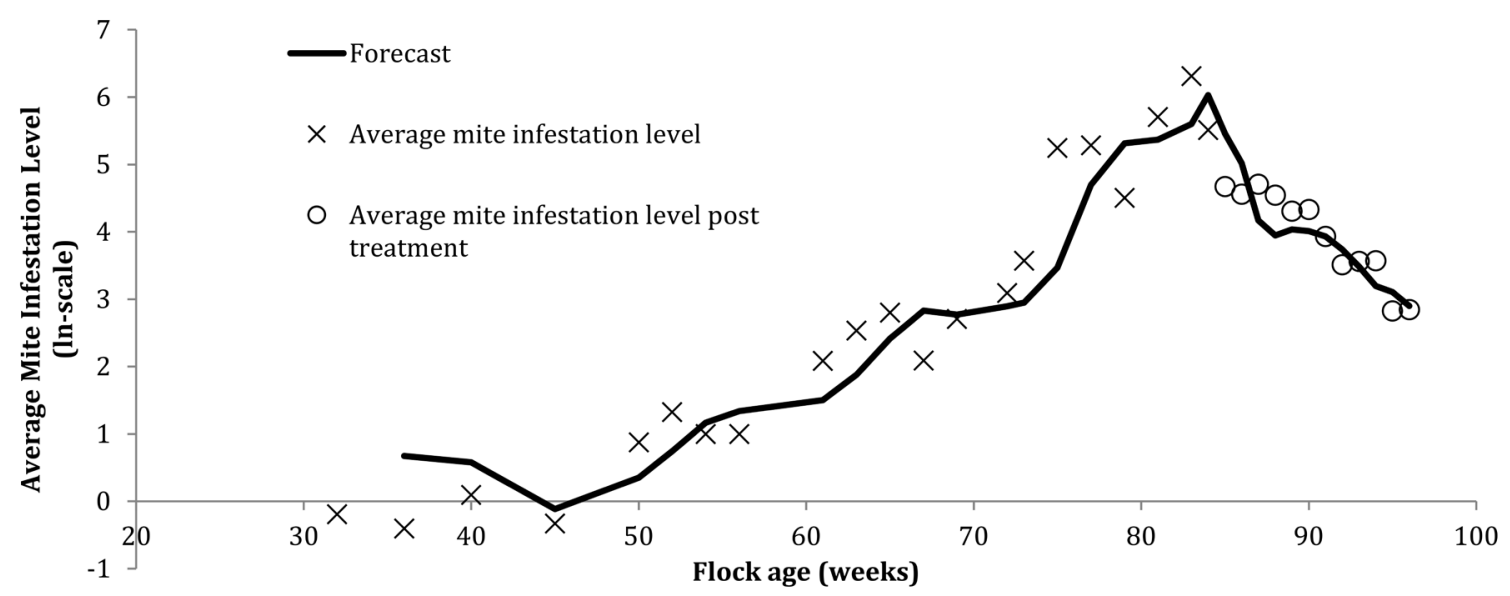

Figure 6.3 Population dynamics of Dermanyssus gallinae over a period of 64 weeks from Dataset 2. The average mite infestation levels (AMIL) were determined using the 40 data points collected in a French laying hen farm with the SAT method. The line shows the model forecast of the AMIL of next week

Dataset 3 (SPT method) is shown in Figure 6.4. During the latter part of the laying round, 12 treatments were applied on a weekly basis. The highest average mite infestation level determined from 88 trapping points was almost 2.5 when hens were 83 weeks old. A remarkable observation can be seen in week 84 with a decline in AMIL without the application of a silica treatment. The solid line shows the model forecast which will be discussed in Section 'Model demonstration'. 


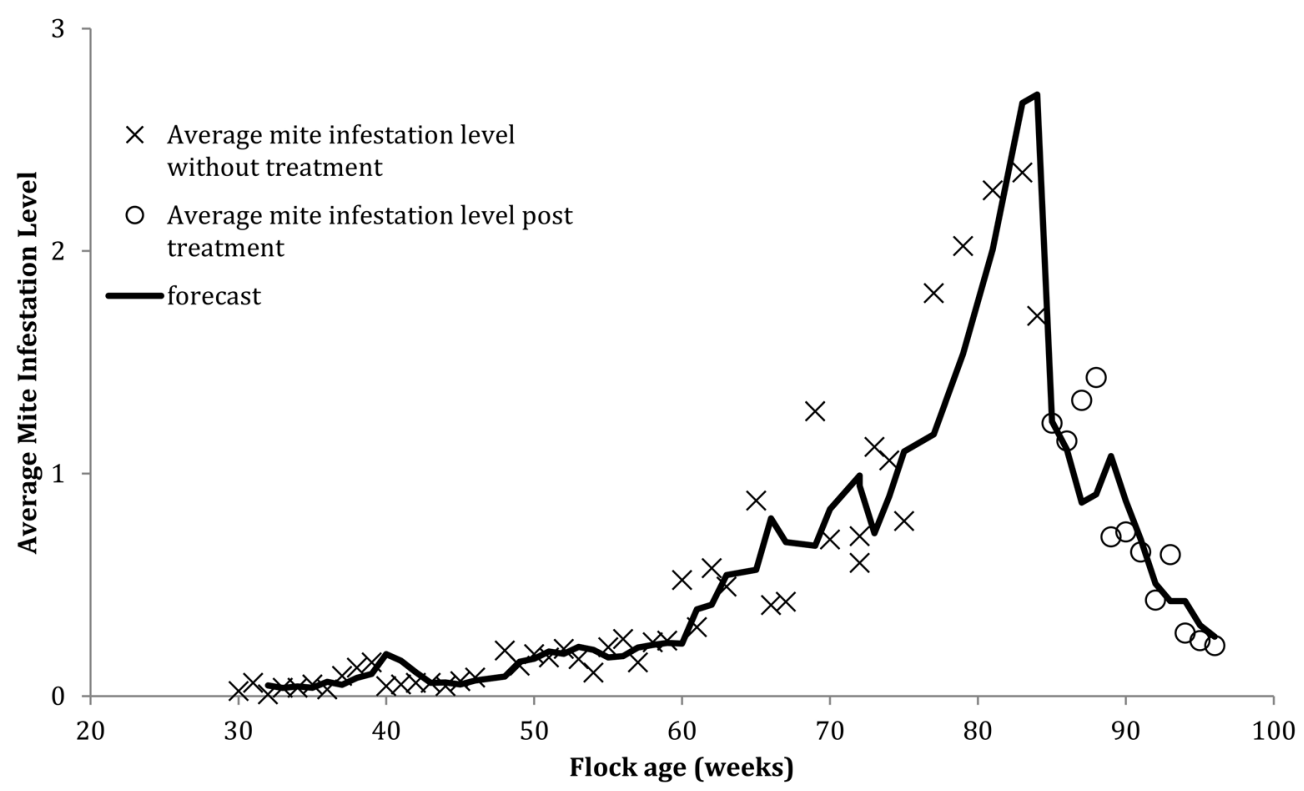

Figure 6.4 Population dynamics of Dermanyssus gallinae over a period of 66 weeks from Dataset 3 with the average mite infestation level (AMIL) versus Flock age (weeks). AMIL was determined using the 88 data points collected in a French laying hen farm with the SPT method. The line shows the model forecast of the AMIL of next week

\section{Variation in population growth}

The effect of flock age on the growth rate of a D. gallinae population in an average flock was estimated with $\beta_{0}$ (intercept of effect of flock age without treatment) $=-0.22(95 \%$ Confidence Interval: $-0.07,0.37$ ), and $\beta_{1}$ (regression coefficient for the effect of flock age without treatment $)=16.4$ (95\% Confidence Interval: 7.8, 25). For example, at a flock age of 40 weeks, the population growth rate was $-0.22+16.4(1 / 40)=0.19$, meaning that the mite population increased by ( $\left.e^{0.19}=1.209\right) 21 \%$ in one week compared to the last measured population size.It is worth noting that this was the case without a treatment and at a temperature of $20^{\circ} \mathrm{C}$.

The effect of treatment was age dependent and was estimated with $\alpha_{0}$ (difference in intercept of effect of flock age post treatment $)=0.24(0.02,0.46)$ and $\alpha_{1}$ (difference in linear effect of flock age post treatment $)=-19.9(-31.7,-8.1)$. For example, when a treatment was applied at a flock age of 40 weeks, the mite population growth rate was $(-0.22+0.24)+$ $(16.4-19.9) *(1 / 40)=-0.0825$, meaning that the mite population would be $\left(e^{-0.0825}=\right.$ 0.9208 ) $92 \%$ of the last measured population size, i.e. a population reduction of $8 \%$. 
The estimated effect of flock age on growth rate post treatment and without treatment in Dataset 1 are displayed graphically in Figure 6.5.

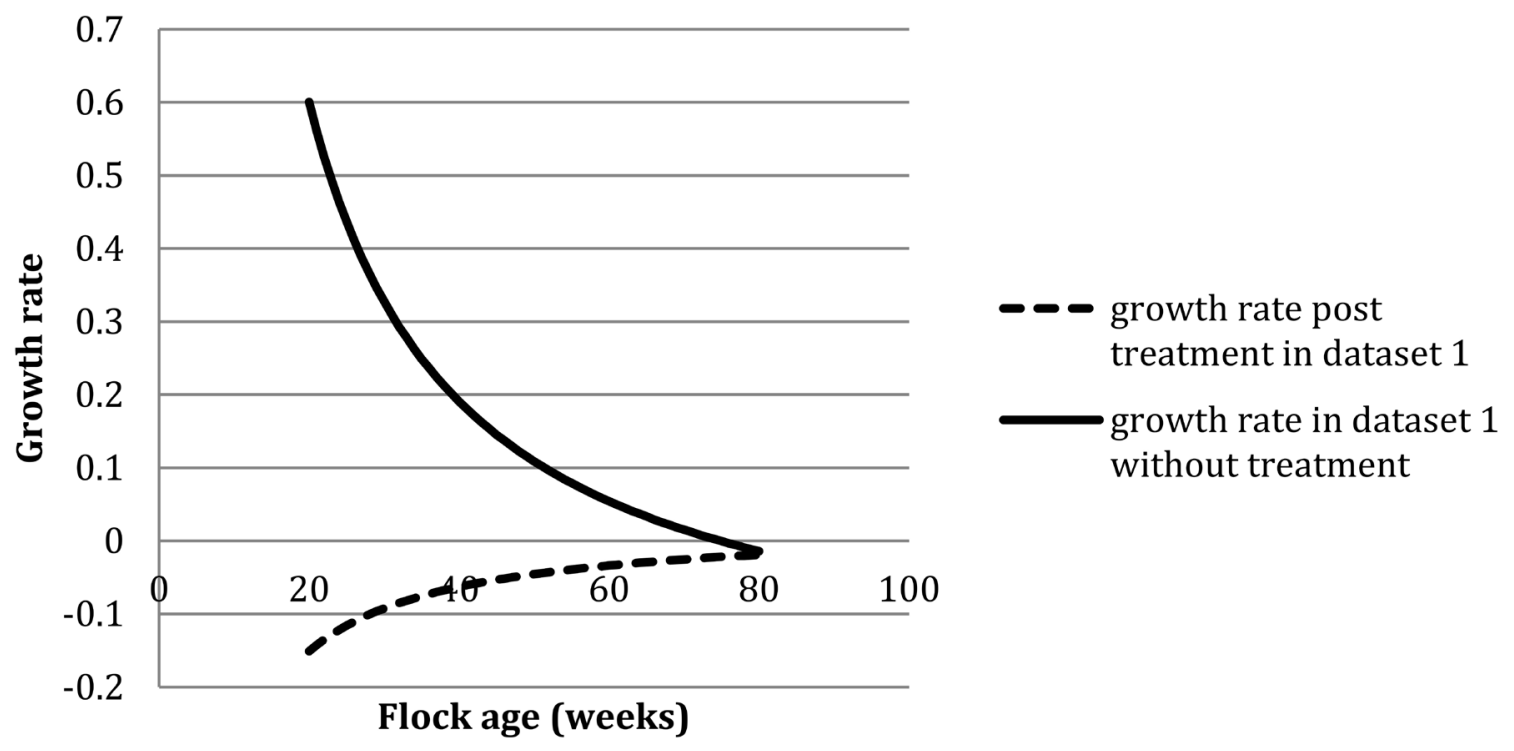

Figure 6.5 Effect of flock age on the population growth rate of Dermanyssus gallinae post treatment and without treatment in Dataset 1 . Fixed effects of flock age and treatment are estimated with $\left(\beta_{0}+\alpha_{0}\right)+\left(\beta_{1}+\alpha_{1}\right) * \frac{1}{\text { flock age }}$

The effect of temperature is independent from treatment, flock age or compartment, as the interactions with temperature were found to be non-significant ( $p>0.05)$, and thus described as an additional effect. The effect of temperature on growth rate was estimated with $\beta_{2}=0.019$ (95\% Confidence interval: 0.002, 0.036). This means, for example, that at a temperature of $25{ }^{\circ} \mathrm{C}$, the growth rate will increase by $0.019 *(25-20)=0.095$. The $D$. gallinae population in a forty week old flock without a treatment at a temperature of $25{ }^{\circ} \mathrm{C}$ was estimated to increase by $\left(e^{0.19+0.095}=1.33\right) 33 \%$ in one week.

The effect of compartment was age dependent and was estimated with $\pi_{1 j}$ (difference in linear effect of flock age post treatment compared with Compartment D) $=+6.88(95 \%$ Confidence Interval: $0.41,13.35)$ for Compartment $A,-6.55(-13.02,-0.082)$ for Compartment $B$ and -0.93 for Compartment $C(-7.4,5.54)$. The effect of flock age in Compartments $A$ and $B$ was significantly different $(\mathrm{P}<0.05)$. For example, the growth rate post treatment in Compartment $\mathrm{B}$ at a flock age of 40 weeks and at a temperature of $20^{\circ} \mathrm{C}$ was estimated to be $((-0.22+0.24)+(16.4-19.9-6.55) *(1 / 40)=-0.231$, compared with Compartment D. 
Including the random regression term in the model resulted in a significant model improvement $(\mathrm{p}<0.05)$ explaining $17.1 \%$ of the variation instead of $13.2 \%$ without the random regression term. This means that the systematic factors (flock age, temperature, and treatment) do not fully describe and explain the variation in the population growth rate. A substantial part of the variation is unexplained. Moreover, a part of the variation among flocks was temporal meaning that flocks had different slopes for the age effect as displayed graphically in Figure 6.6. The population growth rate of the first flock in Compartments A and $C$ cannot be seen as the level of mite infestation was almost always equal to zero. 

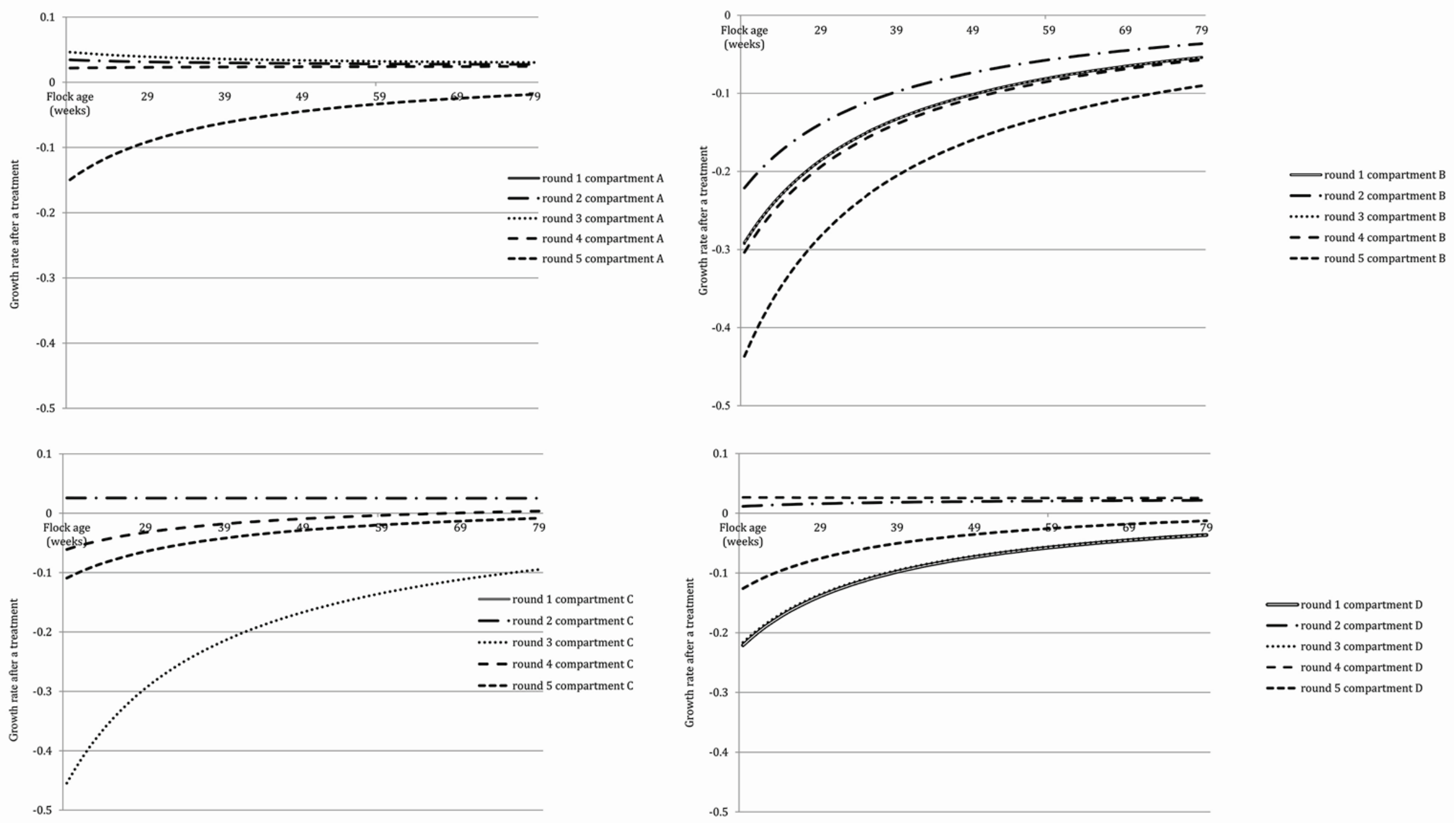

Cround 1 compartment D

- $\cdot$ round 2 compartment

...... round 3 compartment $D$

- - round 4 compartment D

--- round 5 compartment $D$

Figure 6.6 Population growth rate of Dermanyssus gallinae post treatment versus Flock age (weeks) per flock (flocks of Compartments A - D) of Dataset 1 


\section{Adaptive Population Model Development}

For estimating responses with unexplained temporal variations, as evidenced in the preceding section, a dynamic model was developed to forecast the growth rate of a $D$. gallinae population in any flock.

The mean (minimum and maximum) values of the time dependent estimation of the parameters $\left(\mathrm{C}_{\mathrm{t}}, \mathrm{C}_{\mathrm{t}}, \mathrm{C} 2_{\mathrm{t}}\right)$ in the developed dynamic adaptive population model were 0.05 $(-0.1,0.4)$ for the intercept $\left(\mathrm{C}_{\mathrm{t}}\right), 0.05(0.02,0.13)$ for temperature $\left(\mathrm{C}_{\mathrm{t}}\right)$, and $-0.07(-0.29$, 0.23 ) for treatment $\left(\mathrm{C}_{2} \mathrm{t}\right)$. The ranges of the values for treatment and the intercept were higher when compared with the values for temperature.

\section{Model demonstration}

The model forecast of the growth rate with Dataset 1 is shown in Appendix A6.5. The model enabled forecasting of D. gallinae population growth for all three housing systems. As an example, the forecast line for growth rate and the determined growth rate as measured with the MMS method is shown in Figure 6.7 for the fifth flock of Compartment D. At a flock age of 38 weeks, the effect of a treatment on mite population growth rate, as forecasted by the model, was lower than the measured effect. This is probably best explained by the effect of the posterior transferred from the end the fourth flock of Compartment D, with old laying hens, to the start of the fifth flock of Compartment D. With increasing flock age, the model adapted and improved. The measurement at a flock age of 33 weeks was considered as an outlier by the model, most likely as a result of the scale of the MMS method. Figure 6.8 shows the model forecast of the AMIL for the fifth flock of Compartment D. This figure shows that the outlier at a flock age of 33 weeks was the first measurement with a relative high increased growth rate compared to the growth rate prior to 33 weeks. The forecast of the model at the first measurement after 60 weeks was considerably different than the measured AMIL. 


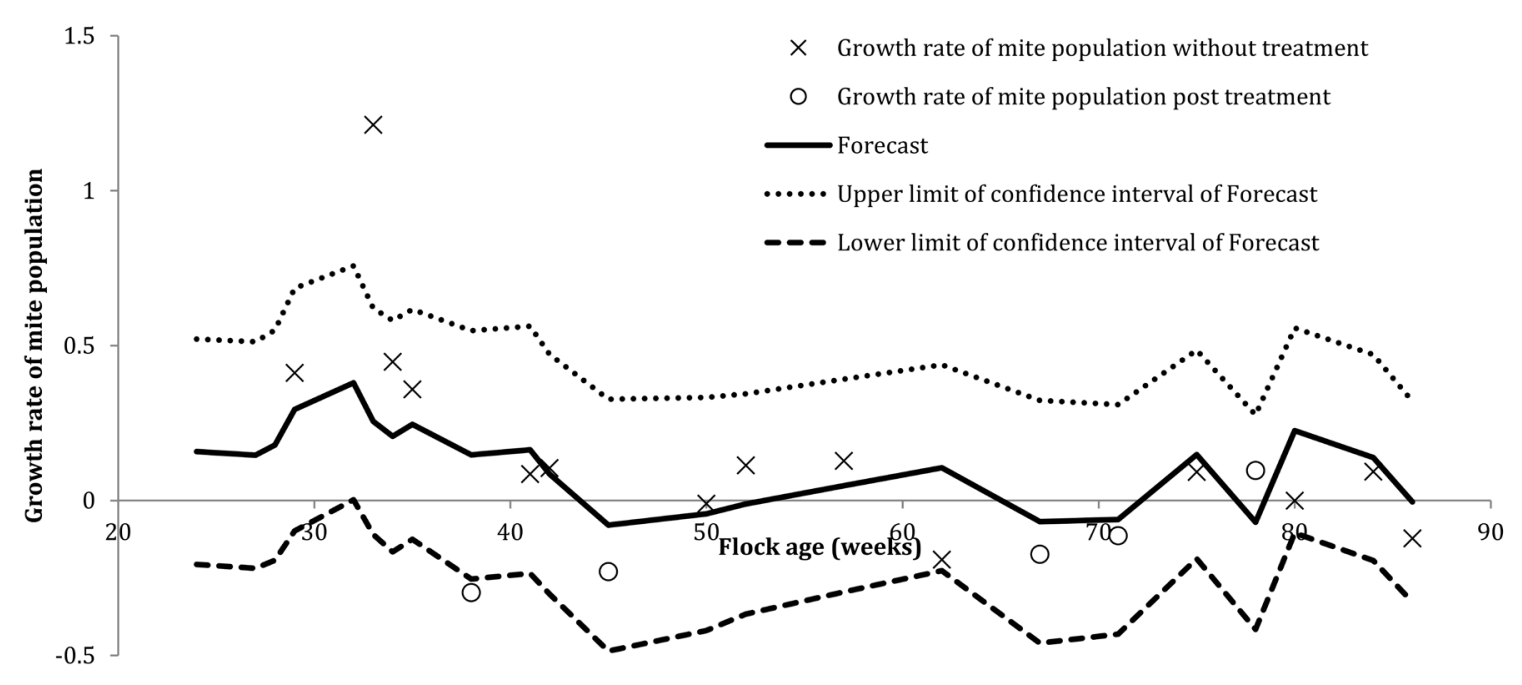

Figure 6.7 Model forecast (black solid line) of the population growth rate of Dermanyssus gallinae versus Flock age (weeks), determined with monitoring data from Compartment D of Dataset 1 during the fifth flock

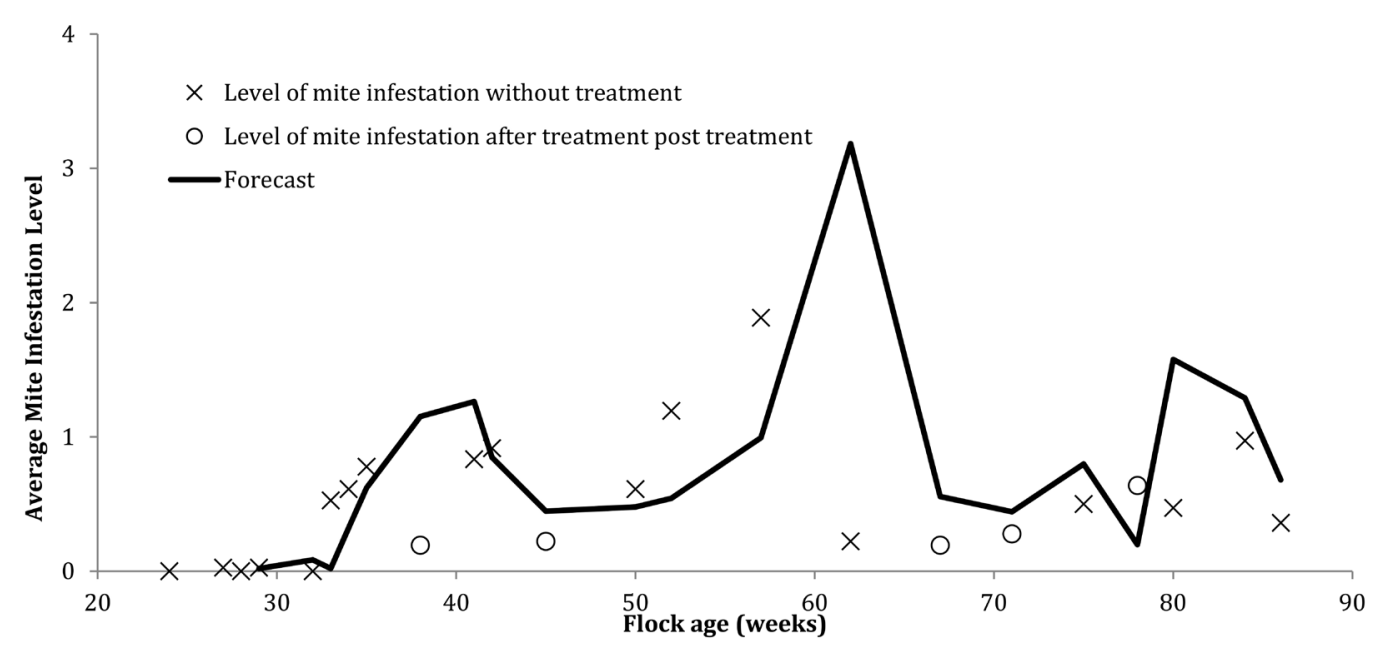

Figure 6.8 Model forecast of the average Dermanyssus gallinae infestation level (AMIL) (black solid line) versus Flock age (weeks), determined with monitoring data from Compartment D during the fifth flock of Dataset 1

The population dynamics model was able to forecast the mite population growth rate with Datasets 2 and 3, using data obtained from other methods aside from MMS (see Figures 6.9 and 6.10). In Figure 6.3, the model forecast with Dataset 2 is shown with the forecasted AMIL and the measured values. Figure 6.9 shows the model forecast of the population growth rate and the true values determined with Dataset 2. In Figure 6.4, the model forecast with Dataset 3 is shown with the forecasted AMIL and the measured values. Figure 6.10 shows the model forecast of the growth rate and the true values determined with Dataset 3. 
In Figure 6.9 the determined population growth rate and the forecast growth rate both show a positive growth until silica treatments were applied, which resulted in negative growth rates as would be expected. A sudden increase of the population growth was observed, but not forecast at a flock age of 75 weeks.

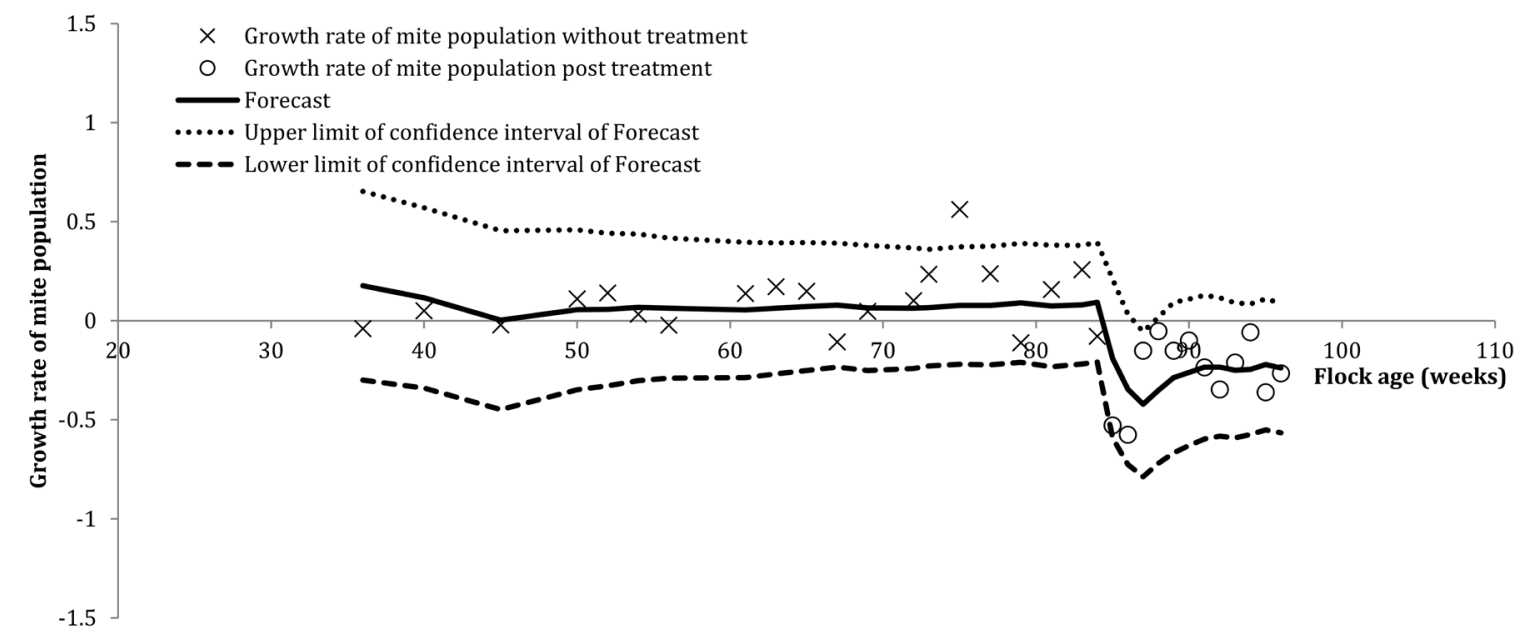

Figure 6.9 Model forecast (black solid line) of the growth rate of the Dermanyssus gallinae population versus Flock age (weeks) determined with Dataset 2

In Figure 6.10, the three outliers between a flock age of 30 weeks and 42 weeks, occurred in the period when the AMIL oscillated around zero. Small fluctuations around zero may result in bigger growth rate fluctuations compared to small fluctuations around two because of the nature of the growth rate calculation (equation (1)).

The population dynamics model of Datasets 2 and 3 showed highly comparable growth rates at a flock age of 96 weeks, being -0.265 and -0.270 respectively. 


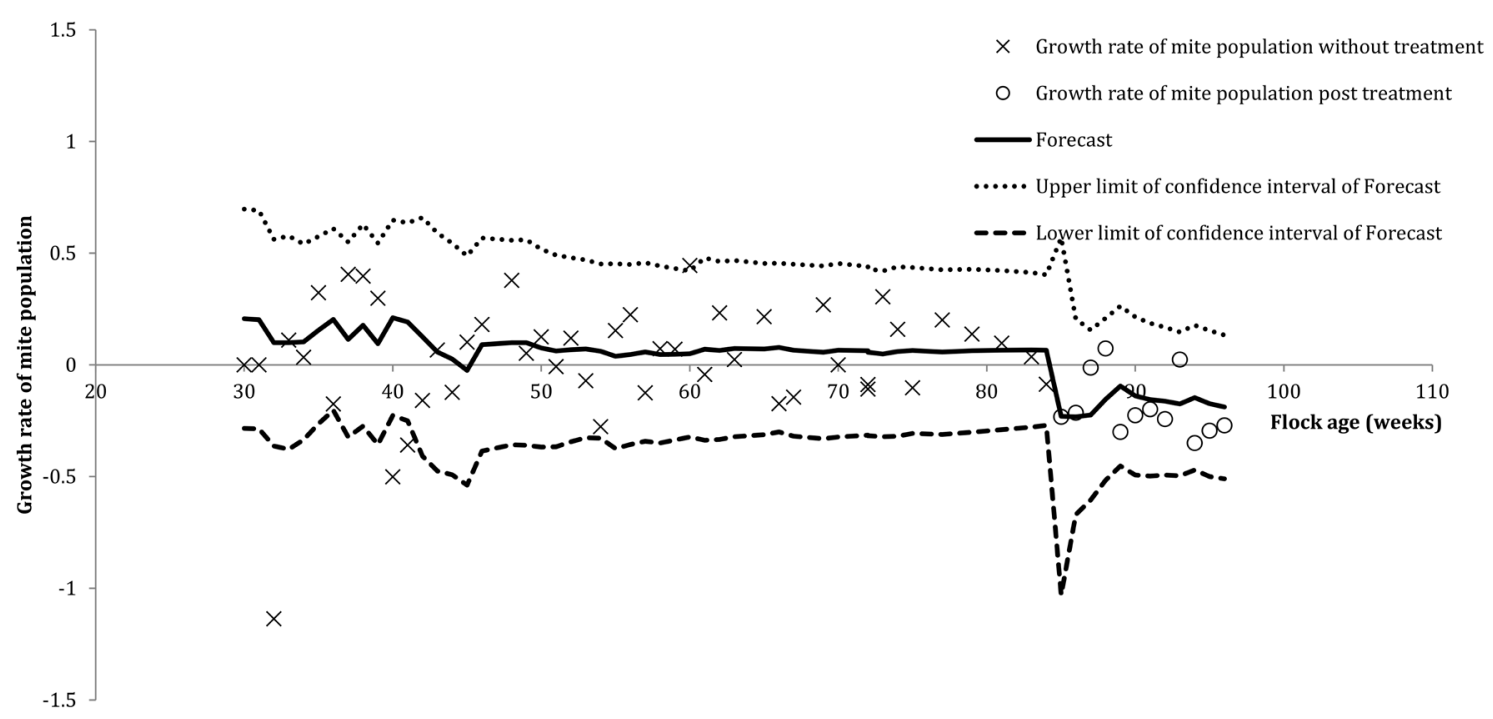

Figure 6.10 Model forecast (black solid line) of the growth rate of the Dermanyssus gallinae population versus Flock age (weeks) determined with Dataset 3

The prediction or forecast quality of the model is shown in Table 6.2 with all assessed MSPE of Dataset 1. The forecast quality of the model, expressed as MSPE excluding outliers, increased considerably from laying round 1 (Compartment A-D) to laying round 2 (Compartment A-D), as shown by a lower MSPE, but reached a steady state around 0.024.

Table 6.2 Forecast quality of the Dermanyssus gallinae population model, expressed as Mean Squared Prediction Error (MSPE) including and excluding outliers, assessed with Dataset 1

\begin{tabular}{llllll}
\hline $\begin{array}{l}\text { Laying } \\
\text { round }\end{array}$ & $\begin{array}{l}\text { Number of } \\
\text { records } \\
\text { (monitoring } \\
\text { data) }\end{array}$ & $\begin{array}{l}\text { Number of records } \\
\text { with information on } \\
\text { growth rate }\end{array}$ & $\begin{array}{l}\text { Number of } \\
\text { records } \\
\text { identified as } \\
\text { outlier }\end{array}$ & MSPE* & $\begin{array}{l}\text { MSPE, } \\
\text { excluding } \\
\text { outliers }\end{array}$ \\
\hline 1 & 228 & 61 & 2 & 0.154 & 0.130 \\
2 & 123 & 88 & 2 & 0.049 & 0.032 \\
3 & 106 & 54 & 9 & 0.094 & 0.024 \\
4 & 50 & 31 & 2 & 0.039 & 0.026 \\
5 & 81 & 54 & 4 & 0.063 & 0.024 \\
\hline
\end{tabular}

*Mean Squared Prediction Error

Table 6.3 shows the MSPE assessed with Dataset 2 and a reduced Dataset 3 . The reduced Dataset 3 includes data from dates which were available in both Dataset 2 and 3, and therefore excludes dates which were only available in Dataset 3. The difference between the assessed MSPE (excluding outliers) of Dataset 2 and 3 was not significant ( $p>0.05$ ). 
Table 6.3 Forecast quality of the population model, expressed as Mean Squared Prediction Error (MSPE), assessed with Dataset 2 and 3 with data from the same measuring dates

\begin{tabular}{llllll}
\hline $\begin{array}{l}\text { Monitoring } \\
\text { method }\end{array}$ & $\begin{array}{l}\text { Number of } \\
\text { records } \\
\text { (monitoring } \\
\text { data) }\end{array}$ & $\begin{array}{l}\text { Number of records } \\
\text { with information } \\
\text { on growth rate }\end{array}$ & $\begin{array}{l}\text { Number of } \\
\text { records } \\
\text { identified as } \\
\text { outlier }\end{array}$ & MSPE & $\begin{array}{l}\text { MSPE, } \\
\text { excluding } \\
\text { outliers** }\end{array}$ \\
\hline $\begin{array}{l}\text { Dataset 2 } \\
\text { (SAT) }\end{array}$ & 33 & 32 & 1 & 0.030 & 0.024 \\
$\begin{array}{l}\text { Dataset 3 } \\
\text { reduced* }\end{array}$ & $33^{*}$ & 33 & 0 & 0.016 & 0.016 \\
$\begin{array}{l}\text { (SPT) } \\
* \text { Dataset 3 without data from dates which were only available in Dataset 3 }\end{array}$ & & & \\
\hline
\end{tabular}

** Differences between dataset 2 and 3 were not significant $(\mathrm{p}>0.05)$ 


\section{Discussion}

The current study is the first revealing a high variation in the growth rate of D. gallinae populations in laying hen houses. Moreover, we are the first reporting that this high variation was partly explained by temperature, treatment, compartment and flock age. A substantial part of the total variation, however, was temporal and unexplained. This in mind, the model developed herein to forecast the population dynamics of D. gallinae in laying hen facilities utilised a dynamic adaptive approach, adjusting itself after each measurement to forecast the population dynamics of D. gallinae. The remainder of this section discusses the source of the variation of the mite population growth rate, as well as the development, assessment and possible improvements that could be made to the dynamic adaptive population model described. In addition, we discuss the requirements of the model developed that, if satisfied, would optimise its contribution to the implementation of improved IPM for D. gallinae in laying hen facilities.

To develop the dynamic adaptive population model described, and to acquire an indication on the source of the high variation observed, all monitoring data was converted to 'growth rate'. The growth rate expresses relative increase or decrease of the mite population per week, assuming exponential growth in periods without treatment. Density independent growth rate was also assumed in practice; no correlation between 'growth rate' and 'AMIL' was found in Dataset 1 (correlation coefficient $=0.01$ ), confirming that growth rate was independent from the mite infestation level. The model described also assumed that monitoring of the mite population starts at the beginning of the flock, and that treatment applied prevent the mite population reaching a steady state.

The growth rate post-treatment of the mite population from Dataset 1 was estimated using a linear random regression model, also called a mixed model. The results of the model suggest that with increasing age of the hens, the growth rate of the mite population gradually declines, even without treatment. This effect can also be seen in data published elsewhere. Arkle et al. (2004), for example, observed declining D. gallinae populations from the start of a trial with laying hens of 52 weeks of age. Other work reports fluctuations in mite numbers (Nordenfors et al. 2001; Chirico and Tauson 2002), or declines after treatment (Meyer-Kühling et al. 2007: George et al. 2010). More mite monitoring data from flocks older than 40 weeks may confirm the observed effect of flock age on population size, and is a worthy area for future research. It is perhaps plausible that the laying hens immunological reaction to D. gallinae may contribute this effect (Arkle et al. 2006; Harrington et al. 2010), regardless of any treatment, though this hypothesis remains to be explored. The accumulation of dust and debris in laying hen houses over time, hampering the efficacy of acaricides due to absorption and/or reduced adherence to surfaces, could similarly explain reduced efficacy of treatment with flock age (Maurer and Perler 2006; Kipinen and Steenberg 2009).

The effect of temperature on the growth rate of a D. gallinae population was found to be 0.019 , meaning that with every temperature increase or decrease starting from $20^{\circ} \mathrm{C}$, the 
growth rate of the mite population respectively increases or decreases. This higher growth rate with increasing temperature is in agreement with the findings of Maurer and Baumgärtner (1992), Nordenfors et al. (1999) and Tucci et al. (2008). However, Maurer and Baumgärtner (1992) and Tucci et al. (2008) both suggest maximum growth or lifecycle development at temperatures higher than $30^{\circ} \mathrm{C}$. Monitoring data at such high temperatures was not available in Dataset 1; indeed, the operational accuracy of the mixed model used remains to be confirmed outside the temperature range of $14.2-26.8^{\circ} \mathrm{C}$.

The effect of compartment was found to be age dependent. Furthermore a significant difference of this effect was determined between Compartments A and B with Compartment $B$ having a larger reduction in population growth rate after a treament when compared to Compartment A. The staff from the Experimental Poultry Centre in Geel (Belgium) with the four compartments, could not explain the difference as the management measures in all compartments were the same.

With the mixed model used, the residual effects of treatment on D. gallinae population responses could for 17.1 percent be explained by flock age, temperature, treatment and compartment; a substantial part of the population growth rate variation could not be explained. The effect of management measures, and possibly the measurement error of the monitoring method, were potentially responsible for at least part of this unexplained variation. Unexplained temporal variation of the residual effects, will limit accurate forecasting of the population growth rate via a model with fixed effects as such a model will exclude flock specific effects. With an adaptive model, however, such flock specific effects are, with increasing flock data, increasingly incorporated in the forecasting. Examples of such adaptive models are models with a Kalman filter (Harvey 1989), or dynamic adaptive models (West and Harrison 1997). To illustrate that the forecasting quality is limited with a model with fixed effects compared to an adaptive model, the quality of the forecast of the adaptive model was compared with a simple regression model with a fixed temperature and treatment effect. The fixed effects were estimated with data from the third flock in all compartments of Dataset 1 and subsequently used to forecast the growth rate in laying round four. The MSPE of the simple regression model was 0.051 and thus an increase in MSPE of 32\% compared with the MSPE of the adaptive model (0.0386). As the MSPE was determined with the same dataset, an increase in the measurement bias was avoided and the increase of the MSPE could only be explained by an increased model bias. We may therefore conclude that in this case the dynamic model has a better forecasting quality when compared to the simple regression model.

In the developed adaptive population model, the population growth rate followed a linear response to housing temperature and treatment effect. The effect of temperature in the adaptive population model was found to be higher when compared to the temperature effect in the linear random regression model. A possible explanation for this may be the posterior input in the adaptive model. However, this could not be confirmed with temperature effects fluctuating between compartments and flocks from 0.0198 to 0.076 . The difference in 
handling correlations of information between the two types of models, e.g. correlation of higher temperatures and occurrence of treatment, may be another explanation for the difference in temperature effect observed.

The determined MSPE showed a significant reduction for the second laying round compared with the first, which may have resulted from the priors for the parameter values being theory-based at the start of the first laying round. During this first laying round, these parameter values were adapted by the model to more suitable parameters, resulting in lower MSPE. After the first laying round, the MSPE is more likely to reflect flock dependent measurement errors (accuracy) of the monitoring method and could be partially explained by a lack of fit of the model. It can be expected that monitoring techniques employing a scale method would be less sensitive and less temporally robust than count methods. Nevertheless, this was not supported when comparing the determined MSPE using Dataset 2 (counts) to the determined MSPE using Dataset 3 (scale). It should be noted, however, that the scale in Dataset 3 was clearly defined and dependent on counts $(0,<10,>10$, clusters $(=$ uncountable)), possibly resulting in higher interrater reliability and agreement (Kottner et al. 2011) than the MMS method.

Improvements of the model forecast may be achieved by including extra model parameters (e.g. flock age or management measures). As mentioned previously, in Figure 6.8 an unexpected decline was shown at the first measurement after reaching a flock age of 60 weeks. This decline followed mechanical cleaning of nest pads to remove D. gallinae, which was not considered as a treatment, but rather as a general husbandry measure to reduce the mite population. Incorporating such husbandry measures into the model may improve its forecasting quality. Additionally, a correction for hen age may also result in model improvement, particularly considering the reduction of treatment effect with increasing hen age described herein. Modifying the estimated treatment effect at the end of the laying round for age effect, to have better priors for the next laying round at the Experimental Poultry Centre in Geel, resulted in an improvement of the forecast quality for the first treatments in a laying round (data not shown). This age effect, however, was not included in the adaptive model, as this model should be generic. Furthermore, additional variables could improve model forecast accuracy for a specific farm, they would need to be carefully selected and included with caution, if at all. Including additional variables is not recommended as with increasing numbers of variables in a dynamic adaptive model, the stability of the model decreases (as the model determines all variances and covariance's for all parameters).

The current work confirms that monitoring methods based on either scales or counts are compatible with the dynamic adaptive model developed to forecast the population dynamics of D. gallinae in a layer house. Further improvement of the models forecasting quality may occur with more frequent monitoring, but achieving this via manual assessment would necessitate a significant increase in labour. The use of an automated monitoring device (Mul 
et al. 2015), however, could permit regular (e.g. daily) assessment of population levels to improve model forecasting without requiring additional labour input.

The dynamic adaptive model described has the potential to contribute to improved IPM for D. gallinae. As shown in the results presented, the dynamic adaptive model used was able to satisfactorily forecast the population dynamics and response to treatment of D. gallinae given only three easily obtainable input parameters: monitoring data, layer house temperature and treatment date. Furthermore, the model functioned equally well given data from different monitoring methods utilising both infestation classes and count data, also correcting for location specific interactions. Moreover, the model was able to handle time dependent and highly variable factors, e.g. different types of laying hens, feed, climates, management and treatment regimes. Therefore, most requirements for practical models for advancing improved IPM programmes or the required input are fulfilled with this model.

In order to further improve the model described for use on-farm, future developments are already being researched by the authors. These include the development of a population dynamics model able to forecast in 4D (time and three dimensions of the laying hen facility) as well as a treatment advice module. This $4 \mathrm{D}$ model should be able to forecast the population dynamics of pest 'hot spots' and thus advise on localised treatments. The treatment advice module will incorporate the forecast of the population dynamics model and production outputs of the laying hens (e.g. number of eggs, egg weight, egg quality, feed conversion) in order to determine the exact moment when the economic threshold will be exceeded. The treatment advice delivered to farmers will be based on this economic threshold, fulfilling another key requirement of IPM programmes.

\section{Conclusion}

The population growth rate of D. gallinae could partly be explained by temperature, flock age, treatment and compartment. A substantial part of the total variation in mite population growth is temporal and unexplained, thus supporting a dynamic approach to forecast population development. A dynamic adaptive model was therefore developed to forecast a $D$. gallinae population in any laying hen house using only frequently measured population monitoring data, indoor temperature data and date of treatment application. The model was able to forecast the population dynamics of D. gallinae and growth rate post-treatment and without treatment compensating for location (laying hen house) and time specific interactions (e.g. temperature, management), and coped with the variability of the parameters of interest (e.g. variation in growth rate after a treatment). This in mind, and with its ability to work with data obtained using different monitoring methods, the developed model could contribute to adopting improved Integrated Pest Management for $D$. gallinae in laying hen facilities. 


\section{Acknowledgement}

This research was funded by the Dutch Product Board for Poultry and Eggs and the Dutch Ministry of Economic Affairs within the framework of the public-private collaboration project 'Poultry4Food' (TKI-AF-12048). We are grateful to Izak Vermeij (Wageningen University and Research Livestock Research), Hugo Bens (layer farmer), Peter van Horne (LEI Wageningen University and Research), Committee "Aanpak bloedluis", Ellen Vervaet (Experimental Poultry Centre, Geel, Belgium), Geoffrey Chiron, Solange Same and Arthur Varescon (ITAVI) for their knowledgeable contribution to this research. The authors would like to acknowledge networking support by the COST Action FA1404.

Monique Mul and Johan van Riel contributed equally to this article. 


\section{References}

André G, Berentsen PBM, Duinkerken G van, Engel B, Oude Lansink AGJM (2010) Economic potential of individual variation in milk yield response to concentrate intake of dairy cows. J Agr Sci 148: 263-276

Anonymous (2006) Genstat Release 9 Reference Manual. VSN International, Hemel Hempsted, UK

Anonymous (2010) Klimaatplatform Pluimveehouderij. Leghennen volièrestal. http://www.wageningenur.nl/upload_mm/b/a/6/7e1c04a9-a6ca-4059-a506-

fb7f0481126d_Klimaatrichtlijnen\%20leghennen\%20voliere\%20okt\%202010.pdf_(31-2015)

Arkle S, Guy JH, Blackett SM, Sparagano O (2004) Variation in the population of Dermanysssus gallinae in a free range laying unit and effectiveness of chemical control. 2004 Spring Meeting of the WPSA UK Branch Posters, Br Poult Sci 45 sup 1: S45-S46

Arkle S, Guy JH, Sparagano O (2006) Immunological effects and productivity variation of red mite (Dermanyssus gallinae) on laying hens-implications for egg production and quality. World Poult Sci J 62: 249-257

Axtell RC, Arends JJ (1990) Ecology and management of arthropod pests of poultry. Annu Rev Entomol 35: 101-126

Benbrook CM, Groth E, Halloran JM, Hansen MK, Marquardt S (1996) Pest management at the crossroads. Consumers Union, Yonkers, New York

Cafiero MA, Galante D, Camarda A, Giangaspero A, Sparagano O (2011) Why dermanyssosis should be listed as an occupational hazard. Occup Environ Med 68: 628

Chauve CM (1998) The poultry red mite Dermanyssus gallinae (De Geer, 1778) : current situation and future prospects for control. Vet Parasitol 79: 239-245

Chirico J, Tauson R (2002) Traps containing acaricides for the control of Dermanyssus gallinae. Vet Parasitol 110: 109-116

Chiron G, Varescon A, Lubac S, Bicout DJ, Roy L (2014) Méthode d'aide à la prise de décision de traitement contre Dermanyssus gallinae (pou rouge) en élevage de ponte. TeMA 32 : 27-34

Cox M, De Baere K, Vervaet E, Zoons J, Fiks-Van Niekerk T (2009) Red mites: monitoring method and treatment. In: Book of Abstracts 8th European Symposium on Poultry Welfare, Cervia, Italy, 18-22 May: 83

Dent D (1995) Integrated pest management. First ed., Chapman and Hall, London, UK, 356 $\mathrm{pp}$

Dent D (2000) Insect pest management. Second ed., CABI Bioscience, Ascot, UK, 410 pp.

Dively G (2015) Integrated pest management overview.

http://extension.udel.edu/ag/insect-management/mid-atlantic-cca-information-andtraining/integrated-pest-management-overview/

Edelstein-Keshet L (1988) Mathematical models in biology. First Edition, McGraw-Hill, Inc., New York 
George DR, Shiel RS, Appleby WGC, Knox A, Guy JH (2010) In vitro and in vivo acaricidal activity and residual toxicity of spinosad to the poultry red mite, Dermanyssus gallinae. Vet Parasitol 173: 307-316

George DR, Finn RD, Graham KM, Mul MF, Maurer V, Moro CV, Sparagano OAE (2015) Should the poultry red mite Dermanyssus gallinae be of wider concern for veterinary and medical science? Parasit Vectors 8: 178

Harrington D, Robinson K, Guy J, Sparagano $O$ (2010) Characterization of the Immunological Response to Dermanyssus gallinae Infestation in Domestic Fowl. Transbound Emerg Dis 57: 107-110

Harrington DWJ, George DR, Guy JH, Sparagano OAE (2011) Opportunities for integrated pest management to control the poultry red mite, Dermanyssus gallinae. World Poult Sci J 67: 83-93

Harvey AC (1989) Forecasting, structural time series models and the Kalman filter. Cambridge University Press, Cambridge UK, 554 pp

Huber K, Zenner L, Bicout DJ (2011) Modelling population dynamics and response to management options in the poultry red mite Dermanyssus gallinae (Acari: Dermanyssidae). Vet Parasitol 176: 65-73

Kilpinen 0, Steenberg $\mathrm{T}$ (2009) Inert dusts and their effects on the poultry red mite (Dermanyssus gallinae). Exp Appl Acarol 48: 51-62

Kilpinen O, Roepstorff A, Permin A, Nørgaard-Nielsen G, Lawson LG, Simonsen HB (2005) Influence of Dermanyssus gallinae and Ascaridia galli infections on behaviour and health of lying hens (Gallus gallus domesticus). Br Poult Sci 45: 26-34

Kogan M (1998) Integrated Pest Management: Historical perspectives and contemporary developments. Ann Rev Entomol 43: 243-270

Kottner J, Audigé L, Brorson S, Donner A, Gajewski BJ, Hróbjartsson A, Roberts C, Shoukri M, Streiner DL (2011) Guidelines for reporting reliability and agreement Studies (GRRAS) were proposed. J Clin Epidemiol 64: 96-106

Legg DE (2004) The relevance of modelling in successful implementation of IPM. In: Koul 0, Dhaliwal GS, Cuperus GW(Eds.), Integrated pest management: Potential, constraints and challenges. CABI Publishing: 39-54

Maurer V, Bieri M, Fölsch DW (1988) Das suchverhalten von Dermanyssus gallinae in hühnerställen. Arch Geflügelk 52 (5) 209-215

Maurer V, Baumgärtner J (1992) Temperature influence on life table statistics of the chicken mite Dermanyssus gallinae (Acari: Dermanyssidae). Exp Appl Acarol 15: 27-40

Maurer V, Baumgärtner J (1994) A population model for Dermanyssus gallinae (Acari: Dermanyssidae). Exp Appl Acarol 18: 409-422

Maurer V, Perler E (2006) Silicas for control of the poultry red mite Dermanyssus gallinae. In: Proc Joint Organic Congress, Odense, May 30-31: 504-505 
Meyer-Kühling B, Heine J, Müller-Lindloff J, Pfister K (2007) Epidemiology of Dermanyssus gallinae and acaricidal efficacy of phoxim 50\% in alternative housing systems during the laying period of hens. Parasitol Res 101: S1-S12

Mul M, Niekerk T van, Chirico J, Maurer V, Kilpinen O, Sparagano O, Thind B, Zoons J, Moore D, Bell B, Gjevre A-G, Chauve C (2009) Control methods for Dermanyssus gallinae in systems for laying hens: results of an international seminar. World Poult Sci J 6: 589600

Mul MF, Van Riel JW, Meerburg BG, Dicke M, George DR, Groot Koerkamp PWG (2015) Validation of an automated mite counter for Dermanyssus gallinae in experimental laying hen cages. Exp App Acarol 66: 589-603

Mul MF, Ploegaert JPM, George DR, Meerburg BG, Dicke M, Groot Koerkamp PWG (2016) Structured design of an automated monitoring tool for pest species. Biosyst Eng 151: 126-140

Nordenfors H, Höglund J, Uggla A (1999) Effects of temperature and humidity on oviposition, molting, and longevity of Dermanyssus gallinae (Acari: Dermanyssidae). J Med Entomol 36: $68-72$

Nordenfors H, Höglund J, Tauson R, Chirico J (2001) Effect of permethrin impregnated plastic strips on Dermanyssus gallinae in loose-housing systems for laying hens. Vet Parasitol 102: 121-131

Radcliffe EB, Hutchinson WB, Cancelado RE (2015) Radcliffe's IPM world textbook, URL http://IPMworld.umn.edu, University of Minnesota, St. Paul, MN

Roy L, Chiron G, Lubac S, Bicout DJ (2014) Tape-traps as an easy-to-use tool for monitoring and surveillance of the poultry red mite in cage and free-range layer farms. XIVth European Poultry Conference, Stavanger (Norway), June 23-27th 2014

Searle SR, Cassella G, McCullouch CE (1992) Variance components. Wiley, New York

Sikes RK, Chamberlain RW (1954) Laboratory observations on three species of bird mites. J Parasitol 40: 691-697

Sparagano OAE, George DR, Harrington DWJ, Giangaspero A (2014) Significance and control of poultry red mite, Dermanyssus gallinae. Ann Rev Entomol 59: 447-466

Tucci EC, Prado AP, Araújo RP (2008) Development of Dermanyssus gallinae (Acari: Dermanyssidae) at different temperatures. Vet Parasitol 155: 127-132

Van Emous RA, Fiks-van Niekerk TGCM, Mul MF (2005) E11 miljoen schade voor de sector: enquete vogelmijten op leghennenbedrijven. (€ 11 million damage for the sector: enquiry into the cost of mites to the poultry industry (In Dutch). De pluimveehouderij 35: 8-9

Valiente Moro C, Fravalo P, Amelot M, Chauve C, Zenner L, Salvat G (2007a) Colonization and organ invasion in chicks experimentally infected with Dermanyssus gallinae contaminated by Salmonella Enteritidis. Avian Pathol 36: 307-311

Valiente Moro C, Chauve C, Zenner L (2007b) Experimental infection of Salmonella Enteritidis by the poultry red mite, Dermanyssus gallinae. Vet Parasit 146: 329-336 
Valiente Moro C, Luna CJ de, Tod A, Guy JH, Sparagano OAE, Zenner L (2009) The poultry red mite (Dermanyssus gallinae): a potential vector of pathogenic agents. Exp Appl Acarol 48: 93-104

West M, Harrison J (1997) Bayesian forecasting and dynamic models. Second Edition, Springer-verlag, New York 


\section{Appendix 6}

\section{A6.1 Insight into variation in D. gallinae population growth}

The effects of a) housing, b) temperature and c) age of the flock of hens (flock age) on mite population growth rate were determined using available growth rate records from Dataset 1. Growth rates were analysed with a linear random regression model (REML), using the statistical software package GenStat for Windows (17th edition 2015) (Anonymous, 2006). Parameters were estimated by REML (Searle et al. 1992).

The linear random regression model used was:

$$
\underline{R}_{i j k}=\left\{\beta_{0}+\pi_{0 j}+\alpha_{0 k}+\underline{\varepsilon}_{0 i j}\right\}+\left\{\beta_{1}+\pi_{1 j}+\alpha_{1 k}+\underline{\varepsilon}_{1 i j}\right\} * A^{-1}+\beta_{2} *(T-20)+\underline{\varepsilon}_{i t}
$$

where: $\underline{R}_{i j k}=$ weekly growth rate of flock (or laying round) $i$ of Compartment $j$ after a treatment $k(0,1)\left(\ln \left(\right.\right.$ AMIL)/week); $A^{-1}=$ inverse of flock age of hens (in weeks); $T=$ compartment temperature (in Celsius); $\beta_{0}, \beta_{1}=$ intercept and slope of effect of $\frac{1}{\text { flock age }}$ for Compartment A when no treatment was applied; $\pi_{0 j}, \pi_{1 j}=$ Difference in intercept and slope of effect of flock age ${ }^{-1}$ for other compartments (compared to D); $\alpha_{0 j}, \alpha_{1 j}=$ difference in intercept and linear effect when treatment if applied compared to when treatment is not applied; $\beta_{2}=$ effect of temperature; $\underline{\varepsilon}_{0 i j}, \underline{\varepsilon}_{1 i j}=$ random effect (or difference in) of flock (or laying round) $i$ of Compartment $j$ for intercept and slope of effect of $\frac{1}{\text { flock age }}, \underline{\varepsilon}_{i t}=$ residual at week $t$, representing residual variation.

In the final model $\pi_{0}$ was omitted because it did not significantly contribute to the model. 


\section{A6.2 Development of the Population Dynamics Model}

The general univariate dynamic linear model (DLM) is written as:

Observation Equation: $R_{t}=F_{t}^{\prime} \theta_{t}+v_{t} \quad v_{t} \sim N\left(0, V_{t}\right)$

System Equation: $\theta_{t}=G_{t} \theta_{t-1}+\omega_{t} \quad \omega_{t} \sim N\left(0, W_{t}\right)$

In this notation $F_{t}$ is the set of regression vectors, meaning the information of a record being post-treatment ( 0 or 1$)$ and the average temperature of the housing between week $t$ and week t-1. $\theta_{t}$ is the set of time-dependent parameter estimates for the effects of treatment and temperature, where $v_{t}$ is the random observational error at week t. $G_{t}$ is a matrix of known coefficients (set of discount factors) that defines the systematic evolution of parameter estimates across time. $\omega_{t}$ represents purely random, unpredictable changes of the parameter estimates. $v_{t}$ and $\omega_{t}$ are independent.

In the developed adaptive model (DLM), it was assumed that the growth rate $\left(R_{t}\right)$ of equation 3 is a linear response to housing temperature $\left(T_{t}\right)$ and treatment effect $\left(D_{t}\right)$ :

$\mathrm{R}_{\mathrm{t}}=\mathrm{C} 0_{\mathrm{t}}+\mathrm{C} 1_{\mathrm{t}}^{*}\left(\mathrm{~T}_{\mathrm{t}}-20\right)+\mathrm{C} 2_{\mathrm{t}}^{*} \mathrm{D}_{\mathrm{t}}$

where: $\mathrm{C}_{\mathrm{t}}=$ the intercept or base level (growth rate at indoor temperature of $20^{\circ} \mathrm{C}$, without treatment); $\mathrm{C} 1_{\mathrm{t}}=$ the linear effect of temperature; $\mathrm{C} 2 \mathrm{t}=$ the treatment effect.

The growth rate, $\mathrm{Rt}$, was implemented in the regression vector $\left(\mathrm{F}^{\prime}\right)$.

Before the first data record was applied into the model, prior information (priors) was incorporated. The structure, the matrix of known coefficients and the initial parameters of the dynamic adaptive population model were derived using the data from laying round 1, Dataset 1. Final estimated parameters (posteriors) of the former laying rounds were used as prior values for the next laying round within the same compartment. The influence of the set priors was less in laying rounds 2-5 when compared to the first laying round. Therefore, parameters (temperature at $20{ }^{\circ} \mathrm{C}$, growth rate post treatment and intercept (growth rate without treatment at a temperature of $20^{\circ} \mathrm{C}$ )) were estimated for laying rounds $2-5$ only for all compartments of Dataset 1.

The correlations of the parameters for treatment effect and temperature $\left(\omega_{t}\right)$ were set at 0 at the start of the first laying round. After five laying rounds, the correlations of parameter estimates were determined for all four compartments. These parameter estimates provided the correlations for the model as used with Datasets 2 and 3. 
The MSPE was calculated as:

$M S P E=\frac{1}{n} \sum_{i=1}^{n}(\hat{Y} i-Y i)^{2}$

where: $\hat{Y}=$ the forecasted growth rate (in week i). This growth rate was generated by the model after input of monitoring data into the model; $\mathrm{Y}=$ the measured growth rate. 
A6.4 Population dynamics per flock of Database 1

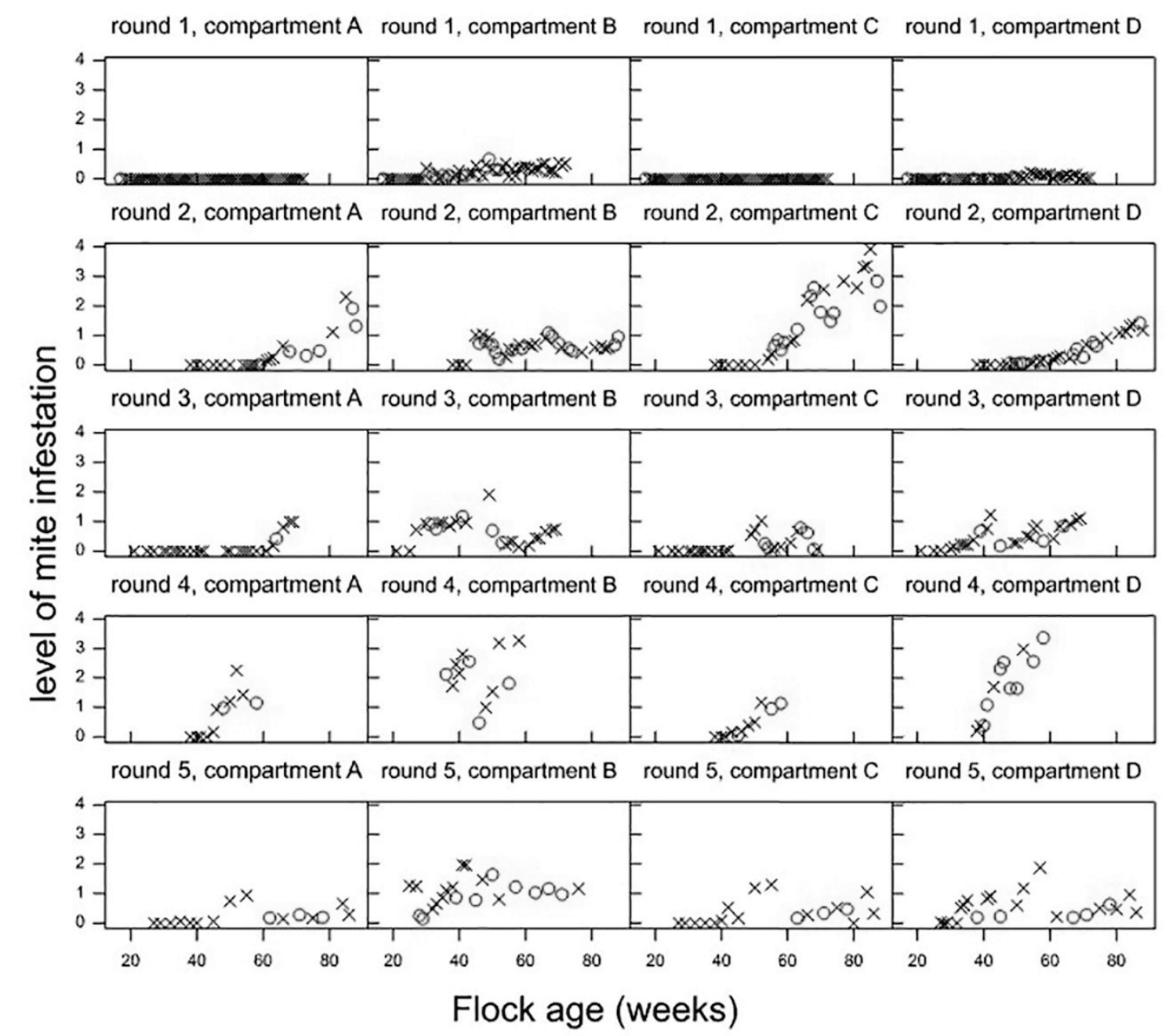

Figure A6.1 The population dynamics in the four different laying compartment during five flocks in Database 1 with the average mite infestation level (AMIL) of the 36 measuring points per monitoring date versus Flock age (weeks).

$\mathrm{x}$ : level of mite infestation without treatment

o: level of mite infestation post treatment 
A6.5 Forecasted population dynamics per flock of Database 1

round 1, compartment $A$ round 1, compartment $B$ round 1, compartment $C$ round 1, compartment $D$

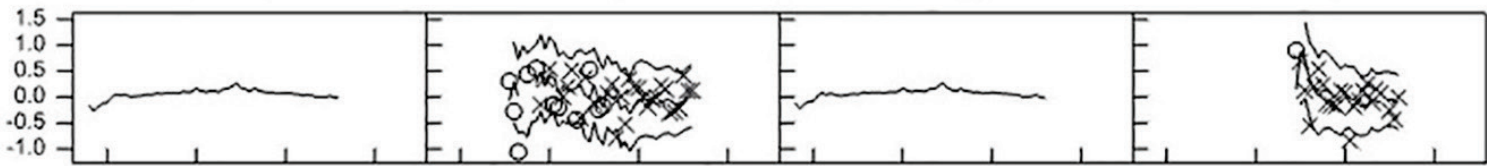

round 2, compartment A round 2, compartment B round 2, compartment C round 2, compartment D

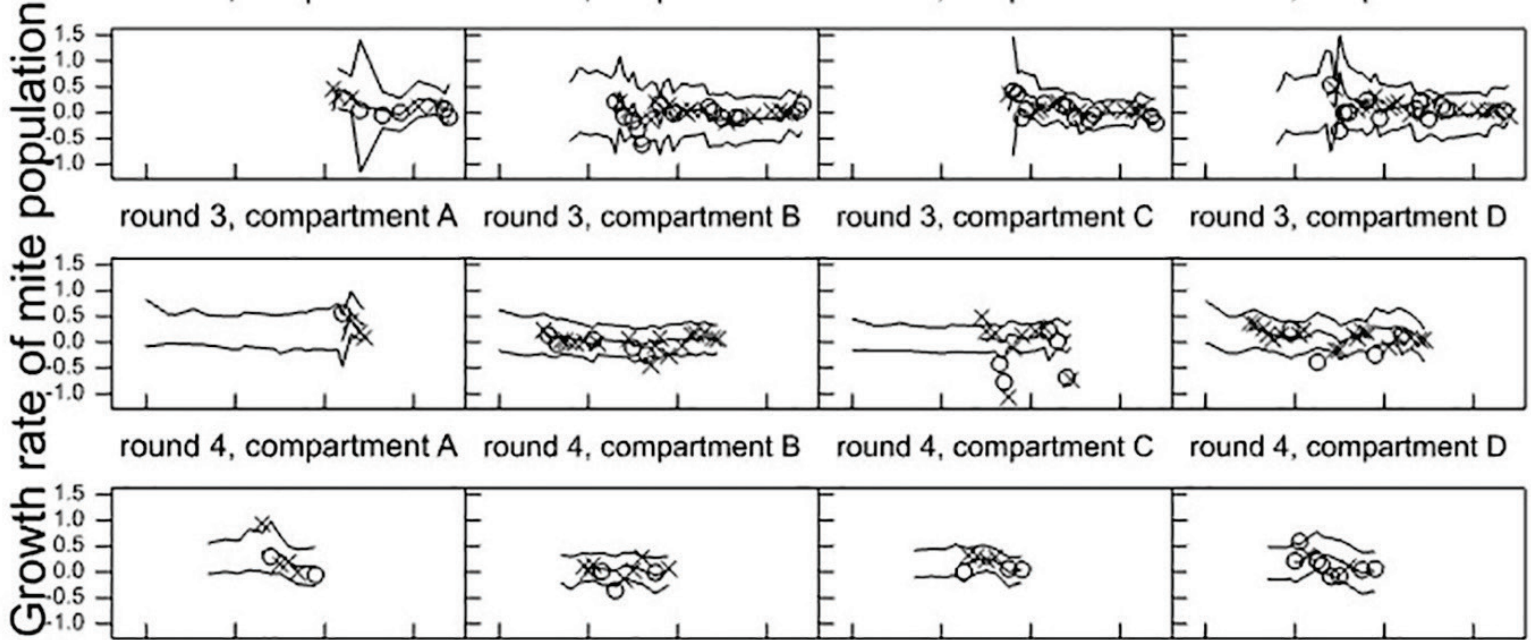

round 5, compartment A round 5, compartment B round 5, compartment $C$ round 5, compartment $D$

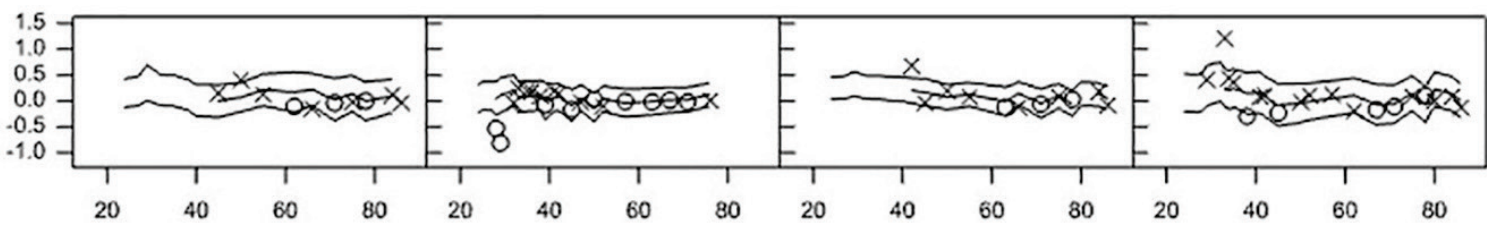

Flock age (weeks)

Figure A6.2 The growth rate forecast determined by the population dynamics model and the determined average mite infestation level of the 36 measuring points per monitoring date versus Flock age (weeks) in the four different laying compartment during five flock of Database 1.

$\mathrm{x}$ : growth rate of mite population without treatment,

O: growth rate of mite population post treatment.

Lines shown depict the model forecast (middle line), and the upper and lower level of the $95 \%$ confidence interval 


\section{Chapter 7}

General discussion 


\section{Introduction}

Infestations of the poultry red mite Dermanyssus gallinae, the most common ectoparasite in laying hen facilities worldwide, result in reduced hen health and welfare and can result in severe economic losses to the egg production industry (Chauve 1998, Van Emous et al. 2005). Successful control of this pest is hampered by the mites lifestyle; they reside in cracks and crevices in the neighbourhood of the hen and only spend one hour every few days outside these refuges to feed on hens (Maurer et al. 1988). It is only during this short window that the mites may come into contact with standard contact acaricides that are applied to control them. Post-treatment, however, most mites will not encounter such products because of the limited residual activities of currently authorized acaricides. Moreover, D. gallinae have developed resistance to multiple chemical acaricides, further limiting the effect of treatments (Chauve 1988; Nordenfors et al. 2001). Other products against D. gallinae have been withdrawn from the market due to stricter legislation (Sparagano et al. 2014a). With the above in mind, it can be concluded that use of 'conventional' acaricides is unlikely to be a sustainable solution to D. gallinae control, underlining the need to develop alternative control measures. Integrated Pest Management (IPM) has proven to be an effective tool for combatting numerous other pests, incorporating the use of pesticides only as a last resort and avoiding the use of ecologically disruptive products (Benbrook et al. 1996). More rigorous IPM programmes for D. gallinae have been suggested (Arends and Robertson 1986; Axtell and Arends 1990; Axtel 1999; Harrington et al. 2011, Sparagano et al. 2014b), though implementation of IPM for D. gallinae has remained restricted to a combination of limited preventive measures and the use of acaricides or similar treatments.

The main aim of the research described in this thesis was to further our understanding of D. gallinae and develop methods and tools to contribute to more advanced IPM programmes for this pest in laying hen facilities. With prevention and monitoring being key to IPM programmes, these were selected as focal areas for research. I first assessed the most up to date knowledge on the biology of $D$. gallinae, the negative effects of this pest in laying hen facilities and the available and the most promising control methods for D. gallinae (Chapter 2). In achieving its main aim, the research conducted has generated knowledge and developed methods to:

1) Better prevent or suppress D. gallinae in laying hen facilities (Chapter 3),

2) Design (Chapter 4) a monitoring tool including an automated mite detection sensor and validate (Chapter 5) the designed and developed sensor for continuous monitoring of $D$. gallinae, and

3) Predict D. gallinae population dynamics and treatment efficacy in laying hen facilities, for facilitating decision making based on monitoring and thresholds and for evaluation of preventive and curative measures (Chapter 6). 


\section{Main research findings}

The main research findings, as detailed in Chapters 2 to 6 in this thesis, are described in brief below.

\section{Knowledge assessment}

Chapter 2 describes the available knowledge on D. gallinae found in the literature and collected during a seminar with European researchers actively involved in D. gallinae research. The seminar enabled collection of unpublished knowledge from D. gallinae experts. Participants of the seminar concluded that more knowledge is required on the biology and negative effects of $D$. gallinae in laying hen facilities. Monitoring was found to be an 'important instrument in recognising and admitting the problem by the egg production industry and in taking timely measures'. Further, it was concluded that the number of available and legal acaricides has declined quickly in European countries. Available control methods for D. galline at that time were silica, heating up the hen house in combination with a chemical treatment and enforcing biosecurity measures. The most promising future control methods were thought to be entomopathogenic fungi, vaccination, and predatory mites, which are discussed in more detail later. Furthermore, it was concluded that integration of knowledge from different research fields may help to identify new methods for better control of D. gallinae. The above summarized findings gave insight into promising directions for further research to facilitate the implementation of advanced IPM programmes for D. gallinae in laying hen facilities. Moreover, the pre-existing and newly generated knowledge obtained through this activity contributed to the further aims of this thesis, addressed in Chapters 3 to 6.

\section{Preventive measures for Dermanyssus gallinae}

To be able to propose preventive measures for D. gallinae infestations in laying hen facilities, the routes of introduction and spread of $D$. gallinae in such systems were determined using the framework of Hazard Analysis and Critical Control Points (HACCP) in Chapter 3. The most important routes for introduction of D. gallinae in laying hen facilities were via the introduction of new flocks, the introduction of containers and crates, and via farmers and employees. The most important routes of spread of D. gallinae within laying hen facilities were determined as via 1) physical transfer routes; mice, rats and flies, wild birds, shared material and equipment, the removal of cadavers, visitors and external personnel, farmers and employees, and via 2) hen house equipment; the hen feeding system, the egg conveyor belt and manure aeration pipes. Based on this knowledge, a checklist with advice on preventive measures for D. gallinae was developed for layer farmers to minimise the risk of on-farm introduction and spread of this pest. This checklist was evaluated by UK and Dutch layer farmers as feasible and useful (Chapter 3). 
Design, development and validation of an automated monitoring tool for D. gallinae

An automated D. gallinae mite monitoring tool, incorporating a novel automated mite detection sensor, was successfully developed using the approach of Reflexive Interactive Design (RIO) (Chapter 4). The RIO approach was adapted to include a testing phase to ensure the solutions for the key functions of the automated mite detection sensor were compatible with live mites, their behaviour and in the context of a laying hen house. In this case, mites were tested with different solutions for the key functions 1) detecting mites (with a through beam sensor), 2) localizing mites (e.g. with a through-beam sensor, luring mites with a heated element), and 3) clearing the detection area (e.g. by blowing away mites, sucking mites up, or incorporating slippery surfaces to remove mites). For the automated mite detection sensor, the best solutions were combined in two different prototypes, which were subsequently tested in the laboratory and on-farm. The most successful prototype was situated under the perch, detecting mites with a through-beam-sensor and an air pump to remove mites from the through-beam-sensor after recording. The novel automated mite detection sensor, hereafter referred to as automated mite counter, was subsequently validated in experimental laying hen cages with live birds and a growing population of $D$. gallinae (Chapter 5). The number of mites counted by the automated mite counter were compared with the total number of mites in the laying hen cages (which were determined by counting all mites present in each cage). The regression line between the 'number of mites counted' by the automated mite counter and the total number of mites present in the experimental laying hen cages demonstrated that the automated mite counter was able to accurately track the dynamics of D. gallinae populations.

The design of the automated mite counter not only resulted in a technically and financially viable automated detection sensor for D. gallinae but resulted also in new knowledge on mite behaviour, which is summarized in Table 7.1. 
Table 7.1 Knowledge of Dermanyssus gallinae behaviour obtained during the design of the automated mite detection sensor

\begin{tabular}{ll}
\hline Newly obtained knowledge & Obtained by \\
\hline $\begin{array}{l}\text { D. gallinae display vertically oriented host seeking behaviour } \\
\text { D. gallinae were more attracted to: }\end{array}$ & $\begin{array}{l}\text { Expert interview } \\
\text { Laboratory test }\end{array}$ \\
- A copper tablet of $33^{\circ} \mathrm{C}$ versus a copper tablet of $20^{\circ} \mathrm{C}$ and & \\
- A non-transparent tube versus a transparent tube & \\
D. gallinae showed no preference for: & Laboratory test \\
- An inner tube diameter of 1.5 versus $4.4 \mathrm{~mm}$, & \\
- Round cavities versus squared cavities, & On-farm test \\
- PVC, steel, brass or copper when tested on farm. & Laboratory test \\
D. gallinae were able to climb on slippery surface. & Laboratory test \\
D. gallinae did not jump or fall towards a heated copper tablet & Laboratory test \\
D. gallinae was dislodged at an air velocity of $20.3 \pm 12.2 \mathrm{~m} / \mathrm{s}$ & \\
$\quad$ when air velocity was gradually increased. & Laboratory test \\
D. gallinae was dislodged at an air velocity of $47.6 \pm 0.07 \mathrm{~m} / \mathrm{s}$ & \\
\hline
\end{tabular}

Development of an adaptive population dynamics model for D. gallinae

To further advance IPM for D. gallinae in laying hen facilities a model was developed forecasting the pests' population dynamics in laying hen facilities pre- and post-treatment. Such a model could be employed to forecast the moment the D. gallinae population exceeds an action threshold and to evaluate the effect of measures implemented to reduce $D$. gallinae population growth. Based on nine years of mite monitoring data on one experimental farm with three different housing systems, it was shown that there is a high variation in $D$. gallinae population growth in laying hen facilities. This variation could partly be explained by treatment, flock age, hen house temperature and hen house compartment. A part of the variation, however, was temporal and a substantial part was unexplained. This temporal variation, meaning that each flock has a different slope for age effect, presented a challenge to model development. However, a dynamic adaptive approach to predict population development of D. gallinae in laying hen facilities accounted for this variation. Chapter 6 presents the developed adaptive population dynamics model for D. gallinae which 1) is able to forecast the mite population dynamics pre- and post-treatment, 2) is applicable to all types of poultry facilities, and 3) contributes to the development and implementation of improved practical IPM programmes for D. gallinae in laying hen facilities. Moreover, this chapter demonstrates that the developed model is compatible with various mite monitoring methods and that it is able to forecast population dynamics of D. gallinae and growth rate, both post-treatment and without treatment, requiring only population monitoring data, indoor temperature data and information of the dates of any D. gallinae treatment interventions. 


\section{Discussion and future developments}

The main research findings in this thesis and their future developments are discussed in the sections below. This complements more detailed discussions presented within Chapter 2 to 6 .

\section{Knowledge assessment regarding Dermanyssus gallinae}

During the last decade, the significance of D. gallinae as a pest of laying hens, and as a potentially wider threat to human and animal health, has increased. Consequently, this pest has been placed higher on the research agendas in many countries, resulting in international seminars, workshops, conferences and COST action network meetings. Despite this increased focus, however, significant gaps in our knowledge of D. gallinae are still present. Though some of these gaps will be addressed through a major European funded programme to establish networks of skilled researchers (COST Action FA1404: Improving current understanding and research for sustainable control of the poultry red mite Dermanyssus gallinae (COREMI)), there remains paucity of research currently underway to offer solutions to control D. gallinae, at least in the short term. One reason for this is that governmental funding bodies consider the D. gallinae problem in laying hen facilities to be one that should be addressed by privately funded industry innovation. As a result, public funding at present tends to support D. gallinae research in a very limited way, both in terms of available funding per se and the number of funding opportunities.

Control of D. gallinae may be improved, for example, by manipulating the mites' host finding behaviour, retardation of its life cycle contributing to lower population growth, or obstructing mite reproduction and thus reduced mating success. To achieve such advances, however, knowledge is necessary on mite preferences, behaviour and biology, including potential diapause and reproduction, physiology, host searching, host location and host acceptance mechanisms. Nevertheless, and as discussed in Chapters 2 and 4, only very few articles related to these subjects have been published in the last eight years (Pritchard et al. 2015; Nechita et al. 2015; Faleiro et al. 2015; Koenraadt and Dicke 2010; Sokol et al. 2008). In order to optimize IPM for D. gallinae, researchers should be encouraged to obtain and publish such essential knowledge. These more fundamental research subjects, however, are unlikely to be funded by farmer groups or private industry as these actors tend to support highly applied research with focus on more 'familiar' solutions, such as new acaricide candidates, potential vaccines or biological control organisms. Such industry-driven advances may generate new knowledge, though sharing of this is likely to be restricted as a result of protected intellectual properties or protection of non-patentable products (e.g. predatory mites, fungi). In such instances, the commercial interest of companies outweighs knowledge exchange and sharing. For finding sustainable solutions for the D. gallinae problem in laying hen facilities, funding of research related to mite biology, behaviour and preferences should, therefore, be supported by national and EU governmental bodies. 
Preventive measures for Dermanyssus gallinae

In Chapter 3 preventive measures against D. gallinae infestations in laying hen facilities were determined by four experts using the HACCP framework, accepting that identification of hazards and critical control points should be based on scientific knowledge if available. With only 654 scientific articles published on D. gallinae since 1910 and 350 articles since 1984 (according to CAB abstracts; Dermanyssus gallinae in 'abstract' or 'broad terms'), the limited available scientific knowledge necessitated that the experts relied largely on their own observations, common sense and unpublished observations provided by other researchers.

With the identification of the most important routes of introduction and spread of $D$. gallinae it became more evident that control of this pest in laying hen facilities could not be achieved without the cooperation of multiple actors in the egg production chain; breeders, pullet rearers, egg producers and egg packing stations. Moreover, we found that internal and external biosecurity measures, already applied by egg producers to prevent introduction of poultry diseases such as zoonotic Salmonella enteritidis or Mycoplasma gallisepticum, could simultaneously reduce the risk of introduction of $D$. gallinae. These findings gave a first indication that IPM for D. gallinae in laying hen facilities should be applied and reinforced by the whole egg production chain to better ensure food safety and increased implementation or adoption of advanced IPM.

Since publishing the HACCP article (Mul and Koenraadt 2009), two independent research projects have provided scientific knowledge supporting and adding to hazard identification for introduction and spread of D. gallinae in laying hen facilities. A joint research project from Sweden and Norway was carried out to determine the routes of D. gallinae transmission by comparing the genetics of D. gallinae (Øines and Brännström 2011) from wild birds and from D. gallinae residing in laying hen facilities. This work found different $D$. gallinae haplotypes from wild birds compared to those from laying hens. Thus, the influence of wild birds on the spread of D. gallinae within poultry facilities may be negligible and consequently measures to prevent this route of transmission may be omitted from the HACCP checklist. Other researchers, however, simultaneously supported a role for wild birds for harbouring D. gallinae associated with commercial poultry in Brazil but not in Europe (Roy and Buronfosse 2011). In Europe the most important routes for the introduction of D. gallinae consist of contaminated materials, such as containers and crates, and new flocks (Mul and Koenraadt 2009; Øines and Brännström 2011). In addition, Øines and Brännström (2011) and Roy and Buronfosse (2011) also suggested that the mites can be transmitted within the egg production chain. This knowledge confirmed that introduction, and therefore control, of D. gallinae in laying hen facilities is influenced by a suite of all preventive and control measures taken within the egg production chain; i.e. in breeding farms, pullet rearing farms, egg packing stations and transportation routes. Control of $D$. gallinae should therefore be a collective effort made by all partners within the egg 
production chain. An example of a 'link crossing' tool within the egg production chain is the additional checklist for "rearing hens before transport to the layer farm".

Unfortunately, the preventive effect of the HACCP checklist has never been fully determined and tested under commercial practice. In Belgium (Dierengezondheidszorg Vlaanderen), however, the table with the identified hazards and associated risks (see Table 3.2 in Chapter 3 ) is currently being applied pre-commercially. In this trial, farmers were asked to determine the risks for the hazards described in the table for their own farm. This activity aims to help the farmers to identify their farms main hazards and risks and encourage them to take preventive measures accordingly. For further implementation of the checklist by egg producers, farmers associations or egg packing stations should encourage their members or suppliers to use the checklist, providing accompanying advices on preventive measures. If applied commercially, resulting industry feedback would provide more insight into the effect of the checklist on control of D. gallinae in layer farms and it would simultaneously contribute to advanced IPM for D. gallinae.

\section{Monitoring tool for Dermanyssus gallinae}

As a part of this thesis, a study on the design and development of a monitoring tool for $D$. gallinae was carried out to overcome the limitations of currently available monitoring methods and devices (Table 7.2), these mostly being laborious, non-continuous, and relatively insensitive. A better monitoring system will contribute to the implementation of IPM for D. gallinae in a manner that is effective and fits easily into the farmers current farm processes. To advance IPM for D. gallinae, an automated mite monitor, including an automated mite counter, was designed (Chapter 4). The automated mite counter was validated by successfully tracking mite populations (Chapter 5). The developed and described automated mite counter showed good promise for further development and application in practice. 
Table 7.2 An overview of D. gallinae monitoring methods and devices

\begin{tabular}{|c|c|}
\hline Monitoring method or device & Reference \\
\hline 1. ADAS@ Mite Monitor & Anonymous (2014) \\
\hline 2. Perch trap & Kirkwood (1963) \\
\hline 3. PVC pipe with 13 holes and towel sheet inside & Tucci et al. (1989) \\
\hline 4. Tube containing a fabric or cloth & Maurer et al. (1993) \\
\hline 5. Corrugated cardboard/plastic trap & Nordenfors et al. (1999) \\
\hline $\begin{array}{l}\text { 6. A tube trap with a wooden stick (Rick Stick) or } \\
\text { corrugated cardboard (Avivet trap) }\end{array}$ & $\begin{array}{l}\text { Van Emous and Ten Napel (2007) } \\
\text { Personal communication } \\
\text { Bronneberg, AviVet.nl }\end{array}$ \\
\hline $\begin{array}{l}\text { 7. Method for detecting D. gallinae in dust, } \\
\text { feathers and impurities (early detection } \\
\text { method) }\end{array}$ & Pavlicevic et al. (2007) \\
\hline $\begin{array}{l}\text { 8. Examining dried droppings for presence of } D \text {. } \\
\text { gallinae }\end{array}$ & Zenner et al. (2009) \\
\hline 9. Mite Monitoring Score (MMS) method & Cox et al. (2009) \\
\hline 10. Automated mite counter & Mul et al. (2015) \\
\hline 11. Modified trap after Safrit and Arends & Schulz (2014) \\
\hline 12. MTT-Velcro band mite trap & Tuovinen et al. (2010) \\
\hline 13. Semi Attractive Trap (SAT) & Chiron et al. (2014) \\
\hline 14. Simplified Passive Trap (SPT) & Roy et al. (2014) \\
\hline 15. Scout box app & Cropwatch BV \\
\hline 16. Folded paper & Zenner et al. (2009) \\
\hline $\begin{array}{l}\text { 17. Q-perch counter (as a spin-off from the Q- } \\
\text { perch) }\end{array}$ & $\begin{array}{l}\text { Van de Ven (2016) Vencomatic } \\
\text { Group BV }\end{array}$ \\
\hline 18. Lohmann trap & Mozafar (2014) \\
\hline 19. Paper tube trap & $\begin{array}{l}\text { Sokol and Koziatek-Sadlowska } \\
\text { (2016) }\end{array}$ \\
\hline 20. Plastic containers with heating pads & Dovc et al. (2016) \\
\hline
\end{tabular}

To realise the potential of the automated mite counter and provide benefit to the farmer, a commercial partner was engaged in the project after the validation of the automated mite counter. Together with this partner the automated mite counter was improved by further reducing the maintenance time necessary for replacing the filter and removing dust from the body of the counter. The new automated mite counter is now incorporated within the perch and blows out the mites instead of sucking them in. A further development will be designing the mite counter to enable mass production, which is part of the path towards a commercially available product.

The extent of the contribution of the automated mite counter to more rigorous IPM programmes partly depends on whether the farmer sees the counter as being advantageous and compatible with current farm processes. To lower the risk of the investment for the farmers, the maximum costs of an automated mite counter, as described in the Brief of Requirements was kept in mind during the design of the mite counter. The total costs of the 
mite counters, including installation, consumption of electricity, maintenance contracts and amortisation, should be less than $€ 0.15$ per laying hen per year, with the mite counter having an expected lifespan of 5 years. The main costs of the validated prototype represents the costs for the small pump used. It is expected that this cost will significantly reduce when buying this component in bulk for commercial production.

The conclusion that D. gallinae population growth could partly be explained by treatment, flock age, hen house and temperature (Chapter 6) was based on monitoring data from one experimental farm with three different housing systems. Longitudinal monitoring data from multiple farms with different housing systems are necessary to determine whether the variation recorded, and explanatory factors of the treatment effect, are generic or only applicable on the one experimental farm where the study was conducted. With the automated mite counters, collecting such additional data will be less time consuming as compared to the other existing monitoring methods.

Further research contributing to an affordable and effective commercially available monitoring tool will focus on the assessment of the required number of automated counters per 1000 laying hens, or per laying hen facility, and optimal counter placement sites for monitoring the D. gallinae population in layer farms. Moreover, future work is planned to test the mite counters for compatibility with four different laying hen housing systems. These planned research activities will further improve the use of the automated mite counter and can be expected to increase the implementation of IPM for D. gallinae in laying hen facilities as supported by the findings of Peshin et al. (2009) briefly summarized in Chapter 1.

The RIO approach, with the new additional step described, could be applied to the future design of automated detection sensors for pests in arable farming or in horticulture. Currently, pests like Macrosiphum euphorbiae in potato fields and Tetranychus urticae in greenhouse cucumber are monitored visually or by using sticky traps. Automated detection sensors will reduce the labour required for monitoring these pests and therefore also contribute to IPM in other sectors.

\section{Dermanyssus gallinae population dynamics model}

A population dynamics model for D. gallinae in laying hen facilities was developed to facilitate decision making regarding the time and place of applying preventive or curative measures, and to evaluate the success of these measures. Chapter 6 demonstrated that the adaptive population dynamics model developed is able to forecast the population dynamics of D. gallinae with data obtained from three different monitoring methods. It is expected that the forecasting quality of this model will improve with a higher frequency of data input, i.e. daily instead of weekly recording. An advantage of the automated mite counter is its ability for high frequency monitoring without the requirement of increased labour input. Preliminary results, with data generated daily from automated mite counters and imported in the developed model, revealed that the confidence interval was reduced as compared 
with weekly monitoring data. This subsequently improved the forecasting quality. Another expected advantage of the automated mite counter is a higher inter-counter reliability when compared with the current available monitoring methods, which have a limited number of scales and rely on human visual observations. This advantage is also likely to lend itself to improved forecasting quality of the model.

As detailed in Chapter 6, the current model is able to forecast the population dynamics of D. gallinae without the requirement for input of numerous variables. A model contributing to advanced IPM requires such an operational model providing easily interpretable data and requiring minimal staff input. The disadvantage of such operational models, when compared to deterministic models, is that they include only the most important controllable variables. Consequently, these models do not provide insight into the relationships between all system components or variables (Legg 2004). These insights could, however, help to identify measures for control of D. gallinae in laying hen facilities. Exploration of other types of models, able to function with high- and temporal variations, as well as many different variables, could help to resolve the drawbacks of the developed adaptive model and result in an increased understanding of $D$. gallinae population growth in laying hen facilities.

Moving forward, a sensitivity analyses of the model will be carried out to reveal the models sensitivity by varying the parameter values. This will provide more information about the models performance and generate suggestions for further improvement of the model. On-farm testing would then follow, carried out preferably with both the automated mite counter and the population dynamics model, to provide a further indication of the performance of the model-counter combination. For the model specifically, such on farm test is necessary to a) provide information about the forecasting quality of the model under practical conditions, b) provide information on the need for further model improvements, and c) to validate the contribution of the model to improving treatment efficacy by allowing rapid assessment of treatment effects. It is envisaged that together the automated mite counter and the population dynamics model will enable farmers to monitor mite populations in real time, allowing informed decisions to be made when to apply appropriate and effective treatments to maximise benefit.

A further development will be a 4D (time and three dimensions of the laying hen facility) adaptive population dynamics model. With multiple mite counters being placed in a 3D-grid in the laying hen facility, the speed and direction of a developing mite population can be forecasted, enabling identification of D. gallinae hotspots. This information can be used to limit the population by application of a spot treatment, thus fulfilling one of the key aims of IPM, i.e. reduction in pesticide use.

\section{Advancing IPM for Dermanyssus gallinae in laying hen facilities}

The aim of the research described in this thesis was to advance IPM for D. gallinae in laying hen facilities. In the General introduction (Chapter 1) the eight steps of IPM were explained and displayed diagrammatically as a jigsaw puzzle indicating the steps and their 
connections (Figure 7.1), as described in Annex III of Framework Directive 2009/128/EC (i.e. 1) Prevention and/or suppression, 2) Monitoring, 3) Decision based on monitoring and thresholds, 4) Non-chemical methods, 5) Pesticide selection, 6) Reduced pesticide use, 7) Anti-resistance strategies, 8) Evaluation) (European Union 2009; Barzman et al. 2015). When these eight steps are adhered to, successful control of pests can be expected, while simultaneously reducing reliance on conventional broad spectrum chemical control and thus limiting the detrimental effects of pesticides. In this section, the contribution of the current research project to advancing IPM for D. gallinae in laying hen facilities will be discussed and suggestions will be made for future research topics in this field. The discussed will be put in the context using the aforementioned eight step IPM framework with steps 1-4 and 8 being those most relevant to the aims of this thesis.

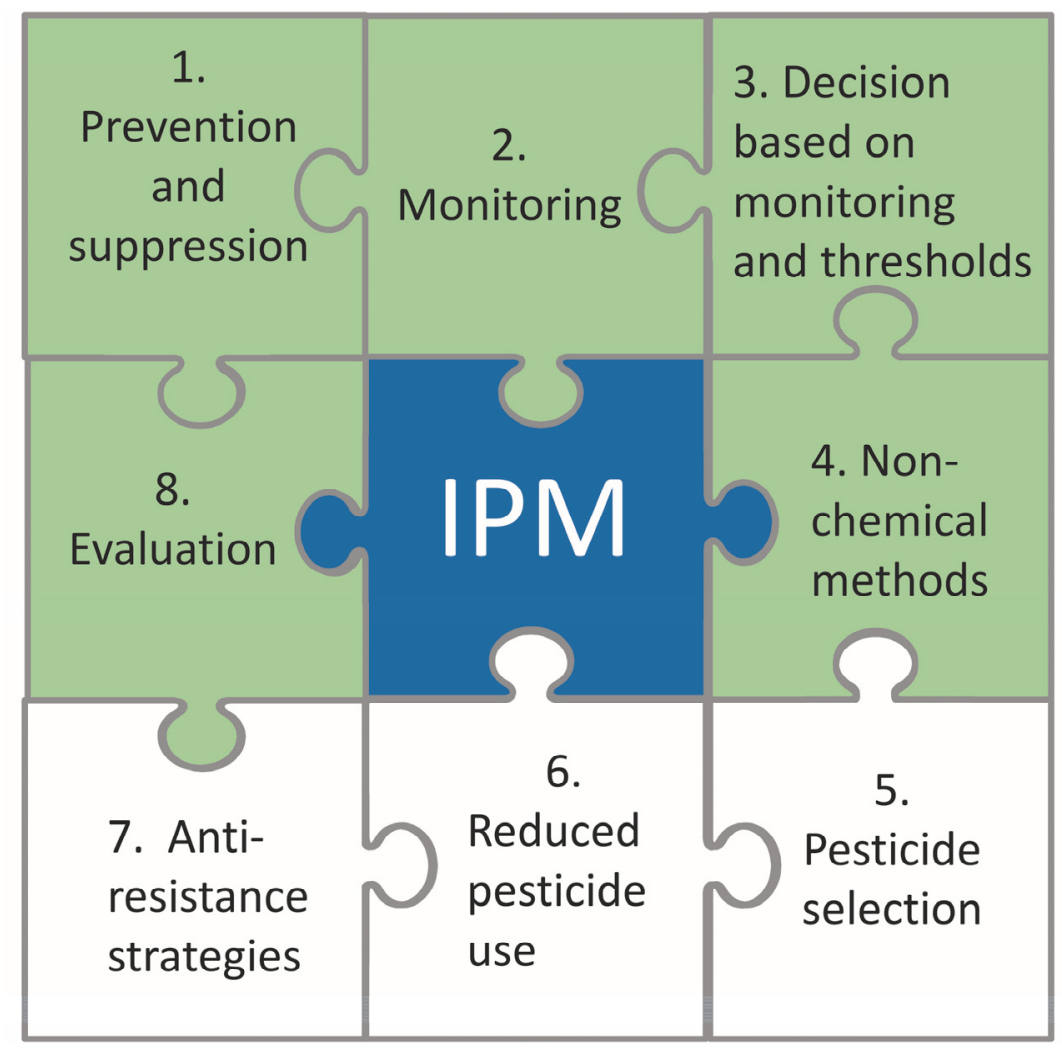

Figure 7.1 Eight steps of IPM and their connections (C I. Vänninen LUKE, Finland). Steps 1-4 and 8, coloured in green, are relevant to the aims of this thesis and are discussed in more detail in the text. 
Step 1 Prevention and suppression of harmful organisms + Step 4 Non-chemical methods

The Framework Directive 2009/128/EC (European Union 2009) describes the first IPM step as: 1. The prevention and/or suppression of harmful organisms should be achieved or supported. The Framework Directive 2009/128/EC (European Union 2009) describes the fourth IPM step as: 4. Sustainable biological, physical and other non-chemical methods must be preferred to chemical methods if they provide satisfactory pest control.

- Contributions of current project to advancing IPM

An important preventive measure for D. gallinae management is the thorough sanitation of housing systems during the period between flocks when the facility is empty. Cleaning, even with water alone, may also represent an effective curative treatment, removing mites from the cracks and crevices in the laying hen house and resulting in reduced numbers of mites (Nordenfors and Hoglund, 2000). In Chapter 2 we described that a combination of cleaning, disinfection, drying and heating the hen house to above $45^{\circ} \mathrm{C}$, combined with a (chemical) treatment, results in laying hen houses being free from D. gallinae. Most likely, when applying the preventive measures described in the HACCP checklist, the number of mites entering the hen house will be minimal. Further research is necessary to determine the long-term effects of this combination of sanitation and preventive measures.

Promising methods to suppress D. gallinae populations in laying hen facilities were, as concluded in Chapter 2, the use of predatory mites, vaccination and entomopathogenic fungi. These novel suppressive measures for D. gallinae have been developed and continue to be the subject of further research. The knowledge obtained in the current project, the developed HACCP checklist, the design and development of the automated mite counter and the developed population dynamics model, can further accelerate and improve the introduction of these methods, thus contribute to IPM Step 1 and 4.

Predatory mites. Predatory mites and other natural "enemies" have been identified (Lesna et al. 2009; Maurer and Hertzberg 2001) and subsequently tested for efficacy against $D$. gallinae in experimental laying hen cages (Maurer and Hertzberg 2001; Lesna et al. 2012). The predators used in these experiments were not able to eradicate the D. gallinae population (Lesna et al. 2012), and suggestions for further research to improve the efficacy were made (e.g. creation of an artificial environment to thrive). For the suppression of a $D$. gallinae population by predatory mites, part of this research should focus on determining release rates of predatory mites to control varying sizes of $D$. gallinae populations, as well as the number and distribution of the release sites (Friesen et al. 2011). Release of too few or too many predators may influence the efficacy of predatory mites (Van Lenteren and Woets 1988). Currently, most IPM programmes advise release of predatory mites when the pest population is low, making regular (weekly) monitoring of the pest population essential (Eliot 1997; Graesch 2016; Van Driesche and Bellow 2001). With the development of an automated mite counter, mite population growth and pest 'hotspots' can now be easily identified, even at low population levels. A subsequent quick release of predators in these 
'hotspots' may result in improved control of the D. gallinae population. An automated mite counter may therefore be an accelerator for the development of effective application of predatory mites to control D. gallinae.

Vaccines. Vaccines for D. gallinae in laying hens are being developed as a, suppressive, control method for the mite population in laying hen facilities (McDevitt et al. 2006; Schicht et al. 2014; Bartley et al. 2015). Vaccine molecules administered to the hen may result in damage to the mite gut or inhibition of the natural function of mite proteins. This may result in increased mite mortality, reduced mite egg production or reduced viability of mite eggs. These effects all lead to a reduction in the proliferation speed of the D. gallinae population (Bartley et al. 2009; Bartley et al. 2012). Even though fast and promising progress has been made in the development of an effective vaccine for D. gallinae in the last few years, it is expected that such a vaccine will be most effective in combination with other preventative or suppressive control methods (e.g. cleaning, drying, disinfection, heat treatment plus additional treatment, measures from the HACCP checklist) (Bartley, 2015). The development of a vaccine may be accelerated when using the automated mite counter, instead of the currently available monitoring methods, to identify the effects of a newly developed vaccine on D. gallinae population dynamics. The automated mite counters provide daily data on the mite population, allowing vaccines response times to be easily and accurately determined, both under controlled and commercial conditions. It can be concluded that in the current thesis the obtained information, the checklist and the automated mite counter could accelerate the development and improve the efficacy of a vaccine against $D$. gallinae in laying hen facilities.

Entomopathogenic fungi. The use of fungi to control D. gallinae populations has been discussed and tested, primarily, under controlled laboratory settings (Oliveira et al 2014; Steenberg and Kilpinen 2014; Immediato et al. 2015). Under semi-commercial conditions trials with fungi to control D. gallinae showed unsatisfactory results (Steenberg et al. 2006), probably as a result of the low humidity limiting fungal performance in poultry units (Harrington et al. 2011). In order to contribute to the development of fungi as a control measure for D. gallinae, we may insert additional variables into the predictive model, humidity included.

In Chapter 6, high variation was found in the population growth of D. gallinae, both post treatment and without treatment, which could partly be explained by flock age, hen house and temperature. With this knowledge of the effect of temperature, the D. gallinae population growth can be suppressed with an indoor temperature kept below a farm specific threshold. The developed automated mite counter and population dynamics model could contribute to determining this laying hen house dependent temperature threshold and thus contribute to Step 1 of IPM.

In the future, the automated mite counter will effortlessly generate data which can be analysed to obtain knowledge on mite behaviour, treatment effects and management measures on D. gallinae population dynamics, as discussed in Chapter 4 . The potential of the 
counter for identifying management measures has already been shown when the counter was tested and developed on-farm (Chapter 4). During this testing, mite counts were stored every five minutes using a data logger. This test-period revealed that mites entered the counter two hours after the on-set of the dark period, continuing until half an hour after the on-set of the light period. The same mite behaviour was observed during the validation test (Chapter 5) and is in agreement with the observations of Maurer et al. (1988) on mite activity periods. Moreover, an increase in mite counts was detected during transport of manure by the manure belt, suggesting that mites moved to other places during this period and that mites are present in manure. Daily removal of manure (and mites) may therefore be a mite suppressive management measure. In the future it is likely that the automated mite counter will reveal more effects of general management on mite behaviour as changes in management may be seen in the daily counted numbers of mites. Furthermore, when multiple automated mite counters are placed in a large number of layer houses and daily mite counts are collected and analysed from a range of settings, insight will be obtained into preventive or suppressive effects of housing systems, risk factors and management measures on mite population dynamics. These insights will contribute to increasingly advanced IPM, satisfying IPM Step 1 to ever-bettered effect.

\section{- Future research contributing to advanced IPM}

The availability of ample mite refuges in the structures of layer houses is one reason for reduced efficacy of 'conventional' mite treatments and consequently high proliferation of $D$. gallinae populations (Sparagano et al. 2014b). Mites hide in these refuges and are not detected by farmers, resulting in treatments only being carried out when the mites are visible, i.e. when mite numbers are high. Moreover, these refuges prevent the mites from coming into contact with contact acaricides, making it difficult to control D. gallinae infestations with such products. Laying hen houses without mite refuges will improve control possibilities for D. gallinae populations. Therefore, new models for laying hen houses should be designed without mite refuges in the future. One method to achieve such a new design is the RIO approach (Bos et al. 2009). Using this approach, the requirements of farmers, laying hens and citizens should be taken into account by the design of a new laying hen housing system, simultaneously considering the requirements of D. gallinae within units to allow these to be 'designed out'. Biocontrol can also be further advanced through this approach by considering the requirements of predatory mites or other natural enemies in new designs for the interior structures of laying hen houses. 


\section{Step 2 Monitoring + Step 8 Evaluation}

The Framework Directive 2009/128/EC (European Union 2009) describes the second IPM step as: Monitoring harmful organisms by adequate methods and tools, where available. Such adequate tools should include observations in the field as well as scientifically sound warning, forecasting and early diagnosis systems where feasible, as well as the use of advice from professionally qualified advisors.

The Framework Directive 2009/128/EC (European Union 2009) describes the eighth IPM step as: Based on the records on the use of pesticides and on the monitoring of harmful organisms the professional user should check the success of the applied plant protection (animal health and welfare) measures.

The novel automated mite counter and the population dynamics model developed as part of this thesis represent significant progression towards achieving an on-farm monitoring step for D. gallinae. These developments were realised, taking into account the requirements of the end-user (the farmer), for monitoring tools and models contributing to advancing IPM. If all further developments on the mite counter and population dynamics model (e.g. design of the mite counter for mass production, on the market for less than €0.15 per laying hen per year, on-farm testing of counter and model) are similarly realised, as discussed in the former section, the automated mite counter and the population model will effortlessly generate data and provide knowledge. The collected data and forecasts can be analysed and provide knowledge about mite population dynamics, treatment effects and effects of management measures on D. gallinae population dynamics. With the model evaluating the treatment effects, farmers can obtain insight into effective and ineffective treatments. This will result in farmers avoiding spend money on ineffective pesticides, thus reducing pesticide use. Furthermore, the automated mite counter will contribute to faster development of new products for combatting D. gallinae populations in laying hen facilities: During experiments to develop and evidence such new products, the automated mite counter will provide researchers daily information on D. gallinae population dynamics, treatment effect and duration of the effect on mite populations, simultaneously reducing labour time for monitoring compared to currently available monitoring methods. We conclude that the automated mite counter and the population dynamics model in the future have potential to contribute to IPM steps 2, 6 and 8, being 'Monitoring', 'Reduced pesticide use', and the 'Evaluation' of the applied methods and strategies. 


\section{Step 3 Decision based on monitoring and thresholds}

The Framework Directive 2009/128/EC (European Union 2009) describes the third IPM step as : Based on the results of the monitoring the professional user has to decide whether and when to apply measures against the pest. Robust and technically sound threshold values are essential components for decision making. For harmful organisms threshold levels defined for the region, specific areas, crops/animals and particular climatic conditions must be taken into account before treatment, where feasible.

Action thresholds are used to inform timings for curative pest management treatments, ensuring that these are only undertaken when pest population levels exceed pre-specified values. Treating pest populations according to action thresholds generally reduces pesticide applications over more 'traditional' methods such as routine treatment regimes, ensuring that treatment is only applied as needed. An action threshold could be set based upon, amongst others, economic losses, health- or safety concerns or aesthetic concerns. In crop protection most thresholds are based on economic losses (Dent, 2000), though many fresh produce crops have a zero tolerance for pests for aesthetic reasons (linked to economics through the risk of crop rejection should any pest be present). Action thresholds, for taking measures to reduce a D. gallinae infestation in laying hen facilities, have been presented and discussed in Chapter 3 and by Tuovinen (2015). In Chapter 3 the critical limit was suggested to be zero mites, because of a) the possibly fast proliferation of the mite population under optimal conditions, b) the limited effects of curative treatments for D. gallinae, and c) available insensitive $D$. gallinae monitoring methods when mite populations are low. This limit, however, is not practical and feasible for farmers willing to incorporate IPM programmes for D. gallinae in their daily work as it requires frequent monitoring and curative measures to be taken after each mite is found in the laying hen facility. With this in mind, the focus of further research on the economic threshold for D. gallinae is urgently needed. To determine the economically optimal time for a treatment application, an economic model and an advisory algorithm is being developed. This algorithm should be developed to advise farmers on the optimal treatment date using a) the population dynamics model predicting the population growth of D. gallinae and the expected treatment effect, and b) an economic model estimating current, and predicting future, economic losses due to mite population growth. These economic losses should also include predicted losses due to mite related welfare issues (e.g. injurious pecking, particularly in non-beak trimmed flocks). In the future, the data generated with the automated mite counter (number of mites) combined with egg production records will provide insight into the effect of various sizes of mite populations on farm economics. Moreover, the obtained data may also provide insight into risk- and preventive factors for a mite infestation in laying hen houses. We therefore conclude that the developed and evaluated automated mite counter (Chapters 4 and 5) and population dynamics model (Chapter 6) facilitates labour friendly daily monitoring of the critical control points for preventing the introduction and spread of D. gallinae in laying hen 
facilities (Step 1 and 2 of IPM), and more importantly it could facilitate determination of the action threshold (Step 3 of IPM).

We conclude that the checklist, the novel automated mite counter, and the population dynamics model will directly facilitate the implementation of advanced IPM programmes for D. gallinae in laying facilities. These developed products are tools for prevention, monitoring, forecasting population dynamics and evaluating treatment effects, thus satisfying the demands of IPM Steps 1, 2, and 8. Indirectly, the acquired knowledge and products have future potential to contribute to IPM Steps 3, 4, 6 and 8. They may accelerate the development of new control measures for D. gallinae and contribute to, for example the determination of an action threshold, and a tool advising farmers on the most effective and economic time for applying a corrective action or hotspot treatment against this pest.

The current measures taken against D. gallinae in laying hen facilities are mostly limited to a combination of cleaning the premises between two flocks, some level of biosecurity and application of chemically or physically acting products or sanitisers. With these measures it can be argued that no defined level of IPM can be attained, as IPM should consist of preventive measures, monitoring of the pest, and use of an action threshold as a minimum (see Chapter 1). When the obtained knowledge and new products are implemented for $D$. gallinae in laying hen farms, major advances are made towards IPM level 1, with respect to preventive measures, monitoring, forecasting population dynamics and evaluating applied treatments. IPM level 1 will not be reached in full, however, as an action threshold is still lacking. If these advances made on IPM are implemented, we expect improved control of $D$. gallinae in laying hen facilities and, consequently, improvement of hen welfare, hen health and farm economics.

\section{Perspectives for further implementation and application}

\section{Implementation of IPM programmes for Dermanyssus gallinae}

The obtained knowledge and tools produced in this research project have the potential to contribute to a more thorough implementation of IPM programmes for D. gallinae as they fulfil the requirements for a better adoption of IPM as described by Peshin et al. (2009). By implementing the knowledge and developed tools described herein, IPM for D. gallinae should become less complex, more low-risk and less time consuming (due to the design of an affordable automated mite counter). Moreover, the developed tools are also compatible with all types of laying hen facilities. Nevertheless, farmers have doubts about the clear advantage of IPM for D. gallinae, as vented by the egg producing members of the farmers unions involved in this research project. Layer farmers compare the efforts required to apply IPM for D. gallinae to the efforts required to apply existing treatments, such as chemical acaricides, silicas, predatory mites or biocontrol products. Moreover, they trust the quality of their own observations to identify the treatment effect. Thus, current egg 
producers monitoring and forecasting population dynamics is cheaper as compared with an automated mite counter and the population dynamics model. In my experience the conclusions of Peshin et al. (2009) therefore hold true for the egg production sector, in that a more thorough adoption or implementation of IPM in practice depends on the perception of farmers. For farmers, pest control is not the main function of their production process. More specifically, the main aim for laying hen farmers is to 'Produce eggs' (Chapter 4). The control of $D$. gallinae is a tertiary sub function meaning that 'Processing eggs', 'Maintaining animal welfare', 'Relocation of goods' and 'Control of economics' are more important than the control of D. gallinae, dictating that this control of D. gallinae should easily fit into the current farm processes. For improved commercial uptake of more thorough IPM programmes for D. gallinae, I recommend increased focus on socially oriented research to elucidate the "unwillingness" of farmers to implement IPM in the egg production sector. In Finland horticultural farmers went through such a process using the Change Laboratory method (Engeström et al. 2016). Adopting a systematic approach, farmers analysed their mutual problem with control of a pest in their greenhouses as well as its causal factors. Together they designed and discussed a new way of working to overcome the problem, implementing the resulting methodology on their farms. The process and the effect of this new way of working was assessed and further improvements were made following the same systematic approach to analysing the problem. This method resulted in farmers gaining insight into what is necessary to improve current methods and subsequently resulted in farmers-led actions to implement IPM programmes (Vänninen et al. 2015). Farmer-learning groups (Vänninen et al. 2015), farmer-science knowledge exchange (Ingram 2014), farmer networks (Wielinga et al. 2007), pilot farms and stakeholder participation (Wijnands et al. 2014) could also be implemented to increase knowledge sharing and co-creation of farmer solutions for better implementation of more thorough IPM programmes in the egg production sector.

\section{IPM in Animal husbandry}

Pests in animal husbandry systems can directly affect animal health, welfare and production, with D. gallinae being a good example (Chapter 2 ). Such pests can also indirectly impact on animal health, welfare and production, for example by transferring diseases. The house fly Musca domestica is a classic example, transmitting Campylobacter spp. (Nichols 2005; Hald et al. 2008), though D. gallinae may also serve as a disease vector (Chapter 2). As illustrated in Figure 7.2 a variety of pest species from outside farm houses can jeopardize animal health, welfare and production. Here, we divide these pests into two groups; pests related to animal production mostly residing in or in the neighbourhood of animal houses and 'wild' or introduced pests living in the surroundings of the farm (B.G. Meerburg, personal communication). Both groups are a threat, but introduction can be prevented using different means as shown in Figure 7.2. The chance of on-farm introduction of pests from the environment or farm surroundings can be reduced via, amongst others, enhanced 
biodiversity, change of environmental conditions and natural barriers. With enhanced biodiversity the chance increases of the presence of the pests' enemies limiting the number of pest organisms (Altieri 1995; Altieri and Nicholls 2004; Wilby and Thomas 2007), though care must be taken to ensure that measures that enhance biodiversity do not unintentionally increase pest abundance. By changing the environmental conditions, e.g. preventing wetland conditions in the farm surroundings or avoiding preferred habitats for pests like midges and mosquitoes, the pest population can be restricted (Van den Berg et al. 2006; Wielgosz et al. 2012). Natural barriers like water, mountains, plains and forests could also prevent pests invading the farm (Hachler 1989; Vosman and Faber 2011; XiaoFei et al. 2013). In practice, most farmers control the introduction of pests from farm surroundings into animal houses via external- and internal- biosecurity measures and climatic measures (Quinlan et al. 2015). Regardless of the method used to prevent introduction of pests into the farm, monitoring should be carried out to evaluate its effectiveness and also to ensure that the measures being taken are not having a beneficial effect on non-target pests of the taken preventive measures. Here, the design of automated monitoring tools for other pest species threatening animal health and welfare could be a supportive tool. Similarly, the path followed in this thesis to advance IPM programmes for D. gallinae (i.e. knowledge assessment, use of the HACCP method to identify preventive measures for pest transmission, use of the RIO approach to design an automated pest monitoring tool, validation of the designed automated counter, and the development of a population dynamics model) could be extrapolated for any other pest in animal production. 
On-farm control measures

- External Biosecurity: All measures taken to prevent introduction of pests and diseases via animals, semen, materials, feed, staff, visitors, transport methods, transport of cadavers, manure

- Internal Biosecurity: Measures taken to prevent spread of diseases on farm e.g. housing compartments, routing, animal health and management measures, cleaning and disinfection procedures

- Internal climate measures: temperature, humidity, air current

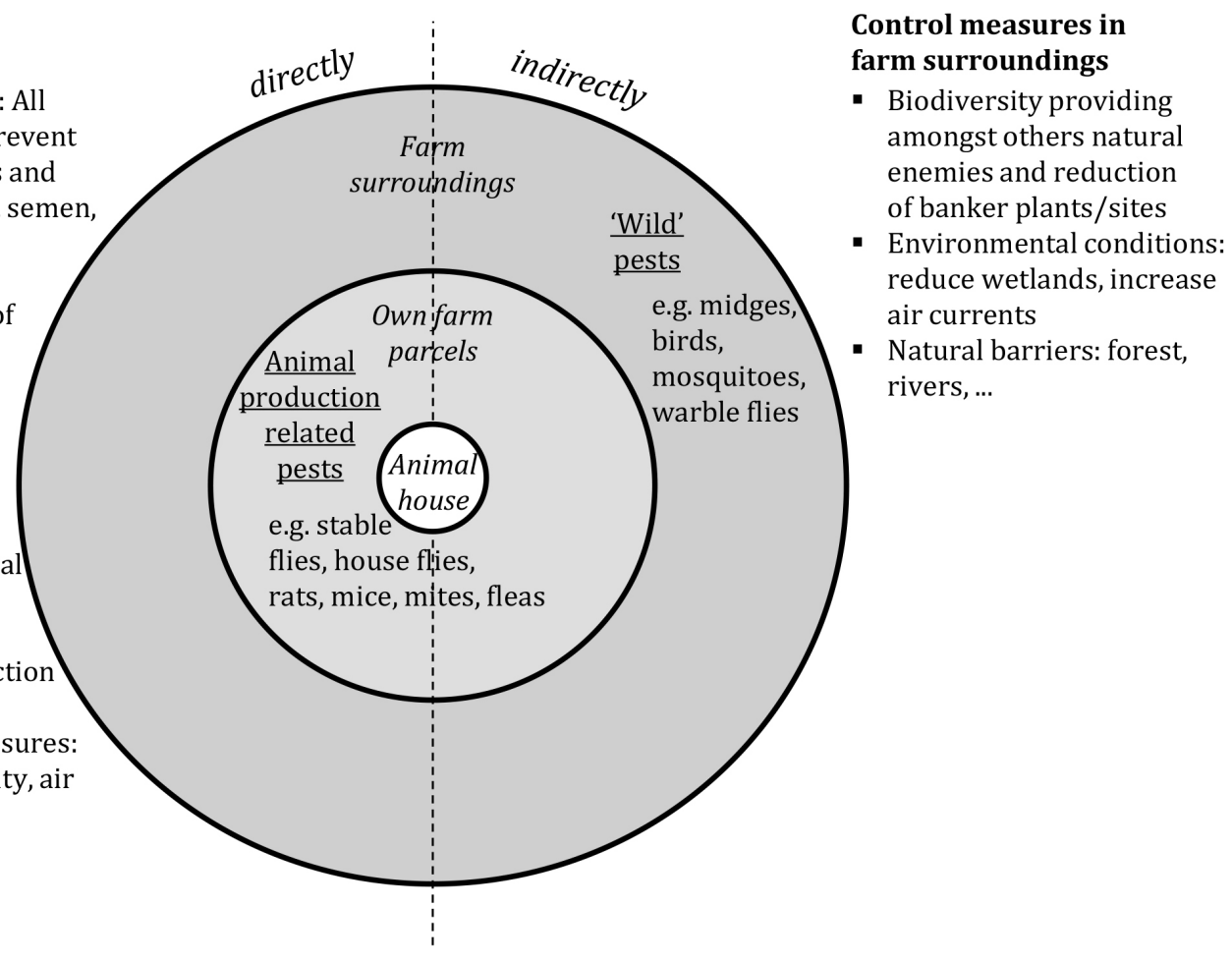

Figure 7.2 Illustration of pests present in the agro-ecosystem affecting animal production including possible control measures

\section{General conclusion}

The main aim of the research described in this thesis was to obtain knowledge on $D$. gallinae and develop methods and tools to contribute to more advanced IPM programmes for this pest in laying hen facilities.

In summary, the main research results are:

a) Three novel products to aid D. gallinae control through enhanced IPM:

- A checklist made for farmers with advice on preventive measures for D. gallinae to minimise the risk of on-farm introduction and spread,

- A technically and financially viable automated mite counter, and

- A mathematical model forecasting the population dynamics of D. gallinae and effects of treatment on these mites which is compatible with different housing systems, flock management regimes and monitoring methods, only requiring monitoring data, temperature data and the dates of any treatment. 
b) A better understanding of:

- Risk factors for the introduction and spread of D. gallinae in laying hen farms,

- Preventative measures for the introduction and spread of D. gallinae in laying hen farms,

- The mites ability to jump and climb on slippery surface,

- Mite preference for materials, temperature, cavity-diameter, -shape, and -transparency,

- The minimum air velocity required to dislodge D. gallinae in a tube, and

- Factors influencing the variation in treatment effect and population growth of $D$. gallinae.

The novel products and knowledge generated by this work provide advances in preventative control, monitoring, forecasting population dynamics and evaluation of preventive or control measures for D. gallinae that could greatly advance IPM programmes for D. gallinae in laying hen facilities. Consequently, this work will also benefit hen welfare and farm economics. Nevertheless, further development of the novel products generated are necessary prior to commercialisation. In the future, socially oriented research is recommended to increase the implementation of more thorough IPM in laying hen facilities. Commercial uptake of the novel products described is nonetheless anticipated in the future and gains are expected when the work undertaken herein with D. gallinae is transferred to other pest species in multiple sectors. 


\section{References}

Altieri (1995) Agroecology: The science of sustainable agriculture. West-view Press, Boulder, CO.

Altieri MA, Nicholls CI (2004) Biodiversity and pest management in agroecosystems. Second edition Food Products Press, New York

Anonymous (2014) Website http://www.theranger.co.uk/News/Keeping-an-eye-on-mitenumbers_38.html (22-8-2016)

Arends JJ, Robertson SH (1986) Integrated pest management for poultry production: implementation through integrated poultry companies. Poult Sci 65: 675-682

Axtell RC, Arends JJ (1990) Ecology and management of arthropod pests of poultry. Annu Rev Entomol 35: 101-126

Axtell R (1999) Poultry integrated pest management: status and future. Integr Pest Manag Rev 4: 53-73

Bartley K (2015) Tackling a mitey problem. Vet Rec 177: 38-39

Bartley K, Wright HW, Huntley JF, Manson EDT, Inglis NF, Mclean K, Nath M, Bartley Y, Nisbet AJ (2015) Identification and evaluation of vaccine candidate antigens from the poultry red mire (Dermanyssus gallinae). Int J Parasitol 45: 819-830

Bartley K, Nisbet AJ, Offer JE, Sparks NHC, Wright HW, Huntley JF (2009) Histamine release factor from Dermanyssus gallinae (De Geer): characterization and in vitro assessment as a protective antigen. Int J Parasitol 39: 447-456

Bartley K, Huntley JF, Wright HW, Nath M, Nisbet AJ (2012) Assessment of cathepsin D and L-like proteinases of poultry red mire, Dermanyssus gallinae (De Geer), as potential vaccine antigens. Parasitology 139: 755-765

Barzman M, Bàrberi P, Birch ANE, Boonekamp P, Dachbrodt-Saaydeh S, Graf B, Hommel B, Jensen JE, Kiss J, Kudsk P, Lamichhane JR, Messéan A, Moonen A-C, Ratnadass A, Ricci P, Sarah JL, Sattin M (2015) Eight priciples of integrated pest management. Agron Sustain Dev 35: 1199-1215

Benbrook CM, Groth E, Halloran JM, Hansen MK, Marquardt S (1996) Pest management at the crossroads. Consumers Union, Yonkers, New York

Bos AP, Groot Koerkamp PWG, Gosselink JMJ, Bokma S (2009) Reflexive interactive design and its application in a project on sustainable dairy husbandry systems. Outlook Agric 38 (2): 137-145

Chauve CM (1998) The poultry red mite Dermanyssus gallinae (De Geer, 1778): current situation and future prospects for control. Vet Parasitol 79: 239-245

Chiron G, Varescon A, Lubac S, Bicout DJ, Roy L (2014) Méthode d'aide à la prise de décision de traitement contre Dermanyssus gallinae (pou rouge) en élevage de ponte. TeMA 32 : 27-34

Cox M, De Baere K, Vervaet E, Zoons J, Fiks-Van Niekerk T (2009) Red mites: monitoring method and treatment. In: Book of Abstracts 8th European Symposium on Poultry Welfare, Cervia, Italy, 18-22 May: 83 
Cropwatch BV http://www.dutchfoodinnovations.com/innovation/standardised-countingof-red-poultry-mite-via-smartphone-camera (22-8-2016)

Dent D (2000) Insect pest management. 2nd edition CABI International, UK. ISBN 0-85199$341-9$

Dovc a, Semrov N, Vergles Rataj A, Lindtner Knific R, Nemec M, Trbovsek T, Bradasevec Z, Zorman Rojs $O$ (2016) Evaluation of alternative method for sampling Dermanyssus gallinae (Acari: Dermanyssidae) in poultry farms. In: Final programme and book of abstract of the $2^{\text {nd }}$ COST conference and management committee (MC) meeting, COST Action FA1404 Improving current understanding and research for sustainable control of the poultry red mite Dermanyssus gallinae (COREMI),1 $1^{\text {st }} 3^{\text {rd }}$ June, Zagreb, Croatia: 23

Elliot D (1997) Biological pest control success in greenhouse tomatoes. Proceedings. 1997 New England vegetable and berry growers conference and trade show. Dec. 16-18: 154-157

http://ipm.uconn.edu/documents/raw2/Biological\%20Pest\%20Control\%20Success \%20in\%20Greenhouse\%20Tomatoes/Biological\%20Pest\%20Control\%20Success\%2 0in\%20Greenhouse\%20Tomatoes.php?aid=45 (2-7-2016)

Engeström Y, Virkkunen J, Helle M, Pihlaja J, Poikela R (2016) The Change laboratory as a ool for transforming work. Center for Activity Theory and Developmental Work Research, University of Helsinki.

http://citeseerx.ist.psu.edu/viewdoc/download?doi=10.1.1.691.8231\&rep=rep1\&typ e=pdf (22-8-2016)

European Union (2009) Directive 2009/128/EC of the European parliament and of the council of 21 October 2009 establishing a framework for community action to achieve the sustainable use of pesticides. Off. J. Eur. Union 52: 71-86 http://eurlex.europa.eu/LexUriServ/LexUriServ.do?uri=0J:L:2009:309:0071:0086:en:PDF (9-52016)

Faleiro DCC, Toldi M, Silva GL, Da Ferla NJ (2015) The ectoparasites Dermanyssus gallinae and Megninia ginglymura: bioecology and natural enemies in commercial egg laying hens. Syst Appl Acarol 20: 861-874

Friesen P, Van Rooij B, Verhoeven A (2011) Bloedmijtbestrijding door inzet roofmijten. Rapport HAS kennistransfer, 's Hertogenbosch

Graesch J (2016) http://www.gpnmag.com/article/pest-monitoring-and-maximizing-usebeneficial-insects / (2-7-2016)

Hachler M (1989) The black cutworm, Agrotis ipsilon Hufn. (Lepidoptera, Noctuidae). A pest of field, market garden and small fruit crops. II Trapping adults with the aid of lighttraps. Rev Suisse Agric 21: 159-168

Hald B, Skovgard H, Pedersen K, Bunkenborg H (2008) Influxed insects as vectors for Campylobacter jejuni and Campylobacter coli in Danish broiler houses. Poult Sci 87: 1428-1434 
Harrington DWJ, George DR, Guy JH, Sparagano OAE (2011) Opportunities for integrated pest management to control the poultry red mite, Dermanyssus gallinae. World Poult Sci J 67 (1): 83-94

Immediato D, Camarda A, Iatta R, Puttili MR, Ramos RAN, Paola G. Giamgaspero A, Otranto D, Cafarchia C (2015) Laboratory evaluation of a native strain of Beauveria bassiana for controlling Dermanyssus gallinae (De Geer, 1778) (Acari: Dermanysssidae). Vet Parasitol 212 (3/4): 478-482

Ingram J (2014) Farmer-Scientist knowledge exchange. In: Encyclopedia of food and agricultural ethics, Springer. Thompson PB, Kaplan DM (Eds.): 722-729

Kirkwood A (1963) Longevity of the Mites Dermanyssus gallinae and Liponyssus sylviarum. Exp Parasit 14: 358-366

Koenraadt CJM, Dicke M (2010) The role of volatiles in aggregation and host-seeking of the haematophagous poultry red mite Dermanyssus gallinae (Acari: Dermanyssidae). Exp Appl Acarol 50: 191-199

Legg, D.E., 2004. The relevance of modelling in successful implementation of IPM. In: Integrated Pest Management: Potential, constraints and challenges. Koul 0, Dhaliwal GS, Cuperus GW (Eds.), CABI Publishing: 39-54

Lesna I, Wolfs P, Faranji, F, Roy L, Komdeur J, Sabelis MW (2009) Candidate predators for biological control of the poultry red mite Dermanyssus gallinae. Exp Appl Acarol 48: 63-80

Lesna I, Sabelis MW, Van Niekerk TGCM, Komdeur J (2012) Laboratory tests for controlling poultry red mites (Dermanyssus gallinae) with predatory mites in small 'laying' hen cages. Exp Appl Acarol 58: 371-383

Maurer V, Hertzberg H (2001) Ökologische legehennenhaltung. Was tun die kleinen vampire? DGS-Mag 40: 49-52

Maurer V, Bieri M, Fölsch DW (1988) Das suchverhalten von Dermanyssus gallinae in hühnerställen. Host-finding of Dermanyssus gallinae in poultry-houses. Arch Geflügelkd 52: 209-215

Maurer V, Baumgärtner J, Bieri M, Fölsch DW (1993) The occurrence of the chicken mite Dermanyssus gallinae in Swiss poultry houses. Mitt Schweiz Entomol Ges 66: 87-97

McDevitt R, Nisbet AJ, Huntley JF (2006) Ability of a proteinase inhibitor mixture to kill poultry red mite, Dermanyssus gallinae, in an in vitro feeding system. Vet Parasitol 141: 380-385

Mul MF, Koenraadt CJM (2009) Preventing introduction and spread of Dermanyssus gallinae in poultry facilities using the HACCP method. Exp Appl Acarol 48: 167-181

Mul MF, Van Riel JW, Meerburg BG, Dicke M, George DR, Groot Koerkamp PWG (2015) Validation of an automated mite counter for Dermanyssus gallinae in experimental laying hen cages. Exp App Acarol 66: 589-603

Mozafar F (2014) Tackling red mite in laying hens remains a challenge. Worldpoultry 30 (1): 22-24 
Nechita IS, Poirel MT, Cozma V, Zenner L (2015) The repellent and persistent toxic effects of essential oils against the poultry red mite, Dermanyssus gallinae. Vet Parasitol 214: 348-352

Nichols GL (2005). Fly transmission of Campylobacter. Em Inf Dis 11: 361-364

Nordenfors H, Höglund J (2000) Long term dynamics of Dermanyssus gallinae in relation to mite control measures in aviary systems for layers. Br Poult Sci 41: 533-540

Nordenfors H, Höglund J, Uggla A (1999) Effects of temperature and humidity on oviposition, molting and longevity of Dermanyssus gallinae (Acari: Dermanyssidae). J Med Entomol 36: $68-72$

Nordenfors H, Höglund J, Tauson R, Chirico J (2001) Effect of permethrin impregnated plastic strips on Dermanyssus gallinae in loose-housing systems for laying hens. Vet Parasitol 102: 121-131

Øines 0, Brännström S (2011) Molecular investigations of cytochrome c oxidase subunit I (COI) and the internal transcribed spacer (ITS) in the poultry red mite, Dermanyssus gallinae, in northern Europe and implications for its transmission between laying poultry farms. Med Vet Entomol 25(4): 402-412

Oliveira DGP, Alves LFA, Sosa-Gomez DR (2014) Advances and perspectives of the use of the entomopathogenic fungi Beauveria bassiana and Metarhizium anisopliae for the control of arthropod pests in poultry production. Braz J Poult Sci 16 (1): 1-12

Pavlicevic A, Pavlovic I, Stajkovic N (2007) Method for early detection of poultry red mite Dermanyssus gallinae (De Geer, 1778). Biotechnol Anim Husb 23 (3-4): 119-127

Peshin R, Bandral RS, Zhang W, Wilson L, Dhawan AK (2009) Integrated pest management: A global overview of history, programs and adoption. In: Integrated pest management volume 1: Innovation-Development Process. Peshin RD, Ashok K (Eds.)

Pritchard J, Kuster T, Sparagano O, Tomley F (2015). Understanding the biology and control of the poultry red mite Dermanyssus gallinae: a review. Avian Pathol 44 (3): 143-153

Quinlan M, Stanaway M, Mengersen K (2015). Biosecurity Surveillance in Agriculture and Environment: a Review. In: Biosecurity surveillance: Quantitative approaches. Jarrad F, Low-Choy S, Mengersen K (Eds.) CABI publishing: 9-42

Roy L, Burronfosse, $\mathrm{T}$ (2011) Using mitochondrial and nuclear sequence data for disentangling population structure in complex pest species: A case study with Dermanyssus gallinae. PLos ONE 6 (7): e22305

Roy L, Chiron G, Lubac S, Bicout DJ (2014) Tape-traps as an easy-to-use tool for monitoring and surveillance of the poultry red mite in cage and free-range layer farms. XIVth European Poultry Conference, Stavanger (Norway), June 23-27th 2014

Schicht S, Qi W, Poveda L, Struve C (2014) The predicted secretome and transmembrane of the poultry red mite Dermanyssus gallinae. Parasit Vectors 6: 259

Schulz J (2014) Massnahmen zur bekämphung der roten vogelmilbe (Dermanyssus gallinae) in der ökologischen legehennenhaltung. Dissertation, Freie Universität Berlin. ISBN: 978-3-863877-505-3 
Sparagano OAE, George DR, Finn RD, Giangaspero A, Mul M, Papadopoulos E, Tomley F, Pritchard J (2014a) Dermanyssus gallinae and poultry production: Impact, management, and a predicted compatibility matrix for integrated approaches. Conference information and proceedings of the XIVth European poultry conference, Stavanger, Norway 23-27 June 2014: 131-141

Sparagano OAE, George DR, Harington DWJ, Giangaspero A (2014b). Significance and control of the poultry red mite, Dermanyssus gallinae. Annu Rev Entomol 59: 447-466

Steenberg T, Kilpinen O (2014) Synergistic interaction between the fungus Beauveria bassiana and desiccant dusts applied against poultry red mites (Dermanyssus gallinae). Exp Appl Acarol 62 (4): 511-524

Steenberg T, Kilpinen O, Moore D (2006) Fungi for control of the poultry red mite, Dermanyssus gallinae. Proceedings of the international workshop 'Implementation of biocontrol in practice in temperate regions - present and near future'. DIAS report 119: 71-74

Sokol R, Szkamelski A, Barski D (2008) Influence of light and darkness on the behaviour of Dermanyssus gallinae on layer farms. Pol J Vet Sci 11 (1): 71-73

Sokol R, Koziatek Sadlowska S (2016) Monitoring the invasion of Dermanyssus gallinae in flocks of layer hens. In: Final programme and Book of abstract of the $2^{\text {nd }}$ COST conference and management committee (MC) meeting, COST Action FA1404 Improving current understanding and research for sustainable control of the poultry red mite Dermanyssus gallinae (COREMI), $1^{\text {st }} 3^{\text {rd }}$ June, Zagreb, Croatia: 24

Tucci EC, Bruno TV, Guimaraes JH (1989) Armadilha para amostragem de Dermanyssus gallinae (Acari Dermanyssidae) em aviários de postura comercial. Arq Inst Biol (São Paulo) Supl 56: 114

Tuovinen T (2015). Lessons to be learned from IPM in horticulture. Integrated management of poultry red mite. In: Proceedings of the 1st COST conference and management committee (MC) meeting, COST Action FA1404 Improving current understanding and research for sustainable control of the poultry red mite Dermanyssus gallinae (COREMI), 28th-29th May, Foggia, Italy: 17

Tuovinen T, Heikkilä P, Juvonen S, Lindqvist B, Tuovinen T (2010) Kanapunkki hallintaan munintakanaloissa. Control of red poultry mite in laying hen houses. Research report MMM12-3/312/2010. MTT Kasvintuotannon tutkimus Joikioinen (In Finnish)

Van de Ven D (2016) Q-perch, electronic control of red mite. In: Final programme and Book of abstract of the $2^{\text {nd }}$ COST conference and management committee (MC) meeting, COST Action FA1404 Improving current understanding and research for sustainable control of the poultry red mite Dermanyssus gallinae (COREMI), $1^{\text {st }} 3^{\text {rd }}$ June, Zagreb, Croatia: 21

Van den Berg H, Das PK, Von Hildebrand A, Ragunathan V (2006) Evaluation of the integrated pest and vector management (IPVM) project in Sri Lanka: mission report, July 2006. New Delhi: WHO Regional Office for South-East Asia; 2006. Available at: 
http://www.searo.who.int/EN/Section23/Section1001/Section1110_12796.htm_(228-2016)

Van Driesche R, Bellow TS jr (2001) Biological control. Kluwer Academic Publishers, Massachussetts, third edition

Van Emous RA, Napel J ten (2007) Buis met stokje zeer geschikt voor bewustwording. De Pluimveehouderij 37: 8-9 (In Dutch)

Van Emous RA van, Fiks-van Niekerk TGCM, Mul MF (2005) Bloedluizen (vogelmijten) op papier en in de praktijk. PraktijkRapport 17 Animal Sciences Group Praktijkonderzoek ISSN 15708624 (In Dutch)

Van Lenteren JC, Woets J (1988) Biological and integrated pest control in greenhouses. Ann Rev Entomol 33: 239-269

Vänninen I, Pereira-Querol M, Engeström Y (2015) Generating transformative agency among horticultural producers: An activity-theoretical approach to transforming integrated pest management. Agricultural Systems 139: 38-49

Vosman B, Faber JH (2011) Functionele agrobiodiversiteit: van concept naar praktijk. Wageningen, Plant Research International, rapport 421 (In Dutch)

Wielgosz B, Mangheni M, Tsegai D, Ringler C (2012) Malaria and agriculture: a global review of the literature with a focus on the application of integrated pest and vector management in East Africa and Uganda. IFPRI - Discussion Papers, (1232): vii. International Food Policy Research Institute, Washington, USA

Wielinga HE, Zaalmink BW, Bergevoet RHM, Geerling-Eiff FA, Holster H, Hoogerwerf L, Vrolijk M (2007) Networks with free actors: encouraging sustainable innovations in animal husbandry by using the FAN approach. Wageningen University and Research $123 \mathrm{pp}$.

Wijnands FG, Brinks H, Schoorlemmer H, De Bie J (2014) Integrated pest management adoption in the Netherlands: Experiences with pilot farm networks and stakeholder participation. In: Integrated Pest Management. Peshin R, Pimentel D (eds.). Springer Science+Business Media Dordrecht: 513-554

Wilby A, Thomas MB (2007) Diversity and pest management in agroecosystems. Some perspectives from ecology. In: Managing biodiversity in agricultural ecosystem. Jarvis DI, Padoch C, Cooper HD (Eds.): 269-291

Xiaofei L, Yan J, Hui Y (2013) Recent spread and climatic ecological niche of the invasive guava fruit fly, Bactrocera correcta, in mainland China. J Pest Sci 86: 449-458

Zenner L, Bon G, Chauve C, Nemoz C, Lubac S (2009) Monitoring of Dermanyssus gallinae in free-range poultry farms. Exp Appl Acarol 48: 157-166 


\section{Summary}


Pest and diseases in agricultural systems reduce the yield and quality of available food and feed worldwide. To meet the global growing demand for these products, losses should be reduced, preferably in a sustainable way. Integrated Pest Management (IPM) is a sustainable method that aims to minimize economic losses due to pests and diseases. IPM is generally based on eight steps: 1) prevention, 2) monitoring, 3) Decision-making based on monitoring and thresholds, 4) use of non-chemical methods, 5) pesticide selection, 6) reduced pesticide use, 7) anti-resistance strategies, and 8) evaluation. With these steps, it is possible to prevent and control pests and diseases whilst deploying pesticides only as a last resort, thus reducing issues with pesticide contamination and resistance. Implementation of IPM by farmers increases when it is clear that it is compatible with existing farm processes and that it results in benefits for them.

Successful IPM is most commonly applied against pests and diseases in crop production. When comparing the number of research articles on IPM in crop production with the number of research articles on IPM in animal production, it becomes clear that a paucity of scientific papers have been published on the latter. In laying hen facilities, for example, the application of all but basic IPM is still rare, even though the benefits of IPM have been described for poultry pests and disease vectors. In laying hen facilities Dermanyssus gallinae (PRM=poultry red mite), an hematophagous parasite, is common in many parts of the world. This mite is hard to control and negatively affects hen health, -welfare and farm economics, with estimated costs of infestation reaching 130 million euro per year in Europe. Currently, implementation of IPM for D. gallinae in laying hen facilities is limited to some combination of cleaning between flocks, limited preventive measures, and application of chemically or physically acting products. Implementation of more advanced IPM programmes for $D$. gallinae should therefore be considered to improve control prospects for this pest in laying hen facilities.

This thesis focuses on the knowledge necessary for advancing IPM for D. gallinae in laying hen facilities. More specifically it focuses on prevention, monitoring and population modelling of this significant pest, with preventive measures and monitoring being key in advancing IPM per se.

Knowledge assessment. To develop IPM for D. gallinae in laying hen facilities, biological and ecological knowledge of D. gallinae and knowledge of the effects of biotic and a-biotic factors on this pests' population development are required (Chapter 2). Therefore, a seminar was organized with eighteen D. gallinae researchers, from eight different European countries, with the aim of amassing existing expertise. This seminar gave insight into the current knowledge and knowledge gaps, regarding D. gallinae, also informing future perspectives and required developments for improving control of D. gallinae in laying hen facilities. During four sessions, the researchers present discussed lifecycle issues, effects of $D$. gallinae on hen and egg production, monitoring methods for D. gallinae infestations in laying hen facilities and control methods for D. gallinae in laying hen facilities. It was concluded that, where the D. gallinae lifecycle is concerned, a lot is still unknown about the mites 
feeding behaviour and preferences, mating behaviour, survival and conditions required for reproduction, host finding, aggregation cues, and attractant and repellent substances. When focusing on the effects of D. gallinae on the hen and on egg production it was agreed that a $D$. gallinae infestation is likely to result in higher water intake, lower egg production, lower feed conversion, increase of the immune response and reduced feather quality. It was also suggested that these effects may be hen genotype dependent, and further noted that effects are rarely quantified and need further investigation. Though monitoring was considered to be most important to improve control of D. gallinae, it was concluded that the available monitoring methods only indicate trends and a robust monitoring plan is lacking. The participants considered heating the hen house combined with a chemical treatment to be the most promising control method. Future promising developments for control of $D$. gallinae were considered to be use of vaccination, predatory mites and entomopathogenic fungi. The effects of D. gallinae on human health were not extensively discussed, but it was concluded that D. gallinae can be of medical significance, either directly via reaction to mite bites, or indirectly via human exposure to the chemicals used to control $D$. gallinae.

Prevention. To acquire knowledge on the routes of introduction and spread of D. gallinae in laying hens facilities, the Hazard Analysis and Critical Control Points (HACCP) system was used (Chapter 3). The structure of this system allows the user to identify the risk factors and the critical control points for the introduction and spread of pathogens and parasites. This method was further used to identify preventive and corrective actions against D. gallinae. Four experts identified 41 hazards for introduction and spread of D. gallinae in laying hen facilities. To prevent these hazards, these experts made several suggestions for corrective actions. The risks of 41 hazards were calculated by multiplying the likelihood $1=$ occurring seldomly/theoretically; $2=$ occurring approximately once a year; $3=$ occurring repeatedly/more than once a year) by the severity $(1=$ low / single place in the facility becomes infested with $D$. gallinae; $2=$ moderate/facility becomes infested at more than one location; $3=$ high/ D. gallinae infestation occurs at almost all places within the laying hen facility) of infestation. Hazards with a risk above 3, or with a severity of 3, were regarded as Critical Control Points (CCP's). The CCP's with the highest risks (risk of 6 and higher) for introduction of D. gallinae in laying hen facilities were: introduction of new flocks, containers and crates, the farmer and their employees. The CCP's with the highest risks (risk of 6 and higher) for spread of D. gallinae between laying hen facilities were mice, rats and flies, wild birds, the feeding system, shared material and equipment, the egg conveyer belt, manure aeration pipes, removal of cadavers, visitors and external personnel, the farmer and their employees. The critical limits, a procedure step of the HACCP system which will be followed by a corrective action when the limit is exceeded, could not be determined as a result of lack of knowledge about thresholds. Subsequently, suggestions were made for monitoring the mite population and for documentation and validation. A checklist was devised using the corrective action from the CCP's with the highest risks. This management tool for layer farmers was evaluated by UK and Dutch layer farmers as feasible and useful. 
Monitoring. The approach of Reflexive Interactive Design (RIO) was used to design an automated monitoring tool for D. gallinae, including an automated mite detection sensor (Chapter 6). The approach generated effective and technically feasible solutions for the key functions of the automated mite detection sensor, these being 1) the assessment of the $D$. gallinae population, 2) localizing the location and assessing the time of detection and 3) removal of mites from the detection area. Three different design concepts were designed using these solutions. As an additional, albeit proven essential step to the RIO approach, the main solutions were tested with live mites ensuring the alignment of solutions with the biology and behaviour of D. gallinae in vivo. A combination of the best solutions were developed in two different prototypes. These prototypes were subsequently tested in the laboratory and on farm. The prototype situated under the perch, with a through beam sensor and a pump to remove mites from the sensor after recording, was the most successful model. The designed automated mite detection sensor, or automated mite counter, for D. gallinae was subsequently validated in experimental laying hen cages with live birds and a growing population of D. gallinae (Chapter 5). The study resulted in 17 data points, each being a combination of 'number of mites counted' by the automated mite counter and the 'number of mites present' in the experimental laying hen cages. The regression line between the 'number of mites counted' and the 'number of mites present' demonstrated that the automated mite counter was able to track the D. gallinae population effectively.

Population modelling. Step 2 of IPM describes not only pest monitoring in the field, but also 'scientifically sound warning, forecasting and early diagnosis systems, where feasible, as well as the use of advice from professionally qualified advisors'. To advance this step for D. gallinae we developed and demonstrated an operational model, forecasting the mite population dynamics and evaluating and forecasting the effect of a treatment application for D. gallinae in laying hen facilities. For IPM this model and the required inputs need to be 1) labour-extensive with minimal staff input, preferably automatically implementing "real time" measurement data into models; 2) operational, providing easily interpretable data, forecasting pest population dynamics and the moment a threshold will be exceeded; 3 ) able to compensate for different locations and time-specific-interactions and variables (e.g. management and temperature), enabling the handling of variability of the parameters of interest; 4) able to identify pest hotspots; 5) able to estimate and forecast treatment efficacy; and 6) applicable for different monitoring methods and therefore able to correct for monitoring measurement errors. Prior to the development of the population dynamics model a high variation in population growth was found which could be only partly explained by temperature, flock age, treatment, and compartment/laying hen facility. A substantial part of the total variation remained unexplained, or was found to be temporal. As a result of this partly temporal variation, a dynamic approach was suggested to improve the forecasting quality of a population dynamics model. With the input of population monitoring data, temperature data and information of the dates of any D. gallinae treatment 
interventions, the developed model was able to forecast the population dynamics of $D$. gallinae post treatment and without treatment while compensating for location and time specific interactions, handling the variability of the parameters. Moreover, this population dynamics model was able to forecast the D. gallinae population using data from different monitoring methods. Together with the models compatibility with different housing systems and its ability to forecast the mite population dynamics (requiring only three relative easy obtainable parameters), this model is an improvement over existing approaches for forecasting D. gallinae that could contribute to steps 2 and 8 of IPM for $D$. gallinae in laying hen facilities.

The results from this study directly facilitate advanced IPM programmes for D. gallinae in laying facilities. The new 'products' developed are tools for prevention, monitoring, forecasting population dynamics and evaluating treatment effects, representing the requirements of IPM steps 1,2 , and 8 . Indirectly the results may accelerate the development of new control measures, with knowledge acquired through use of the developed products it also is likely to contribute to IPM steps 3, 4, 6 and 8 in the future; e.g. the determination of an action threshold, and a tool advising farmers on the most effective and economic time for applying a corrective action or hotspot treatment for D. gallinae.

With the obtained knowledge and new products implemented to control D. gallinae in laying hen farms, major advances can be made in IPM for this pest. More specifically, as a result of this work IPM for D. gallinae in laying hen facilities can be advanced by the identification of preventative control measures, the development of an automated monitoring tool and a model forecasting mite population dynamics and evaluating applied treatments. Consequently, the results of this study can be expected to improve hen health, welfare and farm economics for the egg production industry. In the future, advances in other IPM programmes can be expected when the obtained knowledge, tools and methods are transferred to other pest species in multiple sectors. 


\section{Samenvatting}


Plagen en ziekten in de agrarische sector leiden wereldwijd tot een afname van beschikbaar voedsel en diervoer. Om te kunnen blijven voldoen aan de toenemende vraag naar voedsel en diervoer zullen verliezen beperkt moeten worden, het liefst op een duurzame wijze. Geïntegreerde plaagbeheersing (Integrated Pest Management = IPM) is een duurzame methode om, economische, verliezen door plagen en ziekten te beperken en is gebaseerd op een achttal stappen: 1) Preventie, 2) Monitoren, 3) Beslissingen voor curatieve methoden gebaseerd op monitoring en een drempelwaarde, 4) Gebruik van niet-chemische methoden, 5) Pesticideselectie, 6) Beperken pesticidengebruik, 7) Anti-resistentie strategieën, en 8) Evaluatie. Door het uitvoeren van deze stappen is het mogelijk om plagen te voorkomen en te beheersen waarbij pesticiden alleen gebruikt worden als andere middelen en methoden een te beperkt resultaat geven. De problemen met betrekking tot residuen van pesticiden en resistentie ontwikkeling kan hiermee worden verminderd. IPM zal worden toegepast door agrariërs als de methodiek past binnen de huidige bedrijfsvoering en als het hen voordelen oplevert.

IPM wordt vooral succesvol toegepast tegen plagen en ziekten in de plantenteelt. In de veehouderij wordt IPM ook toegepast, maar in beperktere mate dan in de plantenteelt. Hoewel de voordelen van IPM beschreven zijn voor ziekte en plagen van pluimvee en voor vectoren van pluimveeziekten, wordt deze methodiek in de legpluimveehouderij nog maar mondjesmaat toegepast voor het beheersen van plagen en ziekten. Een plaag in de legpluimveehouderij die momenteel moeilijk te bestrijden is, is Dermanyssus gallinae (vogelmijt of bloedluis). Dit is een bloedzuigende mijt die wereldwijd voorkomt en de diergezondheid, het dierenwelzijn en de productiekengetallen negatief beïnvloedt. In Europa worden de kosten van D. gallinae populaties in de legpluimveehouderij geschat op 130 miljoen euro per jaar. De IPM maatregelen voor D. gallinae die worden toegepast in de legpluimveehouderij zijn momenteel beperkt tot het reinigen tussen de ronden, een aantal preventieve maatregelen en het toepassen van chemische producten of producten die de mijt fysisch aantasten. Uitvoering van verbeterde IPM-programma's voor D. gallinae zal leiden tot een betere beheersing van deze plaag in legpluimveebedrijven.

Dit proefschrift richt zich op de kennis die nodig is voor het verbeteren van IPM voor $D$. gallinae in de legpluimveehouderij. De nadruk ligt op preventie, monitoring en het modelleren van de populatiedynamiek van de plaag.

Kennis inventarisatie. Om IPM-programma's voor D. gallinae verder te ontwikkelen is het noodzakelijk om kennis en inzichten te hebben in de biologie van D. gallinae en in de effecten van biotische en abiotische factoren op de ontwikkeling van D. gallinae populaties. Deze kennis werd verzameld en bediscussieerd tijdens een seminar met achttien D. gallinae onderzoekers uit acht verschillende Europese landen (Hoofdstuk 2). Het seminar gaf inzicht in de reeds bestaande kennis, kennishiaten, toekomstperspectieven en in ontwikkelingen die nodig zijn voor het beter beheersen van D. gallinae in legpluimveestallen. Tijdens het seminar bediscussieerden de D. gallinae-onderzoekers levenscyclus gerelateerde onderwerpen, de effecten van een $D$. gallinae populatie op de hen en de eiproductie, $D$. 
gallinae monitoring-methoden voor legpluimveestallen en methoden en middelen om $D$. gallinae in legpluimveestallen te beheersen. Men concludeerde dat er kennis ontbreekt over de levenscyclus van D. gallinae, het gedrag van de mijt en voorkeuren voor bijvoorbeeld geurstoffen en materialen, het paringsgedrag, vereisten voor overleving en vermeerdering, gastheerherkenning, motivatie voor het vormen van aggregaties, aantrekkelijke en afstotende stoffen en de factoren die de bloedopname van D. gallinae beïnvloeden. Verder concludeerde men dat de gevolgen van een D. gallinae besmetting in legpluimveestallen zich manifesteert in de vorm van hogere water- en voeropname, lagere eiproductie, lagere voederconversie, een toename van de immuunrespons en een verminderde verenkwaliteit. Naar alle waarschijnlijkheid zijn de effecten afhankelijk van het genotype. De bovengenoemde gevolgen zijn zelden gekwantificeerd en verdiepend onderzoek werd als wenselijk beschouwd. "Monitoren" is het meest belangrijke aandachtspunt om D. gallinae beter te kunnen beheersen, aldus de deelnemende onderzoekers. Echter, de huidige monitoring-methoden geven slechts een trend aan in de ontwikkeling van een D. gallinae populatie en daarbij ontbreekt een goed monitoringsplan. De meest perspectiefvolle controlemaatregel tegen D. gallinae was volgens de onderzoekers het verwarmen (verhitten) van een leghennenstal in combinatie met een chemische behandeling. Veelbelovende toekomstige ontwikkelingen voor het beheersen van een D. gallinae besmetting waren volgens de onderzoekers het toepassen van vaccinatie, roofmijten en insectenziektenverwekkende schimmels. De gevolgen van D. gallinae voor de mens werden kort bediscussieerd waarna geconcludeerd werd dat D. gallinae grote gevolgen kan hebben voor de humane gezondheid, enerzijds direct als gevolg van een mijtenbeet en anderzijds indirect als gevolg van de bestrijdingsmiddelen die ingezet worden voor het beheersen van een D. gallinae populatie.

Preventie. Kennis over de introductieroutes en de routes waarlangs D. gallinae zich verspreidt binnen legpluimveestallen werd verkregen door het uitvoeren van de HACCP methodiek (Hazard Analysis and Critical Control Points). Door de gestructureerde aanpak van de methode is het mogelijk om risicofactoren en kritische beheerspunten te bepalen die invloed hebben op de introductie en het verspreiden van pathogenen en parasieten. Daarnaast is het mogelijk om met deze methode preventieve en corrigerende maatregelen te identificeren. Vier experts identificeerden 41 gevaren (hazards) voor de introductie en verspreiding van D. gallinae in legpluimveestallen. Om deze gevaren te voorkomen hebben de experts corrigerende maatregelen voorgesteld. Het risico van het gevaar werd berekend door de kans (1= vindt zelden plaats/theoretisch; $2=$ vindt eens per jaar plaats; $3=$ gebeurd herhaaldelijk/meer dan eens per jaar) te vermenigvuldigen met de ernst $(1=$ laag/een enkele plek in de stal raakt besmet met D. gallinae; $2=$ matig/stal raakt besmet op meer dan één plek; $3=$ hoog/D. gallinae verschijnt op bijna alle plaatsen in de leghennenstal). De gevaren met een risico hoger dan 3 of met een ernst gelijk aan 3 werden aangemerkt als een kritisch beheerspunt (critical control point $=$ CCP). De CCP's met de hoogste risico's (6 of hoger) voor de introductie van D. gallinae in een legpluimveestal waren: aanvoer van een 
nieuw koppel hennen, containers en kratten, pluimveehouder en werknemers. De CCP's met de grootste risico's voor de verspreiding van D. gallinae tussen legpluimveestallen waren: muizen, ratten en vliegen, wilde vogels, het voersysteem, materiaal en gereedschap dat in de verschillende stallen wordt gebruikt, eierbanden, mestbeluchtingspijpen, het verwijderen van kadavers, bezoekers en adviseurs, pluimveehouder en werknemers. De kritische limiet of drempelwaarde, een stap in de HACCP-methode waarna een corrigerende maatregel wordt uitgevoerd zodra de limit wordt overschreden, is niet vastgesteld door een gebrek aan kennis over de drempelwaarde en de consequenties van verschillende populatiegrootten. Vervolgens zijn er suggesties gedaan voor de daaropvolgende stappen; het monitoren van de D. gallinae populatie, de documentatiestap en de validatiestap. Een checklist is opgesteld met behulp van de corrigerende maatregelen van de CCP's met de hoogste risico's. Deze managementtool voor legpluimveehouders is door Britse en Nederlandse legpluimveehouders getest en geëvalueerd als bruikbaar en uitvoerbaar.

Monitoren. De RIO aanpak (Reflexief Interactief Ontwerpen) is toegepast om een automatische monitoringtool, inclusief een sensor voor automatische vogelmijtdetectie, te ontwerpen voor D. gallinae (Hoofdstuk 4). De aanpak leidde tot effectieve en technisch haalbare oplossingen voor de belangrijkste functies van de automatische sensor voor vogelmijtdetectie, te weten 1 ) het vaststellen van de omvang van de D. gallinae populatie, 2) het bepalen van de locatie en het tijdstip van detectie, en 3) het vrijmaken van het detectiegebied. Met deze oplossingen zijn drie verschillende ontwerpconcepten samengesteld. Een noodzakelijke aanvulling op de RIO-aanpak was het testen van de belangrijkste oplossingen met levende mijten waardoor de gebruikte oplossingen aansluiten bij de biologie en het gedrag van $D$. gallinae in vivo. De best geteste oplossingen zijn vervolgens gecombineerd in twee verschillende prototypen sensoren voor automatische vogelmijtdetectie welke achtereenvolgens zijn getest in het laboratorium en in een legpluimveestal. Het meest succesvolle prototype was bevestigd onder de zitstok, was voorzien van een zender-ontvanger sensor en een pomp om de mijten bij de sensor te verwijderen. De ontworpen sensor voor automatische vogelmijtdetectie, of vogelmijtteller is vervolgens gevalideerd in experimentele leghennenkooien met leghennen en een dynamische D. gallinae populatie (Hoofdstuk 5). Dat onderzoek heeft geresulteerd in 17 datapunten. Elk datapunt was een combinatie van 'het aantal getelde mijten' door de vogelmijtteller en 'het aantal aanwezige mijten' in de experimentele kooien. De regressielijn tussen 'het aantal getelde mijten' en 'het aantal aanwezige mijten' toonde aan dat de tellers de D. gallinae populatie doelmatig kon volgen.

Modellering populatiedynamiek. IPM stap 2 schrijft niet alleen het monitoren van een plaag voor, maar ook 'wetenschappelijk verantwoorde waarschuwing, vooruit voorspellen en een systeem voor tijdige diagnose, indien mogelijk, evenals het gebruik en toepassen van adviezen van gekwalificeerde adviseurs'. In het kader van stap 2 van IPM hebben we een operationeel model ontwikkeld dat de populatiedynamiek van een D. gallinae populatie in legpluimveestallen kan voorspellen en het effect van een bestrijding op de omvang van de $D$. 
gallinae populatie kan evalueren en voorspellen. Het ontwikkelde model en de werking ervan laten we zien in Hoofdstuk 6. Om een bijdrage te leveren aan IPM moet dit model én de input van het model voldoen aan de volgende eisen: 1) arbeidsvriendelijk met een minimale hoeveelheid benodigde arbeid, bij voorkeur gebruikmakend van een systeem dat realtime data automatisch invoert in de modellen, 2) operationeel, levert gemakkelijk interpreteerbare gegevens op, kan de populatiedynamiek van een plaag voorspellen en het moment waarop de drempelwaarde wordt overschreden, 3) toepasbaar op verschillende locaties met unieke tijd- en plaatsspecifieke interacties en variabelen (zoals management en temperatuur), 4) kan hotspots identificeren, 5) kan een bestrijdingseffect inschatten en voorspellen, en 6) is geschikt voor verschillende monitoring-methoden en kan corrigeren voor de bijbehorende variërende meetfouten. Voorafgaand aan de ontwikkeling van het populatiedynamicamodel, vonden we een hoge variatie in de populatiegroei, die deels kon worden verklaard door temperatuur, leeftijd van het koppel hennen, toegepaste bestrijdingsmaatregel of door de afdeling danwel stal. Een substantieel deel van de totale variatie van de populatiegroei was onverklaarbaar of temporeel, onder andere doordat het leeftijdseffect van de hennen verschillend was voor ieder koppel. Bij een dergelijke temporele variatie kan, voor een betere voorspellende kwaliteit van een model, gekozen worden voor een dynamisch model. Het ontwikkelde dynamische model kon, met input van monitoringsdata, temperatuur en de datums waarop de bestrijding heeft plaatsgevonden, de populatiedynamiek van D. gallinae voorspellen na een bestrijding en zonder een bestrijding. Er werd daarbij rekening gehouden met bedrijfs- en koppelspecifieke interacties en de variatie van de parameters. Dit model was bovendien in staat om de populatiedynamiek te voorspellen met data van drie verschillende monitoring-methoden. Deze eigenschap van het model, de toepasbaarheid van het model op verschillende huisvestingssystemen en het feit dat dit model de populatiedynamiek kan voorspellen met behulp van drie relatief simpele inputparameters, is een verbetering ten opzichte van de reeds bestaande methoden om de populatiegroei van D. gallinae te voorspellen. Daarmee draagt het bij aan het verbeteren van stap 2 en stap 8 van IPM voor D. gallinae in legpluimveestallen.

De resultaten van het onderliggende onderzoek dragen direct bij aan het verbeteren van IPM voor D. gallinae in de legpluimveehouderij. De nieuw ontwikkelde producten zijn tools voor preventie, het monitoren, het voorspellen van de populatiedynamiek en voor het evalueren van het effect van een bestrijding(-smaatregel). Daarmee levert dit onderzoek een bijdrage aan IPM stappen 1, 2 en 8. Indirect zullen de resultaten van dit onderzoek bijdragen aan het versnellen van de ontwikkeling van nieuwe bestrijdings-methoden en beheersmaatregelen. In de toekomst kan door het gebruik van de producten meer kennis gegenereerd worden die vervolgens een bijdrage kunnen leveren aan IPM stappen 3, 4, 6 en 8. Bijvoorbeeld door het vaststellen van een drempelwaarde en een adviestool dat de pluimveehouder adviseert over het meest economisch en effectieve tijdstip voor het uitvoeren van een (hotspot)bestrijding tegen D. gallinae. Door de verkregen kennis en nieuwe producten daadwerkelijk toe te passen bij het beheersen van D. gallinae in 
legpluimveebedrijven, kunnen grote verbeteringen bereikt worden bij IPM tegen deze plaag. We kunnen dan ook concluderen dat de resultaten van het onderliggende onderzoek IPM voor D. gallinae in legpluimveebedrijven sterk kan verbeteren door de identificatie van preventieve beheersmaatregelen, de ontwikkeling van een automatische monitoringstool en een model dat de populatiedynamiek van de plaag kan voorspellen en de effectiviteit van een bestrijding(-smaatregel) kan bepalen. Als gevolg daarvan kan men verwachten dat de gezondheid en het welzijn van de hen en de bedrijfsresultaten in de leghennenhouderij verbeterd worden. Bovendien kunnen de verkregen kennis, tools en methoden in de toekomst worden toegepast op andere plagen en daarmee een bijdrage leveren aan het verbeteren van IPM-programma's voor andere plagen en in andere sectoren. 


\section{Dankwoord / Acknowledgements}

Tjeempie, dat was het dan. Het proefschrift ligt er. En wat was het leuk! Met zoveel fantastische mensen hebben we gewerkt aan het verkrijgen van nieuwe kennis en nieuwe hulpmiddelen. En al die fantastische mensen hebben hun eigen kennis en kunde gedeeld en geïnvesteerd om te komen tot het verkregen resultaat.

De bovenstaande alinea is geschreven in de verleden tijd. Alsof het project afgesloten is. Klaar. Dat is niet het geval. We gaan namelijk verder; de praktijk in, verbeteren en optimaliseren. En ook daarvoor is kennis en kunde noodzakelijk. Van unieke personen met unieke kwaliteiten. Een aantal van deze groep personen wordt hieronder bij naam genoemd.

\section{BEDANKT,}

Promotoren en co-promotoren. Vier personen wilde ik als begeleider. Omdat ieder zijn eigen kracht heeft. En het heeft gewerkt. Bedankt! Peter Groot Koerkamp. Vanaf de allereerste gedachte tot de allerlaatste minuut heb je jouw wetenschappelijke en sociale vaardigheden ingezet voor het realiseren van een idee, een wens. Zoveel van jou dat jij in dit project hebt gestopt! Een diepe buiging. Bastiaan Meerburg. Je hebt mij een handreiking gedaan om uit de put te komen, en vervolgens het vertrouwen gegeven dat het goed komt. Dat had ik nodig en heeft me verder gebracht. Marcel Dicke. Visie, borging van kwaliteit, zetjes geven in de juiste richting en kleine correcties. Dat, en meer, heb je in dit traject voor mij betekend. David George. How happy I was that you were going to be the second copromotor! Your writing skills and knowledge on D. gallinae enormously improved the quality of the path followed. Most likely this is an understatement.

Collega's WLR. Thea van Niekerk en Rick van Emous. Vanaf het allereerste begin zagen jullie het probleem en de oplossingen. Jullie hebben mij de ruimte gegeven, gesteund en geholpen waar jullie konden. Maudia van Wijhe-Kiezebrink. Jij bracht structuur aan in zaken omtrent projectbeheer en -financiën. Daarnaast ben je ook in sociaal opzicht een onmisbare collega. Johan Ploegaert. Jij hebt je kennis en kunde, je humor en zorgzaamheid gedeeld om te komen tot een automatische vogelmijtteller. Johan van Riel. Jouw bijdrage is niet in één zin uit te drukken. Zonder jou lag dit proefschrift er niet. Zo duidelijk is dat wel. Jij hebt de gedachte van Geert André (postuum bedankt) doorgezet; "Met modellen kunnen we de pluimveehouders inzichten verschaffen". Door dat inzicht weten we nu zoveel meer en zullen we in de toekomst zoveel meer te weten komen. En wat een geduld! En dan ben je ook nog eens mijn paranimf om mij inhoudelijk bij de ceremonie te kunnen ondersteunen. Piet van Wikselaar, Leo Kruijt, Agnes de Wit en Ruud Dekker. Jullie hebben de validatieproef uitvoerbaar en tot een succes gemaakt. Doorzetters zijn jullie, laboratoriumtechniekendeskundigen en sociaalvaardige collega's (noodzakelijk bij het tellen van al die mijten (H4)). En jullie schrikken niet eens als ik jullie weer vraag om te helpen met een vogelmijtproef! Francesca Neijenhuis. Bedankt voor het kundig organiseren 
van de ontwerp workshop. Ferry Leenstra en Ingrid de Jong. Bedankt voor het behartigen van de 'bloedluis' belangen binnen de PPS Poultry4Food.

Medewerkers van de proefaccommodaties. Gerrit Jan Deetman, Jan Truin, Melis van Beek, André Huiskes en Ries Verkerk. Door het meedenken en uitvoeren van de proef waren jullie onmisbaar.

Ontwikkelwerkplaats (Technical Development Studio) medewerkers. Eric Karruppannan en Hans Meijer. Jullie hebben de automatische vogelmijtteller verder ontwikkeld door jullie kennis en kunde toe te passen op het simpele, allereerste prototype.

Begeleidingscommissie Aanpak Bloedluis. Marlies Hanssen, Jan Vroegindeweij, Harrie Ketels, Jan Wijnen, Hugo Bens, Iris Odink-Schrijver, Hans Groot Koerkamp en Alex Spieker. Jullie gaven mij praktische, zinvolle feedback en steun bij het uitvoeren van de gekozen richting en bij zoeken van financiering. Zonder deze unieke groep mensen had dit onderzoek niet plaatsgevonden.

Pluimveehouders. Familie Wisserhof. Jullie gaven mij de mijten voor de laboratoriumproeven. Klaas Jan Salomons en medewerkers. Meer dan een jaar hebben jullie mij de ruimte gegeven om de automatische vogelmijtteller in jullie stal te ontwikkelen. Familie Lagerweij uit Buurmalsen. Jullie maakten het testen van de teller en het model in een praktijkstal mogelijk.

Collega's Livestock Technology. Ellen van Weeghel, Sam Blaauw, Bert Van 't Ooster, Bastiaan Vroegindeweij, Dennis Snoek, Liansun Wu, Peter van Beveren, Hyun Suh and Eldert van Henten. Thank you for providing help, supporting the MSc. students, making the technical drawings, mental support (just by knowing that other persons have to cope with hick-ups as well), and pleasant conversations in the coffee room. In that room there is time to talk about personal interests. Simon van Mourik. Omdat jouw opmerkingen hebben geleid tot een sterk verbeterd artikel en nog meer inzichten.

Collega's Entomologie. Sander Koenraadt. Omdat we samen hebben geleerd; jij over de vogelmijt, ik over methoden in de entomologie en het schrijven van artikelen. Rieta Gols en Jeroen Spitzen. De eerste beginselen over mijten heb ik van jullie geleerd en nog steeds ga ik af en toe bij jullie te rade.

LUKE (Finland) colleagues. Tuomo Tuovinen and Irene Vänninen. Thank you. During my short stay at LUKE, you gave me a fast introduction into IPM and gave me directions for writing the General introduction and General discussion.

Studenten. Roelof de Jong, Kevin Niessen, Corné van Schaik en Sander Bouwknegt. Bedankt voor jullie bijdrage aan de detectie van de vogelmijt, het bepalen van aantrekkelijke materialen en gedragingen van de vogelmijt, het verbeteren van de teller en het model, en het maken van de IDEF-O modellen.

Brainstormers en designers. Renate Smallegange, Fransje Gorter en Eddy Teenstra.

Collega's IBED. Iza Lesna en Maus Sabelis (postuum). Jullie hebben kennis en kunde gedeeld. De onschatbaar waardevolle opmerking van Iza over het specifieke vogelmijt gedrag heeft veel aan het rollen gebracht. 
Hotraco. Ger Schoeber en Diederik Fetter. Jullie zetten je in om de gevalideerde automatische vogelmijtteller beschikbaar te maken voor de gehele pluimveesector.

COST-action FA 1404 COREMI members. Thank you all for the fruitful cooperation and discussions. Special thanks goes to Johan Zoons (Experimental Poultry Center, Geel) and Lise Roy (CEFE, CNRS- Université Montpellier, Université P. Valery) for providing their mite monitoring- and farm economics datasets. These datasets gave so much insight into the development of D. gallinae populations enabling to make the population dynamics model. Moreover, it seems these datasets will reveal also the economic consequences of D. gallinae infestations in laying hen facilities. Kathryn Bartley, thank you for your help with the General discussion. Olivier Sparagano, Annunziata Giangaspero, Elias Papadopoulos , Antonio Camarda, Katerina Tiligada and Danijela Horvatek; together we will make the most and the best of COREMI.

Familie en vrienden. Voor jullie interesse, steun en soms jullie hulp bij het zoeken naar oplossingen. Peter Wijtten. Voor het kritisch doorlezen van de General discussion. José van Ginkel. Voor de extra taak die jij op je hebt genomen; mij emotioneel ondersteunen tijdens de ceremonie.

Mijn ouders. Gerrit en Cock Mul. Voor de steun die ik altijd van jullie heb gekregen. Ik zal nooit het kerstdiner vergeten waarbij, tussen de gangen door, de data kabels gemaakt werden. Het toetje werd daardoor bijna vergeten.

René Könst. Een hoofdstuk apart. Dat ben je en dat heb ik nodig om aan te duiden wat jij hebt bijgedragen aan het feest van de afgelopen jaren. Bedankt!

"Tjeempie, that was that". Here is the thesis. How I enjoyed it. To work with so many fantastic persons to obtain new knowledge and develop new tools. And these persons shared and invested their knowledge and skills to come to the acquired results.

The paragraph above is written in past tense. As if the project is finished. Done. That, however, is not the case. We will continue; test in the field, under commercial circumstances, improve and optimize. And also then we need knowledge and skills. From unique personalities with unique qualities. Above, a number of them was mentioned by name. THANK YOU. 


\section{About the author}

Monique Francisca Mul was born in Wieringerwaard in the North West of The Netherlands in 1971. There she grew up in an agricultural community where her father and mother ran a local car company and bike store. After high school she obtained her BSc. degree in Animal Husbandry at the CAH in Dronten (NL, 1993) with her thesis on Chlamydia psittaci in sheep. During her study she voluntarily attended most of the available courses related to engineering in agriculture. Prior to the start of the study Veterinary Medicine in Ghent (1993, Belgium), she voluntarily worked on a dairy project in the Western part of Romania. In 1994, Monique stopped with the study Veterinary Medicine and started with the study Animal Husbandry at Wageningen University (NL) to obtain her MSc. degree, enabling her to become a researcher in Animal Health and Epidemiology. In 1997, she graduated on an epidemiological cohort study on Neospora caninum in dairy cows and obtained a minor in Educational skills.

In 1997, Monique started her research career in pig health at a pig breeding company. She continued working in this field in 1998 at the Applied Pig Research Station in Rosmalen where she worked on a broad number of themes, mostly on disease prevention and effective management measures to limit the negative effects of pathogens in the animal environment. The Applied Pig Research Station later merged into Wageningen Livestock Research, now a part of Wageningen University and Research.

Monique started working on Dermanyssus gallinae in 2005, leading and participating in numerous projects focusing on this pest in the years that followed. In 2013, she officially started her $\mathrm{PhD}$ focusing on preventive measures and continuous monitoring of D. gallinae in layer farms, enabling poultry producers to minimise the economic losses due to a $D$. gallinae infestation. She worked on her thesis alongside other projects on fly prevention in animal husbandry, Toxoplasma in pigs, facilitation of farmers towards improvement on farm animal health, welfare and economics and on the further development of an automated monitoring tool for D. gallinae.

At present, Monique is a researcher in Animal Health in the department of Animal husbandry and Environment of Wageningen Livestock Research, and Working Group Leader of COST Action FA1404 - COREMI (Improving current understanding and research for sustainable control of the poultry red mite Dermanyssus gallinae), where she coordinates the 'One Health' section. In addition to her research activities, Monique and her partner grow rosehip branches for ornamental purposes (www.rozenbotteltak.nl) in a scenic polder landscape in the North West of Holland. The branches are harvested in the autumn and sold via the flower auction in Aalsmeer, The Netherlands. 


\section{List of publications}

\section{Refereed scientific papers}

Mul MF, Koenraadt CJM (2009) Preventing introduction and spread of Dermanyssus gallinae in poultry facilities using the HACCP method. Exp Appl Acarol 48: 167-181

Sparagano O, Pavlićević A, Murano T, Camarda A, Sahibi H, Kilpinen O, Mul M, Van Emous R, Le Bouquin S, Hoel K, Cafiero MA (2009) Prevalence and key figures for the poultry red mite Dermanyssus gallinae infections in poultry farm systems. Exp Appl Acarol, 48: 310

Mul M, Van Niekerk T, Chirico J, Maurer V, Kilpinen O, Sparagano O, Thind B, Zoons J, Moore D, Bell B, Gjevre A-G, Chauve C (2009) Control methods for Dermanyssus gallinae in systems for laying hens: results of an international seminar. World Poultry Sci J 6: 589600

Mul MF, Van Riel JW, Meerburg BG, Dicke M, George DR, Groot Koerkamp PWG (2015) Validation of an automated mite counter for Dermanyssus gallinae in experimental laying hen cages. Exp Appl Acarol 66, 4: 589-603

George D, Finn R, Graham K, Mul M, Guy J, Strube C, Tomley F, Hernández-Crespo P, Steenberg T, Eriksson H, Øines Ø, Coles G, Cogan T, Stafford K, Nisbet A, Sparagano O (2015) The poultry red mite Dermanyssus gallinae: Developing novel management solutions for a complicated and neglected pest. Antenna Special Edition 2015: 84-85

George DR, Finn RD, Graham KM, Mul MF, Maurer V, Valiente Moro C, Sparagano OAE (2015) Should the poultry red mite Dermanyssus gallinae be of wider concern for veterinary and medical science? Parasite Vector 8: 178

Mul MF, Ploegaert JPM, George DR, Meerburg BG, Dicke M, Groot Koerkamp PWG (2016) Structured design of an automated monitoring tool for pest species. Biosyst Eng 151: 126-140

\section{Submitted paper}

Mul MF, Van Riel JW, Roy L, Zoons J, André G, George DR, Meerburg BG, Dicke M, Van Mourik S, Groot Koerkamp PWG (2016) Model based approaches to forecast Dermanyssus gallinae population dynamics and to describe the source of population growth variation in laying hen facilities for advancing Integrated Pest Management.

\section{Refereed conference papers}

Mul MF, Van Niekerk TGCM, Reuvekamp BFJ, Van Emous RA (2010) Dermanyssus gallinae in Dutch poultry farms: Results of a questionnaire on severity, control treatments, cleaning, and biosecurity. Trends in Acarology Part 15: 513-516

Mul MF, Van Niekerk TGCM, Groot Koerkamp PWG (2010) Biology and monitoring of Dermanyssus gallinae in poultry farms. Parassitologia 52, 1-2: 65-67 
Sparagano OAE, Camarda A, Cafiero MA, Mul M, Giangaspero A (2010) New insights in dermanyssosis control. Parassitologia 52, 1-2: 69-71

\section{Conference contributions}

Fiks-Van Niekerk TGCM, Van Emous RA, Mul MF (2006) Pest status of red chicken mites in the Netherlands. Proceedings of the 12thInternational Congress of Acarology, Amsterdam, The Netherlands: 58

Sparagano 0, Camarda A, Maurer V, Harrington D, George D, Guy J, Circella E, Kilpinen O, Steenberg T, Lesna I, Sabelis M, Chirico J, Giangaspero A, Marangi M, Cafiero MA, Mul M, Van Niekerk T, Koenraadt C, Zenner L, Valiente Moro C, De Luna C (2009) Control del acaro rojo en naves de gallinas ponedoras. 46 Symposium Cientifico de Avicultura, Zaragoza, Spain, Sept 30th-October 2nd, 2009: 133-141 (in Spanish)

Mul M (2009) Elimination of red poultry mite (Dermanyssus gallinae) in poultry facilities. Eliminace čmelíka kuřiho (Dermanyssus gallinae) v chovech drůbeže. 36. česká drůbežářská konference s mezinárodní účastí. Drůbež 2009, Brno, Czech Republic, October 15-16th, 2009: 4-5 (In Czech, invited talk)

Sparagano O, Maurer V, Camarda A, Harrington D, George D, Guy J, Kilpinen O, Circella E, Steenberg T, Chirico J, Lesna I, Sabelis M, Marangi M, Cafiero MA, Koenraadt C, Zenner L, Valiente-Moro C, De Luna C, Van Niekerk T, Mul M, Giangaspero A (2009) New measures to control ectoparasites with reference to red mites. XVIth World Veterinary Poultry Association Congress, Marrakesh, Morocco, November 8-12: 74-80 (invited talk).

Sparagano OAE, Pavlićević A, Murano T, Camarda A, Sahibi H, Kilpinen O, Mul M, Van Emous R, Le Bouquin S, Hoel K, Cafiero MA (2009) Prevalence and key figures for the poultry red mite Dermanyssus gallinae infections in poultry farm systems. World Poultry Sci J, Book of Abstracts, 8th European Symposium on Poultry Welfare, Cervia, Italy, 18-22 May: 75

Mul M (2009) Using the HACCP method for preventing introduction and spread of Dermanyssus gallinae in poultry facilities with a focus on monitoring methods. World's Poultry Science Journal, Book of Abstracts, 8th European Symposium on Poultry Welfare, Cervia, Italy, 18-22 May: 79

Sparagano OAE, Sabelis M, Harrington D, Lesna I, Mul M, Maurer V, Camarda A, Kilpinen O, Circella E, Steenberg T, Chirico J, Marangi M, Cafiero MA, Koenraadt C, Zenner L, Valiente-Moro C, De Luna C, Guy J, Van Emous R, Van Niekerk TGCM, Sahibi H, Rhalem A, Pavlicevic A, Murano T, Giangaspero A, George D (2010) Prevalence and control of poultry red mites. XIIIth European Poultry Conference, Tours, France, 23-27 August. World Poultry Sci J 66: 250-251

Mul MF, Van Niekerk TGCM, Groot Koerkamp PWG (2010) Biology and monitoring of Dermanyssus gallinae in poultry farms. 16th National Congress of the Italian Society for Parasitology, Perugia, June 22-25 
Mul M, Van Niekerk T, Meerburg B, Groot Koerkamp P (2013) Control of poultry red mite (Dermanyssus gallinae) in layer farms using an automated monitoring device. In: Book of Abstracts of XVIIIth WVPA Congress Nantes, France, 19-23 August 2013: 661

George D, Finn B, Graham K, Mul M, Sparagano O (2013) Of mites and men: Preliminary evidence for increasing incidence of avian ectoparasitosis in humans and support for its potential threat to medical health. In: Book of Abstracts of XVIIIth WVPA Congress Nantes, France, 19-23 August 2013: 635-636

Mul MF, Van Niekerk TGCM, Meerburg BG, Groot Koerkamp PWG (2013) Minimizing negative effects of poultry red mite in layer farms using an automated monitoring device. 64th Annual meeting of the European Federation of Animal Science, Nantes, Frances, 26-30 August $2013: 443$

Mul MF, Van Riel JW, Meerburg BG, Zoons J, Groot Koerkamp PWG (2014) Treatment efficacy against Dermanyssus gallinae is affected by flock age and housing system. XIVth European poultry Conference, Stavanger, Norway, 23-27 June 2014: 413

Sparagano OAE, George DR, Finn RD, Giangaspero A, Mul M, Papadopoulos E, Tomley F, Pritchard J (2014) Dermanyssus gallinae and poultry production: Impact, management, and a predicted compatibility matrix for integrated approaches. XIVth European poultry Conference, Stavanger, Norway, 23-27 June 2014 : 131-141 (invited paper)

George D, Finn R, Graham K, Mul M, Guy J, Strube C, Tomley F, Hernández-Crespo P, Kilpinen O, Eriksson E, Øines Ø, Coles G, Cogan T, Stafford K, Nisbet A, Sparagano O, 2014 The poultry red mite Dermanyssus gallinae: developing novel management solutions for a complicated and neglected pest. European Congress of Entomology, $3^{\text {rd }} 8^{\text {th }}$ August, University of York, UK: 47

George DR, Finn RD, Graham KM, Mul MF, Maurer V, Valiente Moro C, Sparagano OAE (2015) Of mites and men: should the poultry red mite Dermanyssus gallinae be of wider concern for medical science? Proceedings of the 1 COST conference and Management meeting on improving current understanding and research for sustainable control of the poultry red mite Dermanyssus gallinae (COREMI) COST Action FA 1404 28-29 May 2015, Foggia, Italy: 27-29

Sparagano O, Bartley K, Roy L, Mul M, Camarda A, Giangaspero A, Papadopoulos E, George D (2015) The poultry red mite: Impacts, challenges and remedial approaches. Proceedings of the 89. Fachgespräch über Geflügelkrankheiten. Tagung der DVG fachgruppe "Geflügelkrakheiten" und der Deutschen gruppe der WVPA 5. und 6. November 2015 in Hannover: 1-2

Mul MF, Van Riel JW, Lesna IKA, Koenraadt CJM, Meerburg BG, Groot Koerkamp PWG, Bens $\mathrm{H}$ (2016) Research advancing IPM for control of Dermanyssus gallinae in The Netherlands (2004-2016). In: Book of Abstract of the $2^{\text {nd }}$ COST conference and Management Committee (MC) Meeting on improving current understanding and research for sustainable control of the poultry red mite Dermanyssus gallinae (COREMI) COST Action FA 1404, 1-3 June 2016, Zagreb, Croatia: 31 
Mul MF, Vänninen I, Tuovinen T (2016) Effective implementation of integrated pest management (IPM) for Dermanyssus gallinae in laying hen facilities. In: Book of Abstract of the 2nd COST conference and Management Committee (MC) Meeting on improving current understanding and research for sustainable control of the poultry red mite Dermanyssus gallinae (COREMI) COST Action FA 1404, 1-3 June 2016, Zagreb, Croatia: 35

Van Riel, JW, Mul MF, Guy JH, George DR (2016) Investigations on economics of operational control of Dermanyssus gallinae (2016) In: Book of Abstract of the 2nd COST conference and Management Committee (MC) Meeting on improving current understanding and research for sustainable control of the poultry red mite Dermanyssus gallinae (COREMI) COST Action FA 1404, 1-3 June 2016, Zagreb, Croatia: 39

\section{Courses}

Mul MF (2013) A practical approach to monitoring and prevention of D. gallinae. WVPAC 2013 workshop \#5 “Current knowledge on the "Red Mite"and its control". August 19th 2013, ONIRIS Ecole Vétérinaire Nantes Atlantique, Nantes, France

\section{Popular media}

Fiks-van Niekerk TGCM, Van Emous RA, Mul MF (2004) Gespuis in de nacht: bloedluizen: wees er op tijd bij. De pluimveehouderij, 34, 25:19

Van Emous, Fiks-van Niekerk TGCM, Mul MF (2005) E11 miljoen schade voor de sector: enquete vogelmijten op leghennenbedrijven. De pluimveehouderij 35, 3: 8-9

Van Emous RA, Fiks-van Niekerk TGCM, Mul MF (2005) Ken uw vijand: wat u moet weten over de vogelmijt. De pluimveehouderij 35, 9: 18-19

Van Emous RA, Fiks-van Niekerk TGCM, Mul MF (2005) Uitzuiger; schade door vogelmijt. De pluimveehouderij 35, 14: 14-15

Van Emous RA, Fiks-van Niekerk TGCM, Mul MF (2005) Dure kostganger; bloedluisbestrijding al gauw lonend. De pluimveehouderij, 35, 19: 14-15

Van Emous RA, Fiks-van Niekerk TGCM, Mul MF (2005) Van vier kanten aanvallen: oorlog tegen de mijten. De pluimveehouderij, 35, 24: 14-16

Mul MF, Mullens BA, Koenraadt CJM (2009) Foute familie. Pluimveehouderij, 39, 24 april: 20-21

Mul MF, Mullens BA, Koenraadt CJM (2009) Bloedzuigers in pluimveestallen. Dierplagen, 12, 2: $13-15$

Mul M, Mullens B, Koenraadt S (2010) Bloedzuigers in pluimveestallen. Kleindier Magazine, 124, 6: 14-16

Mul M, André G (2012) Een plaag te snel af zijn. Pluimveehouderij, 42e jaargang, 31 augustus 2012: 26-27

Mul M, Bens H, Odink-Schrijver I (2013) Fact sheet Poultry Red Mite 
Mul M, Bens H, Odink-Schrijver I, Hanssen M (2013) Slimme monitor bindt strijd aan met bloedluis. V-focus+ januari 2-14:20-21

\section{Reports}

Van Emous RA, Fiks-van Niekerk TGCM, Mul MF (2006) Bloedluizen (vogelmijten) op papier en in de praktijk. PraktijkRapport pluimvee nr. 17, Animal Sciences GroupPraktijkonderzoek ISSN 15708624 (In Dutch with English summary) 


\section{PE\&RC Training and Education Statement}

With the training and education activities listed below the PhD candidate has complied with the requirements set by the C.T. de Wit Graduate School for Production Ecology and Resource Conservation (PE\&RC) which comprises of a minimum total of 32 ECTS (= 22 weeks of activities)

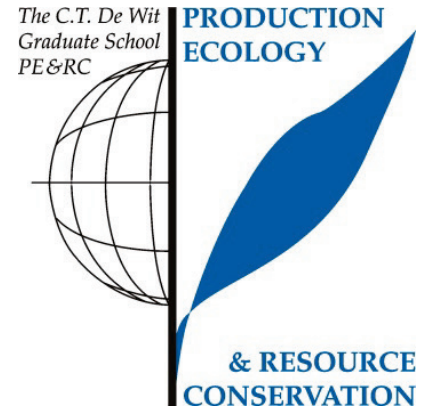

\section{Review of literature (6 ECTS)}

- Control methods for Dermanyssus gallinae in systems for laying hens (2009)

- Biology and monitoring of Dermanyssus gallinae in poultry farms (2010)

\section{Writing of project proposal (4.5 ECTS)}

- Development of an automated poultry red mite monitoring system (2013)

\section{Post-graduate courses (3 ECTS)}

- Poultry Red Mite meeting; discussions, efficacy testing, oral presentation; Northumbria University, New Castle (2012)

- Bayesian statistics; PE\&RC (2014)

- Introduction to R; PE\&RC (2015)

- Generalized linear models; PE\&RC (2015)

- $\quad$ Mixed linear models; PE\&RC (2015)

\section{Laboratory training and working visits (3.5 ECTS)}

- Ornithonyssus sylviarum, another blood sucking mite of poultry; University of California, Riverside (2008)

- $\quad$ STSM Finland IPM and poultry red mite; LUKE, Forssa, Finland (2015)

\section{Invited review of (unpublished) journal manuscript (2 ECTS)}

- Experimental and Applied Acarology: Dermanyssus and essential oils (2009)

- Medical and Veterinary Entomology: Dermanyssus gallinae and Megninia ginglymura: bio-ecology and natural enemies in commercial egg-laying hens (2015)

\section{Deficiency, refresh, brush-up courses (1.6 ECTS)}

- Training voedselveiligheid HACCP; DNV (2001)

- Toegepaste statistiek; Praktijkonderzoek Veehouderij en Centrum voor Biometrie (2001)

\section{Competence strengthening / skills courses (15.4 ECTS)}

- Projectleiderschap; Animal Sciences Group(2004)

- Leren innoveren; Animal Sciences Group (2005)

- Innovatief projectleiden; Animal Sciences Group (2007)

- Course techniques for scientific writing; Animal Sciences Group (2007)

- Effectief beïnvloeden; ICM (2013)

- Commerciële vaardigheden; Wageningen UR Livestock Research (2014)

- Mobilising your scientific network; PE\&RC (2015) 
- Network facilitators training; School of Veterinary Science, Bristol (2015)

- $\quad 2^{\text {nd }}$ Network facilitators training; School of Veterinary Science, Bristol (2016)

\section{PE\&RC Annual meetings, seminars and the PE\&RC weekend (0.6 ECTS)}

- PE\&RC Day $(2014,2015)$

\section{Discussion groups / local seminars / other scientific meetings (7.4 ECTS)}

- Seminar control of Dermanyssus galllinae; Wageningen, The Netherlands (2016)

- Meeting researchers poultry red mite during BSP spring, Trypanosomiasis/Leishmaniasis \& Malaria meetings; New Castle, Unite Kingdom (2007)

- Pre-congress program WVPA: moderator at workshop with discussion; Nantes, France (2013)

- BEMB Seminar; London, United Kingdom (2013)

- MSN Discussion groups (2014-2015)

- COST Action program (2014-2016)

- WEES Talk and workshop; Doug Landis (2015)

- COST workshop Development of an on-farm monitoring protocol (2015)

- KNAW Seminar: Van chemie naar ecologie (2016)

- High strategy meeting: Identification of clinical aspects and prevalence PRM on humans; Mini Rondeel, Amsterdam, The Netherlands (2016)

- COREMI WG1 Coordinators meeting; Moredun Research Institute, Edinburgh, United Kingdom (2016)

\section{International symposia, workshops and conferences (18.1 ECTS)}

- $12^{\text {th }}$ International Congress of acarology; Amsterdam, The Netherlands (2006)

- $\quad 8^{\text {th }}$ European symposium on poultry welfare; two oral presentations; Cervia, Italy (2009)

- $36^{\text {th }}$ Ceska drubezarska konference s mezinarodni uncasti; oral presentation; Brno, Czech Republic (2009)

- $16^{\text {th }}$ Congresso nazionale della Societa Italiana di Parassitologia; oral presentation; Perugia, Italy (2010)

- EAAP; oral presentation; Nantes, France (2013)

- WVPA Congress; poster presentation; Nantes, France (2013)

- ECP; oral presentation; Stavanger, Norway (2014)

- COST Conference COREMI; oral presentation; Foggia, Italy (2015)

- Drielanden pluimvee overleg; oral presentation; Deventer, The Netherlands (2015)

- $\quad 2^{\text {nd }}$ COST Conference COREMI; poster and oral presentation; Zagreb, Croatia (2016)

\section{Lecturing / supervision of practicals / tutorials (1.8 ECTS)}

- Practical course Entomology (2007)

- Training school with the Experimental Poultry Centre in Geel, Belgium (2015)

\section{Supervision of MSc students}

- Design of a sensor for poultry red mite in laying hen houses

- Detection of poultry red mite by an automated counter in poultry houses

- Towards a deployable Automated Monitoring Tool (AMT) for poultry red mite 


\section{Colophon}

The research described in this thesis was financially supported by the Dutch Product Board for Poultry and Eggs and the Dutch Ministry of Economic Affairs within the framework of the public-private collaboration project 'Poultry4Food' (TKI-AF-12048). The authors would like to acknowledge networking support by the COST Action FA1404.

Cover illustration: Sjaakkooij.com

Lay-out: Wilma Office Support

Cover lay out: WAV productions

Printed by: GVO drukkers \& vormgevers B.V., Ede, The Netherlands 
